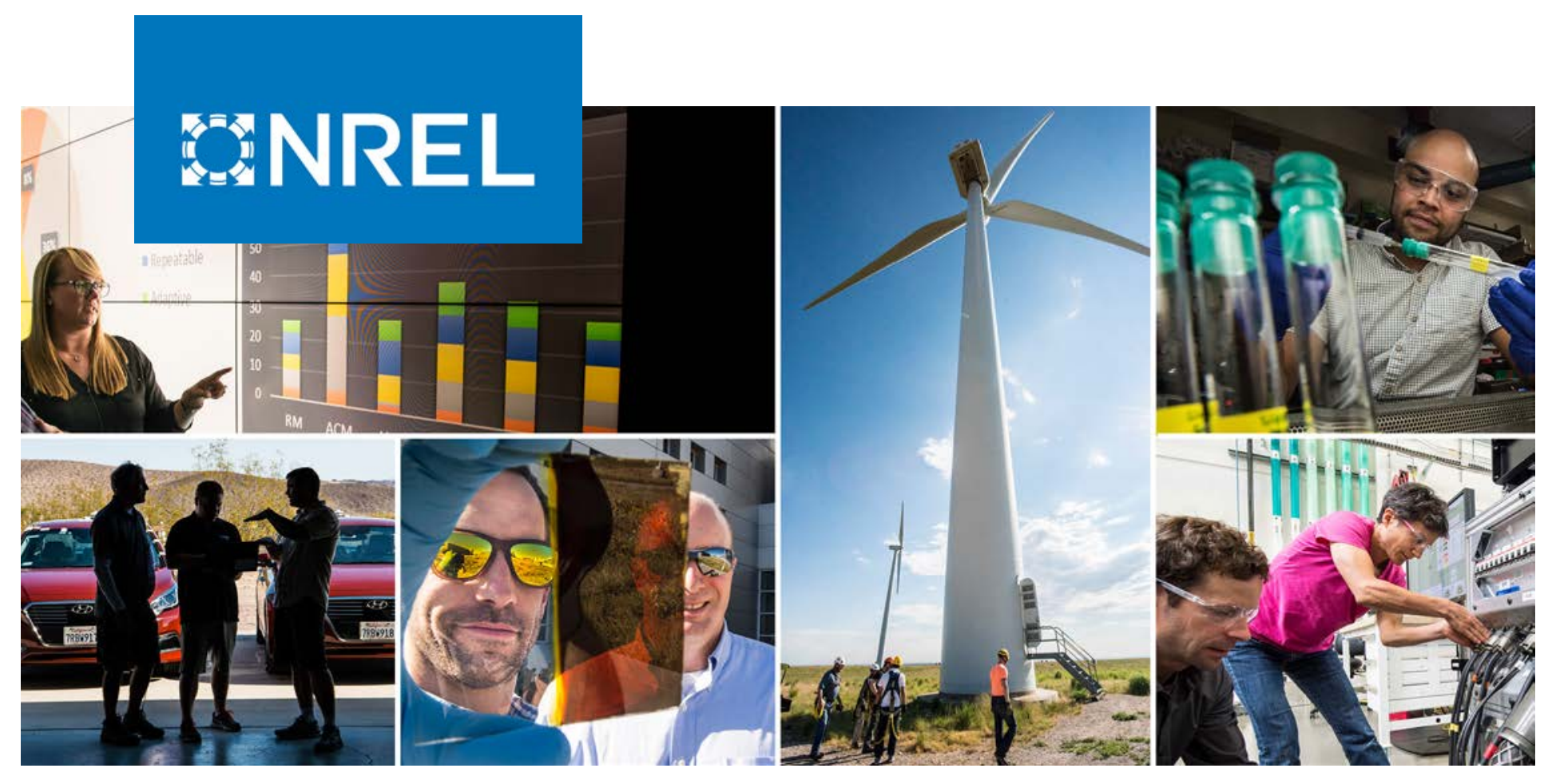

\title{
Carbon-Free Resource Integration Study
}

Reiko Matsuda-Dunn, Michael Emmanuel, Erol Chartan, Bri-Mathias Hodge, and Gregory Brinkman

National Renewable Energy Laboratory

NREL is a national laboratory of the U.S. Department of Energy

Office of Energy Efficiency \& Renewable Energy

Operated by the Alliance for Sustainable Energy, LLC

This report is available at no cost from the National Renewable Energy Laboratory (NREL) at www.nrel.gov/publications.
Technical Report

NREL/TP-5D00-74337

January 2020 


\section{GNREL}

\section{Carbon-Free Resource Integration Study}

\section{Reiko Matsuda-Dunn, Michael Emmanuel, Erol Chartan, Bri-Mathias Hodge, and Gregory Brinkman}

National Renewable Energy Laboratory

\section{Suggested Citation}

Matsuda-Dunn, Reiko, Michael Emmanuel, Erol Chartan, Bri-Mathias Hodge, and Gregory

Brinkman. 2020. Carbon-Free Resource Integration Study. Golden, CO: National

Renewable Energy Laboratory. NREL/TP-5D00-74337.

https://www.nrel.gov/docs/fy20osti/74337.pdf.

NREL is a national laboratory of the U.S. Department of Energy Office of Energy Efficiency \& Renewable Energy Operated by the Alliance for Sustainable Energy, LLC

This report is available at no cost from the National Renewable Energy Laboratory (NREL) at www.nrel.gov/publications.

Contract No. DE-AC36-08GO28308
Technical Report

NREL/TP-5D00-74337

January 2020

National Renewable Energy Laboratory 15013 Denver West Parkway Golden, CO 80401

303-275-3000 • www.nrel.gov 


\section{NOTICE}

This work was authored by the National Renewable Energy Laboratory, operated by Alliance for Sustainable Energy, LLC, for the U.S. Department of Energy (DOE) under Contract No. DE-AC36-08GO28308. Funding provided by Duke Energy. The views expressed herein do not necessarily represent the views of the DOE or the U.S. Government.

This report is available at no cost from the National Renewable Energy Laboratory (NREL) at www.nrel.gov/publications.

U.S. Department of Energy (DOE) reports produced after 1991 and a growing number of pre-1991 documents are available free via www.OSTI.gov.

Cover Photos by Dennis Schroeder: (clockwise, left to right) NREL 51934, NREL 45897, NREL 42160, NREL 45891, NREL 48097, NREL 46526.

NREL prints on paper that contains recycled content. 


\section{List of Acronyms}

DEC Duke Energy Carolinas

DEP

NREL

PV

Duke Energy Progress

WIND

National Renewable Energy Laboratory

photovoltaic

Wind Integration National Dataset 


\section{Foreword}

This report covers the results of a preliminary phase 1 analysis conducted by the National Renewable Energy Laboratory (NREL) with Duke Energy, who funded this work and whose expertise, specialist knowledge, and diligence has helped guide the process. This initial effort is a net load analysis which compares estimated hourly solar, wind, net load, and system minimum generation time series for different scenarios. It aims primarily to set up a baseline for more detailed modeling as part of a larger effort between Duke Energy and NREL expected to last multiple years. The full analysis will provide a broader insight into the costs, challenges, and opportunities of renewable energy integration in the Duke Energy service territory in the Carolinas. This report and the full analysis are not financial plans and are not intended to replace Duke Energy's integrated resource planning process. Rather, they examine the operational considerations of integrating additional carbon-free resources onto the Duke Energy Carolinas and Duke Energy Progress system. 


\section{Executive Summary}

This report presents a net load analysis, geospatial analysis, and a web application for the Duke Energy Carbon-Free Resource Integration Study. In this collaborative engagement, the National Renewable Energy Laboratory (NREL) provides research support to Duke Energy to analyze the impacts of integrating significant amounts of new solar photovoltaic (PV) power into its service territory under a variety of scenarios. This analysis covers Duke Energy's territories in North Carolina and South Carolina, including two balancing authorities-Duke Energy Progress (DEP) and Duke Energy Carolinas (DEC) — with detailed assessments and discussions of the operations of the existing fleet, particularly nuclear generation, under high-penetration scenarios of solar PV. In addition to quantifying the solar potential, NREL is working with Duke Energy to identify possible opportunities for wind, storage, demand-side resources, and other technologies.

\section{Scenario Analysis}

This analysis looks at a variety of solar power penetration levels in Duke Energy's service territory in the Carolinas - compared to load and system-wide minimum generation levels - that best represent potential challenges and opportunities for renewable generation integration. An example of this includes an analysis of balancing solar and load for typical days during different seasons and extreme days, such as minimum and peak net load days. Net load is defined as the customer load less wind power and solar power generation. This analysis is performed by comparing estimated hourly solar, wind, net load, and system minimum generation time series for the different scenarios. The overall aim is to help Duke Energy understand initial estimates of possible curtailment, key periods of ramping, and load-following requirements. Further, this analysis captures net load impacts across different seasons and operational issues related to generation flexibility limit during periods of low load with high penetrations of solar energy.

\section{Key Findings}

Table ES-1 shows the results of the annual metrics, including annual percentage of load met by carbon-free generation, annual percentage of curtailed energy, annual hours of curtailment, and annual maximum instantaneous curtailment for all scenarios. For scenarios 1 through 11, both balancing authorities (DEC and DEP) are modeled as a single region, whereas Scenario 12 models DEP and DEC separately with an interconnection limit between them.

In scenarios 1 through 7, as solar energy penetration increases, the percentage of load met by carbon-free generation increases, until the flexibility limit is reached, when PV production must be curtailed, and additional solar power has a marginal impact. The average annual percentage of load met by carbon-free generation ranges from $60 \%$ to $77 \%$, for these aforementioned scenarios, as shown in Table ES-1. As the PV penetration level increases, the marginal contribution to carbon-free generation suffers diminishing returns, due to the inability to shift the timing of PV generation to match the early and late hour net demand, especially from $20 \%$ through 35\% PV energy penetration. 
Table ES-1. Annual Metrics Evaluation for All Scenarios in the Net Load Analysis

\begin{tabular}{|c|c|c|c|c|c|c|}
\hline Scenario & $\begin{array}{l}\text { DEP and } \\
\text { DEC } \\
\text { Modeled } \\
\text { as a } \\
\text { Single } \\
\text { Region or } \\
\text { Separately }\end{array}$ & Definition & $\begin{array}{c}\text { Annual Load } \\
\text { Met by } \\
\text { Carbon-Free } \\
\text { Generation } \\
(\%)\end{array}$ & $\begin{array}{c}\text { Annual } \\
\text { Curtailed } \\
\text { Renewable } \\
\text { Energy (\%) }\end{array}$ & $\begin{array}{c}\text { Annual } \\
\text { Hours of } \\
\text { Curtailment }\end{array}$ & $\begin{array}{c}\text { Annual } \\
\text { Maximum } \\
\text { Instantaneous } \\
\text { Curtailment } \\
\text { (MW) }\end{array}$ \\
\hline $\begin{array}{l}\text { 1. Solar energy } \\
\text { penetration } 5 \%\end{array}$ & $\begin{array}{l}\text { Single } \\
\text { region }\end{array}$ & $\begin{array}{l}4,109 \mathrm{MW}, 5.5 \% \\
\text { of total solar is } \\
\text { rooftop }\end{array}$ & $60.4 \%$ & $0 \%$ & 6 & 530 \\
\hline $\begin{array}{l}\text { 2. Solar energy } \\
\text { penetration } \\
10 \%\end{array}$ & $\begin{array}{l}\text { Single } \\
\text { region }\end{array}$ & $\begin{array}{l}8,219 \mathrm{MW}, 5.5 \% \\
\text { of total solar is } \\
\text { rooftop }\end{array}$ & $65.5 \%$ & $1 \%$ & 179 & 3,323 \\
\hline $\begin{array}{l}\text { 3. Solar energy } \\
\text { penetration } \\
15 \%\end{array}$ & $\begin{array}{l}\text { Single } \\
\text { region }\end{array}$ & $\begin{array}{l}12,328 \mathrm{MW}, 5.5 \% \\
\text { of total solar is } \\
\text { rooftop }\end{array}$ & $69.7 \%$ & $8 \%$ & 882 & 6,618 \\
\hline $\begin{array}{l}\text { 4. Solar energy } \\
\text { penetration } \\
20 \%\end{array}$ & $\begin{array}{l}\text { Single } \\
\text { region }\end{array}$ & $\begin{array}{l}16,438 \mathrm{MW}, 5.5 \% \\
\text { of total solar is } \\
\text { rooftop }\end{array}$ & $72.5 \%$ & $17 \%$ & 1,506 & 10,003 \\
\hline $\begin{array}{l}\text { 5. Solar energy } \\
\text { penetration } \\
25 \%\end{array}$ & $\begin{array}{l}\text { Single } \\
\text { region }\end{array}$ & $\begin{array}{l}20,547 \mathrm{MW}, 5.5 \% \\
\text { of total solar is } \\
\text { rooftop }\end{array}$ & $74.4 \%$ & $27 \%$ & 2,016 & 13,504 \\
\hline $\begin{array}{l}\text { 6. Solar energy } \\
\text { penetration } \\
30 \%\end{array}$ & $\begin{array}{l}\text { Single } \\
\text { region }\end{array}$ & $\begin{array}{l}24,656 \mathrm{MW}, 5.5 \% \\
\text { of total solar is } \\
\text { rooftop }\end{array}$ & $75.6 \%$ & $35 \%$ & 2,355 & 17,207 \\
\hline $\begin{array}{l}\text { 7. Solar energy } \\
\text { penetration } \\
35 \%\end{array}$ & $\begin{array}{l}\text { Single } \\
\text { region }\end{array}$ & $\begin{array}{l}28,766 \mathrm{MW}, 5.5 \% \\
\text { of total solar is } \\
\text { rooftop }\end{array}$ & $76.5 \%$ & $42 \%$ & 2,587 & 20,909 \\
\hline $\begin{array}{l}\text { 8. Higher ratio } \\
\text { of distributed to } \\
\text { utility solar } \\
\text { added to the } \\
\text { system }\end{array}$ & $\begin{array}{l}\text { Single } \\
\text { region }\end{array}$ & $\begin{array}{l}\text { Based on the } \\
25 \% \text { solar energy } \\
\text { penetration } \\
\text { scenario, } 18.91 \% \\
\text { of PV is } \\
\text { uncurtailable } \\
\text { rooftop }\end{array}$ & $74.4 \%$ & $27 \%$ & 2,017 & 13,548 \\
\hline
\end{tabular}




\begin{tabular}{|c|c|c|c|c|c|c|}
\hline Scenario & $\begin{array}{l}\text { DEP and } \\
\text { DEC } \\
\text { Modeled } \\
\text { as a } \\
\text { Single } \\
\text { Region or } \\
\text { Separately }\end{array}$ & Definition & $\begin{array}{c}\text { Annual Load } \\
\text { Met by } \\
\text { Carbon-Free } \\
\text { Generation } \\
(\%)\end{array}$ & $\begin{array}{c}\text { Annual } \\
\text { Curtailed } \\
\text { Renewable } \\
\text { Energy (\%) }\end{array}$ & $\begin{array}{c}\text { Annual } \\
\text { Hours of } \\
\text { Curtailment }\end{array}$ & $\begin{array}{c}\text { Annual } \\
\text { Maximum } \\
\text { Instantaneous } \\
\text { Curtailment } \\
\text { (MW) }\end{array}$ \\
\hline $\begin{array}{l}\text { 9. Additional } \\
\text { storage }\end{array}$ & $\begin{array}{l}\text { Single } \\
\text { region }\end{array}$ & $\begin{array}{l}\text { Based on the } \\
25 \% \text { solar energy } \\
\text { penetration } \\
\text { scenario, addition } \\
\text { of } 1,000 \mathrm{MW} \text { of } 4- \\
\text { hour storage, } \\
1,000 \mathrm{MW} \text { of } 6- \\
\text { hour storage, and } \\
2,000 \mathrm{MW} \text { of } 8- \\
\text { hour storage }\end{array}$ & $77.1 \%$ & $12 \%$ & 1,239 & 11,073 \\
\hline $\begin{array}{l}\text { 10. Nuclear } \\
\text { retirement }\end{array}$ & $\begin{array}{l}\text { Single } \\
\text { region }\end{array}$ & $\begin{array}{l}\text { Based on the } \\
25 \% \text { solar energy } \\
\text { penetration } \\
\text { scenario, assume } \\
\text { a } 10 \% \text { nuclear } \\
\text { reduction }\end{array}$ & $70.2 \%$ & $22 \%$ & 1,804 & 12,551 \\
\hline $\begin{array}{l}11 \text {. Additional } \\
\text { wind energy at } \\
5 \% \text { penetration }\end{array}$ & $\begin{array}{l}\text { Single } \\
\text { region }\end{array}$ & $\begin{array}{l}\text { Based on the } \\
30 \% \text { solar energy } \\
\text { penetration } \\
\text { scenario, an } \\
\text { additional } 5 \% \\
\text { wind energy } \\
\text { penetration is } \\
\text { added }\end{array}$ & $79.4 \%$ & $32 \%$ & 2,486 & 17,486 \\
\hline 12-DEC 5\% & $\begin{array}{l}\text { Separate } \\
\text { regions }\end{array}$ & \multirow{6}{*}{$\begin{array}{l}\text { Based on } \\
\text { scenarios 1-3 } \\
\text { inclusive, DEP } \\
\text { and DEC are } \\
\text { analyzed } \\
\text { separately with } \\
\text { an } \\
\text { interconnection } \\
\text { limit between }\end{array}$} & $70 \%$ & $0 \%$ & 5 & 246 \\
\hline 12-DEC $10 \%$ & $\begin{array}{c}\text { Separate } \\
\text { regions }\end{array}$ & & $75 \%$ & $1 \%$ & 213 & 1,886 \\
\hline 12-DEC $15 \%$ & $\begin{array}{l}\text { Separate } \\
\text { regions }\end{array}$ & & $80 \%$ & $7 \%$ & 912 & 3,418 \\
\hline 12-DEP 5\% & $\begin{array}{l}\text { Separate } \\
\text { regions }\end{array}$ & & $50 \%$ & $0 \%$ & 5 & 246 \\
\hline 12-DEP $10 \%$ & $\begin{array}{c}\text { Separate } \\
\text { regions }\end{array}$ & & $54 \%$ & $1 \%$ & 205 & 1,600 \\
\hline 12-DEP $15 \%$ & $\begin{array}{c}\text { Separate } \\
\text { regions }\end{array}$ & & $58 \%$ & $10 \%$ & 905 & 3,418 \\
\hline
\end{tabular}

For scenarios 2 through 7 (solar energy penetration levels of $10 \%$ to $35 \%$ inclusive), analysis shows that the annual percentage curtailment ranges from $1 \%$ to $42 \%$ of total solar energy as PV penetration increases from $10 \%$ to $35 \%$. The majority of the solar energy curtailment occurs during the spring and fall seasons, which are characterized with low load and high renewable energy production. Also, Scenario 7, which has a solar energy penetration level of $35 \%$ and models both balancing authorities as one region, experienced the highest maximum instantaneous curtailment and hours of curtailment: 20,909 MW and 2,587 hours, respectively. 
The increased proportion of private solar PV analyzed in Scenario 8 does not materially affect the curtailment required. This does not infer that significant amount of rooftop will have no impact on system balancing. Given the assumptions of this study, with increasing penetration of rooftop solar from $5.5 \%$ of the total to $18.9 \%$ of the total, there is still sufficient curtailable solar to balance load and generation. Annual curtailment is $33 \%$ of utility solar and $27 \%$ of the total solar, which is the same as the baseline in Scenario 5.

The additional storage $(26,000 \mathrm{MWh})^{1}$ modeled in Scenario 9 results in a $3 \%$ increase in the amount of load met by carbon-free generation compared with the baseline in Scenario 5, which has $25 \% \mathrm{PV}$ penetration. Also, the percentage of renewable energy curtailed decreases by $15 \%$, whereas the $10 \%$ nuclear retirement scenario leads to a $4 \%$ decrease in the amount of load met by carbon-free generation and curtailed solar energy.

Further, the addition of 5\% wind energy penetration to 30\% solar energy in Scenario 11 results in a $2 \%$ increase in carbon-free energy production compared with the $35 \%$ solar energy penetration case. Also, the renewable energy curtailed decreases by $10 \%$ of the total renewable energy production. Thus, this shows that a balanced mix of renewable resources might reduce curtailment and the overall system cost compared to a similar penetration of PV-only generation

When DEC and DEP are modeled as individual balancing authorities with existing limited interconnection between them, Scenario 12 shows that DEP experiences a lower average percentage of load met by carbon-free generation, ranging from $50 \%$ to $58 \%$, compared to DEC, which ranges from $70 \%$ to $80 \%$. A production cost optimization would enable simulation of the interconnection and other transmission constraints in a more realistic manner.

Figure ES-1 (below) shows the annual contribution to carbon-free energy from all the scenarios considered in this study. The largest contribution resource to carbon-free energy is the nuclear power plant, followed by the increasing penetration of PV. Also, Figure ES-1 shows the impact of resource diversity with wind integration in the amount of carbon-free energy contribution with DEP and DEC modeled as a single balancing authority. Scenario 11, with 30\% PV and 5\% wind energy penetration, results in the highest contribution: $79 \%$.

Another important metric used to assess the diminishing returns of increasing levels of variable generation resources added to the system is marginal curtailment. ${ }^{2}$ As PV penetration levels increase, marginal curtailment increases more rapidly than total curtailment, as shown in Figure ES-2. This indicates that an increasing proportion of solar energy capacity will be curtailed as the system approaches high penetration levels of variable solar generation without adding sufficient system flexibility; however, solutions such as the addition of storage and wind power instead of additional solar power result in the marginal curtailment being reduced, as shown in Figure ES-2.

\footnotetext{
${ }^{1}$ This study did not consider the value stacking of storage units (i.e., using storage for other ancillary services, such as frequency regulation, voltage support, spinning and nonspinning reserves); therefore, the load-shifting and flexibility benefit presented in this report cannot be used solely for the economic assessment of storage deployment in the grid.

2 The marginal curtailment rate refers to the curtailment from an additional unit of variable generation capacity added to the system. For example, when increasing the variable generation penetration level from $10 \%$ to $15 \%$, the marginal curtailment is the curtailment rate of the additional $5 \%$ of variable generation.
} 


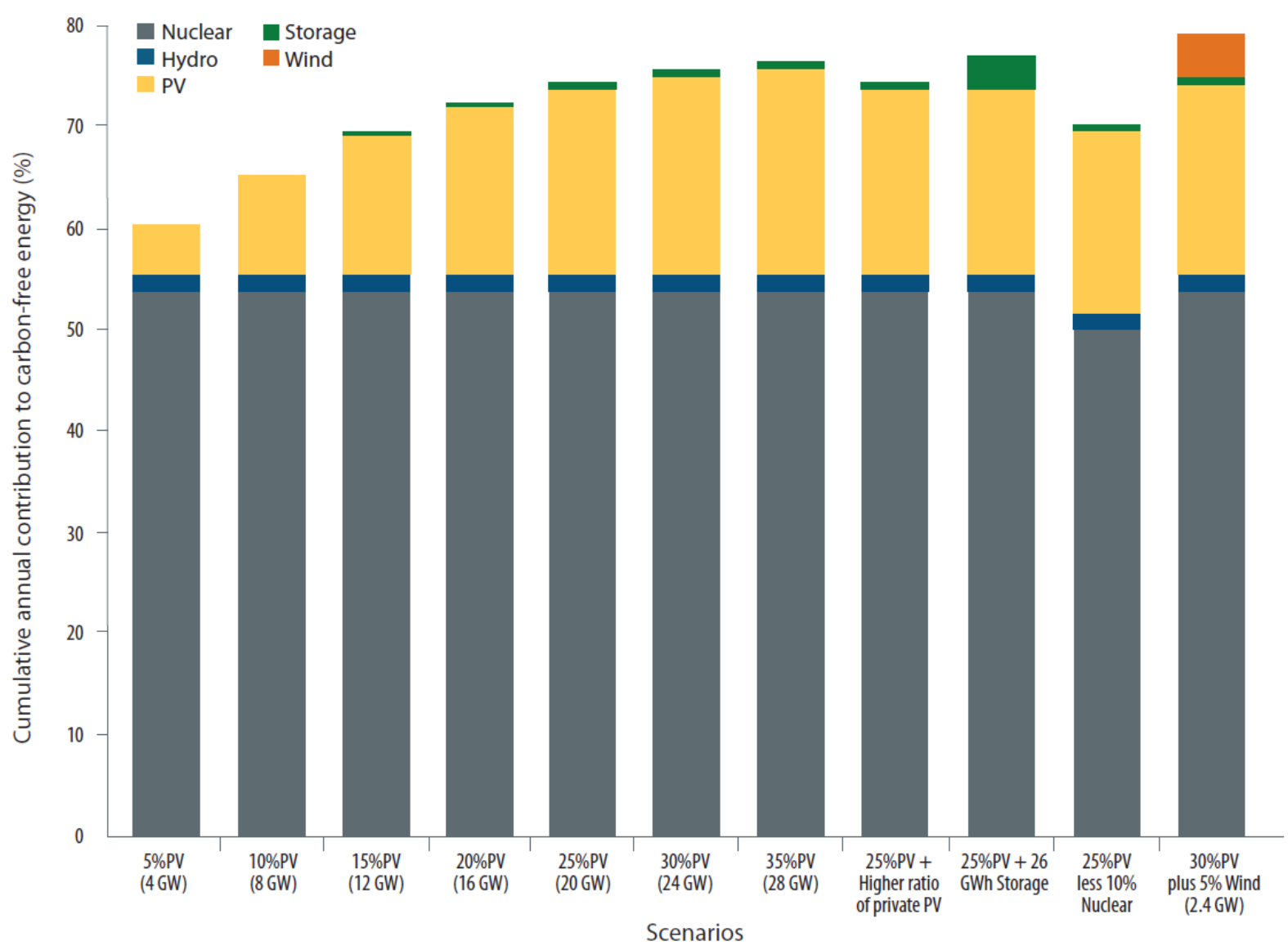

Figure ES-1. Percentage of annual carbon-free energy and contribution from each energy resource with increasing PV penetration, generation retirement, storage, and wind integration 


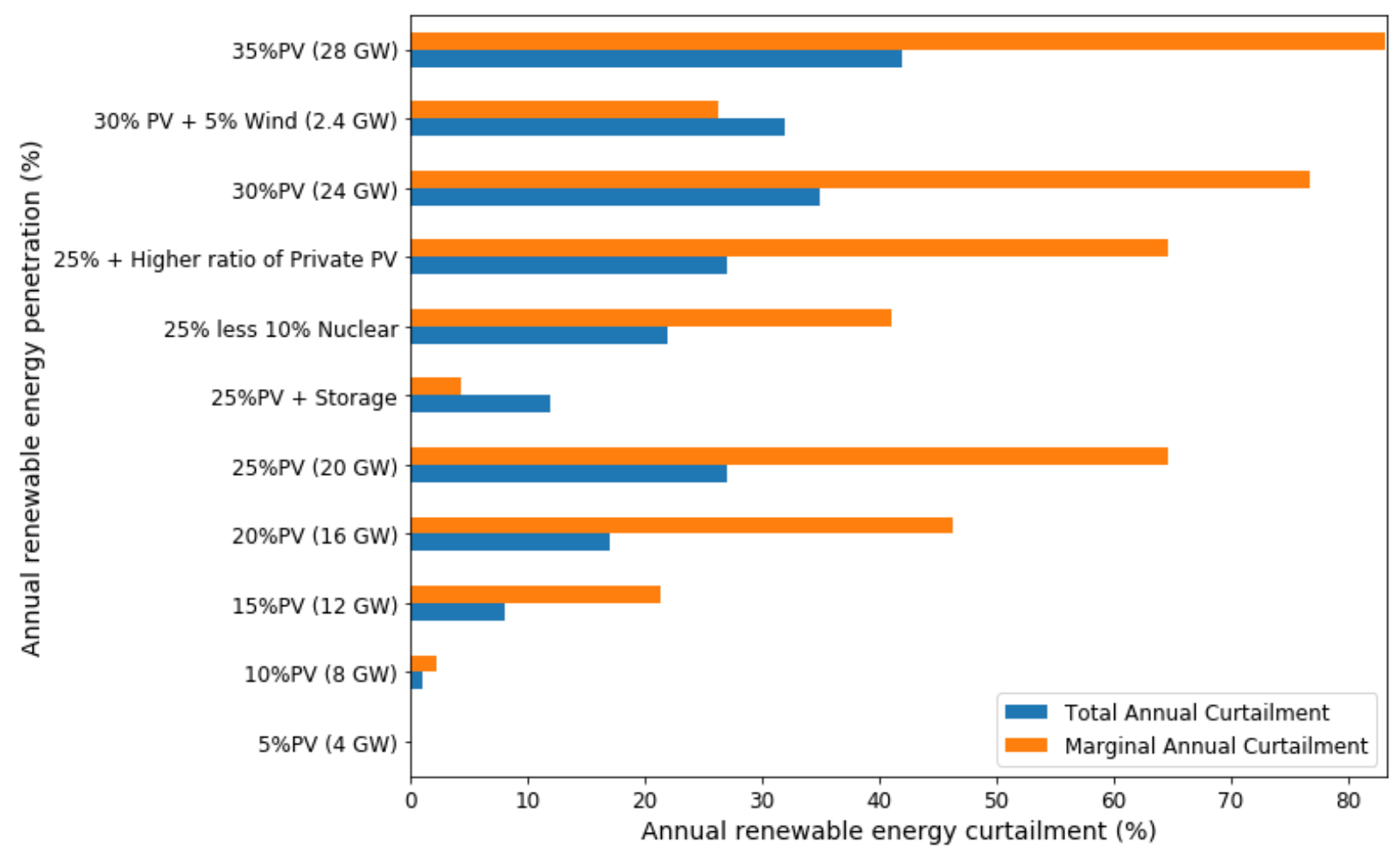

Figure ES-2. Marginal and total curtailment with increasing PV penetration, generation retirement, storage, and wind integration

\section{Conclusions}

The results and analysis of Phase 1 of the Carbon-Free Resource Integration Study presented in this report will help NREL and Duke Energy scope future work in this area to examine and address the identified grid integration challenges in greater technical detail. Further analysis with more advanced models - such as unit commitment and economic dispatch, capacity expansion planning, and dynamic analysis models - will be required to more fully assess system impacts with increasing variable generation penetration levels as well as flexibility opportunities to accommodate variable renewable energy sources to achieve the carbon-free goals of Duke Energy. 


\section{Table of Contents}

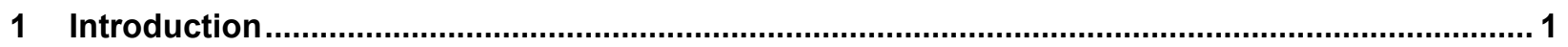

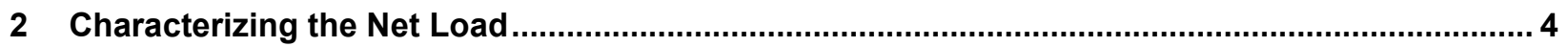

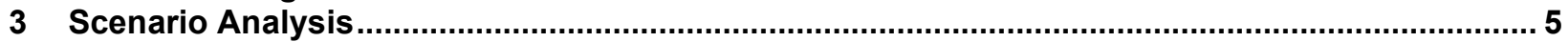

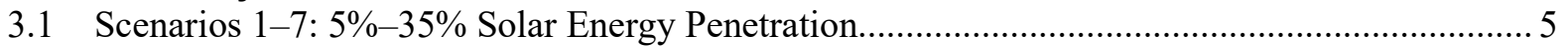

3.2 Scenario 8: Increased Proportion of Distributed Solar Energy …............................................. 13

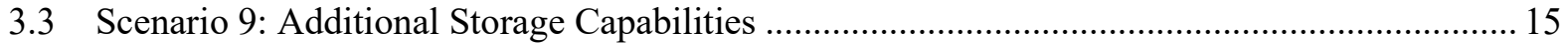

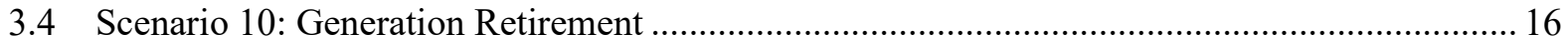

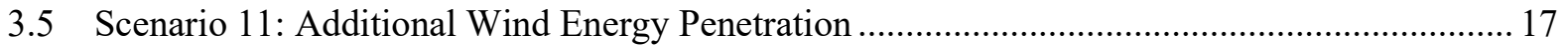

3.6 Scenario 12: DEC and DEP Modeled as Individual Balancing Authorities with a Limited

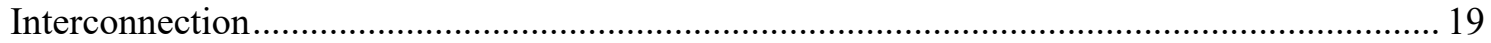

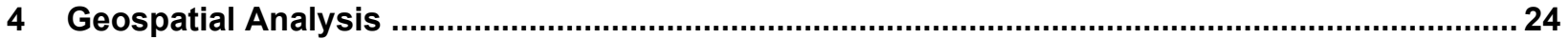

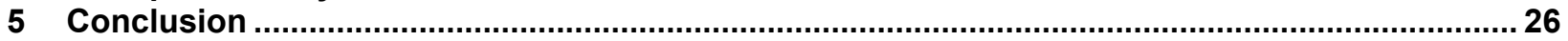

References

Appendix

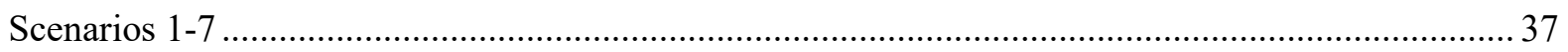

Scenario 8: 25\% PV Penetration and Increased Proportion of Distributed Solar................................ 56

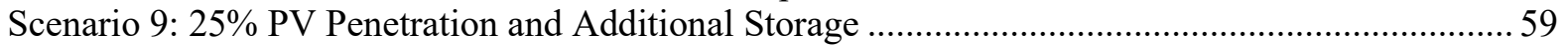

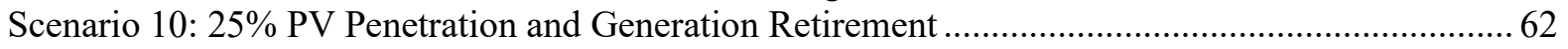

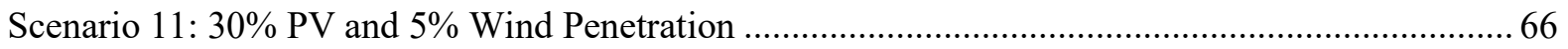

Scenario 12: DEC and DEP Modeled as Separate Balancing Authorities with 5\%, 10\%, and

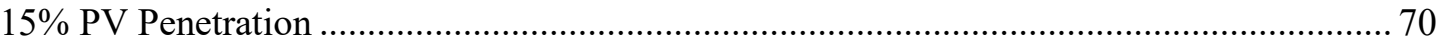

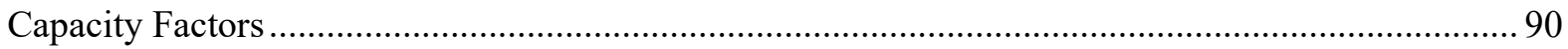

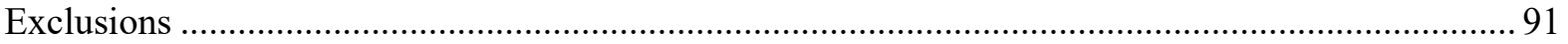

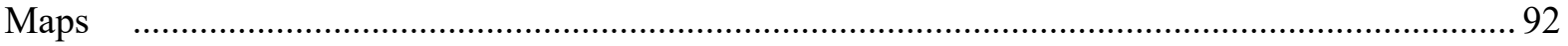




\section{List of Figures}

Figure ES-1. Percentage of annual carbon-free energy and contribution from each energy resource with increasing PV penetration, generation retirement, storage, and wind integration .................ix

Figure ES-2. Marginal and total curtailment with increasing PV penetration, generation retirement, storage, and wind integration......

\section{(1)}

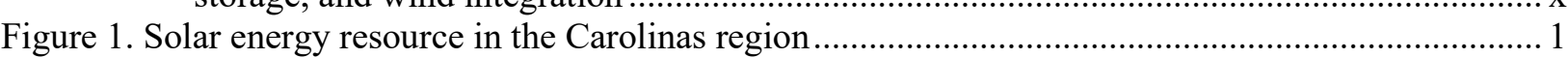

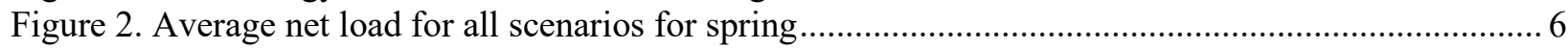

Figure 3. Minimum net load day for spring with $10 \%$ PV penetration............................................ 8

Figure 4. Minimum net load day for spring, the highest curtailment season, with 25\% solar energy

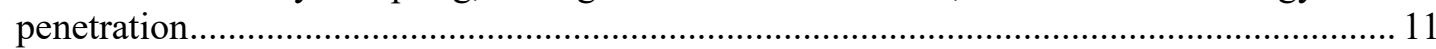

Figure 5. Max net load day for lowest curtailment season, summer, with 25\% solar energy penetration.. 11

Figure 6. Annual load duration curves, load, and net load with 25\% PV penetration .............................. 13

Figure 7. Minimum net load day with an increase in rooftop PV ....................................................... 14

Figure 8. Minimum net load day in winter with additional storage ........................................................ 15

Figure 9. Minimum net load day in winter without additional storage .................................................. 16

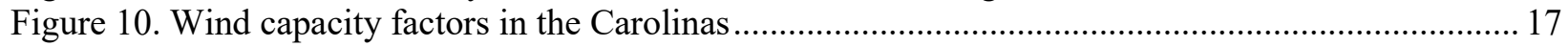

Figure 11. Minimum net load day in spring with 35\% PV energy penetration ..................................... 18

Figure 12. Minimum net load day in spring with $30 \%$ PV plus 5\% wind energy penetration .................. 19

Figure 13. Low net load day for the DEP balancing authority with 10\% PV penetration in spring ........... 21

Figure 14. Low net load day for the DEC balancing authority with $10 \% \mathrm{PV}$ penetration in spring .......... 21

Figure 15. Low net load day with $10 \% \mathrm{PV}$ penetration in spring when the Duke Carolinas territory is

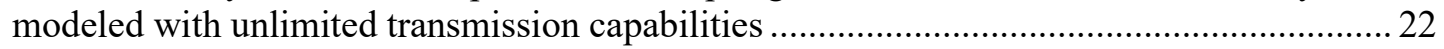

Figure 16. DEC and DEP load duration curves at 15\% PV penetration .............................................. 22

Figure 17. Load duration curve of the Duke Carolinas region modeled as one balancing area at $15 \% \mathrm{PV}$

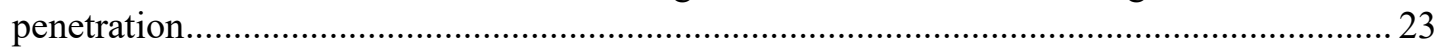

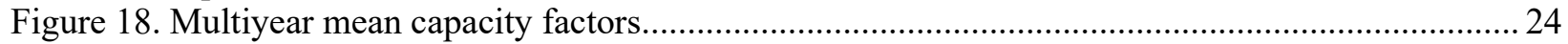

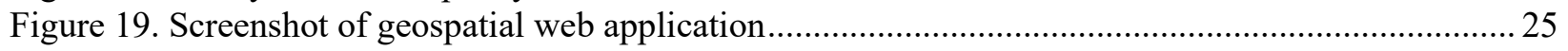




\section{List of Tables}

Table ES-1. Annual Metrics Evaluation for All Scenarios in the Net Load Analysis ............................... vi

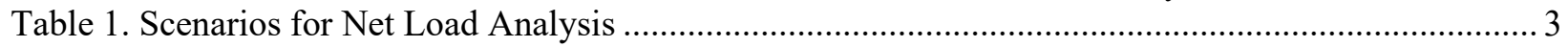

Table 2. PV Capacities for Penetration Levels Defined by Scenarios 1-7 .............................................. 6

Table 3. Average Seasonal Percentage of Load Met by Carbon-Free Generation for Each Scenario .......... 7

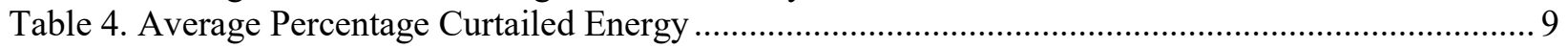

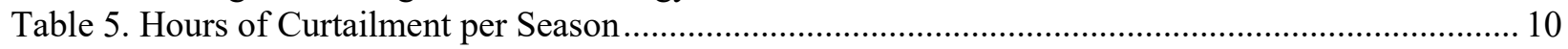

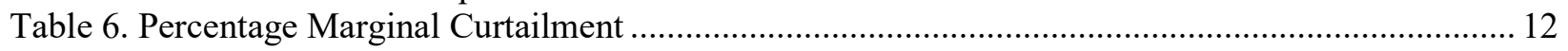

Table 7. Comparison of Curtailment of the System Modeled With and Without Transmission

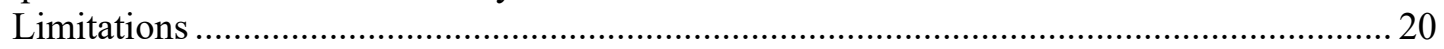

Table 8. Assumptions and Definitions for the Net Load Analysis ........................................................ 29

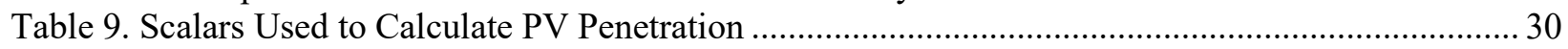

Table 10. Hydropower units corresponding to each region ................................................................... 31

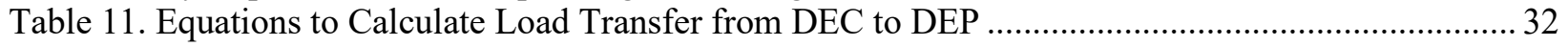

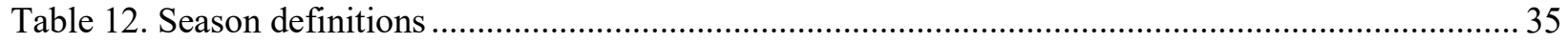

Table 13. Maximum instantaneous curtailment of each season (MW) ................................................... 35

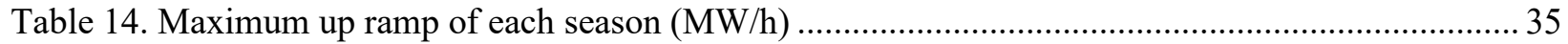

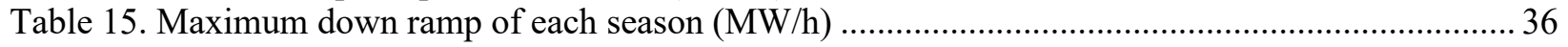




\section{Introduction}

Duke Energy is one of the largest electric power holding companies in the United States. It has more than 30,000 distributed energy resource facilities, with a combined capacity of more than 3,700 MW operating across all Duke Energy jurisdictions. More than $90 \%$ of this capacity is in the Carolinas, where more than 16,000 distributed energy resource sites generate more than 3,200 MW on the transmission and distribution systems, making the Duke Carolinas a national leader for integrating utility-scale solar generation. Duke Energy continues to strengthen its commitment toward carbon-free electricity generation, and during the next several years the capacity of solar generation across Duke Energy is expected to at least double. The incentivization of commercial solar by Duke Energy coupled with the recently launched proposal for $6800 \mathrm{MW}$ under the North Carolina House Bill 589, as well as plans to add $700 \mathrm{MW}$ of solar facilities in Florida, continue to drive the rapid adoption of solar generation across Duke Energy's service territory (Duke Energy, 2018).

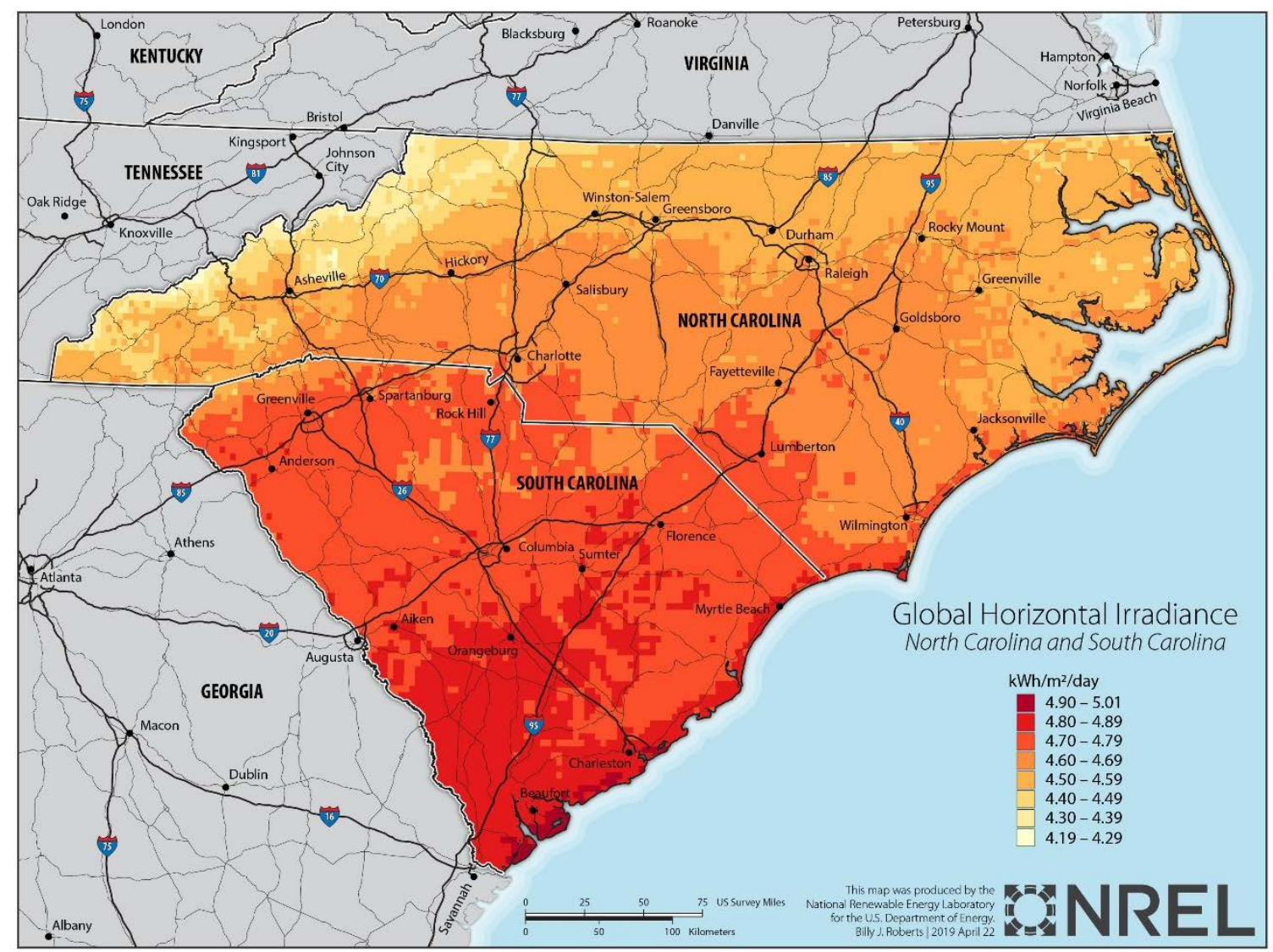

Figure 1. Solar energy resource in the Carolinas region

Duke Energy is seeking to analyze the impacts of integrating significant amounts of new carbonfree power sources into the Duke Energy power system under a variety of penetrations levels. This report focuses on investigating the addition of solar power along with understanding how the integration of variable generation sources, especially at high penetration levels, comes with potential challenges to reliable power system operations. The variability and uncertainty of renewable energy sources are two major constraints to integrating them into the power system. In 
power network operations, generation planners will always need to ensure that there is enough capacity to serve load at any given time. Characterizing variable generation resources in planning operations becomes a challenge because of their tendency to disrupt the balance of the generation portfolio. Consequently, thermal and hydro generators are operated differently to accommodate the variability and uncertainty of renewable electricity generators (Lew, 2013).

Additionally, the integration of variable and uncertain power generation from wind and solar units at high penetration levels introduces another pivotal variable: net load (normal load less wind power and solar power). This creates a new set of requirements for integrated and reliable power system planning operations. The net load variability has created a further need to evaluate system flexibility because of its impacts on system operating costs. The ability of the power system to integrate additional renewable resources is largely a function of its flexibility, which is chiefly driven by the ability of individual plants to change their output to serve these variations in net electricity consumption (Ela, 2014). The key to managing the variability and uncertainty of variable generation sources is to increase the system-wide flexibility in the power system (Mai, et al., 2012).

Duke Energy is committed to creating a carbon-free power system of the future. Currently, the large nuclear fleet contributes to load greatly as carbon-free generation. With the current cost of solar power, it makes sense to investigate increasing solar power capacity to meet higher carbonfree goals. This will likely increase the requirement for Duke's thermal generation sources to be flexible, which will be limited by their nuclear power plants, which typically run only at full output. A detailed understanding of power system flexibility characteristics has become critical because high levels of variable generation will have significant impacts on the operation of the traditional thermal generation fleet.

This report analyzes the net load and presents the impact of high penetration levels of variable generation on the operation of Duke Energy's power system given the flexibility limits set by a combination of the must-run units, hydro schedules, nuclear generators, and storage. These limits dictate curtailing excess solar power during times when there is a greater amount of solar photovoltaic (PV) generation than can be accommodated.

To contextualize subsequent discussions in this report, it is important to define variable generation penetration levels. One power-based definition considers the ratio of variable generation nameplate capacity to system peak load. The definition of penetration level by energy often estimates the amount of renewable energy (pre-curtailment) injected into the grid during a period of time and helps to quantify the amount of displaced fossil-fueled generation, fuel consumption savings, and avoided carbon emissions. The energy-based definition is useful when considering very large systems and long time frames, and it has been adopted in many renewable portfolio standards (Bebic, 2008). Therefore, the analysis presented in this report uses the energy-based definition of penetration level on an annual basis.

In scoping Phase 1 of this collaborative engagement, the National Renewable Energy Laboratory (NREL), in consultation with Duke Energy, designed the scenarios to be considered, as shown in Table 1. These scenarios are analyzed and documented in this report. Note that the penetration levels used in naming the scenarios are approximate numbers based on annual energy before curtailment. 
Table 1. Scenarios for Net Load Analysis

\begin{tabular}{|c|c|}
\hline Scenario & Definition \\
\hline 1. Solar energy penetration $5 \%$ & $4,109 \mathrm{MW}, 5.5 \%$ of total solar is rooftop \\
\hline 2. Solar energy penetration $10 \%$ & $8,219 \mathrm{MW}, 5.5 \%$ of total solar is rooftop \\
\hline 3. Solar energy penetration $15 \%$ & $12,328 \mathrm{MW}, 5.5 \%$ of total solar is rooftop \\
\hline 4. Solar energy penetration $20 \%$ & $16,438 \mathrm{MW}, 5.5 \%$ of total solar is rooftop \\
\hline 5. Solar energy penetration $25 \%$ & $20,547 \mathrm{MW}, 5.5 \%$ of total solar is rooftop \\
\hline 6. Solar energy penetration $30 \%$ & $24,656 \mathrm{MW}, 5.5 \%$ of total solar is rooftop \\
\hline 7. Solar energy penetration $35 \%$ & $28,766 \mathrm{MW}, 5.5 \%$ of total solar is rooftop \\
\hline $\begin{array}{l}\text { 8. Higher ratio of distributed to } \\
\text { utility solar added to the system }\end{array}$ & $\begin{array}{l}\text { Based on the } 25 \% \text { solar energy penetration scenario, } 18.91 \% \text { of PV } \\
\text { is uncurtailable rooftop }\end{array}$ \\
\hline 9. Additional storage & $\begin{array}{l}\text { Based on the } 25 \% \text { solar energy penetration scenario, addition of } \\
1,000 \mathrm{MW} \text { of } 4 \text {-hour storage, } 1,000 \mathrm{MW} \text { of } 6 \text {-hour storage, and } \\
2,000 \mathrm{MW} \text { of } 8 \text {-hour storage }\end{array}$ \\
\hline 10. Nuclear retirement & $\begin{array}{l}\text { Based on the } 25 \% \text { solar energy penetration scenario, assumes a } \\
10 \% \text { nuclear reduction }\end{array}$ \\
\hline $\begin{array}{l}\text { 11. Additional wind energy } \\
\text { penetration } 5 \%\end{array}$ & $\begin{array}{l}\text { Based on the } 30 \% \text { solar energy penetration scenario, an additional } \\
5 \% \text { wind energy penetration is added }\end{array}$ \\
\hline $\begin{array}{l}\text { 12. Scenarios } 1-3 \text { modeled with } \\
\text { two balancing authorities }\end{array}$ & $\begin{array}{l}\text { Based on scenarios } 1-3 \text { inclusive, DEP and DEC are analyzed } \\
\text { separately with an interconnection limit between, defined in the } \\
\text { appendix }\end{array}$ \\
\hline
\end{tabular}

This report examines the amount of renewable energy curtailment as well as the particular hours of curtailment for these scenarios. This report also presents an evaluation of the daily percentage of carbon-free generation from carbon-free plants.

Note that there are some limitations to the net load analysis presented in this report. This analysis does not include unit commitment and economic dispatch models; interconnection to neighbors; market models; system stability metrics such as voltage and/or frequency; or costs - all of which would be essential in recommending a pathway to the future. 


\section{Characterizing the Net Load}

As power system planning continues to move toward adopting an integrated planning approach caused by increasing variable generation integration, it is now critical to begin characterizing the net load. The net load - defined here as the total customer demand minus the variable generation - gives the demand that must be met by traditional dispatchable generation. For this analysis, solar PV is considered to be non-dispatchable, though the utility solar power can be curtailed down. Therefore, its contribution to meeting reserve margins is quantified by how it changes the net load.

The net load analysis can be of interest for several reasons, including:

- At high penetration levels, variable generation can cause a significant shift in the timing of both the minimum and peak net load relative to the system or gross load, which can impact the system generation scheduling, cost of generation, and daily unit commitment and dispatch.

- During low-load conditions, which typically occur during the spring, high penetrations of variable generation can violate the system flexibility limit and result in significant integration issues. Consequently, during such periods renewable generation must be curtailed, which can adversely impact variable generation project economics or contractual arrangements with renewable generators.

- Net load analysis can be a useful tool in assessing power system flexibility in the presence of varying penetration levels of variable generation. Because increasing variable generation penetration levels can lead to increases in net load variability, and thus required thermal unit ramp rates and ramping ranges, the need for the power system to become more flexible increases. This scenario demands that conventional power plants would need to change their output more frequently than traditionally. Situations when the system flexibility requirements are not met could impact the reliable and economic operations of the grid. Impacts could include variable generation curtailment, reserve shortfalls, and potential frequency violations as a result of over- and undergeneration (Milligan, 2015)

- Outputs from net load analysis such as maximum renewable curtailment and the number of hours of curtailment are important metrics that can be used to evaluate system flexibility. Detailed flexibility evaluation, however, requires further analysis using different modeling methods, such as production cost modeling, capacity expansion planning, and dynamic stability analysis. 


\section{Scenario Analysis}

This net load analysis covers the Duke Energy Carolinas (DEC) and Duke Energy Progress (DEP) balancing authorities, with 2019 hourly forecasted load data supplied by Duke Energy. Maintaining load and renewable resource coincident relationships is a primary consideration in net load analysis and assessing its impact on the system operational requirements, such as determining minimum generation levels (GE Energy, 2010). Spatial and temporal correlation of the load and variable generation sources are needed to accurately reflect the underlying weather patterns that drive both load and variable generation.

This report uses 2019 forecasted annual load and solar PV time-series profiles supplied by Duke Energy and based on the same weather period to ensure that the solar profiles are synchronized with the weather assumed in the load. For the net load analysis, thermal generation outside of nuclear, hydropower, and must-run units is considered to be entirely flexible-i.e., there are no constraints on minimum stable level, ramp rates, and outage rates. Rooftop solar is noncurtailable, utility solar is curtailable, and the must-run units are used for local voltage constraints. Table 8 , in the appendix, shows a list of assumptions and definitions used for the net load analysis.

The generation flexibility limit consists of nuclear, hydropower units, and must-run units, offset by the hydropower pumped storage capacity (see Equation 1 in the appendix). Nuclear is assumed to run at $100 \%$ capacity for this analysis. From the data supplied by Duke Energy, note that the must-run units have hourly triggers and therefore could change intra-daily, whereas hydro schedules vary monthly. This explains why the generation flexibility limit line could change seasonally, and possibly daily, which is reflective of the inherent characteristics of the must-run units and hydro capacity considered in this analysis. The renewable energy curtailment per hour is the net load below the flexibility limit, which is calculated using Equation 2 in the appendix. The daily percentage of carbon-free generation includes solar power, wind power, hydropower, and nuclear (using storage), and it is calculated in Equation 3 in the appendix. The presented maximum up-ramp and down-ramp times are based on the ending times of each ramp.

An analysis of the average, minimum, and maximum net load days is performed to illustrate the varying impact of the net load variability across different seasons on key metrics, such as daily percentage of carbon-free generation, percentage of curtailed energy, maximum instantaneous curtailment, and hours of curtailment. The net load curves, as presented in this section, help capture the net load demand that the system must meet in real time for reliable operation of the grid.

\subsection{Scenarios 1-7: 5\%-35\% Solar Energy Penetration}

Seven different levels of solar energy penetration are explored, beginning with $5 \%$ penetration and increasing in 5\% increments through 35\% penetration. The solar output before curtailment is the 2019 PV time series provided by Duke Energy scaled to the specified percentage of the total load. The scalars used for each scenario are provided in Table 3 of the appendix and are calculated using Equation 4. Higher penetrations of solar power are expected to experience geographical smoothing, which the scalers do not account for and thus overestimate the variability. Ramp rates for all the scenarios are calculated as the difference between the net load at a given hour and the hour immediately prior. 
Solar PV capacities for each level of solar penetration are shown in Table 2.

Table 2. PV Capacities for Penetration Levels Defined by Scenarios 1-7

\begin{tabular}{|l|l|l|l|l|l|l|l|}
\hline $\begin{array}{l}\text { PV penetration in terms of annual } \\
\text { energy before curtailment (\%) }\end{array}$ & 5 & 10 & 15 & 20 & 25 & 30 & 35 \\
\hline PV capacity (MW) & 4,109 & 8,219 & 12,328 & 16,438 & 20,547 & 24,656 & 28,766 \\
\hline
\end{tabular}

Average daily values for load, generation flexibility limit, rooftop, and all PV plants are estimated across all seasons. Figure 2 shows these data for scenarios 1-7 in the spring season, which has the highest curtailment. Graphs for the three remaining seasons are available in the appendix. In low penetrations of PV, adding more PV increases the percentage of load met by carbon-free generation until the flexibility limit is reached, at which point curtailment increases and additional solar power has diminishing returns.

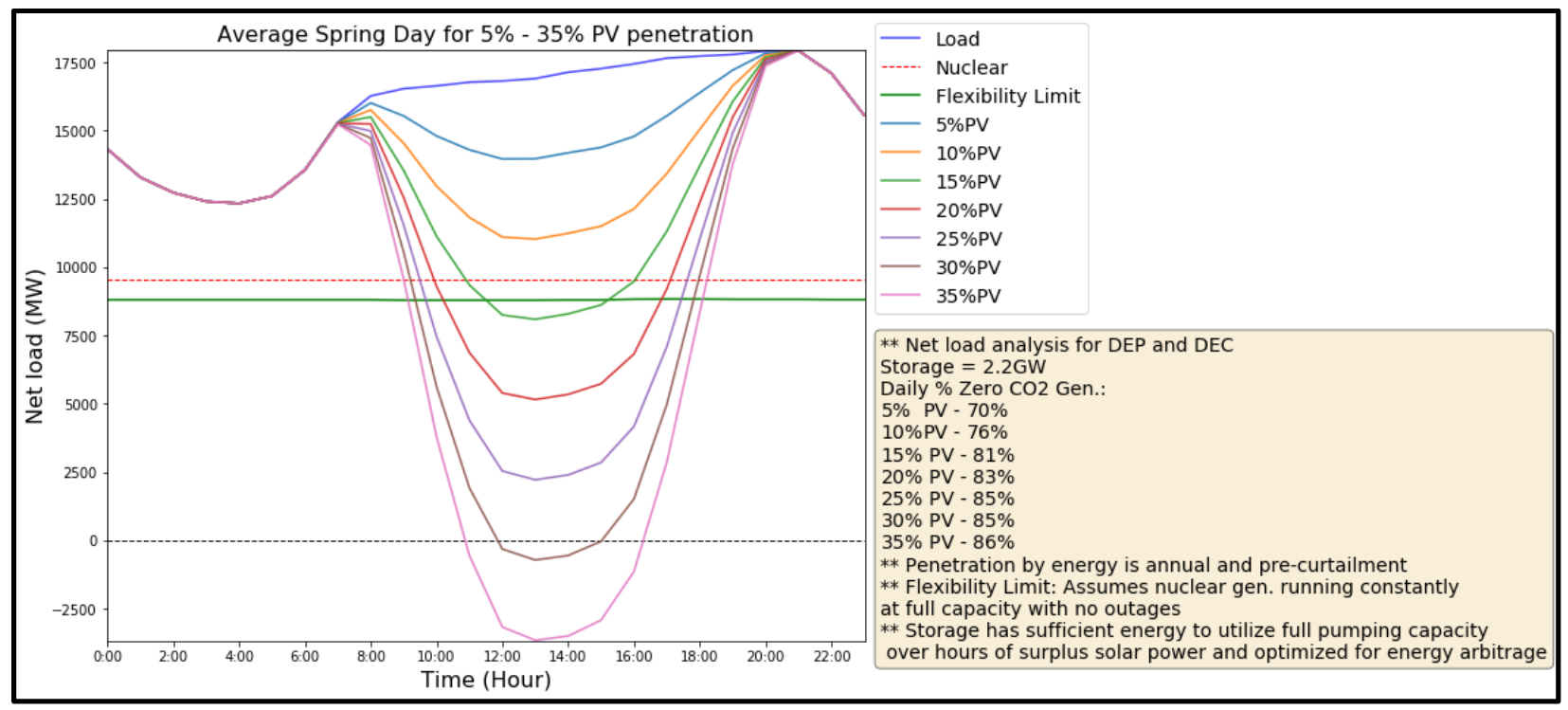

Figure 2. Average net load for all scenarios for spring

Annual average carbon-free generation ranges from $60 \%$ to $77 \%$ from the $5 \% \mathrm{PV}$ penetration case to the $35 \%$ case, respectively. Seasonal values are shown in Table 3. 
Table 3. Average Seasonal Percentage of Load Met by Carbon-Free Generation for Each Scenario

\begin{tabular}{|l|c|c|c|c|c|}
\hline Scenario & Spring & Summer & Fall & Winter & Annual \\
\hline 1. Solar energy penetration 5\% & $69 \%$ & $54 \%$ & $65 \%$ & $57 \%$ & $60 \%$ \\
\hline 2. Solar energy penetration 10\% & $75 \%$ & $59 \%$ & $70 \%$ & $61 \%$ & $65 \%$ \\
\hline 3. Solar energy penetration 15\% & $80 \%$ & $64 \%$ & $74 \%$ & $63 \%$ & $70 \%$ \\
\hline 4. Solar energy penetration 20\% & $83 \%$ & $68 \%$ & $76 \%$ & $65 \%$ & $73 \%$ \\
\hline 5. Solar energy penetration 25\% & $84 \%$ & $71 \%$ & $78 \%$ & $66 \%$ & $74 \%$ \\
\hline 6. Solar energy penetration 30\% & $85 \%$ & $73 \%$ & $79 \%$ & $67 \%$ & $76 \%$ \\
\hline 7. Solar energy penetration 35\% & $86 \%$ & $74 \%$ & $80 \%$ & $68 \%$ & $77 \%$ \\
\hline 8. Increase proportion of distributed solar & $84 \%$ & $71 \%$ & $78 \%$ & $66 \%$ & $74 \%$ \\
\hline 9. Additional storage & $88 \%$ & $73 \%$ & $81 \%$ & $68 \%$ & $77 \%$ \\
\hline 10. Nuclear retirement & $80 \%$ & $67 \%$ & $73 \%$ & $62 \%$ & $70 \%$ \\
\hline 11. Additional wind energy penetration 5\% & $90 \%$ & $76 \%$ & $83 \%$ & $71 \%$ & $79 \%$ \\
\hline 12. Two balancing authorities: DEC 5\% & $80 \%$ & $61 \%$ & $76 \%$ & $66 \%$ & $70 \%$ \\
\hline 12. Two balancing authorities: DEC 10\% & $87 \%$ & $66 \%$ & $82 \%$ & $70 \%$ & $75 \%$ \\
\hline 12. Two balancing authorities: DEC 15\% & $93 \%$ & $71 \%$ & $87 \%$ & $73 \%$ & $80 \%$ \\
\hline 12. Two balancing authorities: DEP 5\% & $56 \%$ & $45 \%$ & $53 \%$ & $47 \%$ & $50 \%$ \\
\hline 12. Two balancing authorities: DEP 10\% & $62 \%$ & $50 \%$ & $57 \%$ & $50 \%$ & $54 \%$ \\
\hline 12. Two balancing authorities: DEP 15\% & $65 \%$ & $55 \%$ & $60 \%$ & $53 \%$ & $58 \%$ \\
\hline
\end{tabular}

With the current flexibility limit, curtailment is necessary at PV penetration levels of $10 \%$ and more. Duke Energy will first experience significant curtailment at the 10\% PV penetration level, at an annual average of 1.1\%. Figure 3 shows a low net load day in spring, during which 20\% curtailment will occur. With 10\% PV energy, $65 \%$ of the annual load is met by carbon-free generation, indicating that in this case nearly $65 \%$ of energy from carbon-free sources could be achieved before any curtailment is needed. In Scenario 12, where DEP and DEC are modeled separately with a total PV penetration of $15 \%$, DEC in spring achieves a carbon-free contribution of more than $100 \%$. This is because we assume that existing storage can charge with energy that would otherwise be curtailed and then release the corresponding energy within the same day. This value suggests that this operation would result in a surplus of generation. 


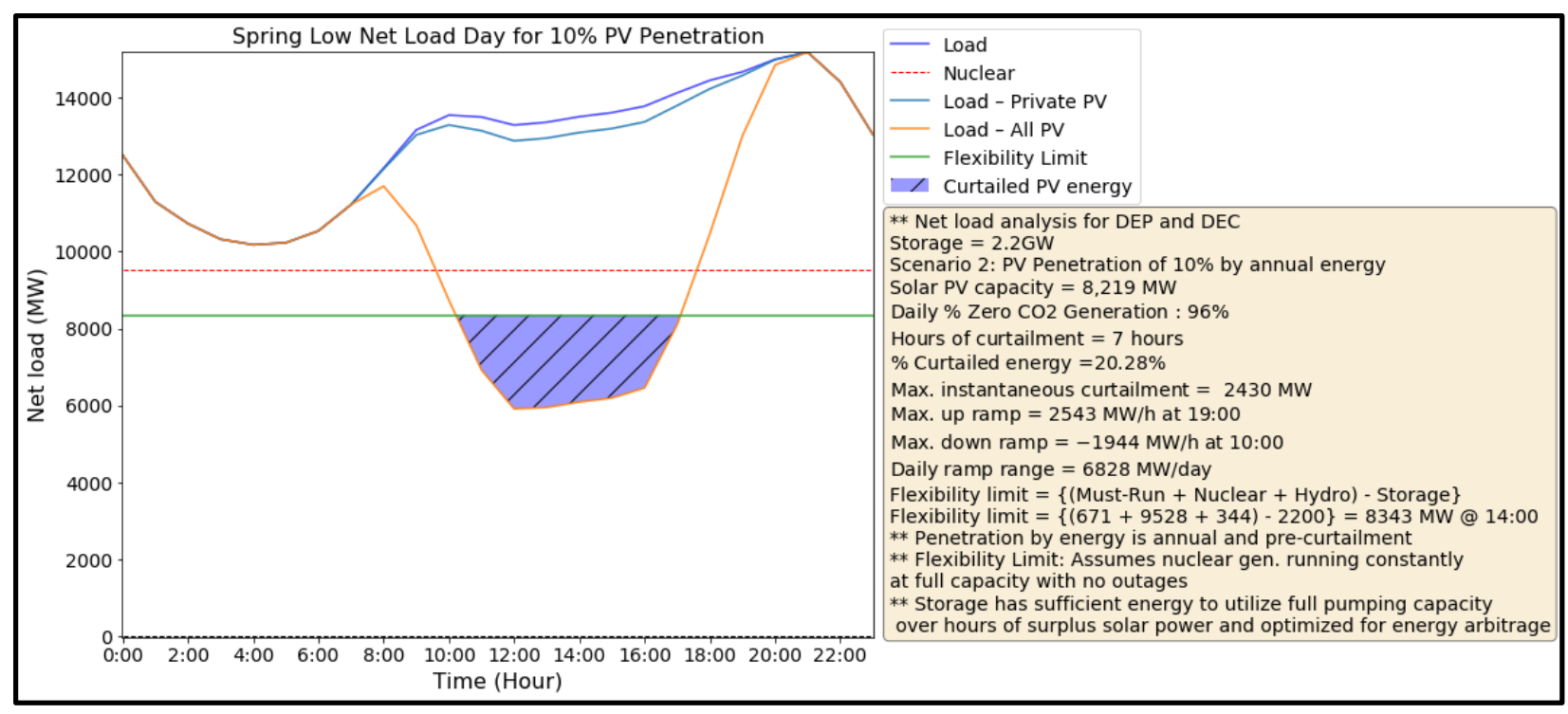

Figure 3. Minimum net load day for spring with $10 \%$ PV penetration

Annual percentage of curtailment ranges from $1.1 \%$ to $42 \%$ of total solar energy for scenarios $2-$ 7. Seasonal and annual percentages of curtailment are shown in Table 4, and hours of curtailment are shown in Table 5. Seasonal maximum instantaneous curtailment is given in Table 13 in the appendix. Generally, the highest curtailment occurs in spring and the lowest in summer. 
Table 4. Average Percentage Curtailed Energy

\begin{tabular}{|l|l|l|l|l|l|}
\hline Scenario & Spring & Summer & Fall & Winter & Annual \\
\hline 1. Solar energy penetration 5\% & $0 \%$ & $0 \%$ & $0 \%$ & $0 \%$ & $0 \%$ \\
\hline 2. Solar energy penetration 10\% & $2 \%$ & $0 \%$ & $1 \%$ & $2 \%$ & $1 \%$ \\
\hline 3. Solar energy penetration 15\% & $12 \%$ & $1 \%$ & $10 \%$ & $10 \%$ & $8 \%$ \\
\hline 4. Solar energy penetration 20\% & $25 \%$ & $4 \%$ & $22 \%$ & $22 \%$ & $17 \%$ \\
\hline 5. Solar energy penetration 25\% & $36 \%$ & $12 \%$ & $32 \%$ & $31 \%$ & $27 \%$ \\
\hline 6. Solar energy penetration 30\% & $44 \%$ & $21 \%$ & $40 \%$ & $39 \%$ & $35 \%$ \\
\hline 7. Solar energy penetration 35\% & $50 \%$ & $29 \%$ & $46 \%$ & $45 \%$ & $42 \%$ \\
\hline 8. Increase proportion of distributed solar & $36 \%$ & $12 \%$ & $32 \%$ & $31 \%$ & $27 \%$ \\
\hline 9. Additional storage & $19 \%$ & $2 \%$ & $15 \%$ & $14 \%$ & $12 \%$ \\
\hline 10. Nuclear retirement & $30 \%$ & $8 \%$ & $27 \%$ & $26 \%$ & $22 \%$ \\
\hline 11. Additional wind energy penetration 5\% & $40 \%$ & $20 \%$ & $36 \%$ & $34 \%$ & $32 \%$ \\
\hline 12. Two balancing authorities: DEC 5\% & $0 \%$ & $0 \%$ & $0 \%$ & $0 \%$ & $0 \%$ \\
\hline 12. Two balancing authorities: DEC 10\% & $2 \%$ & $0 \%$ & $1 \%$ & $1 \%$ & $1 \%$ \\
\hline 12. Two balancing authorities: DEC 15\% & $11 \%$ & $1 \%$ & $9 \%$ & $10 \%$ & $7 \%$ \\
\hline 12. Two balancing authorities: DEP 5\% & $0 \%$ & $0 \%$ & $0 \%$ & $0 \%$ & $0 \%$ \\
\hline 12. Two balancing authorities: DEP 10\% & $2 \%$ & $0 \%$ & $1 \%$ & $1 \%$ & $1 \%$ \\
\hline 12. Two balancing authorities: DEP 15\% & $15 \%$ & $1 \%$ & $13 \%$ & $13 \%$ & $10 \%$ \\
\hline
\end{tabular}


Table 5. Hours of Curtailment per Season

\begin{tabular}{|l|l|l|l|l|l|}
\hline Scenario & Spring & Summer & Fall & Winter & Annual \\
\hline 1. Solar energy penetration 5\% & 0 & 0 & 0 & 6 & 6 \\
\hline 2. Solar energy penetration 10\% & 76 & 0 & 45 & 58 & 179 \\
\hline 3. Solar energy penetration 15\% & 351 & 36 & 275 & 220 & 882 \\
\hline 4. Solar energy penetration 20\% & 533 & 216 & 403 & 354 & 1,506 \\
\hline 5. Solar energy penetration 25\% & 636 & 458 & 494 & 428 & 2,016 \\
\hline 6. Solar energy penetration 30\% & 707 & 598 & 562 & 488 & 2,355 \\
\hline 7. Solar energy penetration 35\% & 752 & 700 & 610 & 525 & 2,587 \\
\hline 8. Increase proportion of distributed solar & 634 & 454 & 496 & 433 & 2,017 \\
\hline 9. Additional storage & 484 & 136 & 341 & 278 & 1,239 \\
\hline 10. Nuclear retirement & 593 & 363 & 457 & 391 & 1,804 \\
\hline 11. Additional wind energy penetration 5\% & 746 & 650 & 584 & 506 & 2,486 \\
\hline 12. Two balancing authorities: DEC 5\% & 0 & 0 & 0 & 5 & 5 \\
\hline 12. Two balancing authorities: DEC 10\% & 91 & 2 & 54 & 66 & 213 \\
\hline 12. Two balancing authorities: DEC 15\% & 358 & 53 & 278 & 223 & 912 \\
\hline 12. Two balancing authorities: DEP 5\% & 0 & 0 & 0 & 5 & 5 \\
\hline 12. Two balancing authorities: DEP 10\% & 90 & 1 & 51 & 63 & 205 \\
\hline 12. Two balancing authorities: DEP 15\% & 361 & 45 & 282 & 217 & 905 \\
\hline
\end{tabular}

In Duke Energy's current system, low load days are important because of the lack of flexible thermal generation that can be relied on to reduce power output, if needed. In the case of high solar power penetration, such as the $25 \%$ case shown in Figure 4 , the minimum net load days are more important because the system becomes more sensitive to solar power forecasting errors and causes greater ramps and variability. In this case, the average curtailment for this season is $25 \%$; however, this particular day shows a sunny low load day reaching $62.9 \%$ curtailment. 


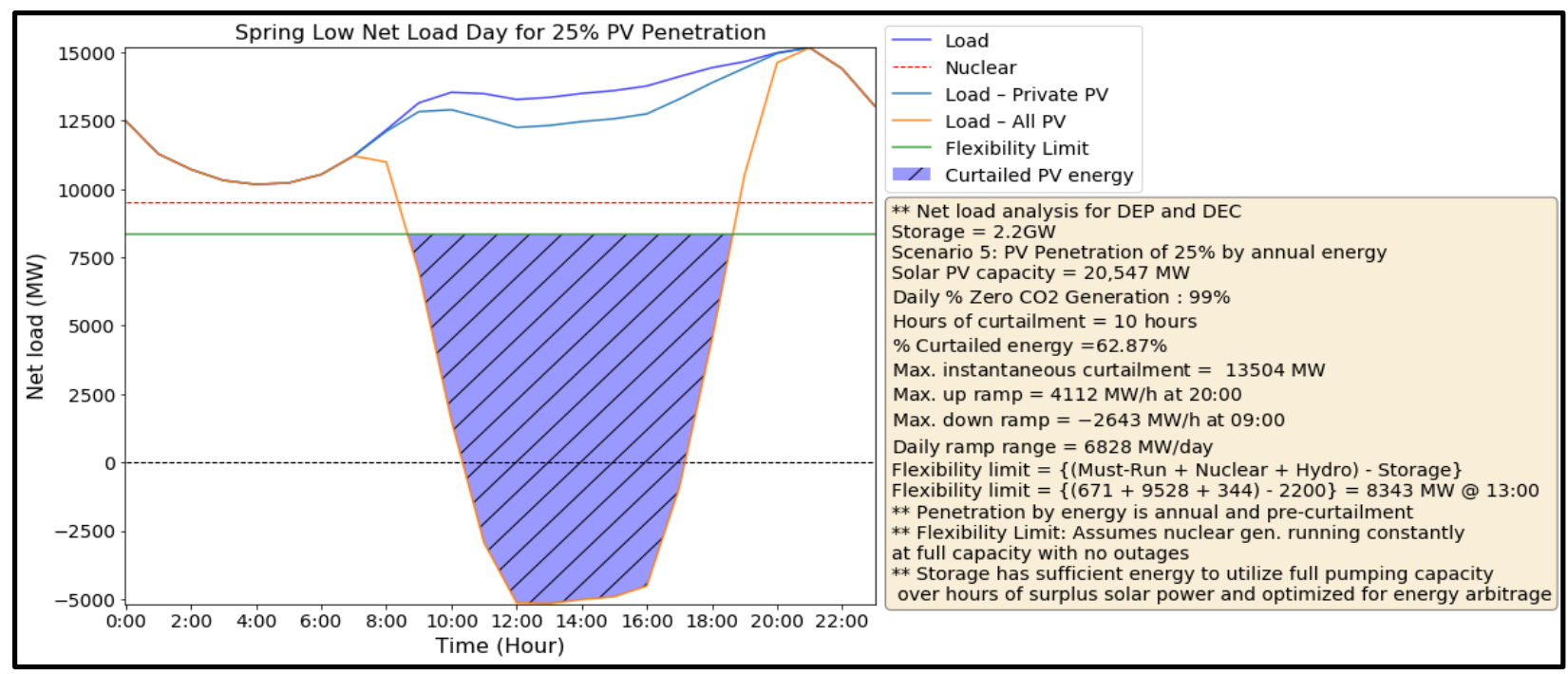

Figure 4. Minimum net load day for spring, the highest curtailment season, with $25 \%$ solar energy penetration

At higher loads, such as the peak load day of summer, which has $25 \% \mathrm{PV}$ penetration, shown in Figure 5, flexible thermal generation needs to increase output, and therefore the system has a greater ability to reduce generation to be replaced with solar power during the day, and less curtailment is required. This is evident in Table 4, which shows that the curtailment during the summer is the minimum of all the values of seasonal curtailment across all scenarios.

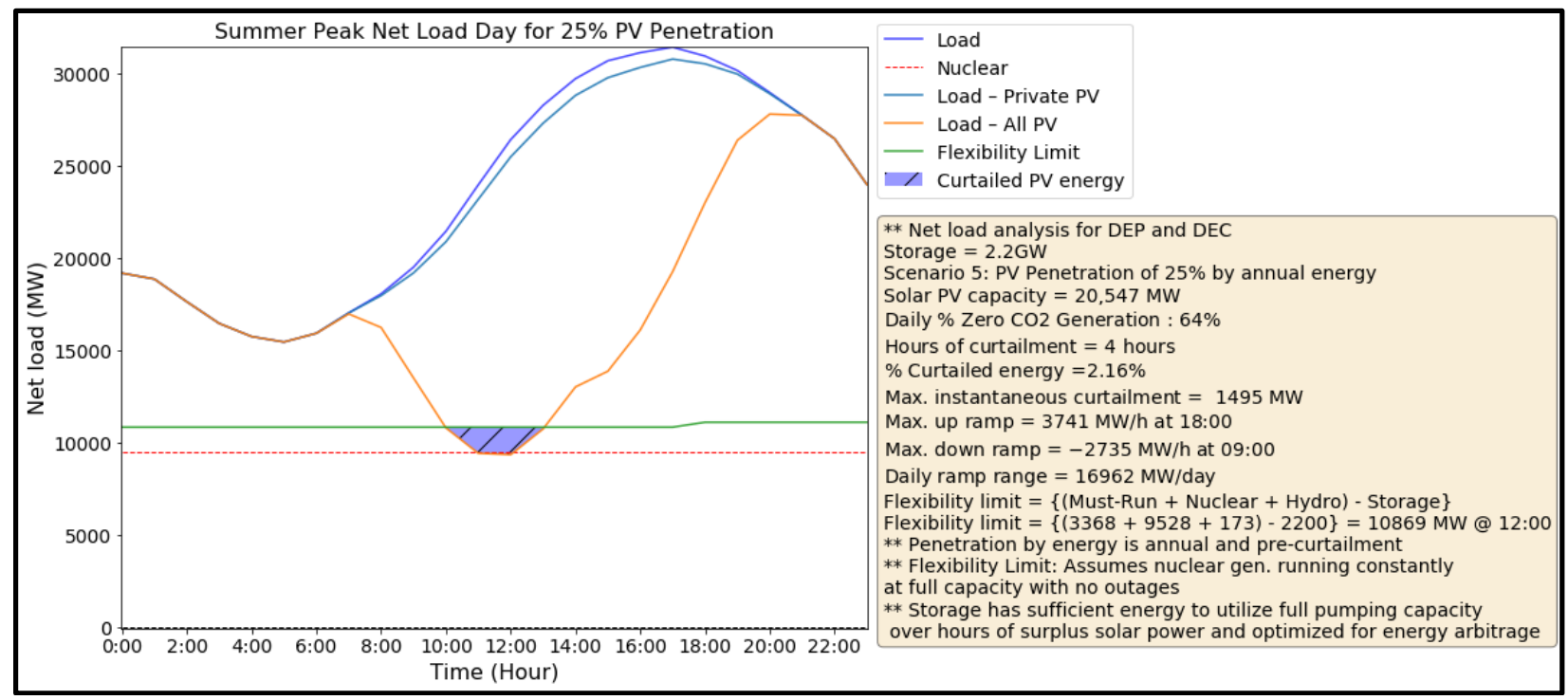

Figure 5. Max net load day for lowest curtailment season, summer, with $25 \%$ solar energy penetration 
Marginal curtailment is defined as the percentage of the additional renewable energy that would be curtailed as the penetration level is increased by $5 \%$ of the load. The curtailment of each scenario is compared to that of the scenario with $5 \%$ less solar. Or, in the case of Scenario 11, which has $5 \%$ wind and $30 \%$ solar penetration, the curtailment is compared to that of Scenario 6 , which has $30 \%$ solar. The marginal curtailment for all applicable scenarios is shown in Table 6 .

Table 6. Percentage Marginal Curtailment

\begin{tabular}{|l|c|}
\hline Scenario & \% Marginal Curtailment \\
\hline 2. Solar energy penetration $10 \%$ & $2.2 \%$ \\
\hline 3. Solar energy penetration $15 \%$ & $21.4 \%$ \\
\hline 4. Solar energy penetration $20 \%$ & $46.3 \%$ \\
\hline 5. Solar energy penetration $25 \%$ & $64.6 \%$ \\
\hline 6. Solar energy penetration 30\% & $76.7 \%$ \\
\hline 7. Solar energy penetration 35\% & $83.2 \%$ \\
\hline 9. Additional storage & $4.3 \%$ \\
\hline 10. Nuclear retirement & $41.0 \%$ \\
\hline 11. Additional wind energy penetration 5\% & $26.3 \%$ \\
\hline 12. Two balancing authorities: 10\% penetration & $2.5 \%$ \\
\hline 12. Two balancing authorities: $15 \%$ penetration & $22.9 \%$ \\
\hline
\end{tabular}

The load duration curve can also be a useful tool to illustrate the impact of variable generation penetration on the system peak and light loads. Load duration curves for the total system load and net load with 25\% PV penetration are shown in Figure 6. The annual peak load is insignificantly reduced by the integration of solar PV because it occurs in winter before sunrise. During certain periods (1,947 hours), however, this penetration level reduces the annual minimum load to less than the minimum generation level set by the nuclear line. This implies that as PV penetration increases, solar PV will start to offset baseload generation or must be curtailed. This effect could vary based on the generation flexibility limit line imposed by the must-run units, hydro schedules, and energy storage systems. 


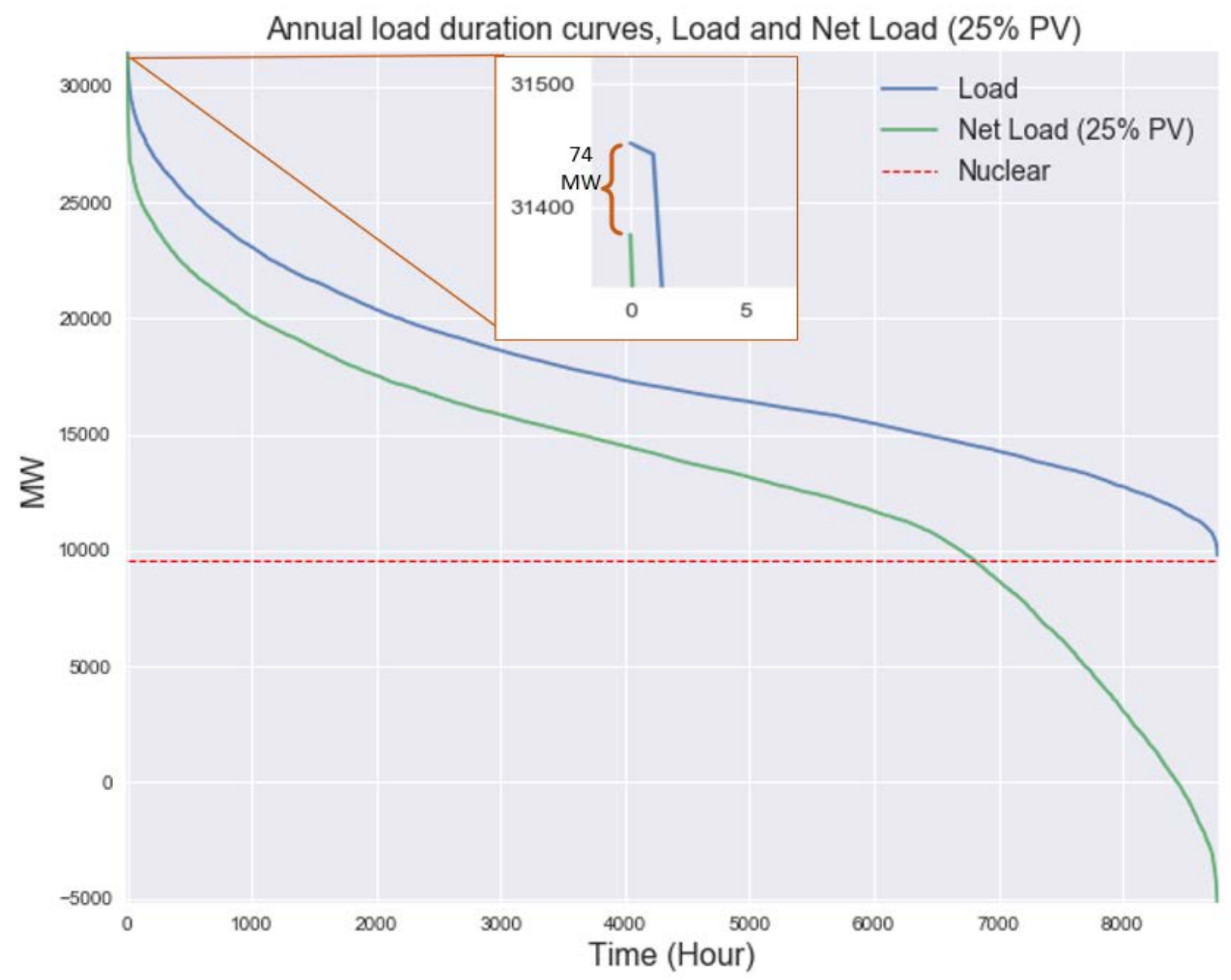

Figure 6. Annual load duration curves, load, and net load with $25 \%$ PV penetration

\subsection{Scenario 8: Increased Proportion of Distributed Solar Energy}

A portion of the PV generation, rooftop PV, is not curtailable by Duke Energy. Scenario 8 examines a relatively high solar penetration scenario of $25 \%$, with the maximum expected proportion of the solar energy from rooftop solar. A model with such a large percentage of rooftop PV for the $25 \%$ solar power penetration by energy case will improve understanding of how the requirements for curtailment of additional PV might change with increased adoption of behind-the-meter solar PV. The PV time series provided by Duke includes separate profiles for rooftop and utility-scale solar energy, so the rooftop time series and utility time series are both scaled to forecast a higher proportion of rooftop solar generation. The scalars and equations used to calculate these profiles are shown in the appendix.

To capture an increase in rooftop PV by 2030, the maximum percentage of total solar PV that might be rooftop PV was assumed to be $18.91 \%$. This percentage was obtained using the NREL- 
developed standard scenarios of the U.S. power sector tool, ${ }^{3}$ which models 42 different scenarios to capture the impacts of fuel prices, demand growth, retirements, technology and financing costs, transmission and resource restrictions, and policy considerations on possible power system capacity expansion futures. The scenario predicting the largest ratio of rooftop solar to utility solar in the Carolinas in 2030 accounts for extended lifetimes of current generation facilities. This Extended Lifetimes Scenario assumes that coal power plant lifetimes are increased by 10 years, there are no retirements of underused coal power plants, and all nuclear power plants have 80 -year lifetimes.

Using Scenario 5 (25\% solar energy penetration) as a baseline, the effect of an increased proportion of distributed PV energy to utility PV energy is modeled. The PV time series corresponding to $25 \%$ solar penetration was scaled by the projected percentage of utility PV energy and the percentage of distributed PV energy to calculate the two projected time series.

The analysis assumes that rooftop PV cannot be curtailed, so an increase in the percentage of rooftop PV results in an increase in utility PV that must be curtailed. Comparing the results of Scenario 8 to Scenario 5 (25\% PV penetration) shows that $33.2 \%$ of utility solar would be curtailed provided a maximum increase in the proportion of rooftop PV versus utility PV, whereas $28.5 \%$ of utility PV would be curtailed if this proportion remains unchanged from the assumptions used in scenarios $1-7$.

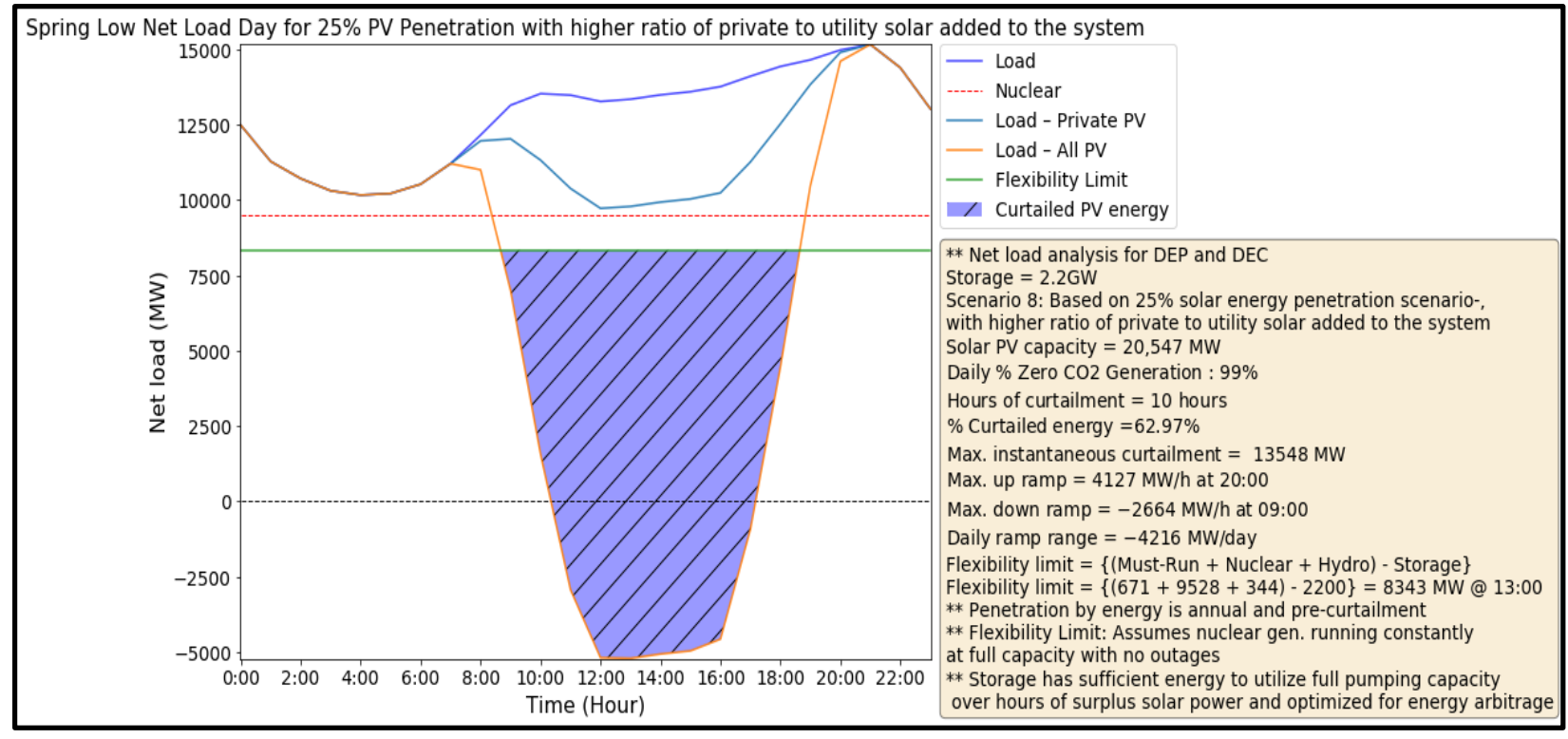

Figure 7. Minimum net load day with an increase in rooftop PV

As shown in Figure 7, even with a maximum increase in rooftop PV to $18.91 \%$, the difference between load and solar as a result of rooftop generation never crosses the flexibility limit at $25 \%$ solar penetration.

${ }^{3}$ https://openei.org/apps/reeds/\# 


\subsection{Scenario 9: Additional Storage Capabilities}

Scenario 9 captures the effect of an increase in storage with $25 \%$ solar energy penetration and demonstrates how this additional technology resource might reduce the curtailment required in a high solar penetration scenario. The hypothetical storage is charged entirely with surplus renewable energy sources and is assumed to discharge throughout the remainder of the day with a round-trip efficiency of $80 \%$. The storage stores energy only during hours of surplus generation. In addition to the existing storage consisting of 2,200 MW of pumped storage hydropower, the additional storage modeled is 1,000 MW of 4-hour storage, 1,000 MW of 6hour storage, and 2,000 MW of 8-hour storage. This is a total of 26,000 MWh of storage.

The storage is given a hierarchy of use preferences: for each modeled day, the 8-hour storage is used to capacity first, followed by the 6-hour storage, and finally the 4-hour storage is used. The generation flexibility limit line is then adjusted to incorporate the additional used storage, and curtailment is adjusted to fit the new flexibility limit.

The addition of such storage results in an improvement in the percentage of renewable energy curtailed from $26.9 \%$ (Scenario 5) to $14.8 \%$. The greatest improvement is seen in the winter, during which time the curtailment decreases from $31.3 \%$ to $14 \%$. The minimum net load day in the winter of Scenario 9 is shown in Figure 6, and that of Scenario 5 is shown in Figure 9.

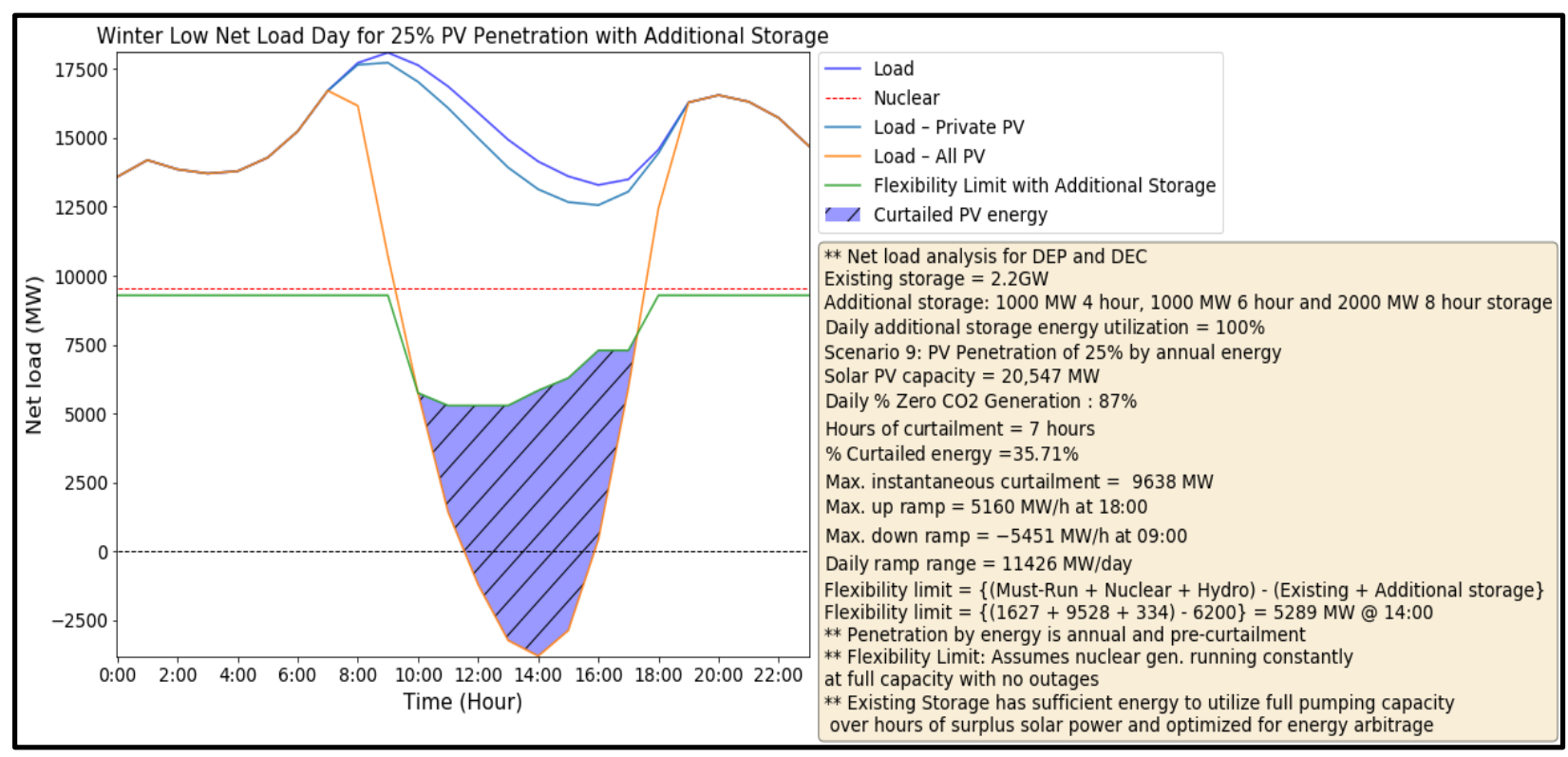

Figure 8. Minimum net load day in winter with additional storage

The additional storage modeled accounts for $7 \%$ of the load on this day. The annual contribution to this additional storage amounts to $3.7 \%$ of annual load. 


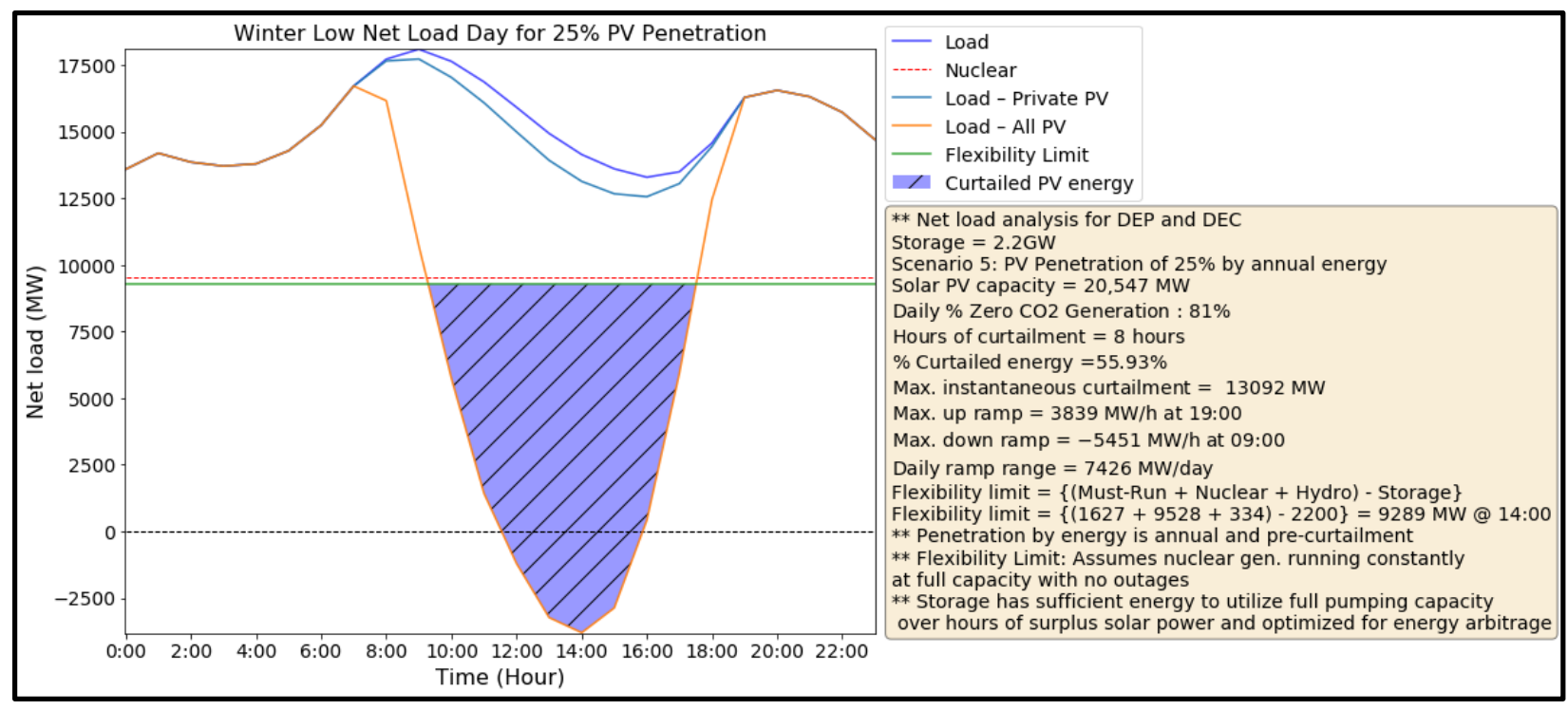

Figure 9. Minimum net load day in winter without additional storage

The smallest impact occurs in the summer, with an improvement from $11.8 \%$ curtailment to $2.3 \%$. For this analysis, storage is assumed to be used exclusively for load-shifting. In reality, storage could also potentially provide ancillary services, such as regulation reserves, especially in the summer seasons, when the load-shifting requirement is minimal. Further, if transmission constraints were considered, the total contribution of storage to saving renewable energy curtailment could be higher.

In this model, energy storage devices are charging only during times of overgeneration. The additional storage modeled results in an annual average of $77 \%$ carbon-free energy, whereas the carbon-free percentage of Scenario 5 is $74 \%$. The additional storage yields a greater percentage of the carbon-free energy resource than that of Scenario 7, the 35\% solar energy penetration model $(77 \%)$.

Further analysis should examine a unit commitment and economic dispatch model, which could help understand the most economical and effective storage solutions to meet the proposed extra flexibility here, including the potential to use controllable electric vehicle charging. Further, such detailed analysis would quantify the economic value and system stability benefits of the additional storage through such examples as additional capacity, enabling higher penetrations of low-cost solar power and providing ancillary services.

\subsection{Scenario 10: Generation Retirement}

The portion of energy from nuclear sources is unique in the Duke Energy Carolinas region, contributing to a large amount of carbon-free generation. For this analysis, the possibility of ramping down nuclear is excluded (see assumptions in Table 8). The flexibility of nuclear is limited, and therefore it impacts the amount of variable energy that must be curtailed, particularly at high penetrations of solar. As current nuclear generation facilities are retired, the generation flexibility limit could decrease, especially if the energy is replaced with flexible thermal sources, allowing for larger contributions from solar and wind energy resources. Scenario 10 looks at the required curtailment resulting from the retirement of $10 \%$ of the nuclear 
generation, again using $25 \%$ solar penetration. A new generation flexibility limit is calculated with the nuclear generation reduced to $90 \%$ to reflect the nuclear retirement. It is assumed that the generation is replaced with flexible thermal generation. The other components of the flexibility limit are the same as those used in scenarios $1-7$, including inflexible hydropower units and must-run units, with additional flexibility provided by hydropower pumped storage.

This reduction in the nuclear generation of the system with $25 \%$ solar penetration reduces the necessary curtailment from $26.9 \%$ of total renewable energy to $22.2 \%$. Despite greater quantities of carbon-free solar power contributing to load, however, the percentage of carbon-free energy is reduced from $74 \%$ to $70 \%$, which is to be expected because nuclear energy is carbon-free and generates consistently throughout the day.

\subsection{Scenario 11: Additional Wind Energy Penetration}

Duke Energy will work toward the goal of carbon-free energy generation primarily by incorporating solar power because solar is a plentiful resource in the Carolinas regions (see Figure 1). As the penetration of solar power increases, however, the imbalance in the availability of solar during a day - with increased power during daylight hours and a complete lack of power otherwise- becomes more problematic. It is therefore beneficial to consider an additional renewable source that can generate at different times of the day, such as wind. Scenario 11 examines the incorporation of $5 \%$ of the annual load generated by wind energy in addition to $30 \%$ solar energy penetration. A map of the wind resource is shown in Figure 10.

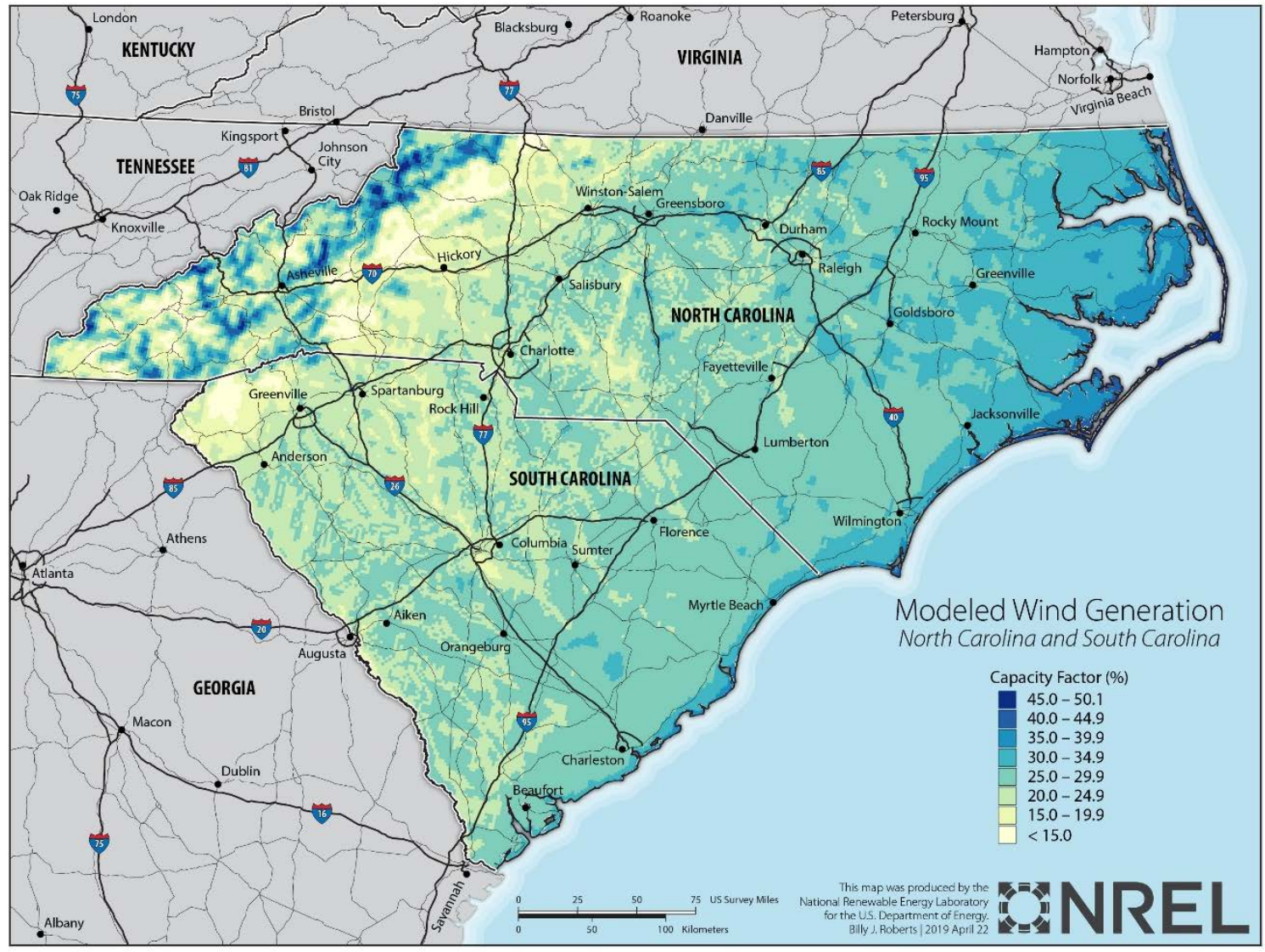

Figure 10. Wind capacity factors in the Carolinas 
The wind time series is a simulated power output from NREL's Wind Integration National Dataset (WIND) Toolkit (Draxl, et al., 2015) based on the 2006 meteorological year. The 5\% wind is calculated in a manner similar to the percentage of solar penetration levels (see Equation 5 in the appendix). The wind power profiles were taken from offshore profiles where the wind resource is high. Further, because the profiles are offshore, we assume that they are insignificantly correlated with load. The wind energy profile was scaled to match $5 \%$ of the load. The net load for this scenario is calculated as the remaining load after the contribution of the 5\% wind and 30\% solar penetration. The curtailment of wind and solar is proportional to the generation of wind and solar, respectively.

Building off of the $30 \% \mathrm{PV}$ scenario (Scenario 6), there is an interesting comparison between adding another $5 \%$ of PV (to get $35 \% \mathrm{PV}$, Scenario 7 )) or adding $5 \%$ wind (Scenario 11). Adding another $5 \% \mathrm{PV}$ (to get to a total of $35 \% \mathrm{PV}$ ) leads to $83.2 \%$ of that additional $5 \%$ of solar being curtailed, while adding $5 \%$ wind (to $30 \% \mathrm{PV}$ ) requires only $26.3 \%$ of that additional wind to be curtailed. Looking at the total renewable curtailment of Scenario 11 compared to Scenario 7 (35\% PV), adding wind improves the total renewable energy curtailment from $42 \%$ to $33.9 \%$.

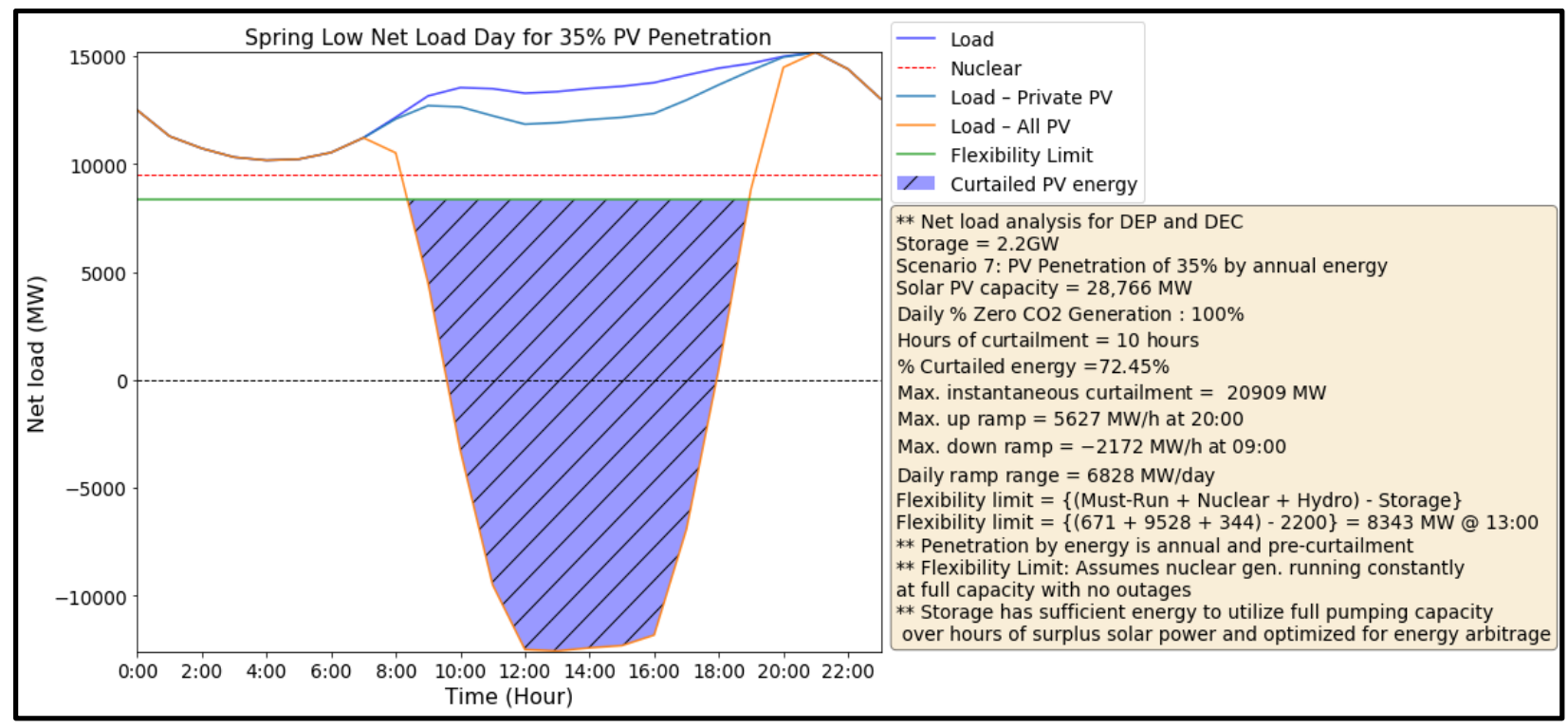

Figure 11. Minimum net load day in spring with 35\% PV energy penetration 


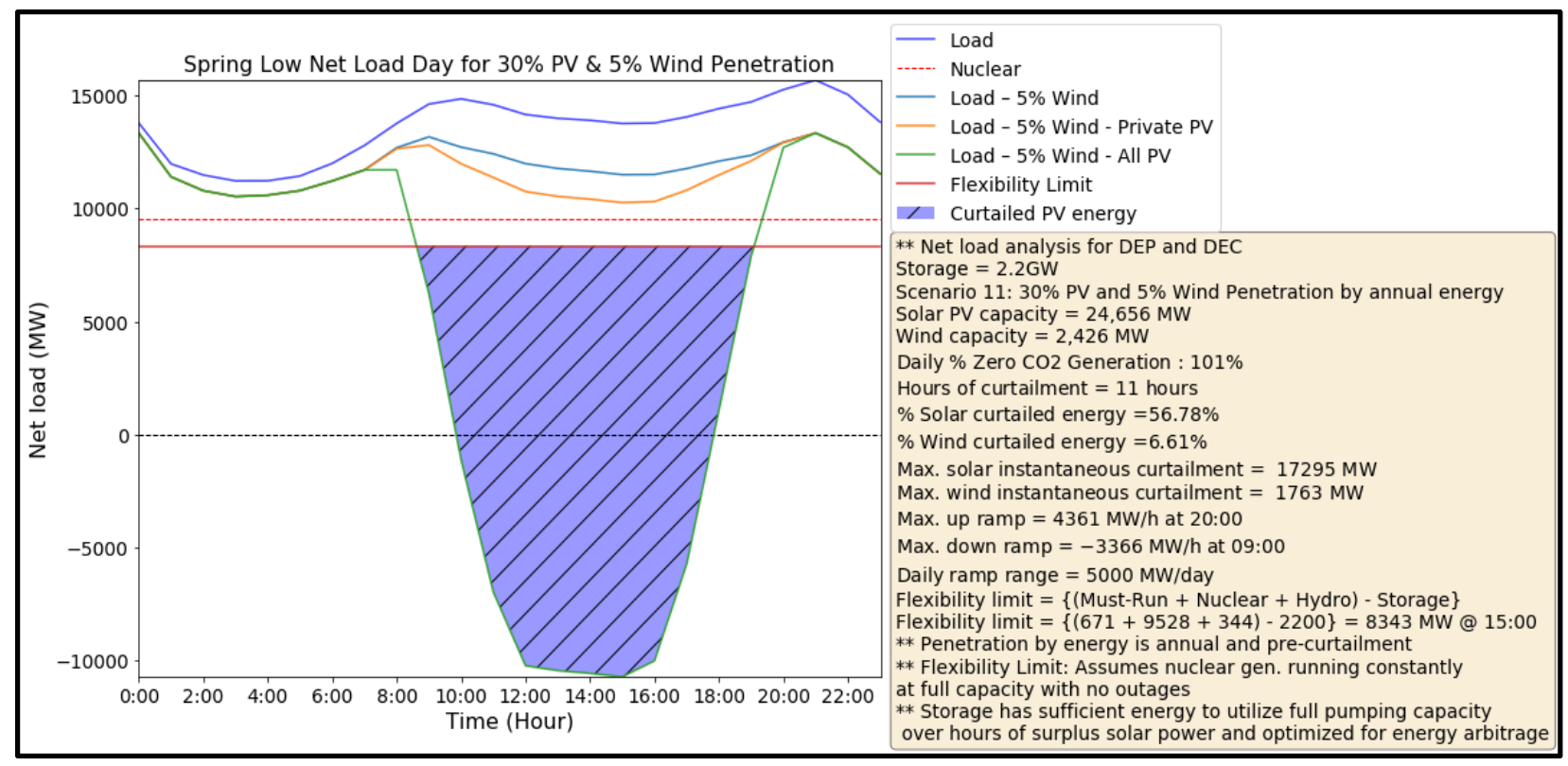

Figure 12. Minimum net load day in spring with $30 \%$ PV plus $5 \%$ wind energy penetration

And, since curtailment is reduced, that also means energy from carbon-free sources improves compared to Scenario 7. The average annual percentage of carbon-free energy in a $35 \% \mathrm{PV}$ penetration scenario is $77 \%$, whereas the percentage of carbon-free energy in a $30 \% \mathrm{PV}, 5 \%$ wind penetration scenario is $79 \%$, the greatest of all examined scenarios.

\subsection{Scenario 12: DEC and DEP Modeled as Individual Balancing Authorities with a Limited Interconnection}

All prior scenarios assume unlimited transfer capability in the Carolinas region. Scenario 12 separates DEC and DEP into separate regions with Duke Energy's existing transfer capability to observe the effect on the net load and curtailment given 5\%,10\%, and 15\% solar penetration levels by energy. The interconnection limit is provided by Duke Energy. It is directional and has different values for nighttime $(0 \mathrm{~h}-7 \mathrm{~h})$ and daytime $(8 \mathrm{~h}-23 \mathrm{~h})$. The separate loads are also provided by Duke Energy (all loads in prior analyses are the sum of these two loads). The generation totals of the must-run units for all prior scenarios are also calculated first for DEC and DEP and then summed, so the isolated values are used in Scenario 12. The generation flexibility limit is parsed between the two balancing authorities by separating must-run units, hydropower (see appendix for hydro assignments to DEC and DEP), nuclear (hourly generation values for DEC and DEP are provided by Duke Energy), and pumped storage (values also provided by Duke Energy). The equation for calculating each generation flexibility limit is the same as that used to calculate the generation flexibility limit for the total area (see Equation 1).

The interconnection is simulated to maintain the same difference between the net load and the flexibility limit of each balancing authority, provided that the transfer limit is not exceeded. This assumption of operating the interconnection to minimize the possibility of curtailment in high solar penetration scenarios was decided with Duke Energy. A production cost optimization would enable simulation of the interconnection and other transmission in a more realistic manner. If the difference between the net load of one balancing authority and its flexibility limit 
is less than that of the other, load is transferred until the difference is equal or the transfer limit in that direction, for that time of day, is met. This analysis uses 12 different equations to calculate 12 different scenarios resulting from variations in the calculations because of the sign and magnitude of the differences and the times of day (see appendix). The results of these 12 scenarios are then summed to produce a time series of load transfer, which is then used to calculate the net load of each balancing authority after the transfer. To calculate the transfer, load transfer to DEC is arbitrarily defined as negative, whereas load transfer to DEP is defined as positive. The resulting net loads of DEC and DEP are calculated with the transfer amount (see appendix).

The sum of the required solar power curtailment for both regions after the interconnection is modeled is greater than the curtailment that results when they are modeled as one balancing authority, or a region without transmission limitations. As shown in Table 7, an increase in transmission capabilities would support increased solar energy penetration. This benefit is minimal at low levels of PV penetration, but it increases at higher percentages.

Table 7. Comparison of Curtailment of the System Modeled With and Without Transmission Limitations

\begin{tabular}{|l|l|l|l|l|}
\hline $\begin{array}{l}\text { Percentage PV } \\
\text { Penetration }\end{array}$ & $\begin{array}{l}\text { Curtailment with } \\
\text { Infinite } \\
\text { Transmission } \\
(\mathrm{MWh})\end{array}$ & $\begin{array}{l}\text { Percentage } \\
\text { Curtailment with } \\
\text { Infinite } \\
\text { Transmission }\end{array}$ & $\begin{array}{l}\text { Curtailment with } \\
\text { Limited } \\
\text { Transmission } \\
\text { (MWh) }\end{array}$ & $\begin{array}{l}\text { Percentage } \\
\text { Curtailment with } \\
\text { Limited } \\
\text { Transmission }\end{array}$ \\
\hline $5 \%$ & 1,570 & $0.0 \%$ & 1,361 & $0.0 \%$ \\
\hline $10 \%$ & 172,444 & $1.1 \%$ & 191,306 & $1.2 \%$ \\
\hline $15 \%$ & $1,824,853$ & $7.9 \%$ & $1,928,162$ & $8.3 \%$ \\
\hline
\end{tabular}

The minimization of curtailment with an increase in transmission capacity is illustrated when the minimum net load days to DEP and DEC, shown in Figure 13 and Figure 14, respectively, are compared to Figure 15. The first two figures of the separate balancing areas display $22 \%$ curtailed energy in DEP and 20\% and DEC, whereas Figure 15 shows 20\% curtailment on the minimum load day when DEP and DEC are modeled as one balancing area with unlimited transmission capabilities. 


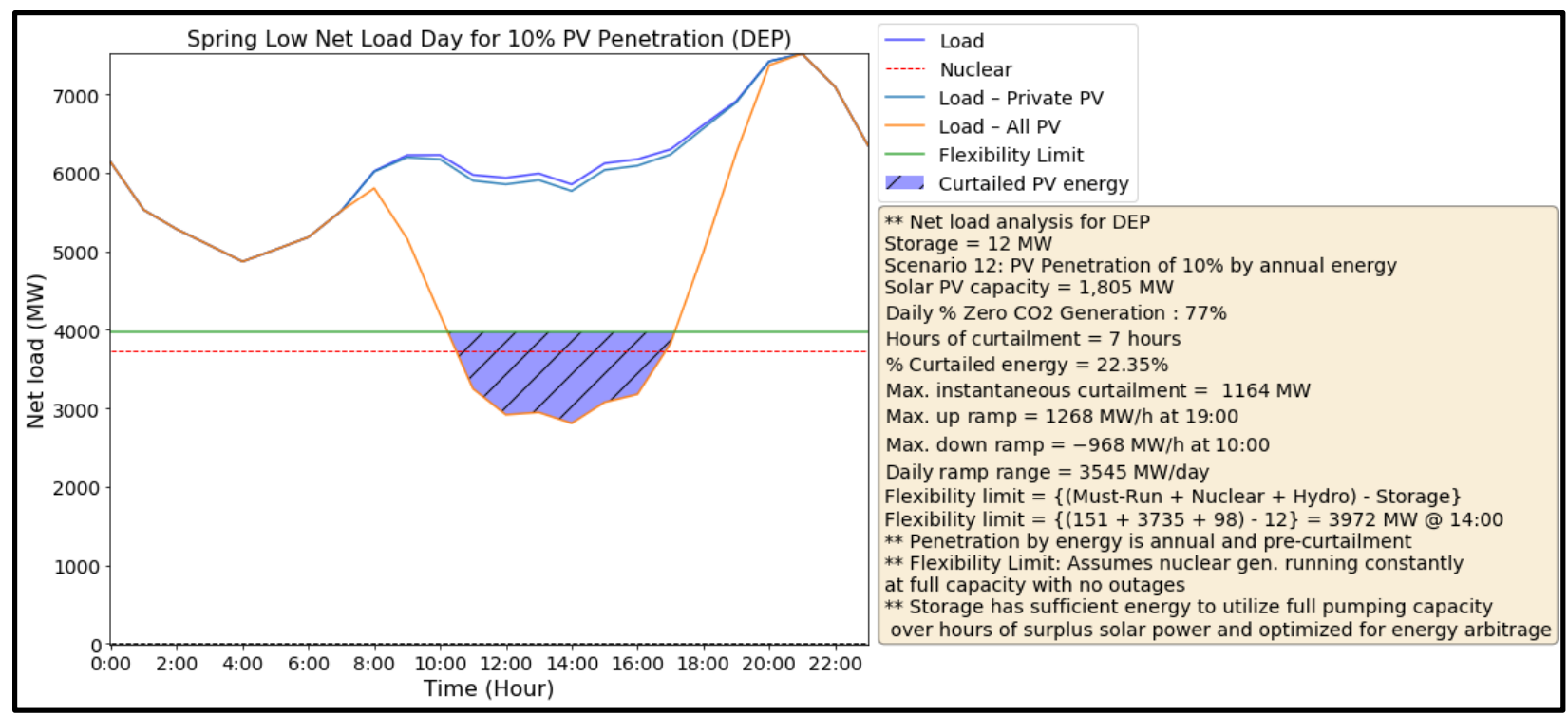

Figure 13. Low net load day for the DEP balancing authority with $10 \%$ PV penetration in spring

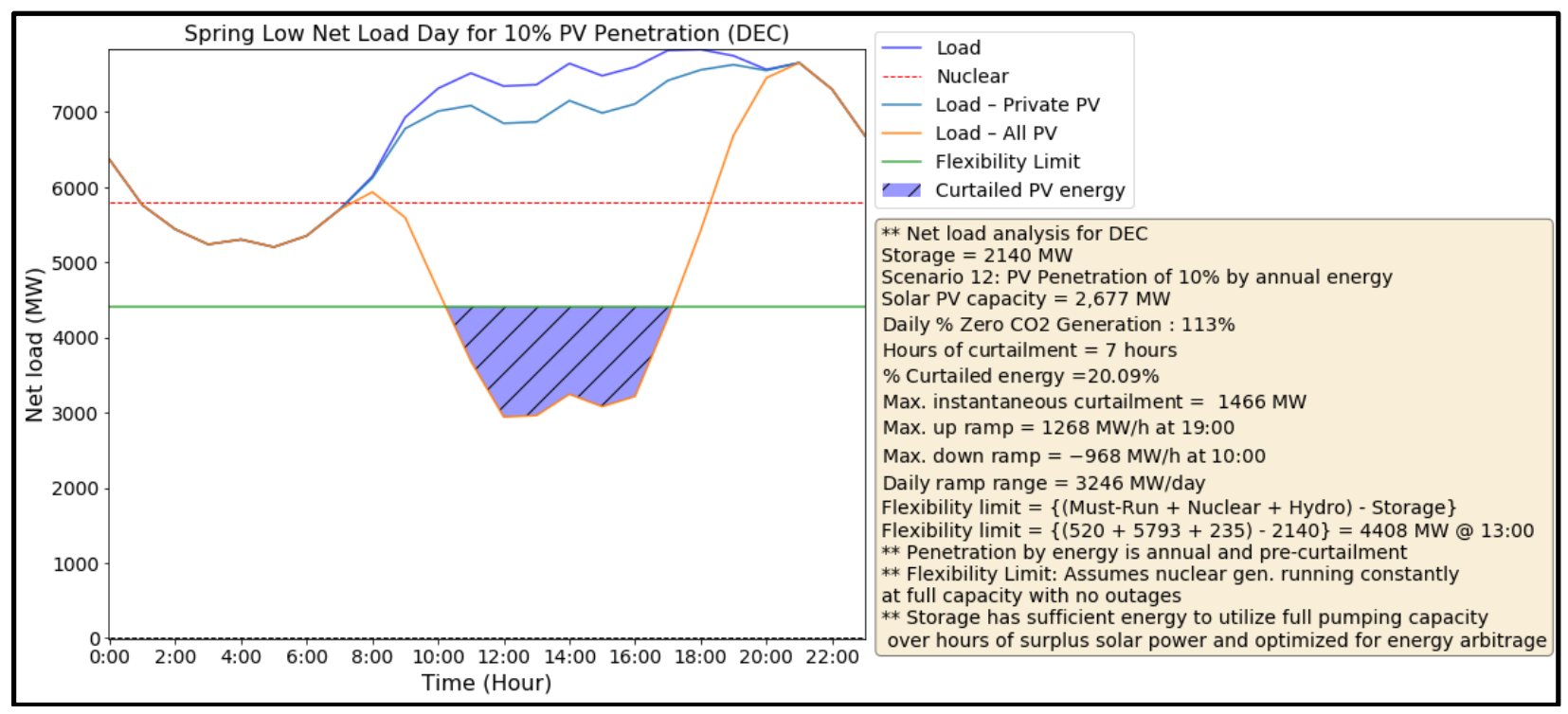

Figure 14. Low net load day for the DEC balancing authority with $10 \%$ PV penetration in spring 


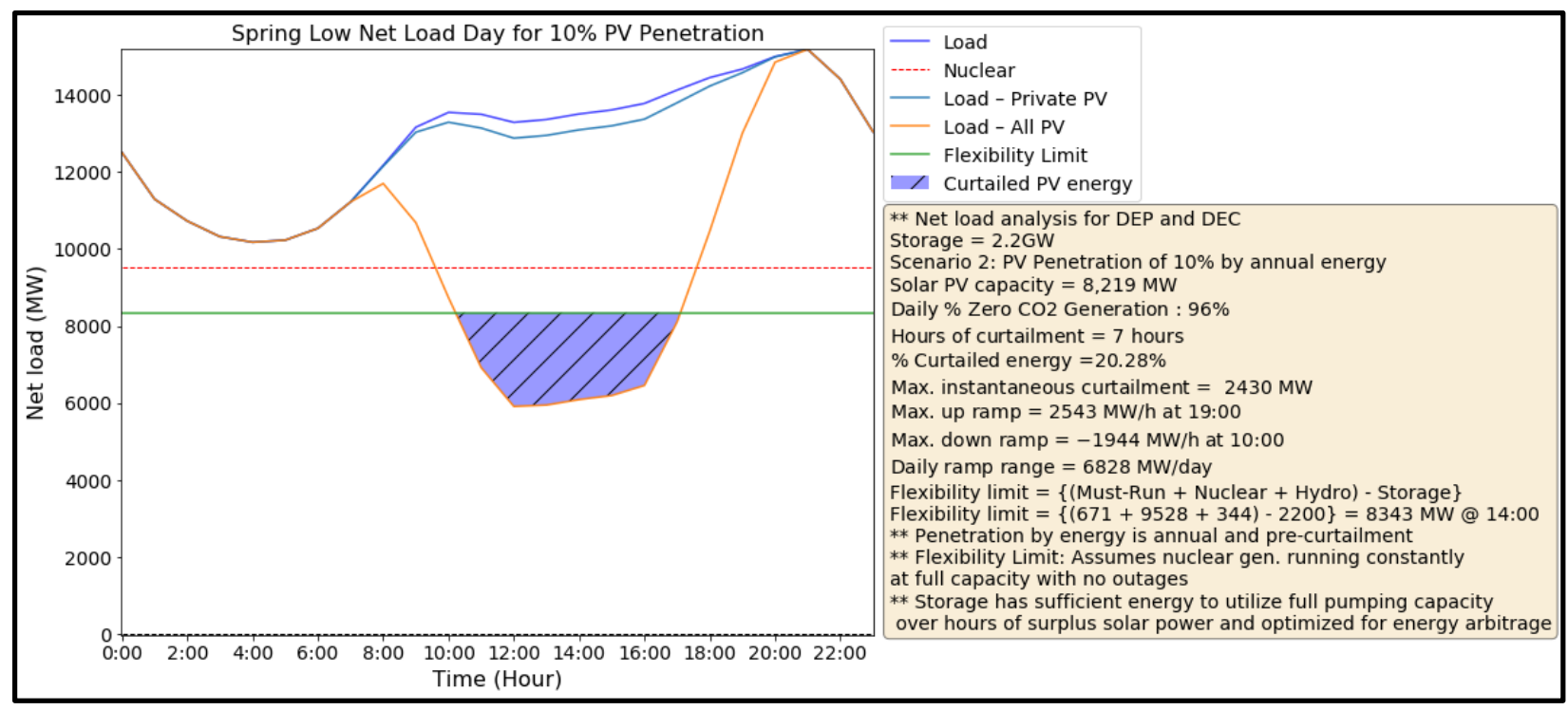

Figure 15. Low net load day with $10 \%$ PV penetration in spring when the Duke Carolinas territory is modeled with unlimited transmission capabilities

There is a difference in solar power output between the two balancing areas, such that DEP currently has roughly twice the solar capacity of DEC. The location of additional solar capacity will affect transmission constraints.
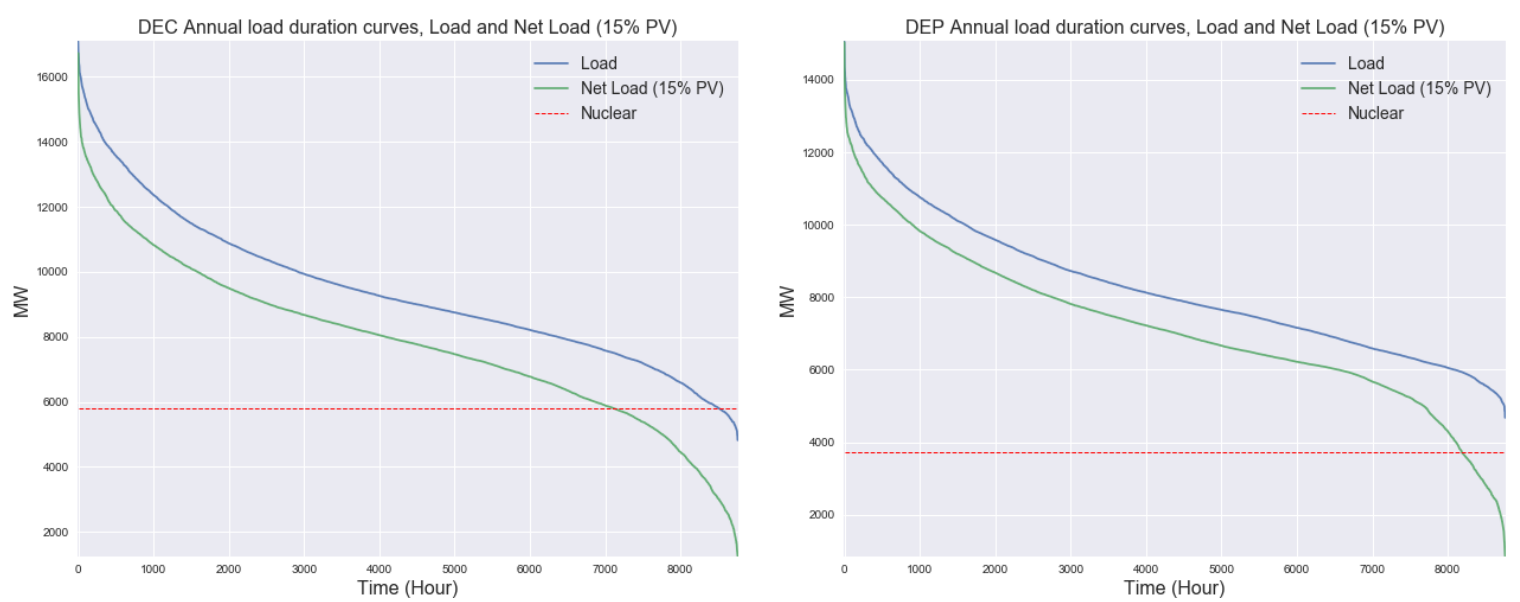

Figure 16. DEC and DEP load duration curves at $15 \%$ PV penetration

The load duration curves of the separate balancing authorities shown in Figure 16 show that at $15 \%$ PV energy penetration, there are 1,635 hours during which the net load dips below the nuclear generation limit in DEC and 577 hours in DEP, summing to 2,212 total hours. The load duration curve of the single balancing authority shown in Figure 17 shows an improvement, with 930 hours during which the net load is less than the nuclear limit. 


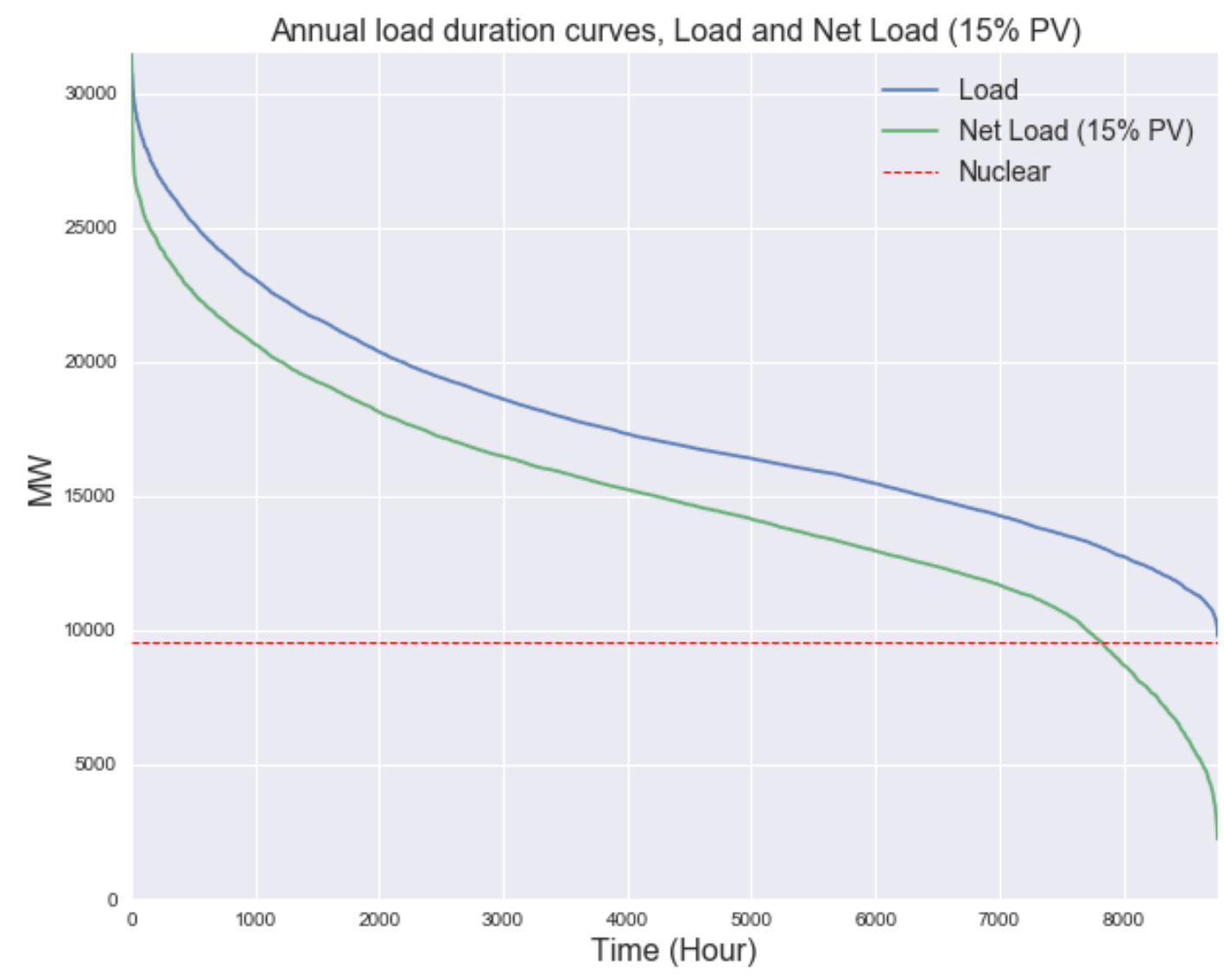

Figure 17. Load duration curve of the Duke Carolinas region modeled as one balancing area at $15 \%$ PV penetration 


\section{Geospatial Analysis}

Several maps and an online application were created by the geospatial analysis team at NREL to visualize the solar and wind resources in the Duke Carolinas territory. The solar energy resource is characterized by global horizontal irradiance, and the wind energy resource is characterized by wind speed. Capacity factors were produced to visualize solar and wind generation, and exclusions ${ }^{4}$ were made based on land categories and use type (see appendix for details). One such map is shown in Figure 18, which shows the capacity factors that are not in excluded areas of the region.

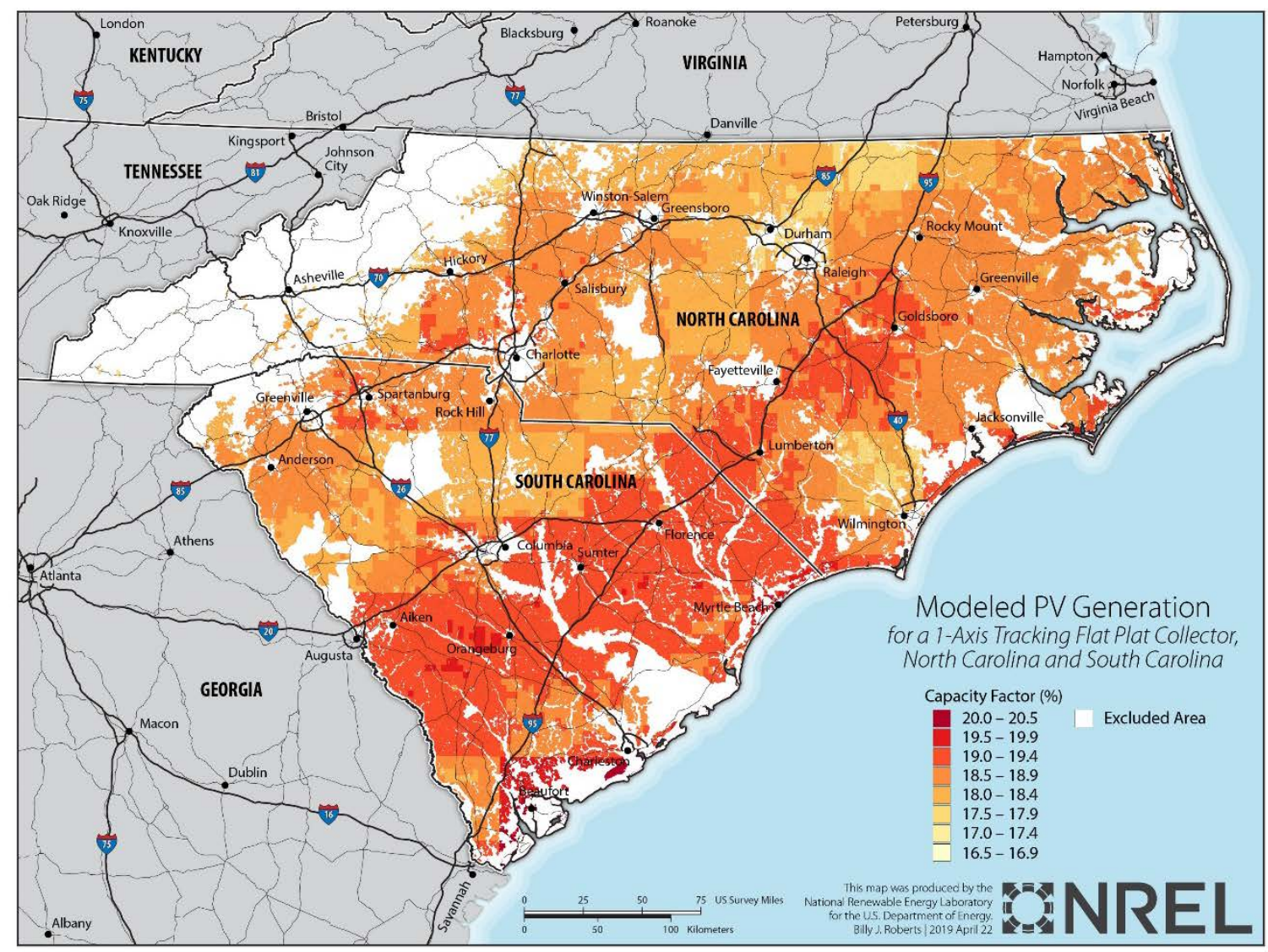

Figure 18. Multiyear mean capacity factors

The web application allows the user to examine these three layers of generation, energy resource, and exclusions for both wind and solar. The URL for the website is: https://maps.nrel.gov/duke. Note, please use Firefox, or Chrome for best results. The following layers are available on the web application:

- Solar exclusions: solar-categorized exclusions

\footnotetext{
${ }^{4}$ Exclusions include a slope $>5 \%$, urban areas, water and wetlands, parks and landmarks, national parks, and other environmentally or culturally sensitive areas.
} 
- Solar generation: multiyear mean PV capacity factors using the listed PV system configurations

- Solar energy resource: Multiyear mean global horizontal irradiance

- Wind exclusions: wind-categorized exclusions. Both $100 \%$ exclusions and $50 \%$ exclusions are listed in this layer, depicting locations that are $100 \%$ excluded and other locations that are $50 \%$ excluded. The decision for $50 \%$ exclusions is based on assumptions used in Lopez (2012).

- Wind generation: multiyear mean wind capacity factors using the listed wind system configurations

- Wind energy resource: multiyear mean wind speed.

The web application allows the user to navigate geospatially and zoom in and out of areas of interest. Any combination of data layers can be displayed at once, including exclusions, generation, and energy resource for solar power and wind power. The legend tab enables the user to filter for ranges of data within each layer and control the transparency to maintain visual clarity, depending on the number of layers selected. This is shown in Figure 19. The query tab enables the user to intuitively retrieve the data being visualized by one of the four following options: the user can (1) select an individual point on the map, (2) query an entire region, (3) draw a custom shape of interest, and (4) filter based on specific attributes. The data behind this web app make it a useful tool to explore future development in the form of production cost models for the continued study of carbon-free resource integration.

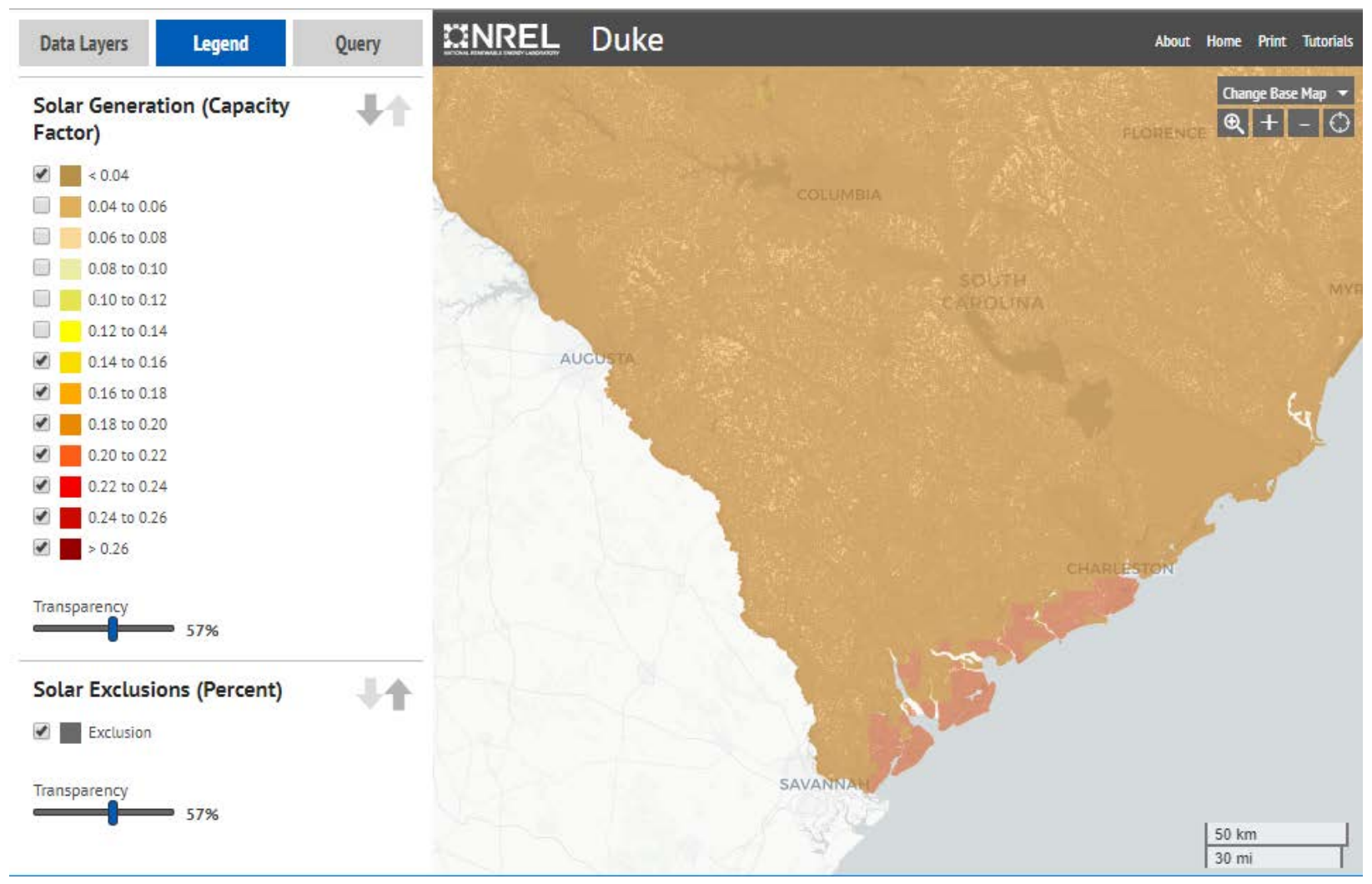

Figure 19. Screenshot of geospatial web application 


\section{Conclusion}

Duke Energy endeavors to increase the proportion of load met by carbon-free generation. With high quantities of nuclear power currently providing carbon-free generation, and given their great solar irradiance resource, Duke Energy seeks to analyze the impact of integrating significant amounts of new solar power into its power system under a variety of penetration levels. This additional solar power will help reach carbon-free goals; however, with the high minimum generation level of existing nuclear power, this net load analysis concludes that curtailment of solar is likely to begin at 10\% solar energy penetration. Thus, the net load analysis becomes an important initial step in realizing this goal while maintaining a reliable and economically viable grid.

This net load analysis shows:

- The greatest curtailment occurs during the spring, which is usually characterized by low load and an oversupply of solar PV power output during the middle of the day.

- The largest ramps remain in winter, through all solar PV penetrations, and for all seasons the ramps increase as solar PV penetration increases.

- The largest maximum instantaneous curtailment, percentage of curtailed energy, and duration of curtailment occur during the spring.

- The system experiences the largest percentage of daily carbon-free generation during the spring, which is the highest compared with other seasons.

- The net load analysis shows a significant reduction in the peak net load and a shift in the timing of the minimum and peak net load. This effect is most significant during the summer because of the time-coincident correlation between the demand and solar output. Thus, solar PV can significantly contribute capacity value to the system during the summer peak load; however, the shift in timing minimum and peak net loads can affect generator outage and maintenance scheduling, and this should be investigated further using unit commitment and economic dispatch models.

- Even at high solar penetration levels of $25 \%$, with the highest anticipated level of rooftop solar, curtailment rights of utility solar is sufficient to avoid an imbalance of supply and load. This net load analysis shows that building wind power after high levels of solar power curtailment are reached and building storage are two solutions that can aid in increasing the share of carbon-free emission generation in Duke Energy's system.

- The analysis of scenarios 12 and 10 show that transmission constraints and nuclear retirement both work against the goal of meeting load with carbon-free generation.

A key constraint in accommodating additional variable generation penetration is the ramping ability of conventional generators, to change their output in response to the fluctuating renewables. For instance, during the spring minimum net load day shown in Figure 4, the traditional generator fleet is required to increase the output rapidly as the sun sets. For Duke Energy, because the nuclear fleet has a high minimum generation limit, increasing system flexibility with technologies that provide fast ramp rates and control over load should be examined to accommodate higher PV penetrations.

In addition, managing system flexibility requires serious operational adjustments coupled with a resource mix that can quickly respond to the balance of electricity demand and net load 
variability. The result of this study further reveals that exceeding $15 \% \mathrm{PV}$ penetration could lead to serious integration issues, especially during the spring, which is characterized by low load and a possible frequent overgeneration scenario.

Further analysis with more advanced models - such as unit commitment and economic dispatch, capacity expansion planning, and dynamic analysis models - will be required to more fully assess system impacts with increasing variable generation penetration as well as flexibility opportunities for accommodating variable renewable energy sources with conventional generation. 


\section{References}

Anthony Lopez, Billy Roberts, Donna Heimiller, Nate Blair, and Gian Porro. 2012. U.S. Renewable Energy Technical Potentials: A GIS-Based Analysis. Golden : National Renewable Energy Laboratory, 2012.

Bebic, J. and Kroposki, B. 2008. Power System Planning:Emerging Practices Suitable for Evaluating the Impact of High-Penetration Photovoltaics. Golden, CO : National Renewable Energy Laboratory, NREL/SR-581-42297, 2008.

C. Draxl, B.-M. Hodge, and A. Clifton. 2015. Overview and Meteorological Validation of the Wind Integration National Dataset Toolkit. Golden : National Renewable Energy Laboratory, 2015.

Draxl, C., Hodge, B. and Clifton, A. 2015. Overview and Meteorological Validation of the Wind Integration National Dataset Toolkit. Golden : National Renewable Energy Laboratory, 2015.

Duke Energy. 2018. Transforming the Future: Duke Energy 2018 Annual Report and Form 10$K$. Carolina : Duke Energy, 2018.

Ela, E., M. Milligan, A. Bloom, A. Botterud, A. Townsend, and T. Levin. 2014. Evolution of Wholesale Electricity Market Design with Increasing Levels of Renewable Generation. Golden, CO. : National Renewable Energy Laboratory, NREL/TP-5D00-61765, 2014.

GE Energy. 2010. The Western Wind and Solar Integration Study Phase 1. Schenectady, New York : GE Energy/No. AAM-8-77557-01, 2010.

Lew, Debra, Greg Brinkman, Eduardo Ibanez, Bri-Mathias Hodge, M. Hummon, A. Florita, and M. Heaney. 2013. The Western Wind and Solar Integration Study Phase 2. Golden, Colorado : National Renewable Energy Laboratory, NREL/TP-5500-55588, 2013.

Mai, T., et al. 2012. Exploration of High-Penetration Renewable Electricity Futures. Vol. 1 of Renewable Electricity Futures Study. Golden, CO : National Renewable Energy Laboratory, NREL/TP-6A20-52409-1, 2012.

Milligan, M., Frew, B., Zhou, E., and Arent, D. J. 2015. Advancing System Flexibility for High Penetration Renewable. Golden, CO. : National Renewable Energy Laboratory, NREL/TP6A20-64864, 2015.

Sengupta, M., Xie, Y., Lopez, A., Habte, A., Maclaurin, G., \& Shelby, J. (2018). The National Solar Radiation Data Base (NSRDB). Renewable and Sustainable Energy Reviews, 89, 51-60. https://doi.org/10.1016/j.rser.2018.03.003 


\section{Appendix}

\section{A.1 Data Sources and Assumptions}

In the context of data and files provided by Duke Energy, for both Duke Energy Progress and Duke Energy Corporation, the capacity factors from the "Third Party Non-Curtailable" sheet are multiplied by the rooftop solar capacity for 2019. The capacity factors from the "Utility Owned" tab are multiplied by the sum of the utility nameplate capacities. "Net Metered (Rooftop) Solar" is assumed to be rooftop solar PV, whereas "D-Tied Universal Solar" and "T-Tied Universal Solar" are assumed to be utility. Hydro schedules are from "Carolinas Hydro Schedules_Capacity and Energy_Confidential.xlsx.”

Table 8. Assumptions and Definitions for the Net Load Analysis

Assumptions for Scenarios 1 - 7
Penetration by energy is annual and pre-curtailment.
$\begin{aligned} & \text { Storage is } 2.2 \mathrm{GW} \text {, which represents the existing pumped hydro storage } \\ & \text { capacity. }\end{aligned}$

Storage has sufficient energy capacity to use full pumping capacity during hours of surplus solar power and is optimized for energy arbitrage.

The percentage of curtailed energy is estimated as a percentage of total PV output energy.

Must-run units are defined relative to the highest load within the last week because the majority of must-run units have a weeklong minimum up time.

Nuclear runs consistently at full capacity and has no outages.

No contingency reserve is added to the flexibility limit line.

Interconnections to neighboring regions are not considered 


\section{A.2 Equations for Scenario Analysis}

The inflexibility generation limit line, $G_{e n} n_{\text {inflex }}$, is given as:

Gen $_{\text {inflex }}=$

$$
\left\{(\text { MustRun units }+ \text { Nuclear capacity }+ \text { Hydro units })-\text { Storage }^{5}\right\} M W
$$

Renewable energy curtailment is given as:

$$
V G^{6} \text { curtailment }=\left\{\begin{array}{rr}
\text { Gen }_{\text {inflex }}-\text { Net load, } & \text { Gen }_{\text {inflex }}>\text { Net load } \\
0, & \text { Gen }_{\text {inflex }}<\text { Net load }
\end{array}\right.
$$

Daily ratio of carbon-free generation is given as:

$$
\sum_{n=1}^{24} \frac{\left(\text { Nuclear }_{n}+\text { Hydro }_{n}+0.8 * \text { Storage }_{n}+\text { VG } \text { precurtailment }_{n}-\text { VG } \text { curtailment }_{n}\right)}{\text { Total load }_{n}}
$$

Table 9. Scalars Used to Calculate PV Penetration

\begin{tabular}{|l|l|}
\hline Scenario No. & Scalar \\
\hline 1 & 0.9642 \\
\hline 2 & 1.9284 \\
\hline 3 & 2.8926 \\
\hline 4 & 3.8568 \\
\hline 5 & 4.8210 \\
\hline 6 & 5.7852 \\
\hline 7 & 6.7494 \\
\hline
\end{tabular}

The scalars to calculate the solar penetration required to meet the specified percentage of load were found with the following Equation:

$$
\{(\text { Percent Penetration }) \cdot(\text { AnnualLoad }) /(\text { AnnualPV })\}
$$

\footnotetext{
${ }^{5}$ Storage represents the total pumped storage hydropower pumping capacity.
}

${ }^{6}$ Variable generation refers to solar and wind (where applicable) power plants. 
The solar time-series was then multiplied by each scalar to produce the appropriate amount of annual solar to achieve the targeted penetration level for each Scenario. For example, to create the PV time-series for Scenario 1 with 5\% solar penetration, the solar time-series was multiplied by 0.9642 .

In Scenario 8 illustrates $25 \%$ solar energy penetration with $18.91 \%$ of solar due to rooftop solar generation. $18.91 \%$ of $25 \%$ of the load was calculated to find the amount of rooftop PV. A scalar to adjust the rooftop PV time-series was calculated similarly to the scalars used to calculate the time-series for Scenarios 1-7:

$$
\{(\text { Percent Rooftop) } \cdot(25 \% \text { of AnnualLoad }) /(\text { AnnualRooftopPV })\}
$$

The calculation for the remaining $89.09 \%$ of solar from utility is analogous:

$$
\{(\text { Percent Utility) } \cdot(25 \% \text { of AnnualLoad }) /(\text { AnnualUtilityPV })\}
$$

Additional storage in Scenario 9 is calculated according to the following rules:

If the curtailment is required, eight-hour storage is used to store as much of the curtailment required as possible, limited to $2000 \mathrm{MW}$ inside of an hour. The maximum eight-hour storage over a 14-hour window is $2000 \mathrm{MW} * 8$ hours $=16000 \mathrm{MWh}$, so any renewable generation beyond that must be stored by the six- or four-hour storage units. Next, the six-hour storage is used to store up to $1000 \mathrm{MW}$ of excess energy in an hour, with the maximum storage over a 14hour window of $6000 \mathrm{MWh}$. Finally, the four-hour storage is used to store up to $1000 \mathrm{MW}$ of excess energy in an hour, with the maximum storage over a 14-hour window of $4000 \mathrm{MWh}$.

In Scenario 11, the wind time series is scaled by 0.6680 to match $5 \%$ of the total load, and is found with:

$$
\{(0.05) \cdot(\text { AnnualLoad }) /(\text { AnnualWind })\}
$$

The wind time-series was then multiplied by 0.6680 to produce an annual generation equal to $5 \%$ of the load.

For Scenario 12, the location of hydropower units in each of the modelled BAs is as follows:

Table 10. Hydropower units corresponding to each region

\begin{tabular}{|c|c|}
\hline DEC & DEP \\
\hline Cowans Ford Hydro & \\
Keowee Hydro & Blewett Hydro \\
Lower Catawba Hydro & Marshall Hydro \\
Misc ROR Hydro & Tillery Hydro \\
Nantahala Hydro & Walters Hydro \\
Upper Catawba Hydro & \\
\hline
\end{tabular}


The Equations for calculating load transfer are listed in Table 11. "DEC" refers to the net load of DEC minus the flexibility limit of DEC, while "DEP" refers to the net load of DEP minus the flexibility limit of DEP.

Table 11. Equations to Calculate Load Transfer from DEC to DEP

\begin{tabular}{|c|c|c|c|c|}
\hline \multicolumn{3}{|c|}{ (Net Load -Flexibility Limit) } & \multirow{2}{*}{$\begin{array}{l}\text { Time of } \\
\text { Day }\end{array}$} & \multirow{2}{*}{ Equation } \\
\hline DEC & DEP & Comparison & & \\
\hline$<0$ & $<0$ & $|D E C|<|D E P|$ & 8:00-23:00 & 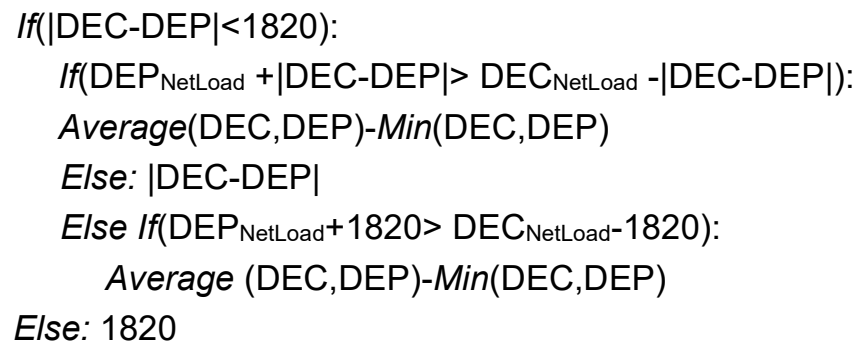 \\
\hline$<0$ & $<0$ & $|\mathrm{DEC}|>|\mathrm{DEP}|$ & $8: 00-23: 00$ & 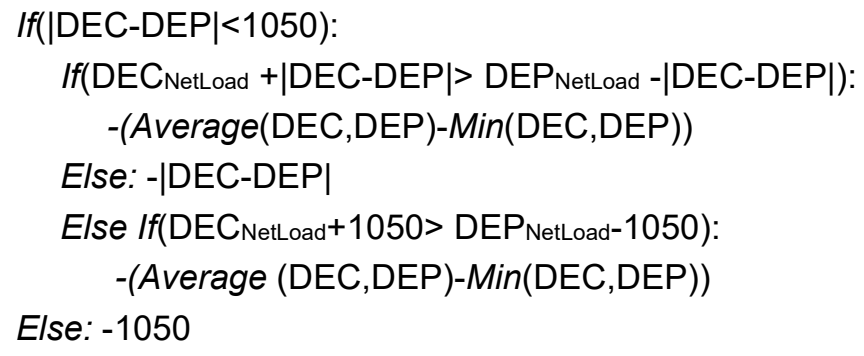 \\
\hline$<0$ & $>0$ & & $8: 00-23: 00$ & 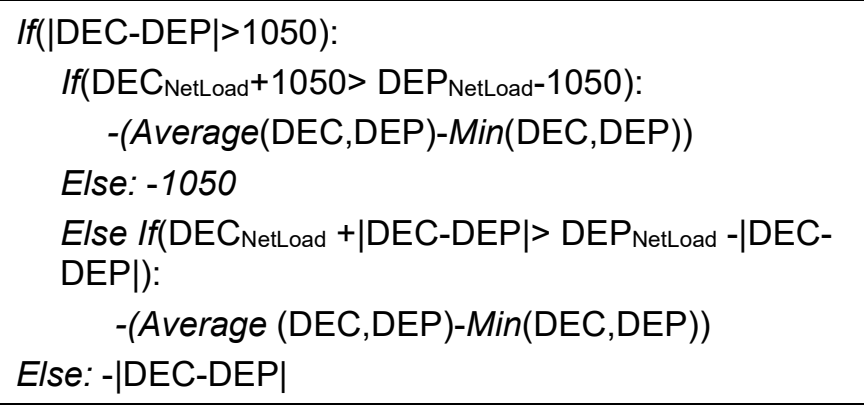 \\
\hline$>0$ & $<0$ & & $8: 00-23: 00$ & 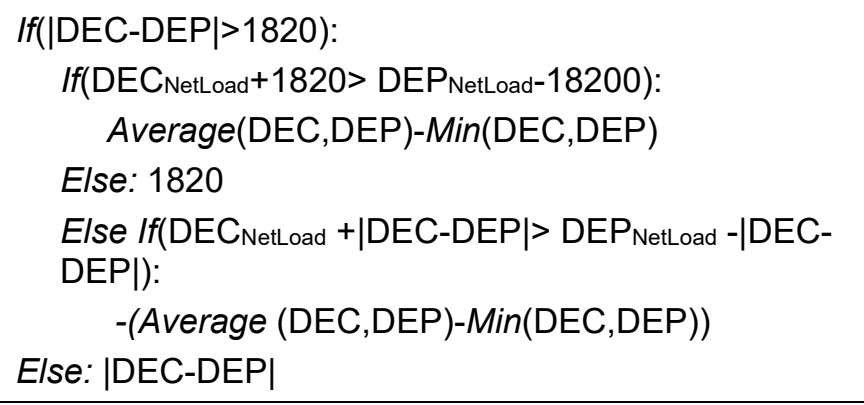 \\
\hline$>0$ & $>0$ & $|\mathrm{DEC}|<|\mathrm{DEP}|$ & 8:00-23:00 & 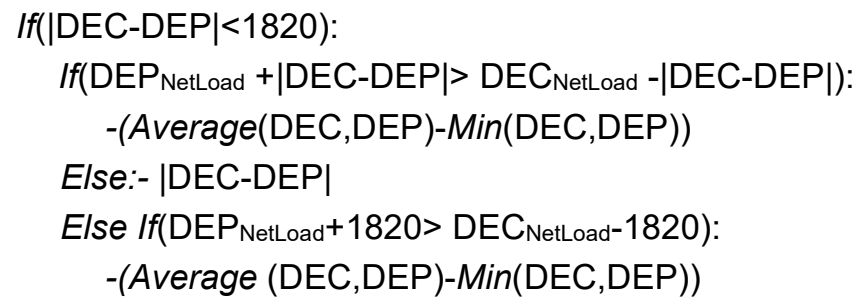 \\
\hline
\end{tabular}




\begin{tabular}{|c|c|c|c|c|}
\hline \multicolumn{3}{|c|}{ (Net Load -Flexibility Limit) } & \multirow{2}{*}{$\begin{array}{c}\text { Time of } \\
\text { Day }\end{array}$} & \multirow{2}{*}{ Equation } \\
\hline DEC & DEP & Comparison & & \\
\hline & & & & Else: -1820 \\
\hline$>0$ & $>0$ & $|\mathrm{DEC}|>|\mathrm{DEP}|$ & 8:00-23:00 & 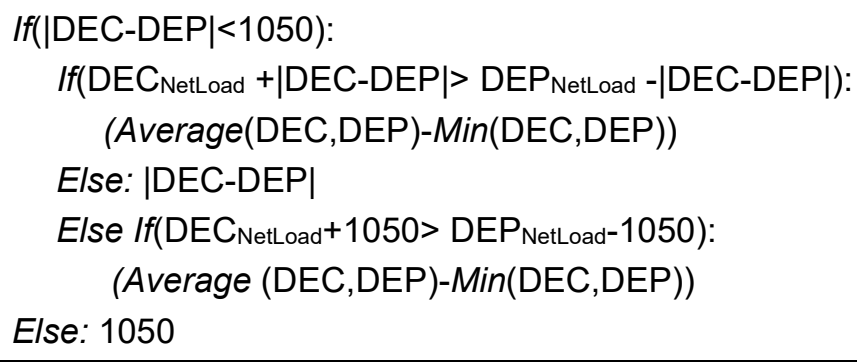 \\
\hline$<0$ & $<0$ & $|\mathrm{DEC}|<|\mathrm{DEP}|$ & 0:00-7:00 & $\begin{array}{l}\text { If(|DEC'-DEP|<2933): } \\
\left.\quad \text { If(DEP } \text { NetLoad }+|\mathrm{DEC}-\mathrm{DEP}|>\mathrm{DEC}_{\text {NetLoad }}-|\mathrm{DEC}-\mathrm{DEP}|\right) \text { : } \\
\text { Average(DEC,DEP)-Min(DEC,DEP) } \\
\text { Else: }|\mathrm{DEC}-\mathrm{DEP}| \\
\text { Else If(DEP } \\
\quad \text { Average (DEC,DEP)-Min(DEC,DEP) } \\
\text { Else: } 2933\end{array}$ \\
\hline$<0$ & $<0$ & $|D E C|>|D E P|$ & 0:00-7:00 & 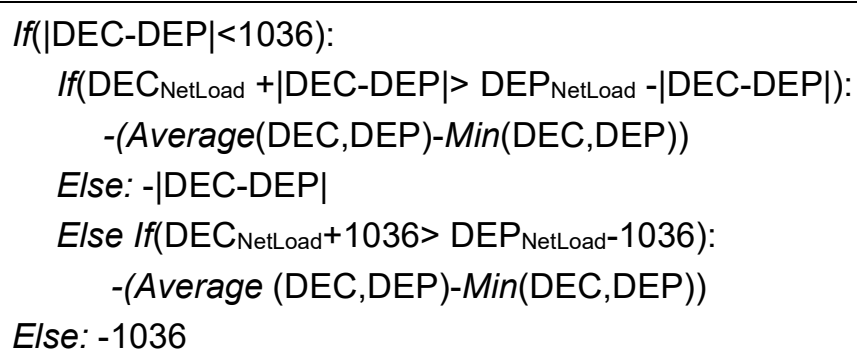 \\
\hline$<0$ & $>0$ & & 0:00-7:00 & 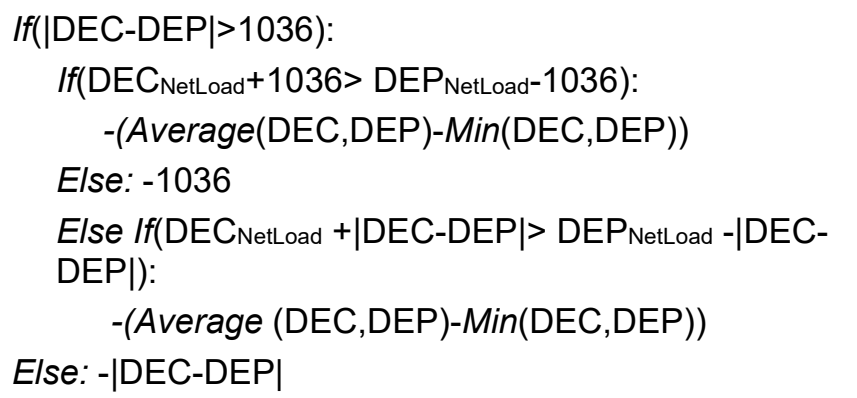 \\
\hline$>0$ & $<0$ & & 0:00-7:00 & 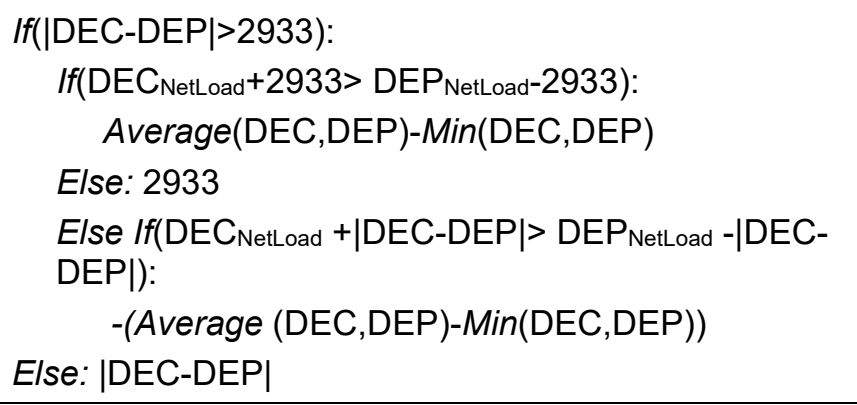 \\
\hline$>0$ & $>0$ & $|D E C|<|D E P|$ & 0:00-7:00 & $\begin{array}{l}\text { If(|DEC-DEP|<2933): } \\
\left.\text { If(DEP } \text { NetLoad }^{+|D E C-D E P|>~ D E C} C_{\text {NetLoad }}-|D E C-D E P|\right) \text { : } \\
\quad-(\text { Average(DEC,DEP)-Min (DEC,DEP }))\end{array}$ \\
\hline
\end{tabular}




\begin{tabular}{|c|c|c|c|c|}
\hline \multicolumn{3}{|c|}{ (Net Load -Flexibility Limit) } & \multirow{2}{*}{$\begin{array}{c}\text { Time of } \\
\text { Day }\end{array}$} & \multirow{2}{*}{ Equation } \\
\hline DEC & DEP & Comparison & & \\
\hline & & & & 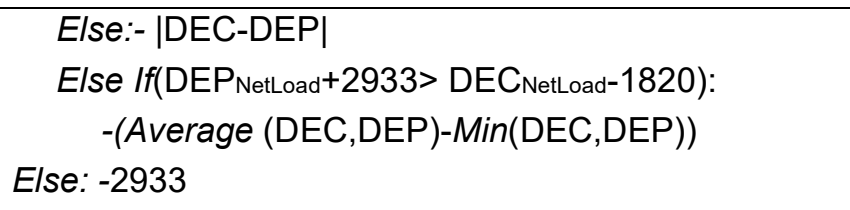 \\
\hline$>0$ & $>0$ & $|D E C|>|D E P|$ & $0: 00-7: 00$ & 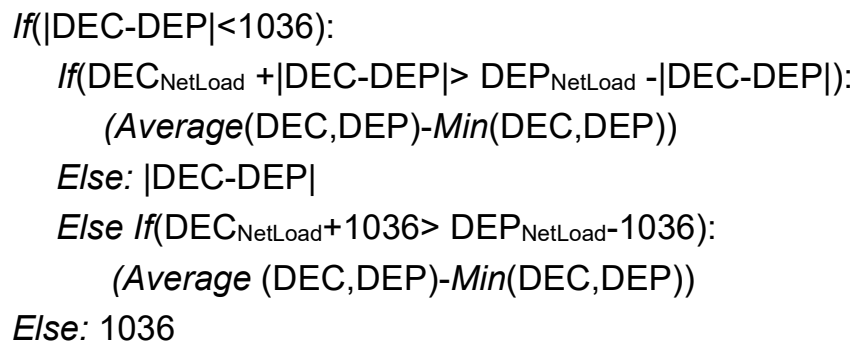 \\
\hline
\end{tabular}

Equations 8 and 9 show how the net load of each BA is changed by the interconnection after the load transfer is calculated.

$$
\begin{aligned}
& \{(\text { DEC Net Load Before })-(\text { Load Transfer })=(\text { DEC Net Load After })\} \\
& \{(\text { DEP Net Load Before })+(\text { Load Transfer })=(\text { DEP Net Load After })\}
\end{aligned}
$$




\section{A.3 Seasonal Metrics}

The dates of each season are defined in Table 12.

Table 12. Season definitions

\begin{tabular}{|l|l|l|}
\hline & Start Date & End Date \\
\hline Spring & $3 / 1 / 2019$ & $5 / 31 / 2019$ \\
\hline Summer & $6 / 1 / 2019$ & $8 / 31 / 2019$ \\
\hline Fall & $9 / 1 / 2019$ & $11 / 30 / 2019$ \\
\hline Winter & $12 / 1 / 2019$ & $2 / 28 / 2019$ \\
\hline
\end{tabular}

Table 13. Maximum instantaneous curtailment of each season (MW)

\begin{tabular}{|l|l|l|l|l|}
\hline Scenario & Spring & Summer & Fall & Winter \\
\hline 1 & 0 & 0 & 0 & 530 \\
\hline 2 & 2430 & 0 & 2752 & 3233 \\
\hline 3 & 6113 & 2913 & 5897 & 6618 \\
\hline 4 & 9801 & 6106 & 9183 & 10003 \\
\hline 5 & 13504 & 9299 & 12560 & 13389 \\
\hline 6 & 17207 & 12542 & 16023 & 16774 \\
\hline 7 & 20909 & 16143 & 19689 & 20271 \\
\hline 8 & 13548 & 9248 & 12568 & 13452 \\
\hline 9 & 11073 & 5769 & 9185 & 9842 \\
\hline 10 & 12551 & 8346 & 11607 & 12436 \\
\hline 11 & 17486 & 13326 & 16273 & 17084 \\
\hline $12-$ DEC $5 \%$ & 0 & 0 & 0 & 246 \\
\hline $12-$ DEC $10 \%$ & 1466 & 252 & 1390 & 1886 \\
\hline $12-$ DEC $15 \%$ & 3116 & 1878 & 2958 & 3418 \\
\hline $12-$ DEP $5 \%$ & 0 & 0 & 0 & 246 \\
\hline $12-$ DEP $10 \%$ & 1234 & 117 & 1390 & 1600 \\
\hline $12-$ DEP $15 \%$ & 3116 & 1630 & 2958 & 3418 \\
\hline
\end{tabular}

Table 14. Maximum up ramp of each season (MW/h)

\begin{tabular}{|l|l|l|l|l|}
\hline Scenario & Spring & Summer & Fall & Winter \\
\hline 1 & 2927 & 2355 & 3839 & 4039 \\
\hline 2 & 3244 & 2272 & 3839 & 4384 \\
\hline 3 & 4539 & 3294 & 4412 & 5341 \\
\hline 4 & 5443 & 4316 & 5474 & 6609 \\
\hline 5 & 5964 & 5338 & 5960 & 7252 \\
\hline
\end{tabular}




\begin{tabular}{|l|l|l|l|l|}
\hline Scenario & Spring & Summer & Fall & Winter \\
\hline 6 & 6277 & 6360 & 6813 & 8362 \\
\hline 7 & 6583 & 6360 & 7508 & 9472 \\
\hline 8 & 5924 & 5408 & 5986 & 7278 \\
\hline 9 & 6873 & 5338 & 6717 & 7876 \\
\hline 10 & 6564 & 5338 & 6489 & 7481 \\
\hline 11 & 6179 & 5943 & 6757 & 8401 \\
\hline $12-$ DEC $5 \%$ & 1724 & 1369 & 1900 & 2594 \\
\hline $12-$ DEC $10 \%$ & 1722 & 1539 & 2093 & 2594 \\
\hline $12-$ DEC $15 \%$ & 2306 & 2242 & 2988 & 3030 \\
\hline $12-$ DEP 5\% & 1502 & 1130 & 1941 & 2003 \\
\hline $12-$ DEP $10 \%$ & 1629 & 1754 & 1941 & 2309 \\
\hline $12-$ DEP $15 \%$ & 2266 & 2385 & 2102 & 3068 \\
\hline
\end{tabular}

Table 15. Maximum down ramp of each season (MW/h)

\begin{tabular}{|l|l|l|l|l|}
\hline Scenario & Spring & Summer & Fall & Winter \\
\hline 1 & -3080 & -4090 & -2830 & -5873 \\
\hline 2 & -3406 & -4090 & -3403 & -5873 \\
\hline 3 & -4712 & -4090 & -4354 & -5873 \\
\hline 4 & -6069 & -4090 & -5658 & -6699 \\
\hline 5 & -7427 & -4090 & -6964 & -7894 \\
\hline 6 & -8784 & -4406 & -8270 & -9090 \\
\hline 7 & -9869 & -4482 & -9577 & -10286 \\
\hline 8 & -7419 & -4090 & -6951 & -7906 \\
\hline 9 & -7427 & -4090 & -6964 & -7894 \\
\hline 10 & -7427 & -4090 & -6964 & -7894 \\
\hline 11 & -8673 & -4461 & -8427 & -9555 \\
\hline $12-$ DEC 5\% & -2047 & -2313 & -1480 & -3122 \\
\hline $12-$ DEC 10\% & -2047 & -2313 & -1865 & -3122 \\
\hline $12-$ DEC 15\% & -2413 & -2313 & -2621 & -3320 \\
\hline $12-$ DEP 5\% & -1390 & -1874 & -1660 & -2750 \\
\hline $12-$ DEP 10\% & -1707 & -1874 & -1714 & -2750 \\
\hline $12-$ DEP 15\% & -2349 & -1874 & -2519 & -2750 \\
\hline
\end{tabular}




\section{A.4 Additional Figures}

\section{Scenarios 1-7}

Seasonal Average for 5\%-35\% PV Penetration

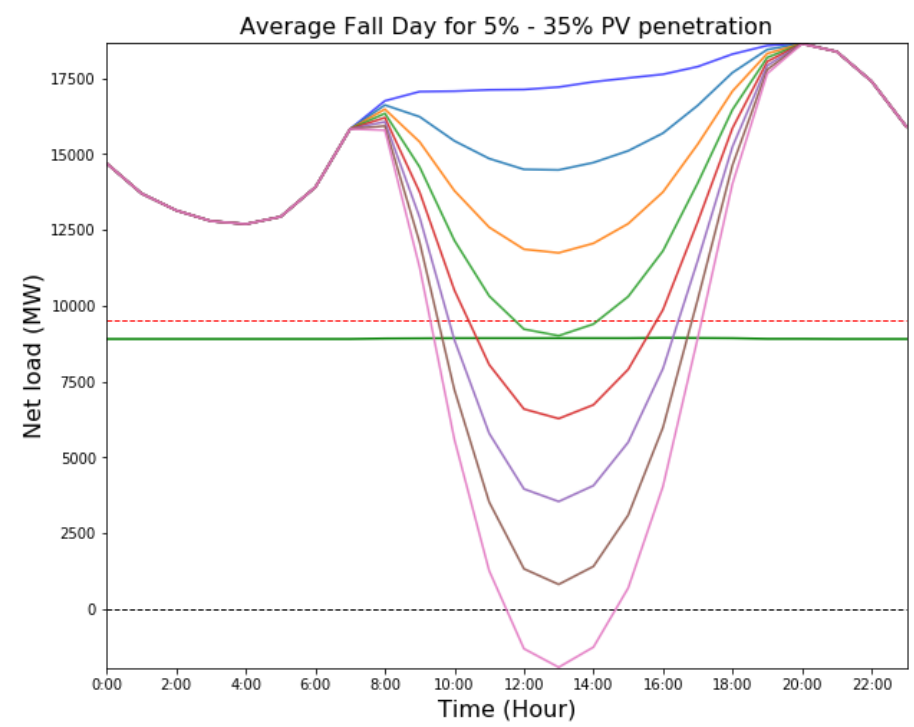

$\begin{array}{ll}- & \text { Load } \\ - & \text { Nuclear } \\ - & \text { Flexibility Limit } \\ - & 5 \% \mathrm{PV} \\ - & 10 \% \mathrm{PV} \\ - & 15 \% \mathrm{PV} \\ - & 20 \% \mathrm{PV} \\ - & 25 \% \mathrm{PV} \\ - & 30 \% \mathrm{PV} \\ - & 35 \% \mathrm{PV}\end{array}$

\section{** Net load analysis for DEP and DEC}

Storage $=2.2 \mathrm{GW}$

Daily \% Zero $\mathrm{CO} 2 \mathrm{Gen}$.:

$5 \%$ PV $-67 \%$

$10 \%$ PV $-72 \%$

$15 \%$ PV $-76 \%$

$25 \%$ PV $-79 \%$

$25 \%$ PV $-79 \%$

$30 \%$ PV $-80 \%$

** Penetration by energy is annual and pre-curtailment

** Flexibility Limit: Assumes nuclear gen. running constantly

at full capacity with no outages

** Storage has sufficient energy to utilize full pumping capacity

over hours of surplus solar power and optimized for energy arbitrage
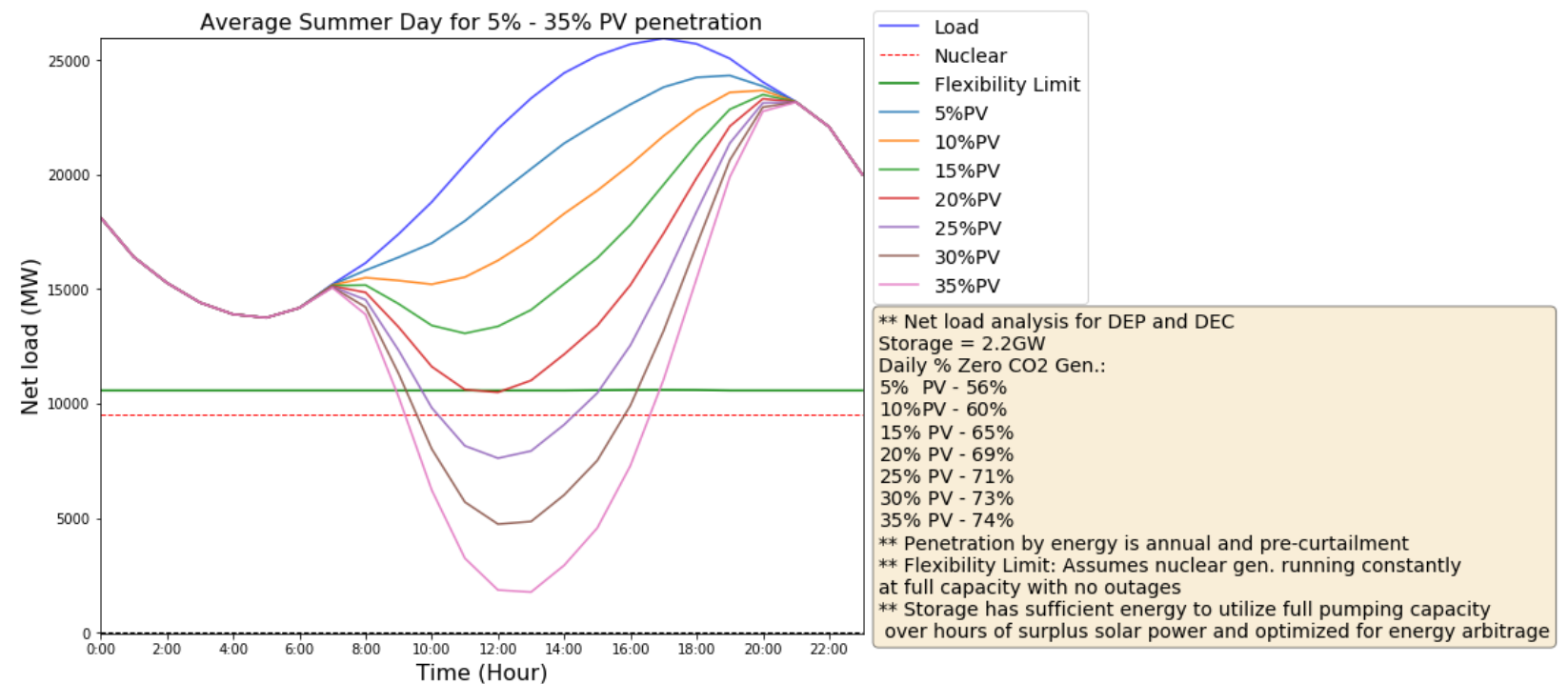

This report is available at no cost from the National Renewable Energy Laboratory (NREL) at www.nrel.gov/publications. 


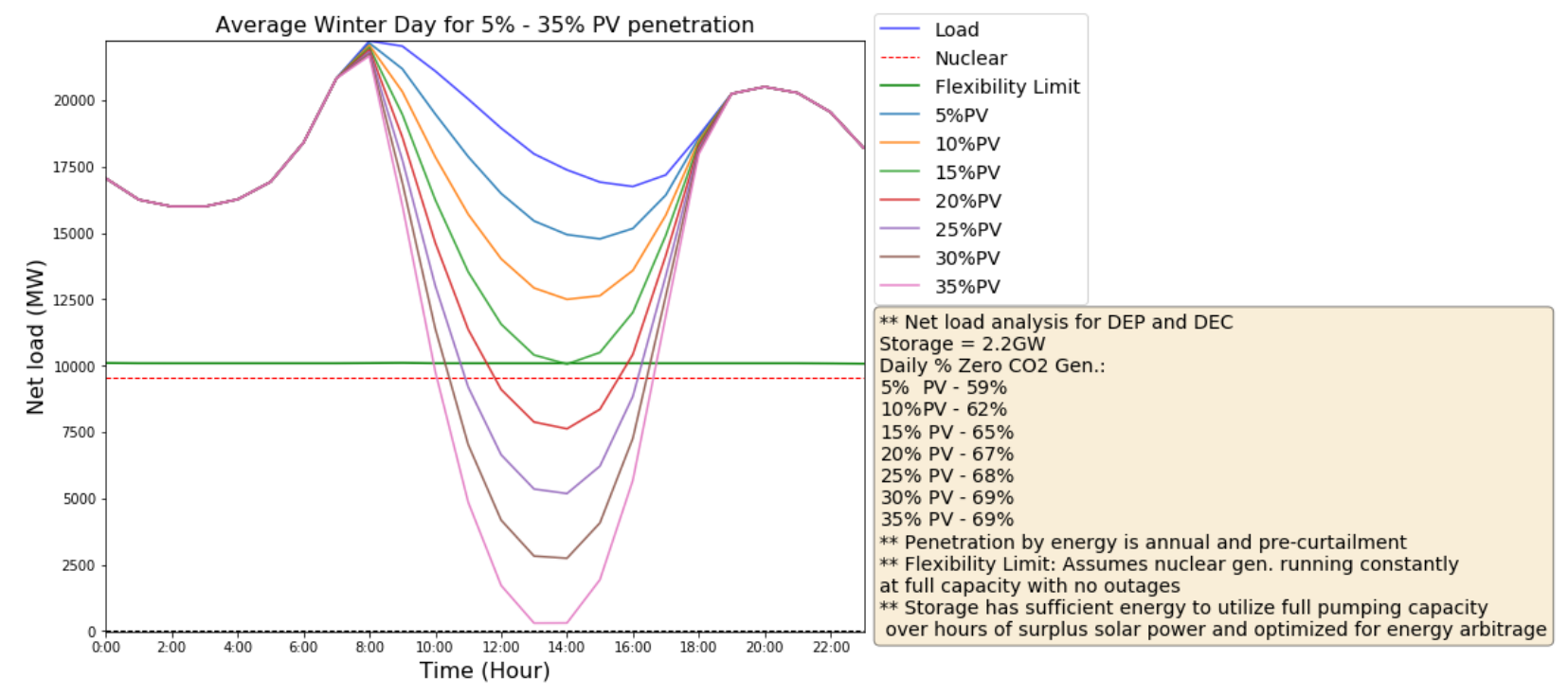

This report is available at no cost from the National Renewable Energy Laboratory (NREL) at www.nrel.gov/publications. 
Seasonal Low Net Load Days: 10\% PV Penetration

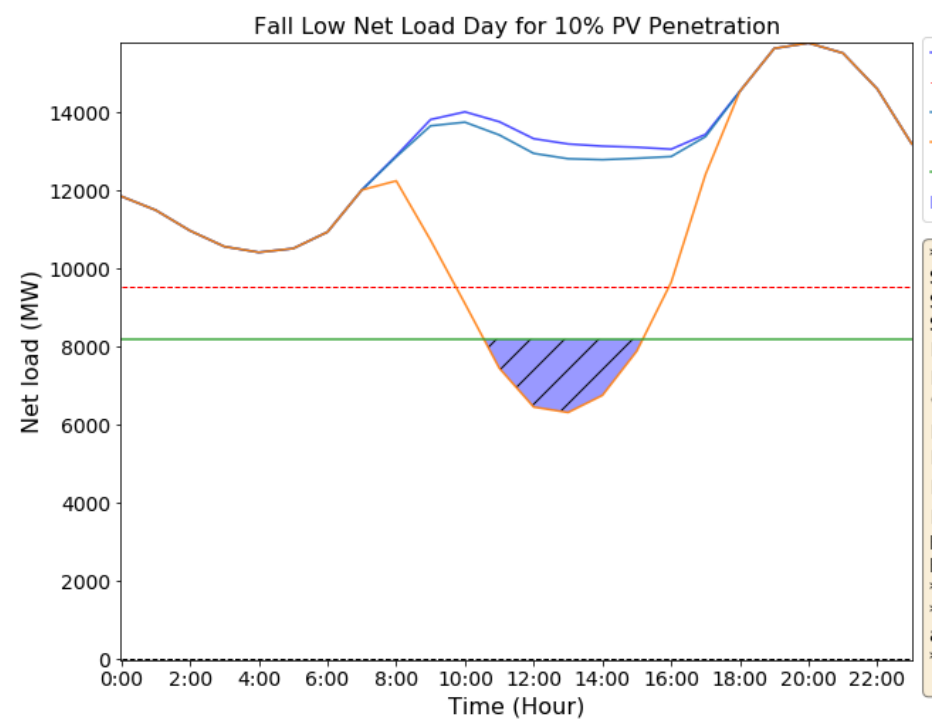

$\begin{array}{ll}- & \text { Load } \\ - & \text { Nuclear } \\ \square & \text { Load - Private PV } \\ \square & \text { Load - All PV } \\ \square & \text { Flexibility Limit } \\ \square & \text { Curtailed PV energy }\end{array}$

** Net load analysis for DEP and DEC

Storage $=2.2 \mathrm{GW}$

Scenario 2: PV Penetration of $10 \%$ by annual energy

Solar PV capacity $=8,219 \mathrm{MW}$

Daily \% Zero $\mathrm{CO} 2$ Generation : $90 \%$

Hours of curtailment $=5$ hours

$\%$ Curtailed energy $=13.64 \%$

Max. instantaneous curtailment $=1877 \mathrm{MW}$

Max. up ramp $=2764 \mathrm{MW} / \mathrm{h}$ at $17: 00$

Max. down ramp $=-1623 \mathrm{MW} / \mathrm{h}$ at 10:00

Daily ramp range $=7583 \mathrm{MW} /$ day

Flexibility limit $=\{$ (Must-Run + Nuclear + Hydro $)-$ Storage $\}$

Flexibility limit $=\{(671+9528+198)-2200\}=8197 \mathrm{MW} @ 13: 00$

** Penetration by energy is annual and pre-curtailment

** Flexibility Limit: Assumes nuclear gen. running constantly

at full capacity with no outages

* Storage has sufficient energy to utilize full pumping capacity over hours of surplus solar power and optimized for energy arbitrage
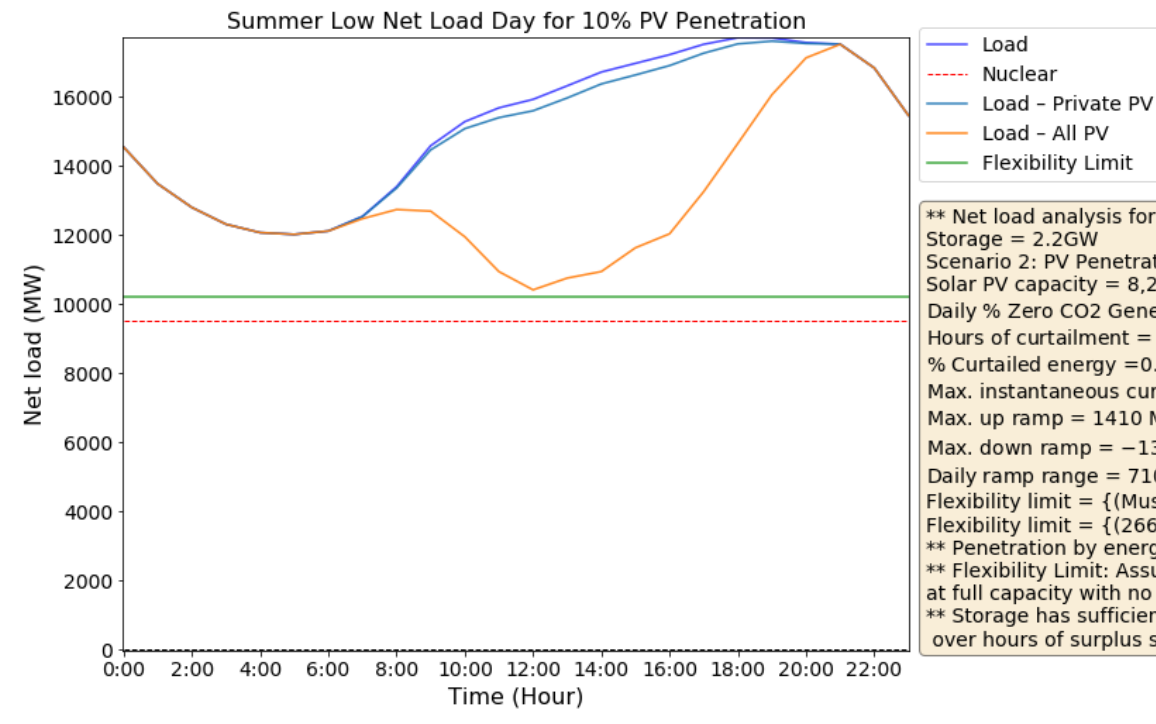

- Flexibility Limit

* Net load analysis for DEP and DEC

Nerage $=2.2 \mathrm{GW}$

cenario 2: PV Penetration of $10 \%$ by annual energy

Solar PV capacity $=8,219 \mathrm{MW}$

Daily \% Zero $\mathrm{CO} 2$ Generation : $77 \%$

Hours of curtailment $=0$ hours

$\%$ Curtailed energy $=0.00 \%$

Max. instantaneous curtailment $=0 \mathrm{MW}$

Max. up ramp $=1410 \mathrm{MW} / \mathrm{h}$ at 19:00

Max. down ramp $=-1371 \mathrm{MW} / \mathrm{h}$ at 23:00

Daily ramp range $=7102 \mathrm{MW} /$ day

Flexibility limit $=\{($ Must-Run + Nuclear + Hydro $)-$ Storage $\}$

Fexibility limit $=\{(2662+9528+234)-2200\}=10224 \mathrm{MW} @ 13: 00$

* Penetration by energy is annual and pre-curtailment

* Flexibility Limit: Assumes nuclear gen. running constantly

at full capacity with no outages

* Storage has sufficient energy to utilize full pumping capacity over hours of surplus solar power and optimized for energy arbitrage

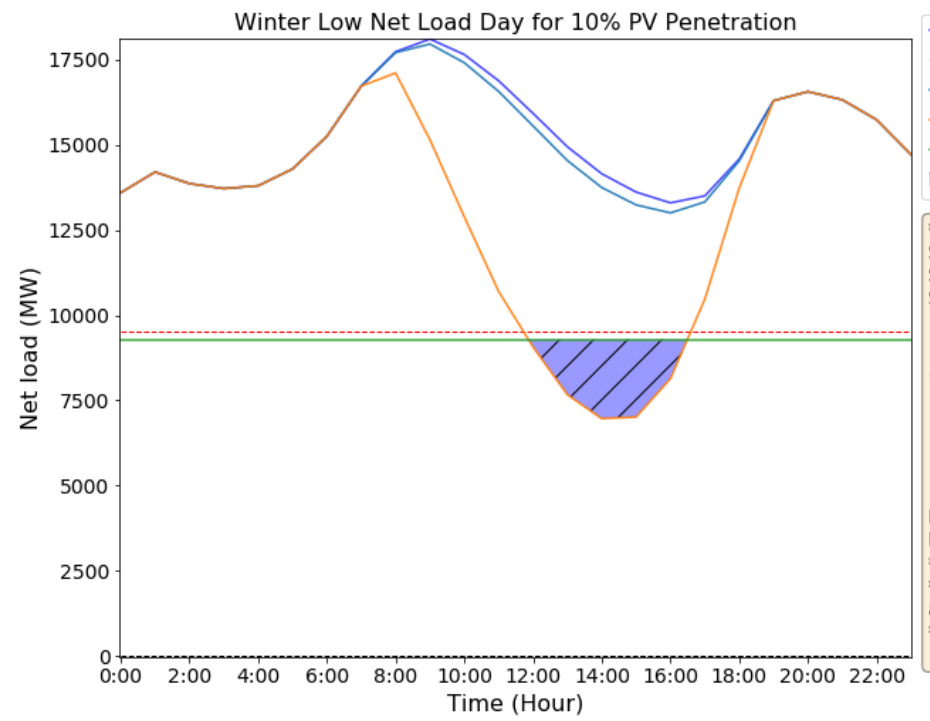

- Load

-.-. Nuclear

— Load - Private PV

L Load - All PV

- Flexibility Limit

C Curtailed PV energy

** Net load analysis for DEP and DEC

Storage $=2.2 \mathrm{GW}$

Scenario 2: PV Penetration of $10 \%$ by annual energy

Solar PV capacity $=8,219 \mathrm{MW}$

Daily \% Zero CO2 Generation : $78 \%$

Hours of curtailment $=5$ hours

$\%$ Curtailed energy $=14.76 \%$

Max. instantaneous curtailment $=2323 \mathrm{MW}$

Max. up ramp $=3253 \mathrm{MW} / \mathrm{h}$ at 18

Max. down ramp $=-2261 \mathrm{MW} / \mathrm{h}$ at 10:00

Daily ramp range $=7812 \mathrm{MW} /$ day

Flexibility limit $=\{($ Must-Run + Nuclear + Hydro $)-$ Storage $\}$

Flexibility limit $=\{(1627+9528+334)-2200\}=9289 \mathrm{MW} @ 14: 00$

** Penetration by energy is annual and pre-curtailment

** Flexibility Limit: Assumes nuclear gen. running constantly

at full capacity with no outages

** Storage has sufficient energy to utilize full pumping capacity

over hours of surplus solar power and optimized for energy arbitrage

This report is available at no cost from the National Renewable Energy Laboratory (NREL) at www.nrel.gov/publications. 
Seasonal Peak Net Load Days: 10\% PV Penetration

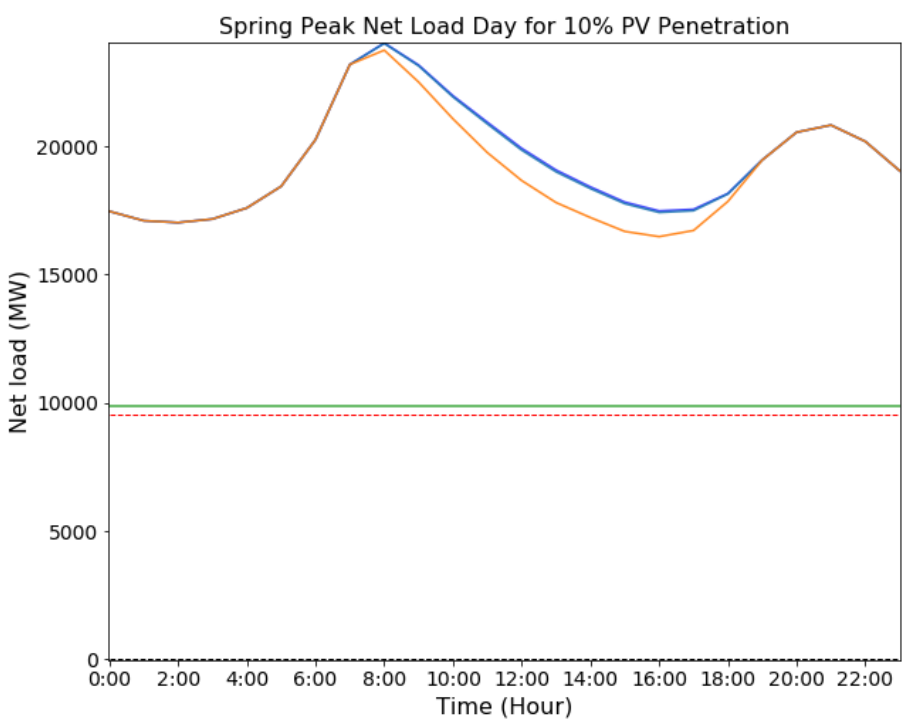

- Load

-..-... Nuclear

— Load - Private PV

Load - All PV

— Flexibility Limit

** Net load analysis for DEP and DEC

Storage $=2.2 \mathrm{GW}$

Scenario 2: PV Penetration of $10 \%$ by annual energy

Solar PV capacity $=8,219 \mathrm{MW}$

Daily \% Zero CO2 Generation : $53 \%$

Hours of curtailment $=0$ hours

$\%$ Curtailed energy $=0.00 \%$

Max. instantaneous curtailment $=0 \mathrm{MW}$

Max. up ramp $=2927 \mathrm{MW} / \mathrm{h}$ at 07:00

Max. down ramp $=-1435 \mathrm{MW} / \mathrm{h}$ at 10:00

Daily ramp range $=7261 \mathrm{MW} /$ day

Flexibility limit $=\{($ Must-Run + Nuclear + Hydro $)-$ Storage $\}$
Flexibility limit $=\{(2125+9528+393)-2200\}=9846 \mathrm{MW} @ 13: 00$

Flexibility limit $=\{(2125+9528+393)-2200\}=9846$
$* *$ Penetration by energy is annual and pre-curtailment

** Flexibility Limit: Assumes nuclear gen. running constantly

at full capacity with no outages

* Storage has sufficient energy to utilize full pumping capacity

over hours of surplus solar power and optimized for energy arbitrage

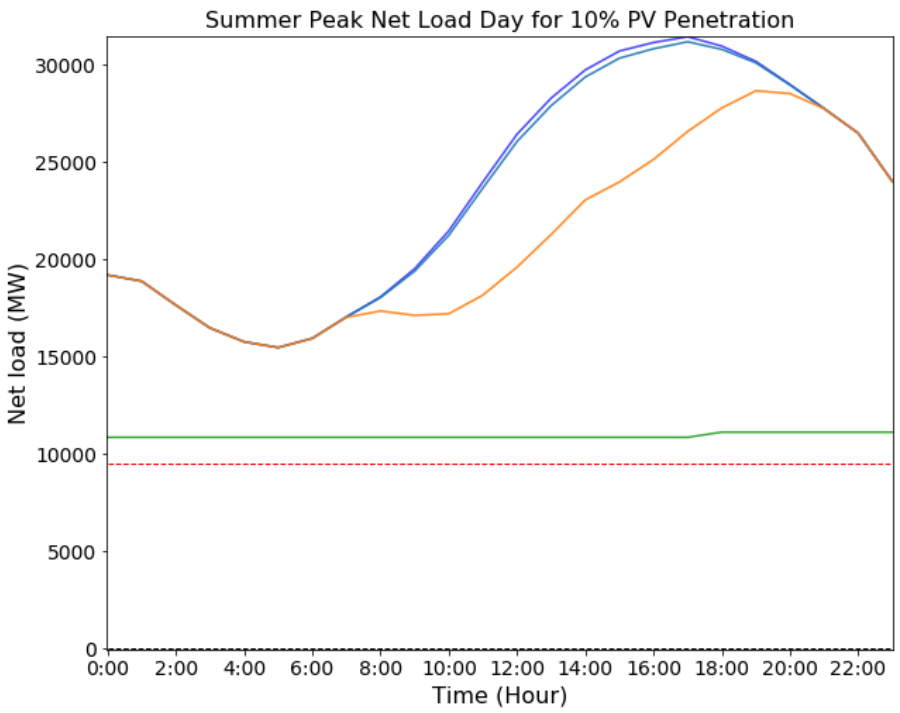

- Load

Nuclear

- Load - Private PV

- Load - All PV

Flexibility Limit

* Net load analysis for DEP and DEC

Storage $=2.2 \mathrm{GW}$

Scenario 2: PV Penetration of $10 \%$ by annual energy

Solar PV capacity $=8,219 \mathrm{MW}$

Daily \% Zero $\mathrm{CO} 2$ Generation : $52 \%$

Hours of curtailment $=0$ hours

$\%$ Curtailed energy $=0.00 \%$

Max. instantaneous curtailment $=0 \mathrm{MW}$

Max. up ramp $=1777 \mathrm{MW} / \mathrm{h}$ at 14:00

Max. down ramp $=-2482 \mathrm{MW} / \mathrm{h}$ at 23:00

Daily ramp range $=13194 \mathrm{MW} /$ day

Flexibility limit $=\{($ Must-Run + Nuclear + Hydro $)-$ Storage $\}$

Flexibility limit $=\{(3368+9528+173)-2200\}=10869 \mathrm{MW} @ 13: 00$ ** Penetration by energy is annual and pre-curtailment

** Flexibility Limit: Assumes nuclear gen. running constantly at full capacity with no outages

* Storage has sufficient energy to utilize full pumping capacity over hours of surplus solar power and optimized for energy arbitrage

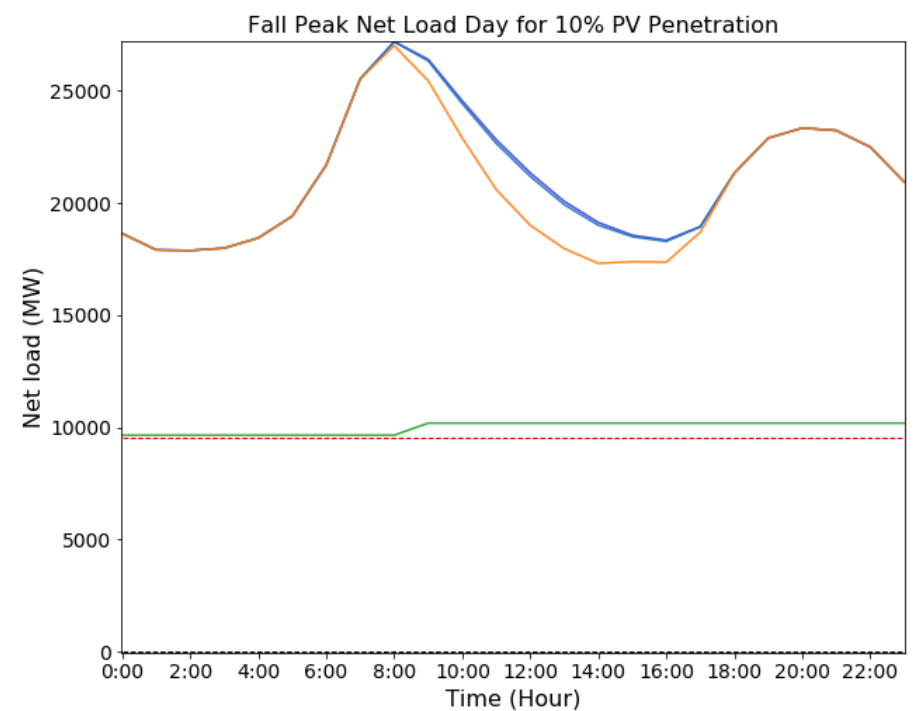

- Load

-... Nuclear

- Load - Private PV

- Load - All PV

- Flexibility Limit

** Net load analysis for DEP and DEC

Storage $=2.2 \mathrm{GW}$

Scenario 2: PV Penetration of $10 \%$ by annual energy

Solar PV capacity $=8,219 \mathrm{MW}$

Daily \% Zero CO2 Generation : $49 \%$

Hours of curtailment $=0$ hours

$\%$ Curtailed energy $=0.00 \%$

Max. instantaneous curtailment $=0 \mathrm{MW}$

Max. up ramp $=3839 \mathrm{MW} / \mathrm{h}$ at 07:00

Max. down ramp $=-2543 \mathrm{MW} / \mathrm{h}$ at 10:00

Daily ramp range $=9691 \mathrm{MW} /$ day

Flexibility limit $=\{($ Must-Run + Nuclear + Hydro $)-$ Storage $\}$

Flexibility limit $=\{(2662+9528+198)-2200\}=10,188 \mathrm{MW} @ 13: 00$

** Penetration by energy is annual and pre-curtailment

** Flexibility Limit: Assumes nuclear gen. running constantly

at full capacity with no outages

** Storage has sufficient energy to utilize full pumping capacity

over hours of surplus solar power and optimized for energy arbitrage

This report is available at no cost from the National Renewable Energy Laboratory (NREL) at www.nrel.gov/publications. 


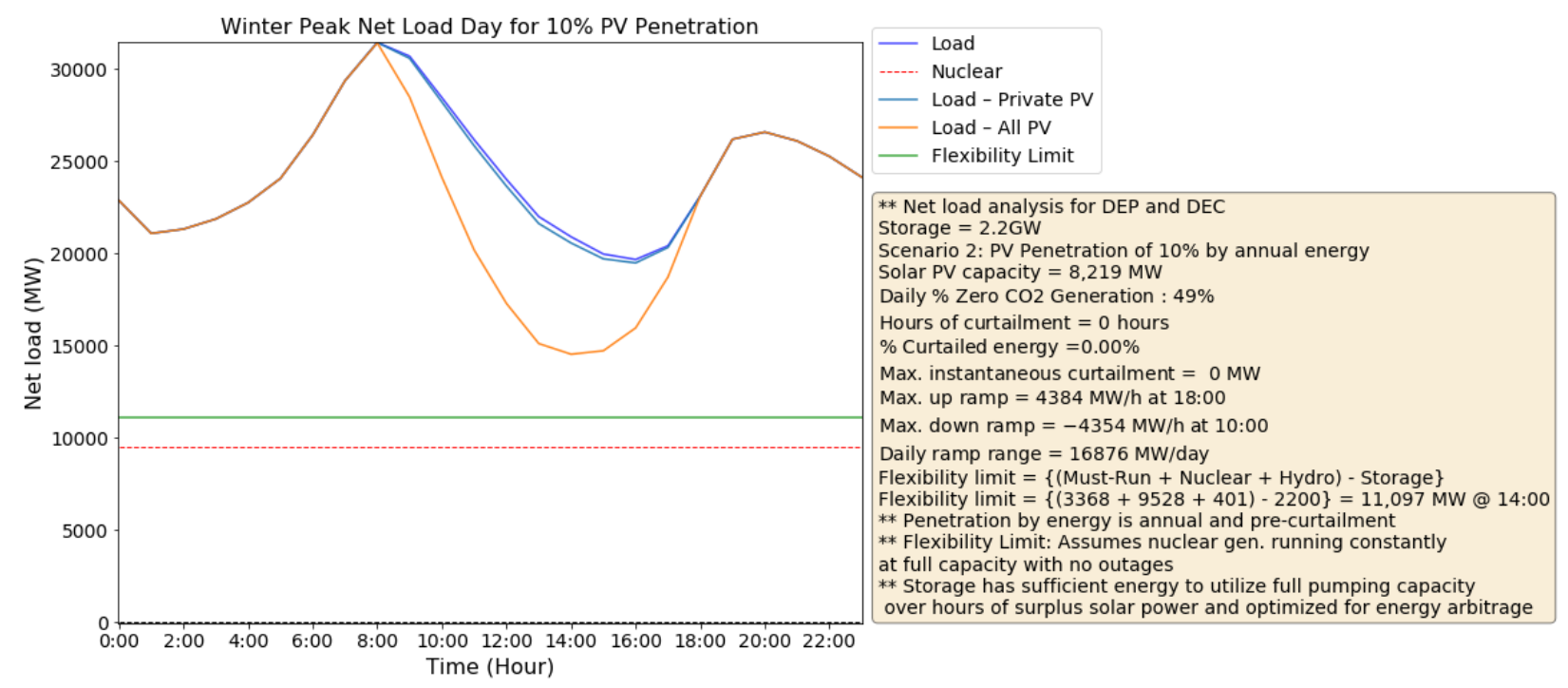

This report is available at no cost from the National Renewable Energy Laboratory (NREL) at www.nrel.gov/publications. 
Seasonal Low Net Load Days: 15\% PV Penetration

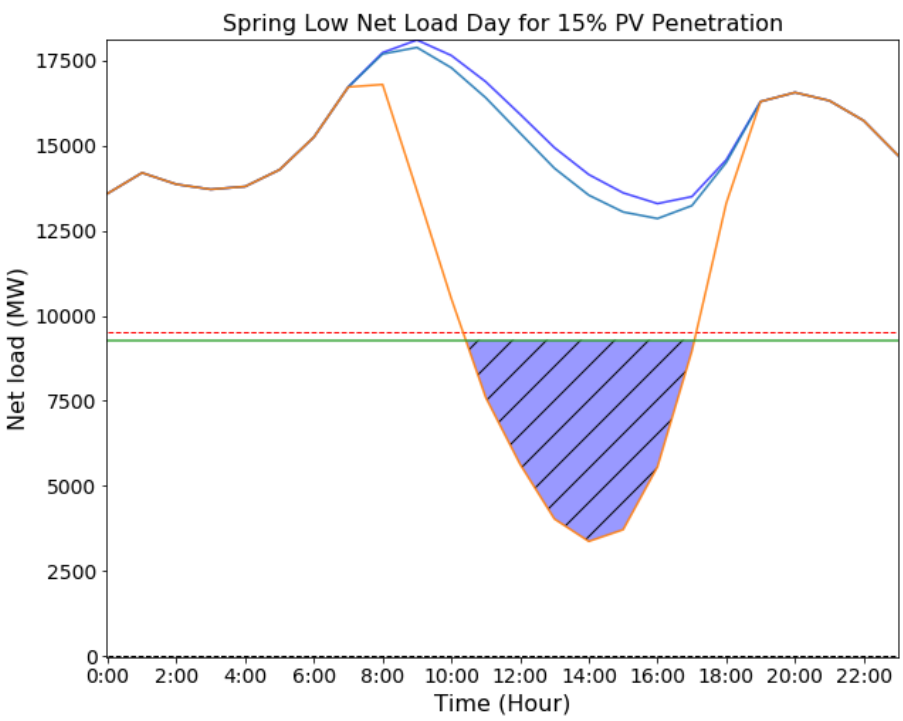

\begin{aligned}- & Load \\ -- & Nuclear \\ - & Load - Private PV \\ - & Load - All PV \\ - & Flexibility Limit \\ \hline & Curtailed PV energy \end{aligned}

** Net load analysis for DEP and DEC

Storage $=2.2 \mathrm{GW}$

Scenario 3: PV Penetration of $15 \%$ by annual energy

Solar PV capacity $=12,328 \mathrm{MW}$

Daily \% Zero CO2 Generation : $80 \%$

Hours of curtailment $=7$ hours

$\%$ Curtailed energy $=33.86 \%$

Max. instantaneous curtailment $=5913 \mathrm{MW}$

Max. up ramp $=4011 \mathrm{MW} / \mathrm{h}$ at 18:00

Max. down ramp $=-3164 \mathrm{MW} / \mathrm{h}$ at 10:00

Daily ramp range $=7500 \mathrm{MW} /$ day

Flexibility limit $=\{($ Must-Run + Nuclear + Hydro $)-$ Storage $\}$

Flexibility limit $=\{(671+9528+344)-2200\}=8343 \mathrm{MW} @ 14: 00$

** Penetration by energy is annual and pre-curtailment

** Flexibility Limit: Assumes nuclear gen. running constantly

at full capacity with no outages

** Storage has sufficient energy to utilize full pumping capacity

over hours of surplus solar power and optimized for energy arbitrage

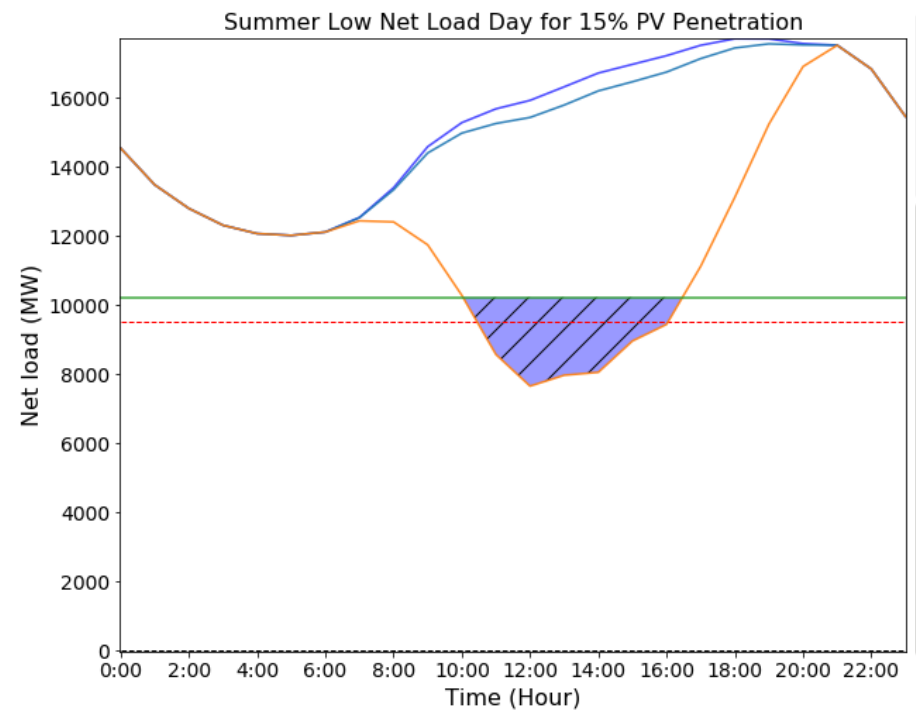

- Load

---.- Nuclear

Load - Private PV

- Load - All PV

- Flexibility Limit

1 Curtailed PV energy

** Net load analysis for DEP and DEC

Storage $=2.2 \mathrm{GW}$

Scenario 3: PV Penetration of $15 \%$ by annual energy

Solar PV capacity $=12,328 \mathrm{MW}$

Daily \% Zero CO2 Generation : $80 \%$

Hours of curtailment $=6$ hours

$\%$ Curtailed energy $=15.02 \%$

Max. instantaneous curtailment $=2568 \mathrm{MW}$

Max. up ramp $=2117 \mathrm{MW} / \mathrm{h}$ at 19:00

Max. down ramp $=-1460 \mathrm{MW} / \mathrm{h}$ at 10:00

Daily ramp range $=7288 \mathrm{MW} /$ day

Flexibility limit $=\{$ (Must-Run + Nuclear + Hydro $)-$ Storage $\}$

Flexibility limit $=\{(2662+9528+234)-2200\}=10224 \mathrm{MW} @ 13: 00$

** Penetration by energy is annual and pre-curtailment

** Flexibility Limit: Assumes nuclear gen. running constantly

at full capacity with no outages

** Storage has sufficient energy to utilize full pumping capacity

over hours of surplus solar power and optimized for energy arbitrage 
Fall Low Net Load Day for 15\% PV Penetration

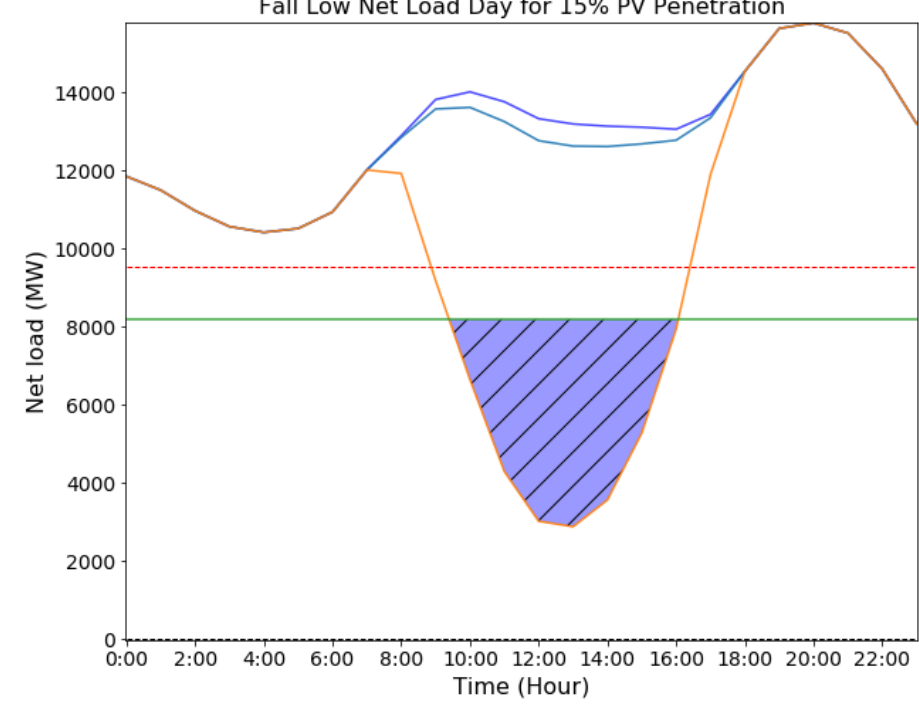

$\begin{array}{ll}- & \text { Load } \\ ---- & \text { Nuclear } \\ - & \text { Load - Private PV } \\ \square & \text { Load - All PV } \\ - & \text { Flexibility Limit } \\ \square & \text { Curtailed PV energy }\end{array}$

** Net load analysis for DEP and DEC

Storage $=2.2 \mathrm{GW}$

Scenario 3: PV Penetration of $15 \%$ by annual energy

Solar PV capacity $=12,328 \mathrm{MW}$

Daily \% Zero CO2 Generation : $92 \%$

Hours of curtailment $=7$ hours

$\%$ Curtailed energy $=35.36 \%$

Max. instantaneous curtailment $=5314 \mathrm{MW}$

Max. up ramp $=3706 \mathrm{MW} / \mathrm{h}$ at 17:00

Max. down ramp $=-2744 \mathrm{MW} / \mathrm{h}$ at 09:00

Daily ramp range $=7583 \mathrm{MW} /$ day

Flexibility limit $=\{$ (Must-Run + Nuclear + Hydro $)-$ Storage $\}$

Flexibility limit $=\{(671+9528+198)-2200\}=8197 \mathrm{MW} @ 13: 00$

** Penetration by energy is annual and pre-curtailment

** Flexibility Limit: Assumes nuclear gen. running constantly

at full capacity with no outages
** Storage has sufficient energy to utilize full pumping capacity

over hours of surplus solar power and optimized for energy arbitrage

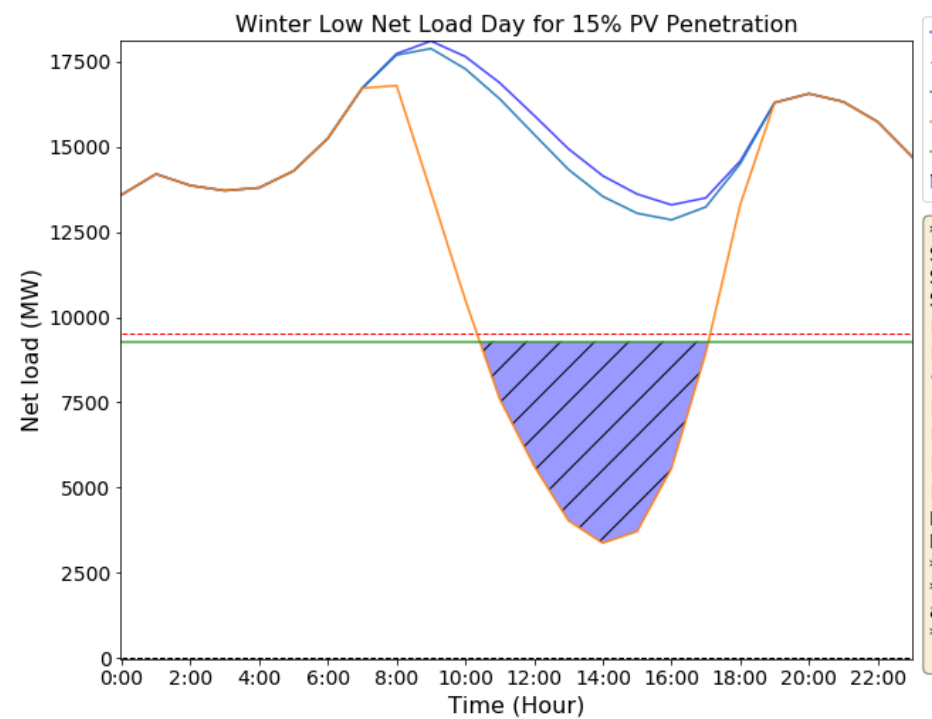

- Load

Nuclear

- Load - Private PV

- Load - All PV

Flexibility Limit

I Curtailed PV energy

** Net load analysis for DEP and DEC

Storage $=2.2 \mathrm{GW}$

Scenario 3. PV Penetration of $15 \%$ by annual energy

Solar PV capacity $=12,328 \mathrm{MW}$

Daily \% Zero CO2 Generation : $80 \%$

Hours of curtailment $=7$ hours

$\%$ Curtailed energy $=33.86 \%$

Max. instantaneous curtailment $=5913 \mathrm{MW}$

Max. up ramp $=4011 \mathrm{MW} / \mathrm{h}$ at $18: 00$

Max. down ramp $=-3164 \mathrm{MW} / \mathrm{h}$ at 10:00

Daily ramp range $=7500 \mathrm{MW} /$ day

Flexibility limit $=\{($ Must-Run + Nuclear + Hydro $)-$ Storage $\}$

Flexibility limit $=\{(1627+9528+334)-2200\}=9289 \mathrm{MW} @ 14: 00$

** Penetration by energy is annual and pre-curtailment

** Flexibility Limit: Assumes nuclear gen. running constantly

at full capacity with no outages

** Storage has sufficient energy to utilize full pumping capacity

over hours of surplus solar power and optimized for energy arbitrage

This report is available at no cost from the National Renewable Energy Laboratory (NREL) at www.nrel.gov/publications. 
Seasonal Peak Net Load Days: 15\% PV Penetration

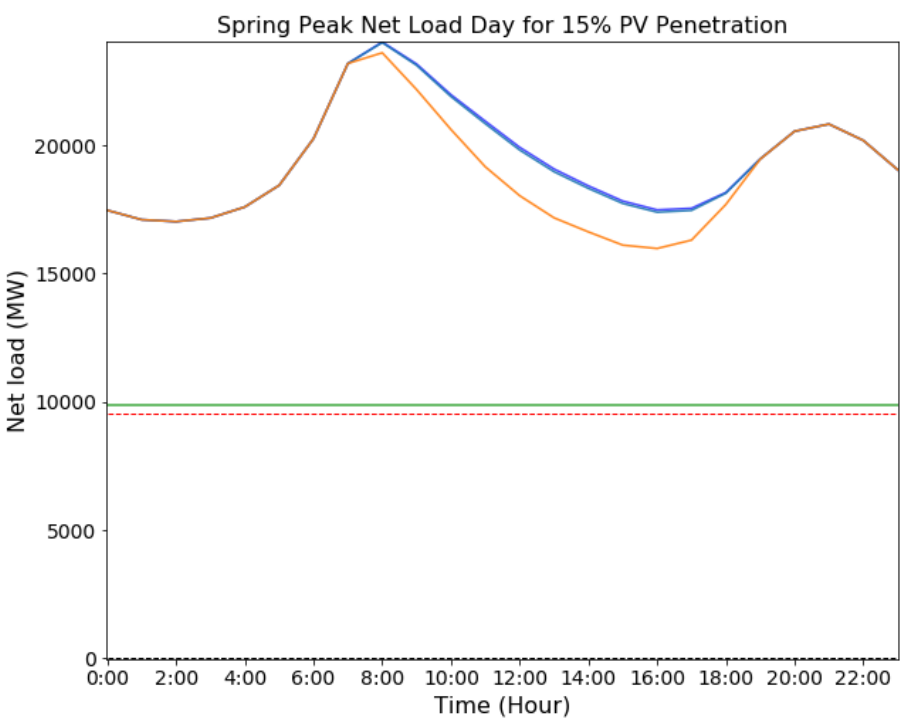

- Load

-..-... Nuclear

- Load - Private PV

Load - All PV

— Flexibility Limit

** Net load analysis for DEP and DEC

Storage $=2.2 \mathrm{GW}$

Scenario 3: PV Penetration of $15 \%$ by annual energy

Solar PV capacity $=12,328 \mathrm{MW}$

Daily \% Zero CO2 Generation : $54 \%$

Hours of curtailment $=0$ hours

$\%$ Curtailed energy $=0.00 \%$

Max. instantaneous curtailment $=0 \mathrm{MW}$

Max. up ramp $=2927 \mathrm{MW} / \mathrm{h}$ at 07:00

Max. down ramp $=-1554 \mathrm{MW} / \mathrm{h}$ at 10:00

Daily ramp range $=7622 \mathrm{MW} /$ day

Flexibility limit $=\{($ Must-Run + Nuclear + Hydro $)-$ Storage $\}$
Flexibility limit $=\{(2125+9528+393)-2200\}=9846 \mathrm{MW} @ 14: 00$

Flexibility limit $=\{(2125+9528+393)-2200\}=9846$
$* *$ Penetration by energy is annual and pre-curtailment

** Flexibility Limit: Assumes nuclear gen. running constantly

at full capacity with no outages

* Storage has sufficient energy to utilize full pumping capacity

over hours of surplus solar power and optimized for energy arbitrage

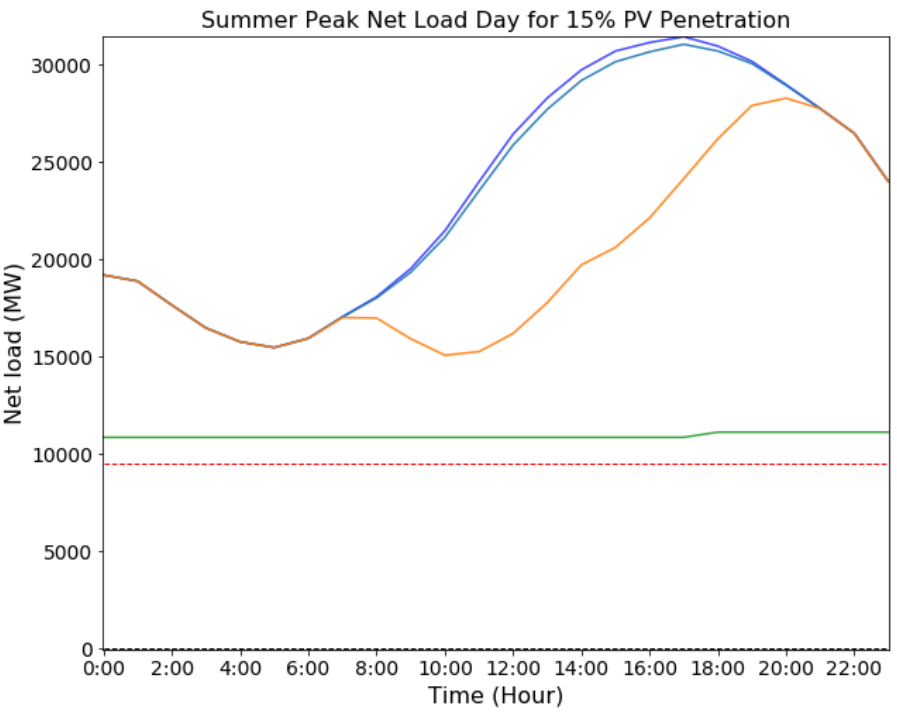

- Load

Nuclear

- Load - Private PV

- Load - All PV

Flexibility Limit

* Net load analysis for DEP and DEC

Storage $=2.2 \mathrm{GW}$

Scenario 3: PV Penetration of $15 \%$ by annual energy

Solar PV capacity $=12,328 \mathrm{MW}$

Daily \% Zero CO2 Generation : $56 \%$

Hours of curtailment $=0$ hours

$\%$ Curtailed energy $=0.00 \%$

Max. instantaneous curtailment $=0 \mathrm{MW}$

Max. up ramp $=2053 \mathrm{MW} / \mathrm{h}$ at 18:00

Max. down ramp $=-2482 \mathrm{MW} / \mathrm{h}$ at 23:00

Daily ramp range $=13208 \mathrm{MW} /$ day

Flexibility limit $=\{($ Must-Run + Nuclear + Hydro $)-$ Storage $\}$

Flexibility limit $=\{(3368+9528+173)-2200\}=10869 \mathrm{MW} @ 14: 00$ ** Penetration by energy is annual and pre-curtailment

** Flexibility Limit: Assumes nuclear gen. running constantly at full capacity with no outages

* Storage has sufficient energy to utilize full pumping capacity over hours of surplus solar power and optimized for energy arbitrage

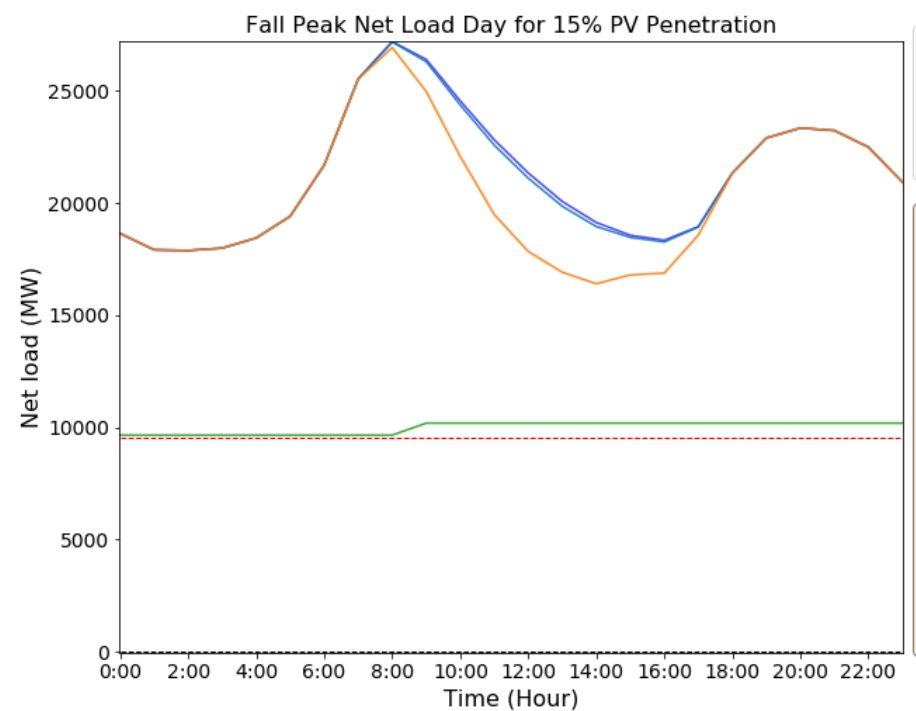

- Load

-... Nuclear

- Load - Private PV

- Load - All PV

- Flexibility Limit

** Net load analysis for DEP and DEC

Storage $=2.2 \mathrm{GW}$

Scenario 3: PV Penetration of $15 \%$ by annual energy

Solar PV capacity $=12,328 \mathrm{MW}$

Daily \% Zero CO2 Generation : $50 \%$

Hours of curtailment $=0$ hours

$\%$ Curtailed energy $=0.00 \%$

Max. instantaneous curtailment $=0 \mathrm{MW}$

Max. up ramp $=3839 \mathrm{MW} / \mathrm{h}$ at 07:00

Max. down ramp $=-2891 \mathrm{MW} / \mathrm{h}$ at 10:00

Daily ramp range $=10511 \mathrm{MW} /$ day

Flexibility limit $=\{$ (Must-Run + Nuclear + Hydro $)-$ Storage $\}$

Flexibility limit $=\{(2662+9528+198)-2200\}=10,188$ MW @ 13:00

** Penetration by energy is annual and pre-curtailment

** Flexibility Limit: Assumes nuclear gen. running constantly

at full capacity with no outages

** Storage has sufficient energy to utilize full pumping capacity

over hours of surplus solar power and optimized for energy arbitrage

This report is available at no cost from the National Renewable Energy Laboratory (NREL) at www.nrel.gov/publications. 


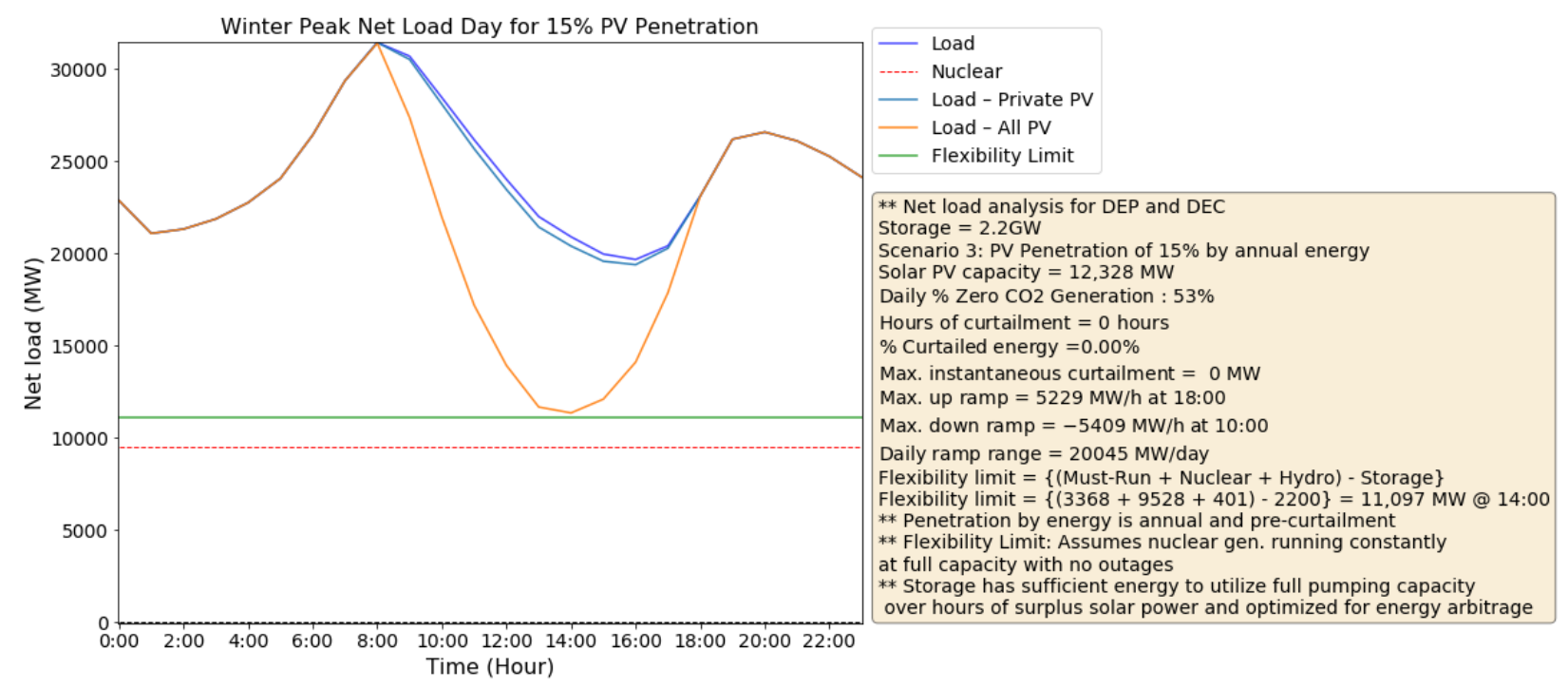

This report is available at no cost from the National Renewable Energy Laboratory (NREL) at www.nrel.gov/publications. 
Seasonal Low Net Load Days: 20\% PV Penetration

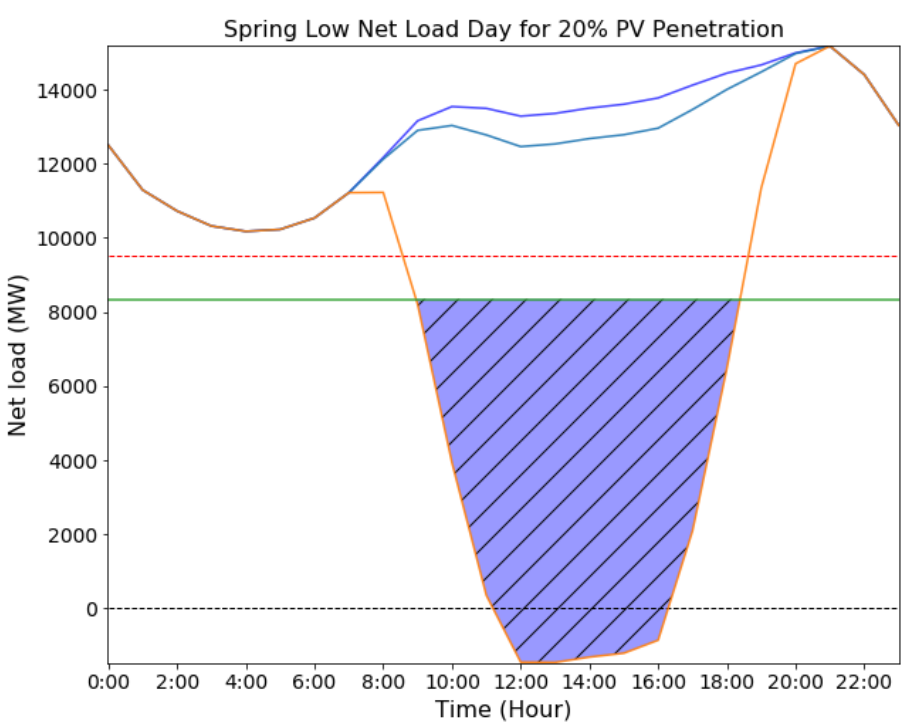

- Load

-.-.- Nuclear

L Load - Private PV

L Load - All PV

- Flexibility Limit

C Curtailed PV energy

** Net load analysis for DEP and DEC

Storage $=2.2 \mathrm{GW}$

Scenario 4: PV Penetration of $20 \%$ by annual energy

Solar PV capacity $=16,438 \mathrm{MW}$

Daily \% Zero CO2 Generation : $99 \%$

Hours of curtailment $=10$ hours

$\%$ Curtailed energy $=54.50 \%$

Max. instantaneous curtailment $=9801 \mathrm{MW}$

Max. up ramp $=3355 \mathrm{MW} / \mathrm{h}$ at 20:00

Max. down ramp $=-2878 \mathrm{MW} / \mathrm{h}$ at 09:00

Daily ramp range $=6828 \mathrm{MW} /$ day

Flexibility limit $=\{($ Must-Run + Nuclear + Hydro $)-$ Storage $\}$

Flexibility limit $=\{(671+9528+344)-2200\}=8343$ MW @ 13:00

** Penetration by energy is annual and pre-curtailment

** Flexibility Limit: Assumes nuclear gen. running constantly

at full capacity with no outages

* Storage has sufficient energy to utilize full pumping capacity over hours of surplus solar power and optimized for energy arbitrage

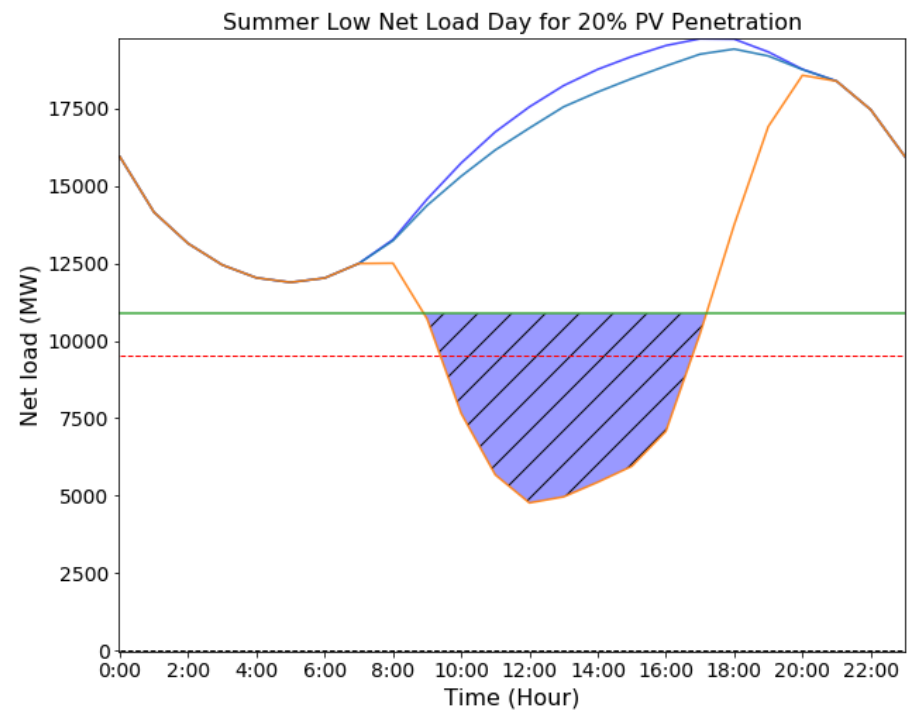

- Load

-.-.- Nuclear

Load - Private PV

Load - All PV

- Flexibility Limit

1 Curtailed PV energy

** Net load analysis for DEP and DEC

Storage $=2.2 \mathrm{GW}$

Scenario 4: PV Penetration of $20 \%$ by annual energy

Solar PV capacity $=16,438 \mathrm{MW}$

Daily \% Zero CO2 Generation : $78 \%$

Hours of curtailment $=9$ hours

$\%$ Curtailed energy $=33.14 \%$

Max. instantaneous curtailment $=6106 \mathrm{MW}$

Max. up ramp $=3175 \mathrm{MW} / \mathrm{h}$ at 19:00

Max. down ramp $=-1788 \mathrm{MW} / \mathrm{h}$ at 01:00

Daily ramp range $=7685 \mathrm{MW} /$ day

Flexibility limit $=\{$ (Must-Run + Nuclear + Hydro $)-$ Storage $\}$

Flexibility limit $=\{(3368+9528+182)-2200\}=10878 \mathrm{MW} @ 13: 00$ ** Penetration by energy is annual and pre-curtailment

** Flexibility Limit: Assumes nuclear gen. running constantly

at full capacity with no outages

** Storage has sufficient energy to utilize full pumping capacity

over hours of surplus solar power and optimized for energy arbitrage

Fall Low Net Load Day for 20\% PV Penetration

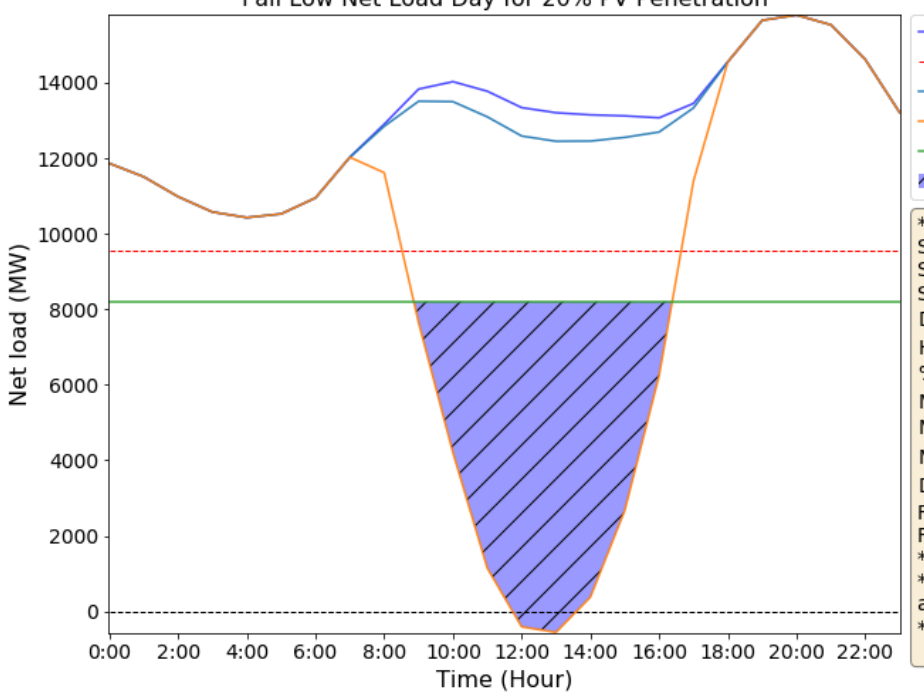

— Load

---. Nuclear

- Load - Private PV

L Load - All PV

- Flexibility Limit

$\checkmark$ Curtailed PV energy

** Net load analysis for DEP and DEC

Storage $=2.2 \mathrm{GW}$

Scenario 4: PV Penetration of $20 \%$ by annual energy

Solar PV capacity $=16,438 \mathrm{MW}$

Daily \% Zero CO2 Generation : $93 \%$

Hours of curtailment $=8$ hours

$\%$ Curtailed energy $=49.48 \%$

Max. instantaneous curtailment $=8751 \mathrm{MW}$

Max. up ramp $=3193 \mathrm{MW} / \mathrm{h}$ at 17:00

Max. down ramp $=-3410 \mathrm{MW} / \mathrm{h}$ at 09:00

Daily ramp range $=7583 \mathrm{MW} /$ day

Flexibility limit $=\{($ Must-Run + Nuclear + Hydro $)-$ Storage $\}$

Flexibility limit $=\{(671+9528+198)-2200\}=8197$ MW @ 13:00

** Penetration by energy is annual and pre-curtailment

** Flexibility Limit: Assumes nuclear gen. running constantly

at full capacity with no outages

** Storage has sufficient energy to utilize full pumping capacity

over hours of surplus solar power and optimized for energy arbitrage

This report is available at no cost from the National Renewable Energy Laboratory (NREL) at www.nrel.gov/publications. 


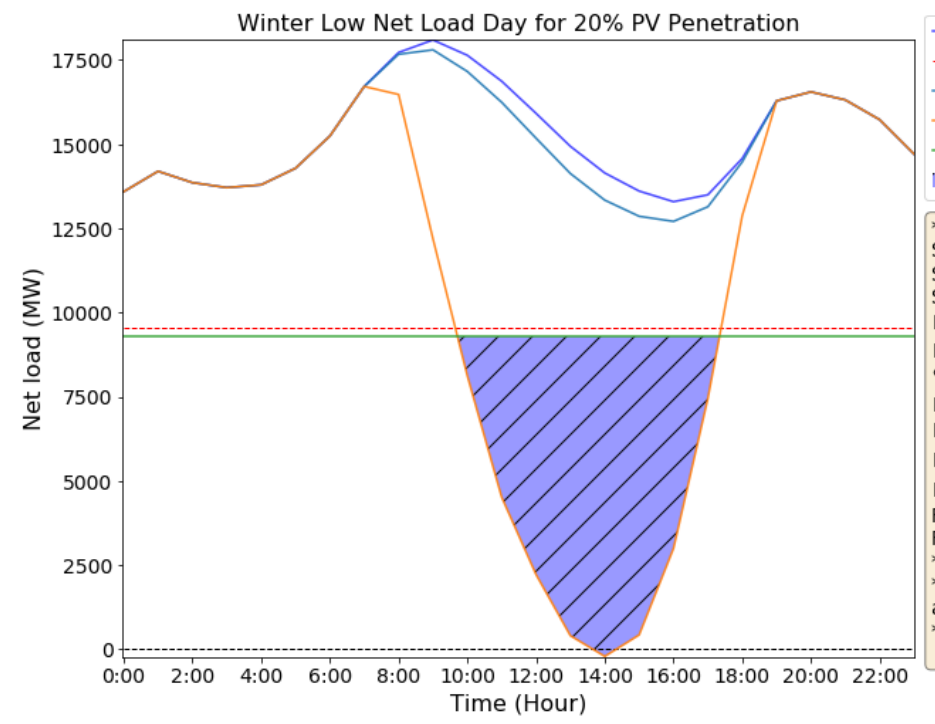


Seasonal Peak Net Load Days: 20\% PV Penetration
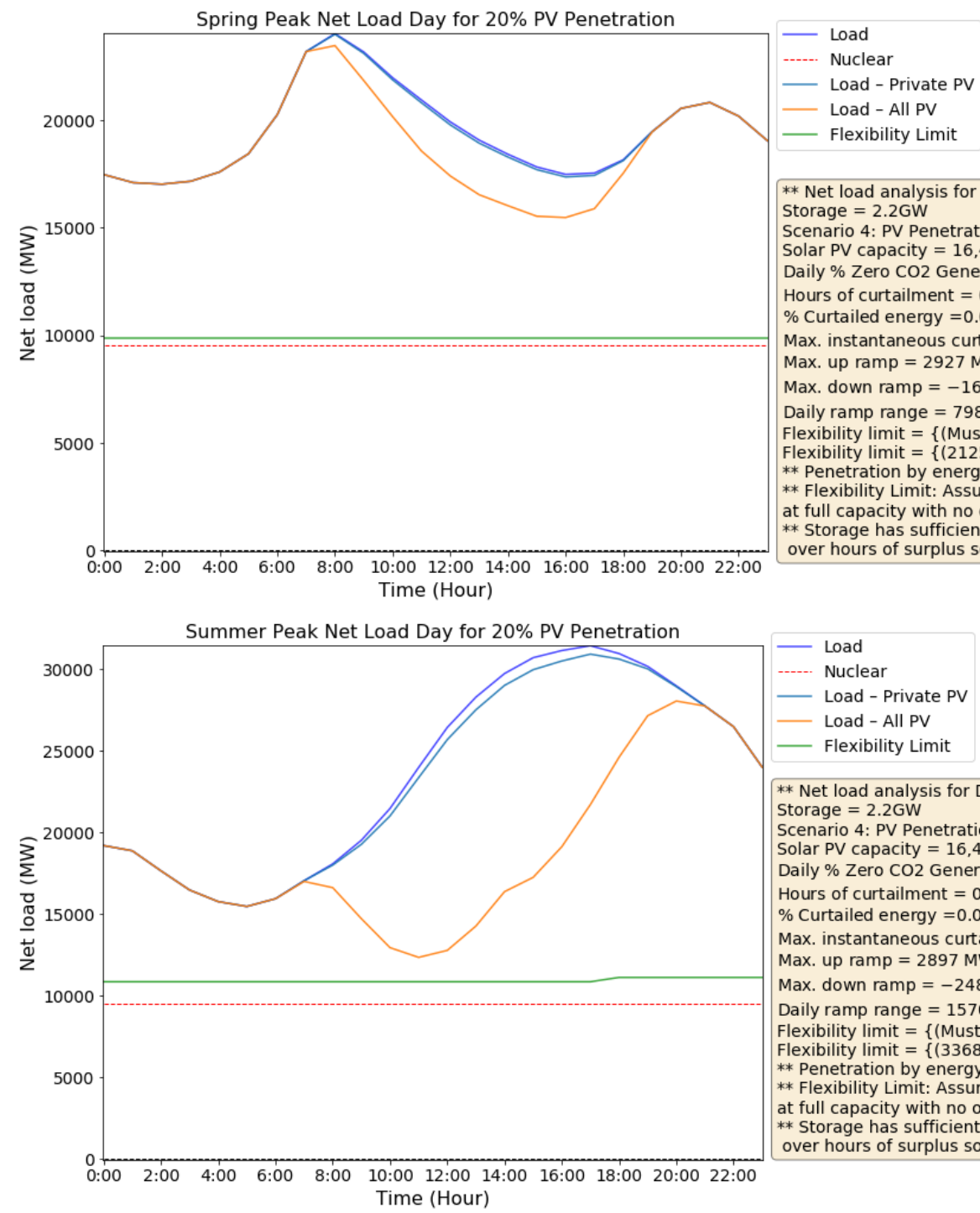

- Load

Nuclear

- Load - Private PV

- Load - All PV

- Flexibility Limit

* Net load analysis for DEP and DEC

Storage $=2.2 \mathrm{GW}$

Scenario 4: PV Penetration of $20 \%$ by annual energy

Solar PV capacity $=16,438 \mathrm{MW}$

Daily \% Zero $\mathrm{CO} 2$ Generation : $61 \%$

Hours of curtailment $=0$ hours

$\%$ Curtailed energy $=0.00 \%$

Max. instantaneous curtailment $=0 \mathrm{MW}$

Max. up ramp $=2897 \mathrm{MW} / \mathrm{h}$ at 18:00

Max. down ramp $=-2482 \mathrm{MW} / \mathrm{h}$ at 23:00

Daily ramp range $=15703 \mathrm{MW} /$ day

Flexibility limit $=\{($ Must-Run + Nuclear + Hydro $)-$ Storage $\}$

Flexibility limit $=\{(3368+9528+173)-2200\}=10869 \mathrm{MW} @ 13: 00$ ** Penetration by energy is annual and pre-curtailment

** Flexibility Limit: Assumes nuclear gen. running constantly at full capacity with no outages

* Storage has sufficient energy to utilize full pumping capacity over hours of surplus solar power and optimized for energy arbitrage

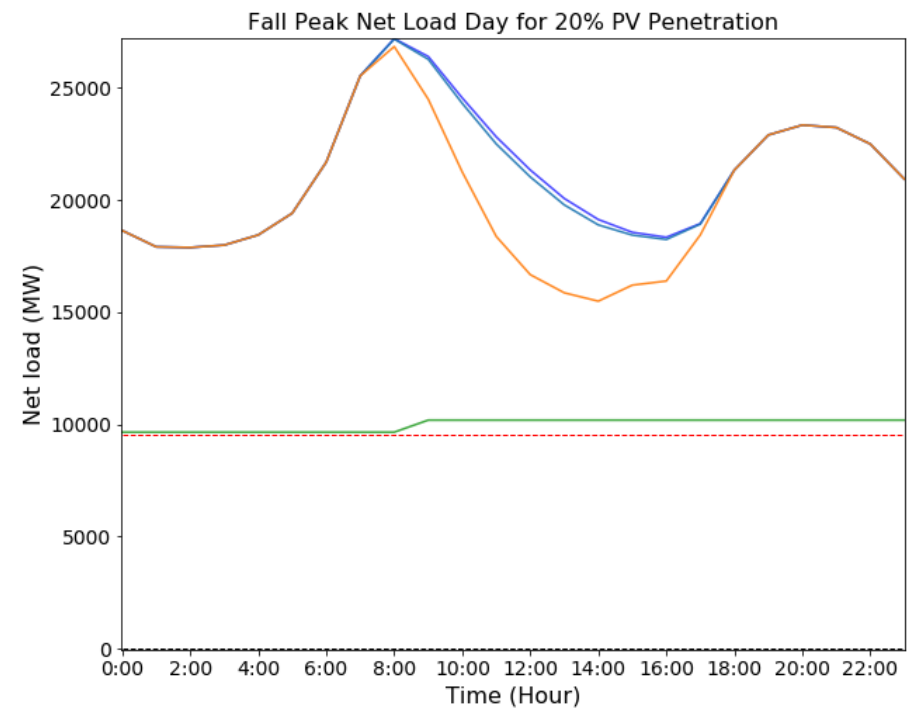

- Load

-... Nuclea

- Load - Private PV

- Load - All PV

- Flexibility Limit

** Net load analysis for DEP and DEC

Storage $=2.2 \mathrm{GW}$

Scenario 4: PV Penetration of $20 \%$ by annual energy

Solar PV capacity $=16,438 \mathrm{MW}$

Daily \% Zero CO2 Generation : $52 \%$

Hours of curtailment $=0$ hours

$\%$ Curtailed energy $=0.00 \%$

Max. instantaneous curtailment $=0 \mathrm{MW}$

Max. up ramp $=3839 \mathrm{MW} / \mathrm{h}$ at 07:00

Max. down ramp $=-3240 \mathrm{MW} / \mathrm{h}$ at $10: 00$

Daily ramp range $=11332 \mathrm{MW} /$ day

Flexibility limit $=\{$ (Must-Run + Nuclear + Hydro $)-$ Storage $\}$

Flexibility limit $=\{(2662+9528+198)-2200\}=10,188 \mathrm{MW} @ 13: 00$

** Penetration by energy is annual and pre-curtailment

** Flexibility Limit: Assumes nuclear gen. running constantly

at full capacity with no outages

** Storage has sufficient energy to utilize full pumping capacity

over hours of surplus solar power and optimized for energy arbitrage

This report is available at no cost from the National Renewable Energy Laboratory (NREL) at www.nrel.gov/publications. 


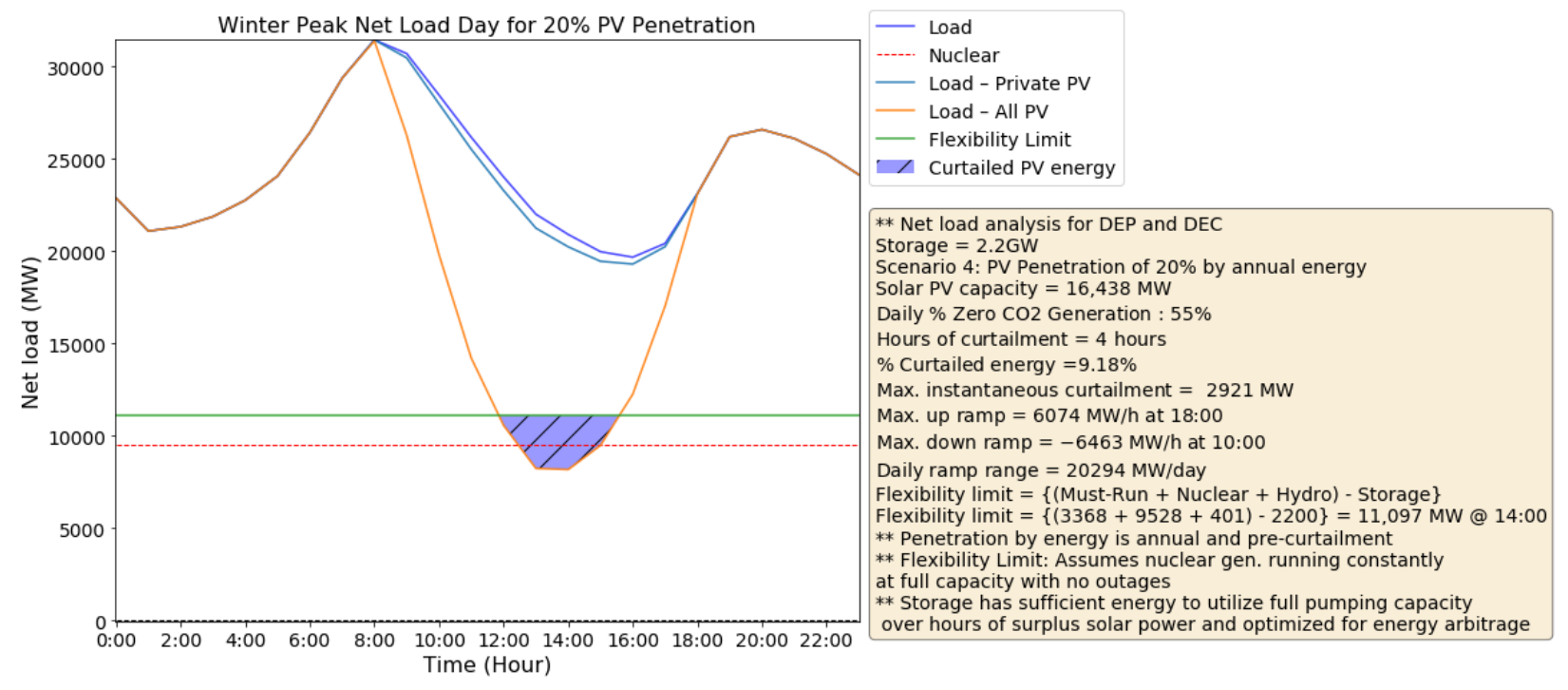

This report is available at no cost from the National Renewable Energy Laboratory (NREL) at www.nrel.gov/publications. 
Seasonal Low Net Load Days: 25\% PV Penetration

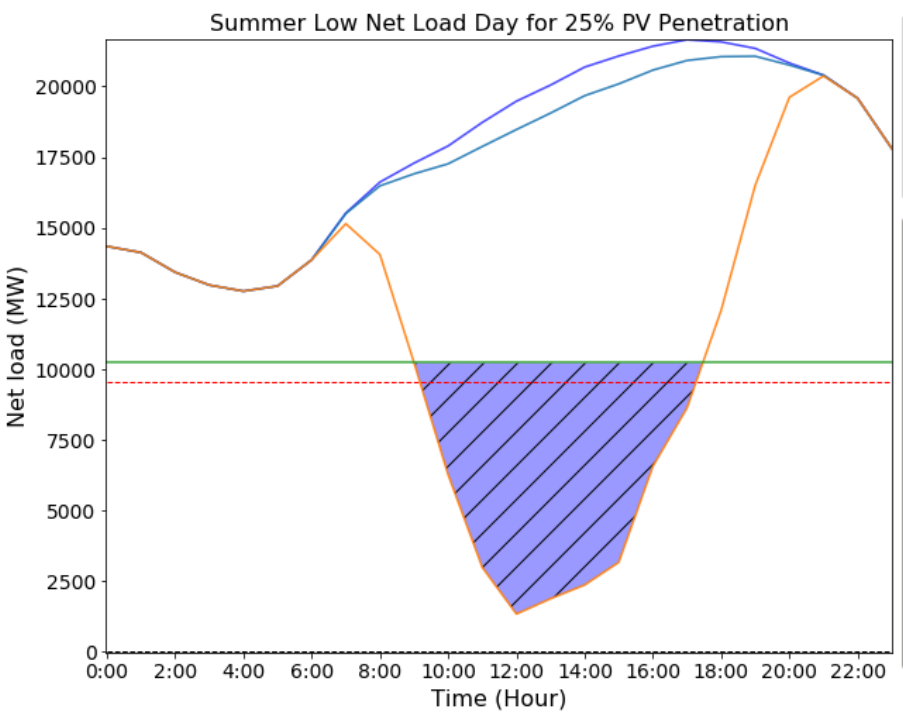

$\begin{array}{ll}- & \text { Load } \\ - & \text { Nuclear } \\ \square & \text { Load - Private PV } \\ - & \text { Load - All PV } \\ - & \text { Flexibility Limit } \\ & \text { Curtailed PV energy }\end{array}$

** Net load analysis for DEP and DEC

Storage $=2.2 \mathrm{GW}$

Scenario 5: PV Penetration of $25 \%$ by annual energy

Solar PV capacity $=20,547 \mathrm{MW}$

Daily \% Zero $\mathrm{CO} 2$ Generation : $78 \%$

Hours of curtailment $=8$ hours

$\%$ Curtailed energy $=31.69 \%$

Max. instantaneous curtailment $=8886 \mathrm{MW}$

Max. up ramp $=4427 \mathrm{MW} / \mathrm{h}$ at 19:00

Max. down ramp $=-3829 \mathrm{MW} / \mathrm{h}$ at 09:00

Daily ramp range $=10148 \mathrm{MW} /$ day

Flexibility limit $=\{($ Must-Run + Nuclear + Hydro $)-$ Storage $\}$

Flexibility limit $=\{(2662+9528+234)-2200\}=10224 \mathrm{MW} @ 12: 00$

** Penetration by energy is annual and pre-curtailment

** Flexibility Limit: Assumes nuclear gen. running constantly

at full capacity with no outages

** Storage has sufficient energy to utilize full pumping capacity

over hours of surplus solar power and optimized for energy arbitrage

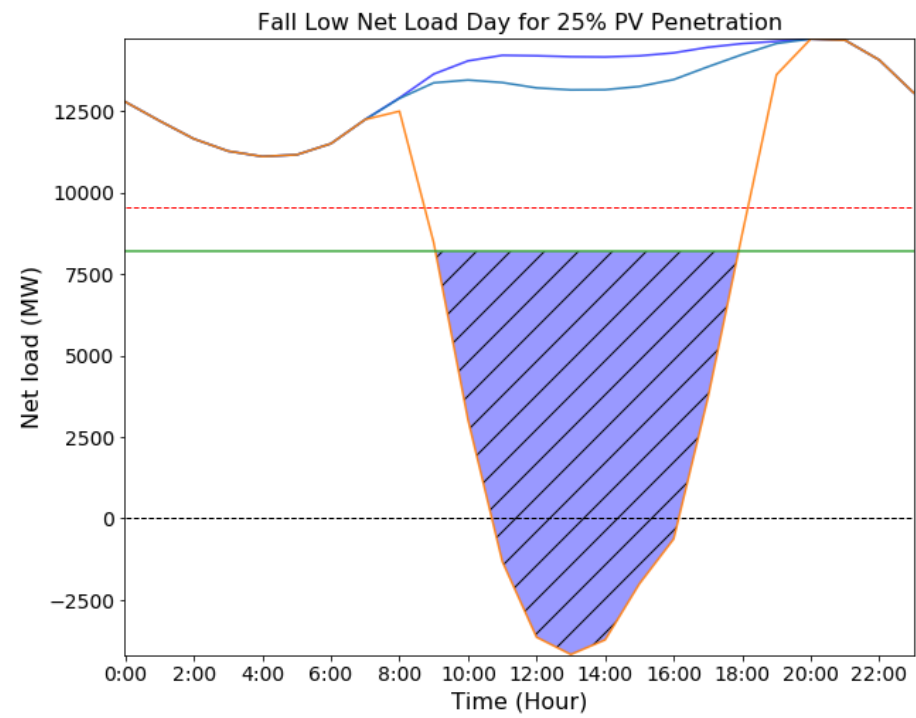

L Load

-..-. Nuclear

- Load - Private PV

L Load - All PV

- Flexibility Limit

C Curtailed PV energy

** Net load analysis for DEP and DEC

Storage $=2.2 \mathrm{GW}$

Scenario 5: PV Penetration of $25 \%$ by annual energy

Solar PV capacity $=20,547 \mathrm{MW}$

Daily \% Zero CO2 Generation : $94 \%$

Hours of curtailment $=8$ hours

$\%$ Curtailed energy $=55.06 \%$

Max. instantaneous curtailment $=12356 \mathrm{MW}$

Max. up ramp $=4881 \mathrm{MW} / \mathrm{h}$ at 19:00

Max. down ramp $=-4037 \mathrm{MW} / \mathrm{h}$ at 09:00

Daily ramp range $=6519 \mathrm{MW} /$ day

Flexibility limit $=\{$ (Must-Run + Nuclear + Hydro $)-$ Storage $\}$

Flexibility limit $=\{(671+9528+188)-2200\}=8187 \mathrm{MW} @ 13: 00$

** Penetration by energy is annual and pre-curtailment

** Penetration by energy is annual and pre-curtailment

at full capacity with no outages

at full capacity with no outages
** Storage has sufficient energy to utilize full pumping capacity

over hours of surplus solar power and optimized for energy arbitrage

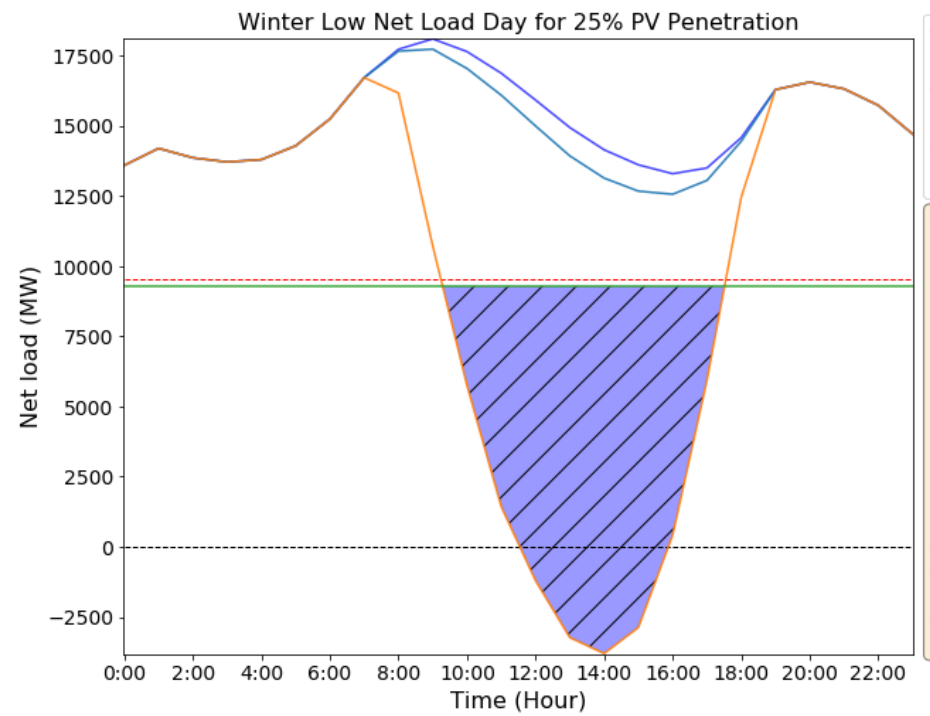

— Load

-.-. Nuclear

- Load - Private PV

- Load - All PV

- Flexibility Limit

- Curtailed PV energy

** Net load analysis for DEP and DEC

Storage $=2.2 \mathrm{GW}$

Scenario 5: PV Penetration of $25 \%$ by annual energy

Solar PV capacity $=20,547 \mathrm{MW}$

Daily \% Zero CO2 Generation : $81 \%$

Hours of curtailment $=8$ hours

$\%$ Curtailed energy $=55.93 \%$

Max. instantaneous curtailment $=13092 \mathrm{MW}$

Max. up ramp $=3839 \mathrm{MW} / \mathrm{h}$ at 19:00

Max. down ramp $=-5451 \mathrm{MW} / \mathrm{h}$ at 09:00

Daily ramp range $=7426 \mathrm{MW} /$ day

Flexibility limit $=\{($ Must-Run + Nuclear + Hydro $)-$ Storage $\}$

Flexibility limit $=\{(1627+9528+334)-2200\}=9289 \mathrm{MW} @ 14: 00$

** Penetration by energy is annual and pre-curtailment

** Flexibility Limit: Assumes nuclear gen. running constantly

at full capacity with no outages

at full capacity with no outages
** Storage has sufficient energy to utilize full pumping capacity

** Storage has sufficient energy to utilize full pumping capacity
over hours of surplus solar power and optimized for energy arbitrage

Time (Hour)

This report is available at no cost from the National Renewable Energy Laboratory (NREL) at www.nrel.gov/publications. 
Seasonal Peak Net Load Days: 25\% PV Penetration

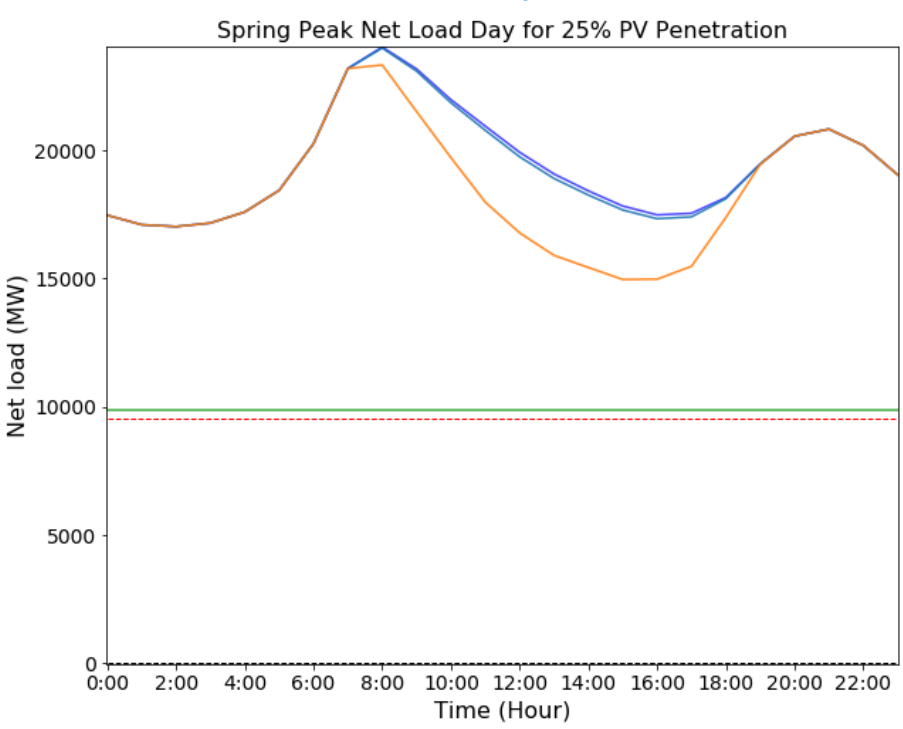

- Load

-.-.- Nuclear

L Load - Private PV

— Load - All PV

Flexibility Limit

** Net load analysis for DEP and DEC

Storage $=2.2 \mathrm{GW}$

Scenario 5: PV Penetration of $25 \%$ by annual energy

Solar PV capacity $=20,547 \mathrm{MW}$

Daily \% Zero CO2 Generation : $56 \%$

Hours of curtailment $=0$ hours

$\%$ Curtailed energy $=0.00 \%$

Max. instantaneous curtailment $=0 \mathrm{MW}$

Max. up ramp $=2927 \mathrm{MW} / \mathrm{h}$ at 07:00

Max. down ramp $=-1818 \mathrm{MW} / \mathrm{h}$ at 09:00

Daily ramp range $=8355 \mathrm{MW} /$ day

Flexibility limit $=\{$ (Must-Run + Nuclear + Hydro $)-$ Storage $\}$

Flexibility limit $=\{(2125+9528+393)-2200\}=9846 \mathrm{MW} @ 13: 00$

** Penetration by energy is annual and pre-curtailment

** Flexibility Limit: Assumes nuclear gen. running constantly

at full capacity with no outages

** Storage has sufficient energy to utilize full pumping capacity over hours of surplus solar power and optimized for energy arbitrage

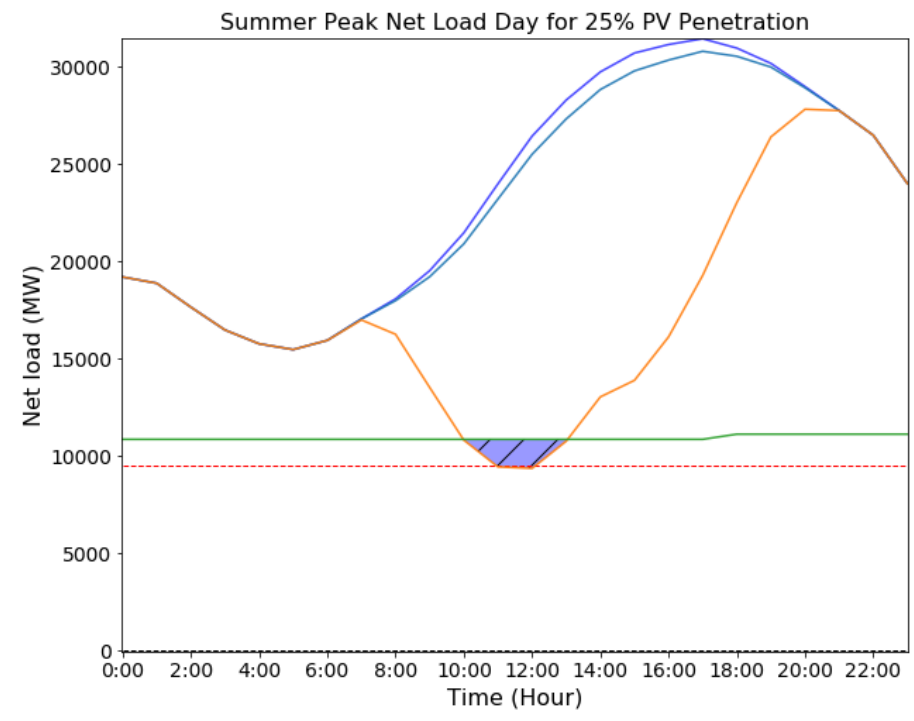

Load

----. Nuclear

Load - Private PV

- Load - All PV

- Flexibility Limit

/ Curtailed PV energy

** Net load analysis for DEP and DEC

Storage $=2.2 \mathrm{GW}$

Scenario 5: PV Penetration of $25 \%$ by annual energy

Solar PV capacity $=20,547 \mathrm{MW}$

Daily \% Zero CO2 Generation : $64 \%$

Hours of curtailment $=4$ hours

$\%$ Curtailed energy $=2.16 \%$

Max. instantaneous curtailment $=1495 \mathrm{MW}$

Max. up ramp $=3741 \mathrm{MW} / \mathrm{h}$ at $18: 00$

Max. down ramp $=-2735 \mathrm{MW} / \mathrm{h}$ at 09:00

Daily ramp range $=16962 \mathrm{MW} /$ day

Flexibility limit $=\{$ (Must-Run + Nuclear + Hydro $)-$ Storage $\}$

Flexibility limit $=\{(3368+9528+173)-2200\}=10869 \mathrm{MW} @ 12: 00$

** Penetration by energy is annual and pre-curtailment

** Flexibility Limit: Assumes nuclear gen. running constantly at full capacity with no outages

* Storage has sufficient energy to utilize full pumping capacity over hours of surplus solar power and optimized for energy arbitrage

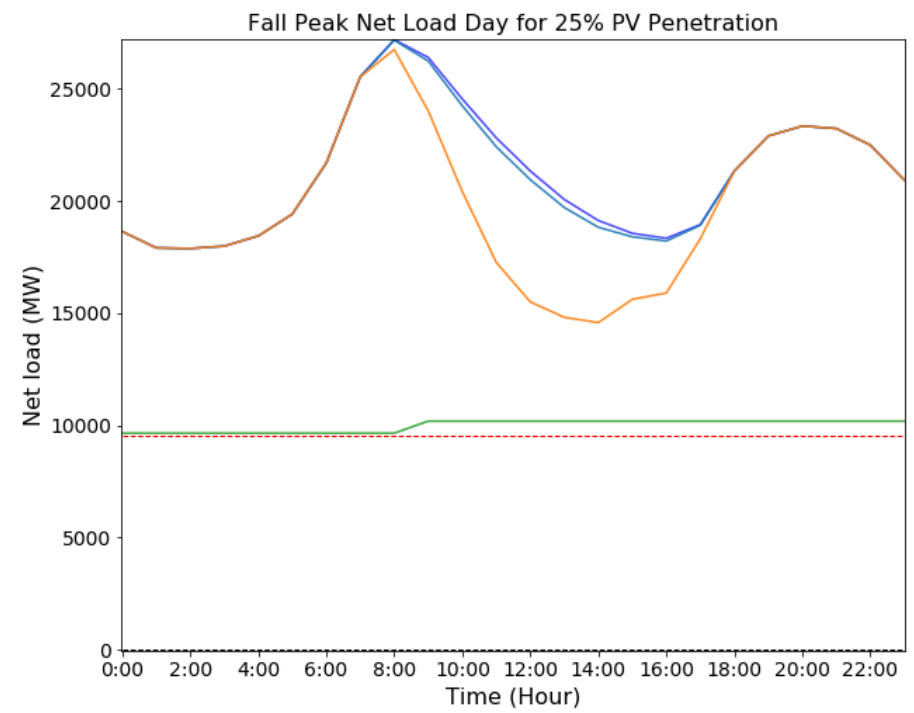

- Load

Nuclear

- Load - Private PV

- Load - All PV

- Flexibility Limit

I Curtailed PV energy

** Net load analysis for DEP and DEC

Storage $=2.2 \mathrm{GW}$

Scenario 5: PV Penetration of $25 \%$ by annual energy

Solar PV capacity $=20,547 \mathrm{MW}$

Daily \% Zero CO2 Generation : $53 \%$

Hours of curtailment $=0$ hours

$\%$ Curtailed energy $=0.00 \%$

Max. instantaneous curtailment $=0 \mathrm{MW}$

Max. up ramp $=3839 \mathrm{MW} / \mathrm{h}$ at 07:00

Max. down ramp $=-3589 \mathrm{MW} / \mathrm{h}$ at 10:00

Daily ramp range $=12153 \mathrm{MW} /$ day

Flexibility limit $=\{$ (Must-Run + Nuclear + Hydro $)-$ Storage $\}$

Flexibility limit $=\{(2662+9528+198)-2200\}=10,188 \mathrm{MW} @ 13: 00$

** Penetration by energy is annual and pre-curtailment

** Flexibility Limit: Assumes nuclear gen. running constantly

at full capacity with no outages

** Storage has sufficient energy to utilize full pumping capacity

over hours of surplus solar power and optimized for energy arbitrage

This report is available at no cost from the National Renewable Energy Laboratory (NREL) at www.nrel.gov/publications. 


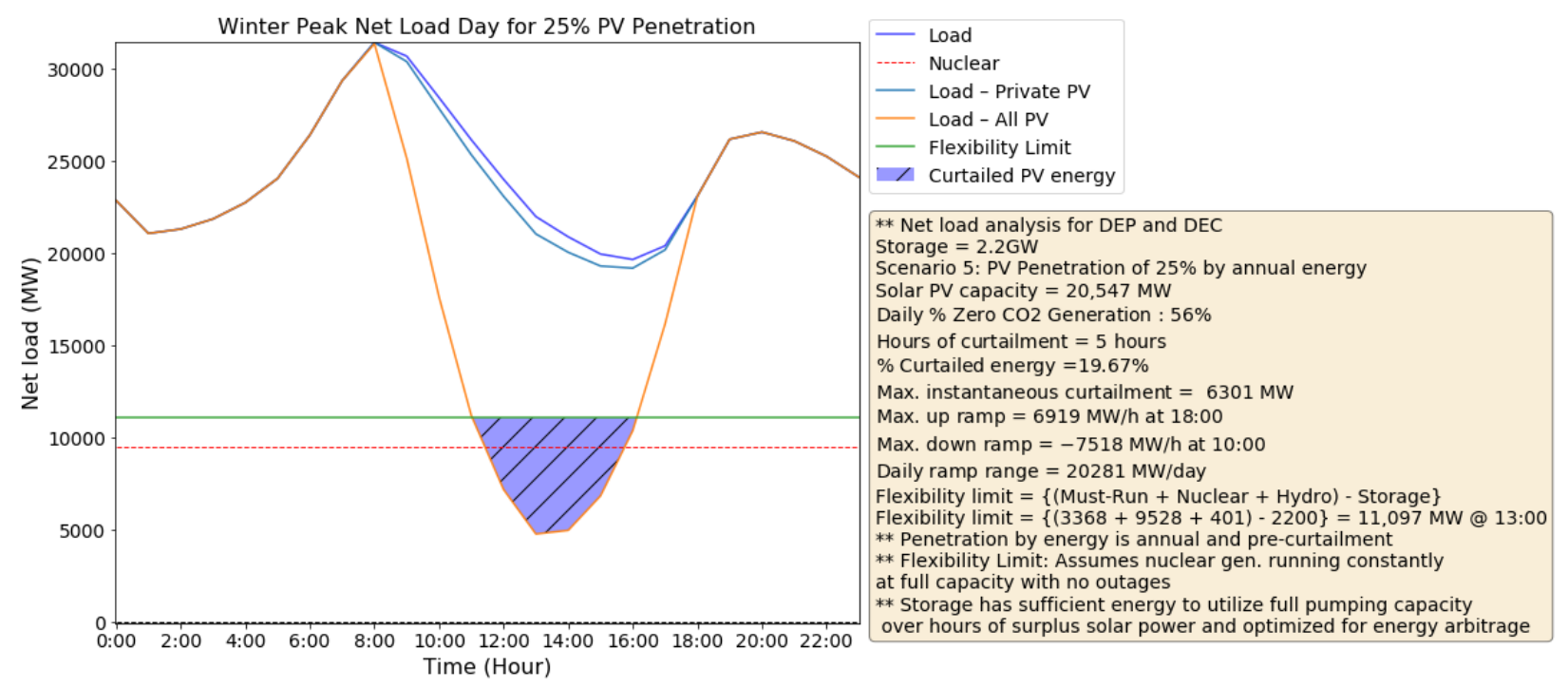


Seasonal Low Net Load Days: 35\% PV Penetration

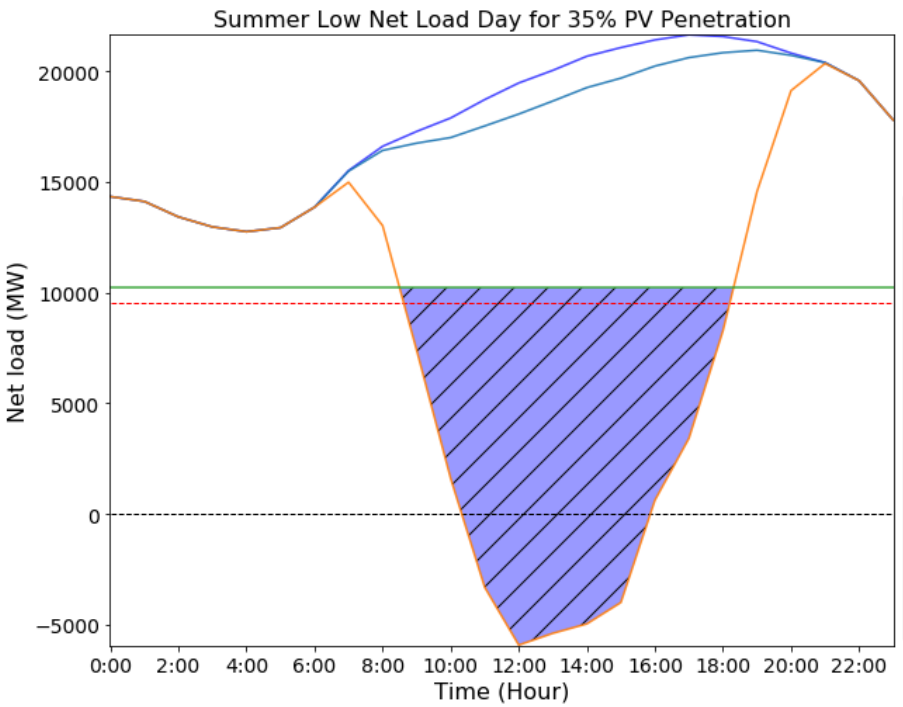

- Load

-..-. Nuclear

- Load - Private PV

- Load - All PV

- Flexibility Limit

1 Curtailed PV energy

** Net load analysis for DEP and DEC

Storage $=2.2 \mathrm{GW}$

Scenario 7: PV Penetration of $35 \%$ by annual energy

Solar PV capacity $=28,766 \mathrm{MW}$

Daily \% Zero CO2 Generation : $79 \%$

Hours of curtailment $=10$ hours

$\%$ Curtailed energy $=48.66 \%$

Max. instantaneous curtailment $=16143 \mathrm{MW}$

Max. up ramp $=4559 \mathrm{MW} / \mathrm{h}$ at 20:00

Max. down ramp $=-2807 \mathrm{MW} / \mathrm{h}$ at 09:00

Daily ramp range $=10136 \mathrm{MW} /$ day

Flexibility limit $=\{($ Must-Run + Nuclear + Hydro $)-$ Storage $\}$

Flexibility limit $=\{(2662+9528+234)-2200\}=10224 \mathrm{MW} @ 12: 00$

** Penetration by energy is annual and pre-curtailment

** Flexibility Limit: Assumes nuclear gen. running constantly

at full capacity with no outages

** Storage has sufficient energy to utilize full pumping capacity

over hours of surplus solar power and optimized for energy arbitrage

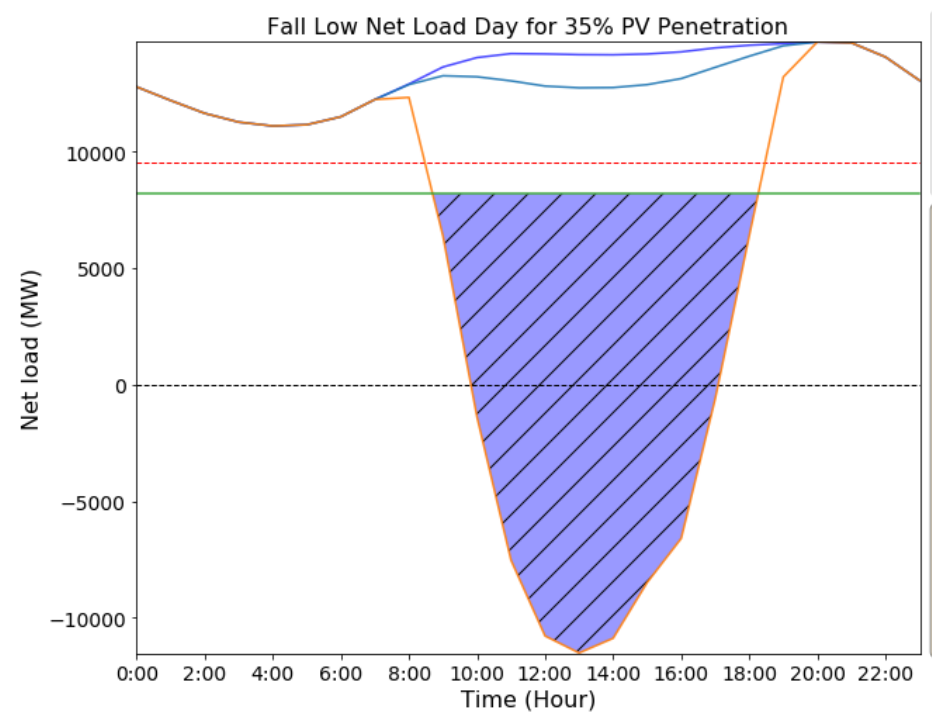

L Load

-.... Nuclear

- Load - Private PV

Load - All PV

- Flexibility Limit

1 Curtailed PV energy

** Net load analysis for DEP and DEC

Storage $=2.2 \mathrm{GW}$

Scenario 7: PV Penetration of $35 \%$ by annual energy

Solar PV capacity $=28,766 \mathrm{MW}$

Daily \% Zero $\mathrm{CO} 2$ Generation : $95 \%$

Hours of curtailment $=10$ hours

$\%$ Curtailed energy $=67.17 \%$

Max. instantaneous curtailment $=19689 \mathrm{MW}$

Max. up ramp $=5016 \mathrm{MW} / \mathrm{h}$ at 19:00

Max. down ramp $=-4140 \mathrm{MW} / \mathrm{h}$ at 09:00

Daily ramp range $=6519 \mathrm{MW} /$ day

Flexibility limit $=\{($ Must-Run + Nuclear + Hydro $)-$ Storage $\}$

Flexibility limit $=\{(671+9528+188)-2200\}=8187 \mathrm{MW} @ 13: 00$

** Penetration by energy is annual and pre-curtailment

** Flexibility Limit: Assumes nuclear gen. running constantly

at full capacity with no outages

** Storage has sufficient energy to utilize full pumping capacity over hours of surplus solar power and optimized for energy arbitrage

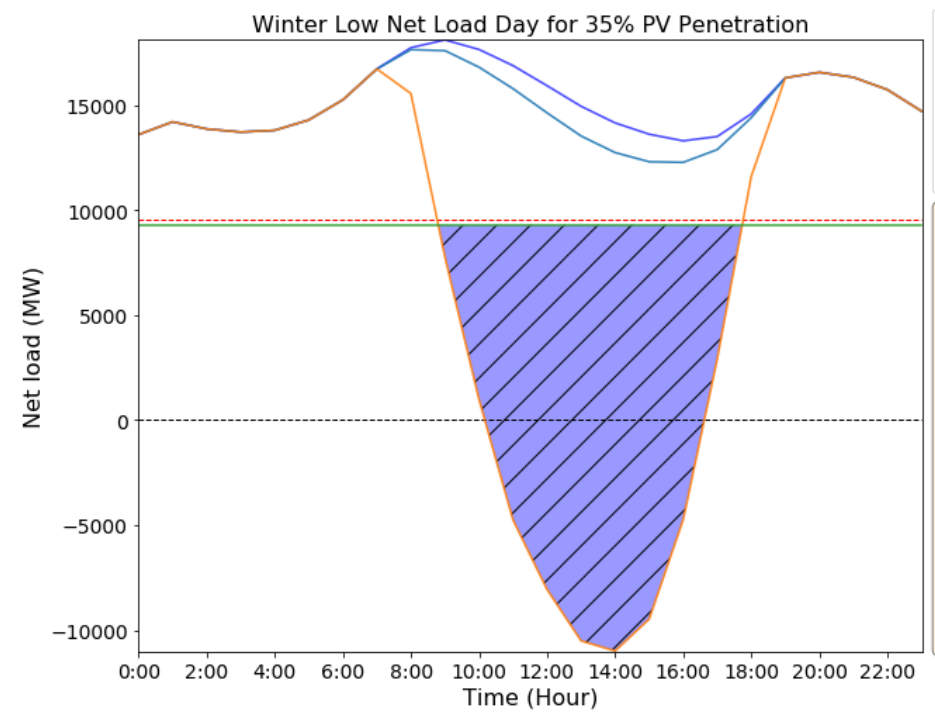

- Load

Nuclear

— Load - Private PV

- Load - All PV

- Flexibility Limit

I. Curtailed PV energy

** Net load analysis for DEP and DEC

Storage $=2.2 \mathrm{GW}$

Scenario 7: PV Penetration of $35 \%$ by annual energy

Solar PV capacity $=28,766 \mathrm{MW}$

Daily \% Zero $\mathrm{CO} 2$ Generation : $82 \%$

Hours of curtailment $=9$ hours

$\%$ Curtailed energy $=66.91 \%$

Max. instantaneous curtailment $=20271 \mathrm{MW}$

Max. up ramp $=4689 \mathrm{MW} / \mathrm{h}$ at 19:00

Max. down ramp $=-6252 \mathrm{MW} / \mathrm{h}$ at 09:00

Daily ramp range $=7426 \mathrm{MW} /$ day

Flexibility limit $=\{$ (Must-Run + Nuclear + Hydro $)-$ Storage $\}$

Flexibility limit $=\{($ Must-Run + Nuclear + Hydro $)-$ Storage $\}$
Flexibility limit $=\{(1627+9528+334)-2200\}=9289 \mathrm{MW} @ 14: 00$

** Penetration by energy is annual and pre-curtailment

** Flexibility Limit: Assumes nuclear gen. running constantly

** Flexibility Limit: Assumes nuc

** Storage has sufficient energy to utilize full pumping capacity over hours of surplus solar power and optimized for energy arbitrage

This report is available at no cost from the National Renewable Energy Laboratory (NREL) at www.nrel.gov/publications. 
Seasonal Peak Net Load Days: 35\% PV Penetration

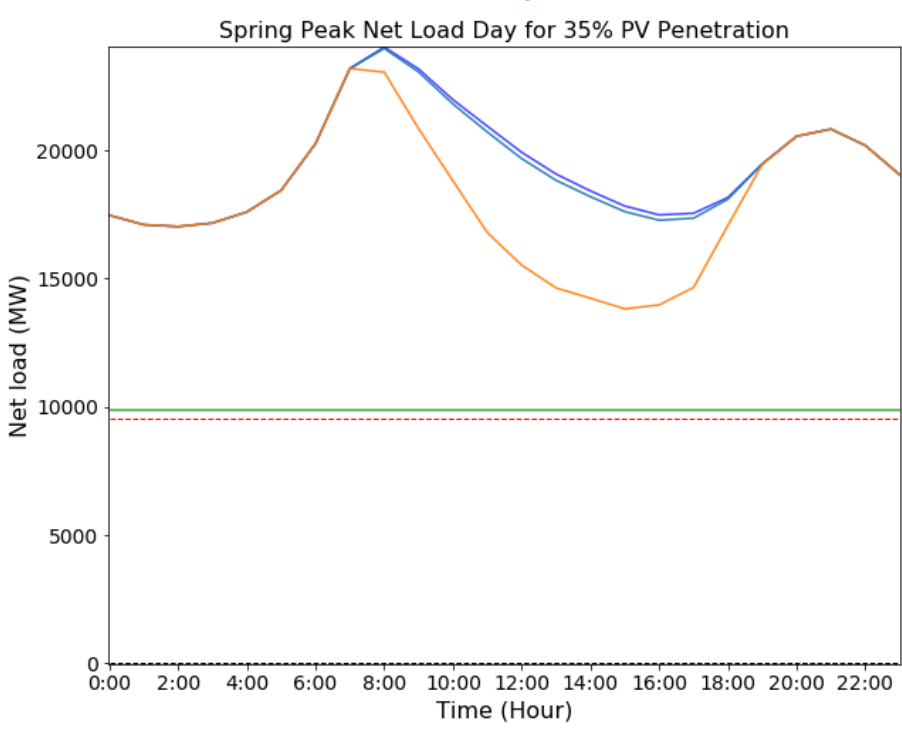

- Load

-..-. Nuclear

_ Load - Private PV

— Load - All PV

- Flexibility Limit

** Net load analysis for DEP and DEC

Storage $=2.2 \mathrm{GW}$

Scenario 7: PV Penetration of $35 \%$ by annual energy

Solar PV capacity $=28,766 \mathrm{MW}$

Daily \% Zero CO2 Generation : $59 \%$

Hours of curtailment $=0$ hours

$\%$ Curtailed energy $=0.00 \%$

Max. instantaneous curtailment $=0 \mathrm{MW}$

Max. up ramp $=2927 \mathrm{MW} / \mathrm{h}$ at 07:00

Max. down ramp $=-2202 \mathrm{MW} / \mathrm{h}$ at 09:00

Daily ramp range $=13323 \mathrm{MW} /$ day

Flexibility limit $=\{$ (Must-Run + Nuclear + Hydro $)-$ Storage $\}$

Flexibility limit $=\{(2125+9528+393)-2200\}=9846 \mathrm{MW} @ 13: 00$

** Penetration by energy is annual and pre-curtailment

** Flexibility Limit: Assumes nuclear gen. running constantly

at full capacity with no outages

* Storage has sufficient energy to utilize full pumping capacity

over hours of surplus solar power and optimized for energy arbitrage

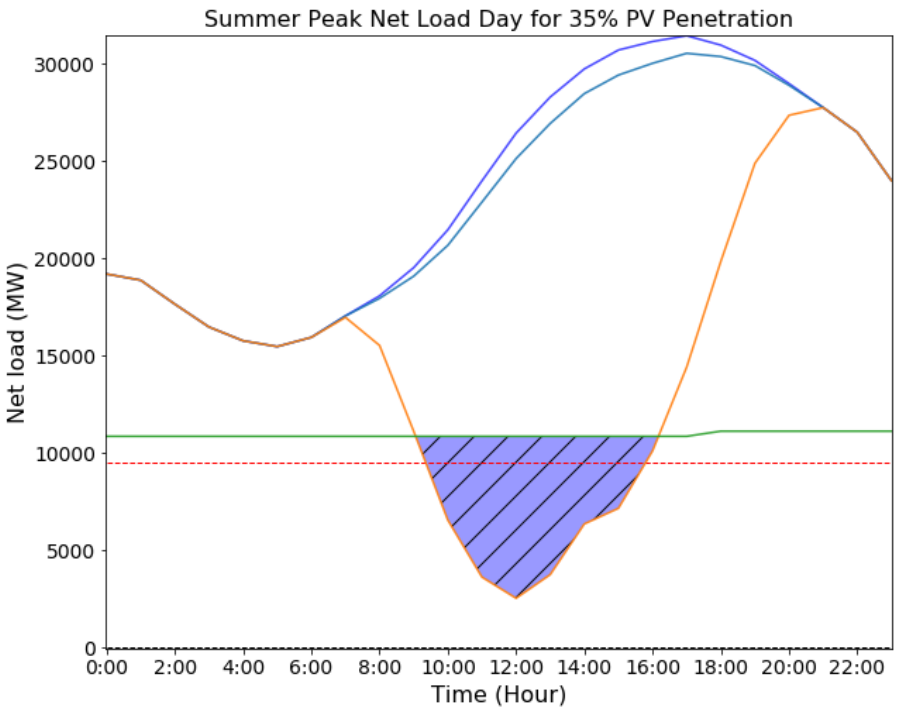

- Load

-...- Nuclear

Load - Private PV

- Load - All PV

- Flexibility Limit

/ Curtailed PV energy

** Net load analysis for DEP and DEC

Storage $=2.2 \mathrm{GW}$

Scenario 7: PV Penetration of $35 \%$ by annual energy

Solar PV capacity $=28,766 \mathrm{MW}$

Daily \% Zero $\mathrm{CO} 2$ Generation : $68 \%$

Hours of curtailment $=7$ hours

$\%$ Curtailed energy $=18.16 \%$

Max. instantaneous curtailment $=8323 \mathrm{MW}$

Max. up ramp $=5429 \mathrm{MW} / \mathrm{h}$ at $18: 00$

Max. down ramp $=-4409 \mathrm{MW} / \mathrm{h}$ at 09:00

Daily ramp range $=16890 \mathrm{MW} /$ day

Flexibility limit $=\{$ (Must-Run + Nuclear + Hydro $)-$ Storage $\}$

Flexibility limit $=\{(3368+9528+173)-2200\}=10869 \mathrm{MW} @ 12: 00$

** Penetration by energy is annual and pre-curtailment

** Flexibility Limit: Assumes nuclear gen. running constantly

at full capacity with no outages

* Storage has sufficient energy to utilize full pumping capacity over hours of surplus solar power and optimized for energy arbitrage

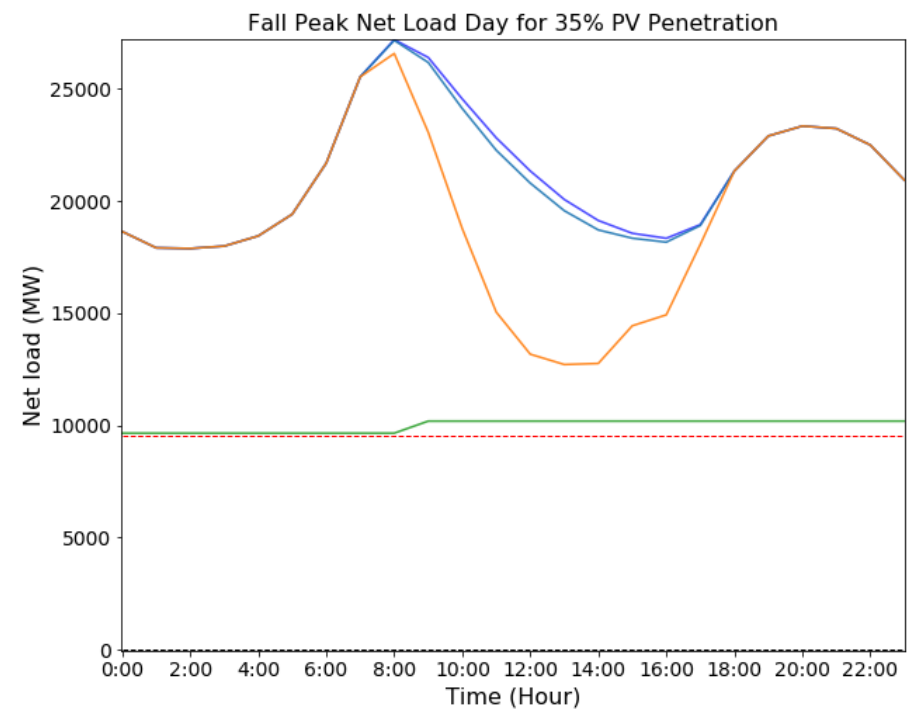

- Load

.... Nuclear

- Load - Private PV

- Load - All PV

- Flexibility Limit

** Net load analysis for DEP and DEC

storage $=2.2 \mathrm{GW}$

Scentration of $35 \%$ by annual energy

Solar PV capacity $=28,766 \mathrm{MW}$

Daily \% Zero CO2 Generation : $56 \%$

Hours of curtailment $=0$ hours

$\%$ Curtailed energy $=0.00 \%$

Max. instantaneous curtailment $=0 \mathrm{MW}$

Max. up ramp $=3839 \mathrm{MW} / \mathrm{h}$ at 07:00

Max. down ramp $=-4287 \mathrm{MW} / \mathrm{h}$ at $10: 00$

Daily ramp range $=13843 \mathrm{MW} /$ day

Flexibility limit $=\{$ (Must-Run + Nuclear + Hydro $)-$ Storage $\}$

Flexibility limit $=\{(2662+9528+198)-2200\}=10,188 \mathrm{MW} @ 13: 00$

** Penetration by energy is annual and pre-curtailment

** Flexibility Limit: Assumes nuclear gen. running constantly

at full capacity with no outages

** Storage has sufficient energy to utilize full pumping capacity

over hours of surplus solar power and optimized for energy arbitrage

This report is available at no cost from the National Renewable Energy Laboratory (NREL) at www.nrel.gov/publications. 


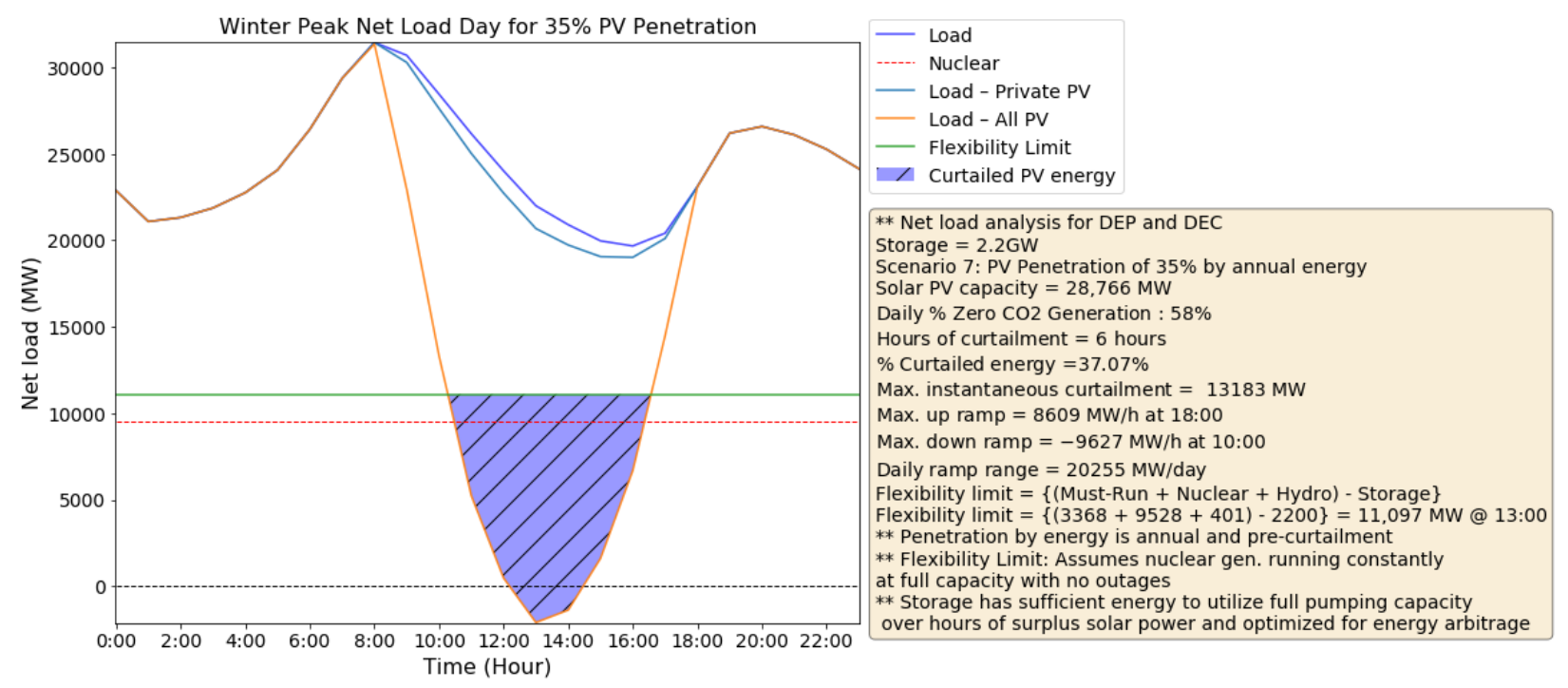




\section{Scenario 8: 25\% PV Penetration and Increased Proportion of Distributed Solar}

\section{Seasonal Low Net Load Days}

Summer Low Net Load Day for 25\% PV Penetration with higher ratio of private to utility solar added to the system

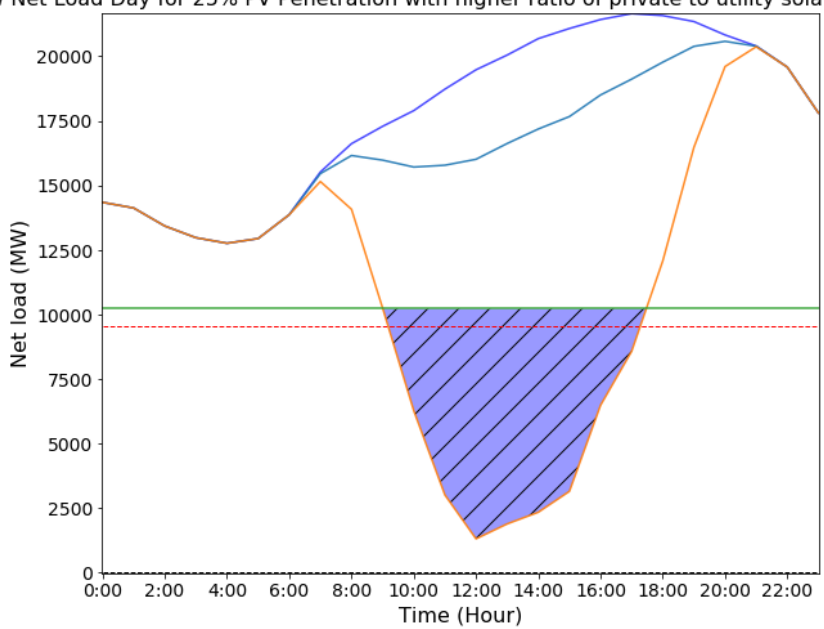

- Load
- Nuclear
- Load - Private PV
Load - All PV
Flexibility Limit
Curtailed PV energy
** Net load analysis for DEP and DEC
Storage $=2.2 \mathrm{GW}$
Scenario $8:$ Based on $25 \%$ solar energy penetration scenario-,
with higher ratio of private to utility solar added to the system
Solar PV capacity $=20,547$ MW
Daily $\%$ Zero CO2 Generation $: 78 \%$
Hours of curtailment $=8$ hours
$\%$ Curtailed energy $=31.80 \%$
Max. instantaneous curtailment $=8914$ MW
Max. up ramp $=4398$ MW/h at $19: 00$
Max. down ramp $=-3829$ MW/h at $09: 00$
Daily ramp range $=-5826$ MW/day
Flexibility limit $=\{$ (Must-Run + Nuclear + Hydro $)$ - Storage $\}$
Flexibility limit $=\{(2662+9528+234)-2200\}=10224$ MW $@ 12: 00$
** Penetration by energy is annual and pre-curtailment
** Flexibility Limit: Assumes nuclear gen. running constantly
at full capacity with no outages
** Storage has sufficient energy to utilize full pumping capacity
over hours of surplus solar power and optimized for energy arbitrage

Fall Low Net Load Day for 25\% PV Penetration with higher ratio of private to utility solar added to the system

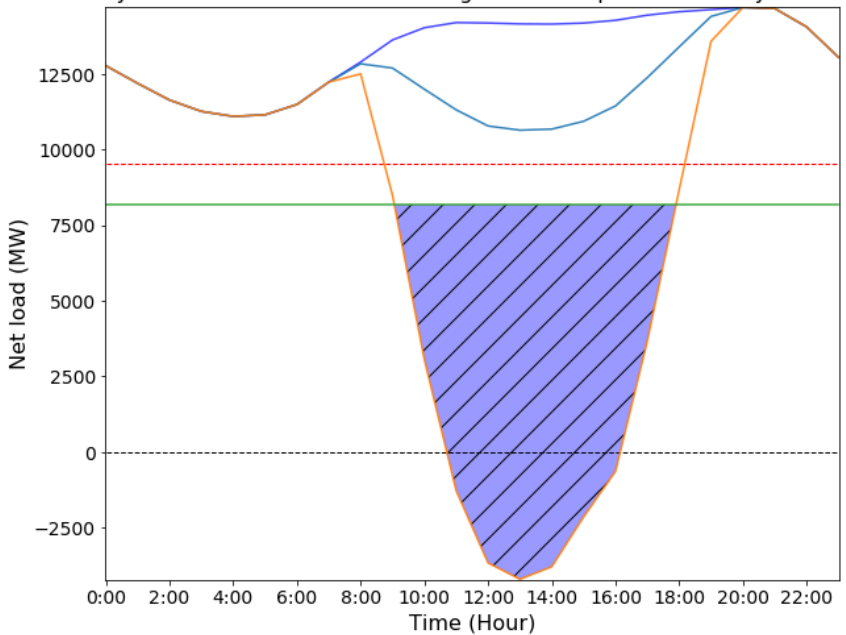

Nuclear
Load - Private PV
Load - All PV
Flexibility Limit
Curtailed PV energy
* Net load analysis for DEP and DEC
Storage $=2.2 \mathrm{GW}$
Scenario $8:$ Based on $25 \%$ solar energy penetration scenario-,
with higher ratio of private to utility solar added to the system
Solar PV capacity $=20,547 \mathrm{MW}$
Daily $\%$ Zero CO2 Generation : $94 \%$
Hours of curtailment $=8$ hours
$\%$ Curtailed energy $=55.23 \%$
Max. instantaneous curtailment $=12393$ MW
Max. up ramp $=4902$ MW/h at $19: 00$
Max. down ramp $=-4016 \mathrm{MW} / \mathrm{h}$ at $09: 00$
Daily ramp range $=-3285 \mathrm{MW} / \mathrm{day}$
Flexibility limit $=\{($ Must-Run + Nuclear + Hydro $)$ - Storage $\}$
Flexibility limit $=\{(671+9528+188)-2200\}=8187$ MW $@ 13: 00$
* Penetration by energy is annual and pre-curtailment
* Flexibility Limit: Assumes nuclear gen. running constantly
t full capacity with no outages
* Storage has sufficient energy to utilize full pumping capacity
over hours of surplus solar power and optimized for energy arbitrage

Winter Low Net Load Day for 25\% PV Penetration with higher ratio of private to utility solar added to the system

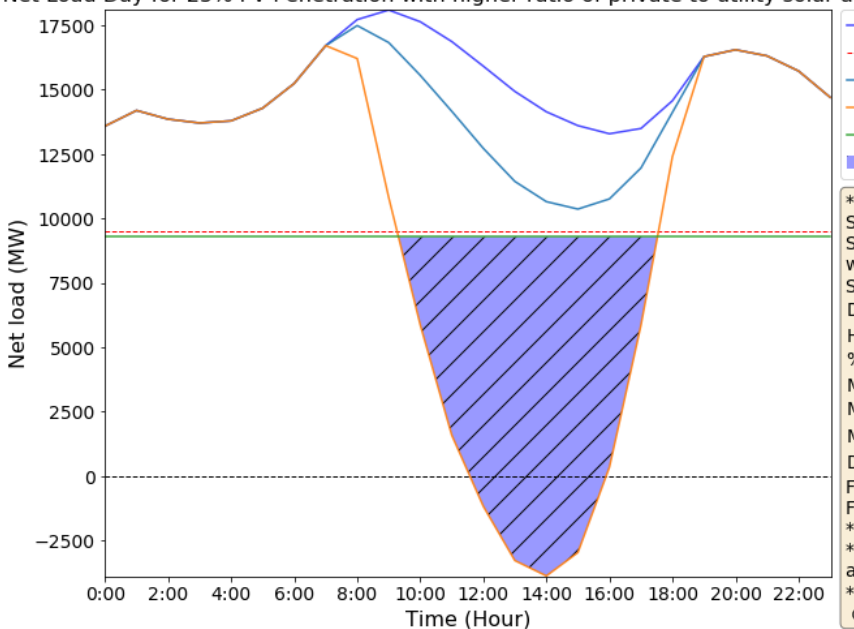

- Load
Nuclear
Load - Private PV
Load - All PV
Flexibility Limit
Curtailed PV energy
** Net load analysis for DEP and DEC
Storage $=2.2 \mathrm{GW}$
Scenario $8:$ Based on $25 \%$ solar energy penetration scenario-,
with higher ratio of private to utility solar added to the system
Solar PV capacity $=20,547 \mathrm{MW}$
Daily $\%$ Zero CO2 Generation $: 81 \%$
Hours of curtailment $=8$ hours
$\%$ Curtailed energy $=55.96 \%$
Max. instantaneous curtailment $=13163$ MW
Max. up ramp $=3874$ MW/h at $19: 00$
Max. down ramp $=-5399$ MW/h at $09: 00$
Daily ramp range $=-5415$ MW/day
Flexibility limit $=\{($ Must-Run + Nuclear + Hydro $)$ - Storage $\}$
Flexibility limit $=\{(1627+9528+334)-2200\}=9289$ MW $@ 14: 00$
** Penetration by energy is annual and pre-curtailment
** Flexibility Limit: Assumes nuclear gen. running constantly
at full capacity with no outages
** Storage has sufficient energy to utilize full pumping capacity
over hours of surplus solar power and optimized for energy arbitrage




\section{Seasonal Peak Net Load Days}

Spring Peak Net Load Day for $25 \%$ PV Penetration with higher ratio of private to utility solar added to the system

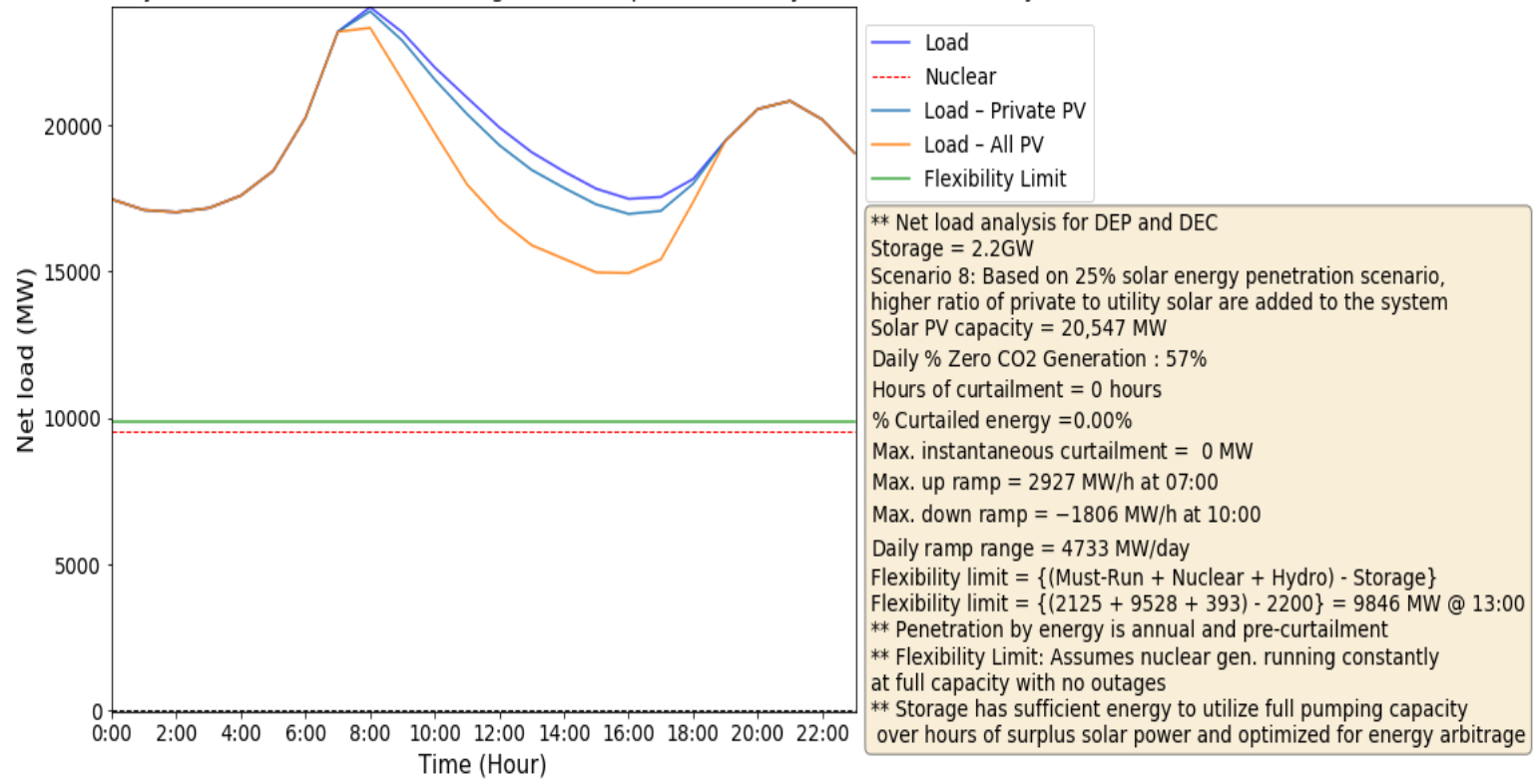

Summer Peak Net Load Day for 25\% PV Penetration with higher ratio of private to utility solar added to the system

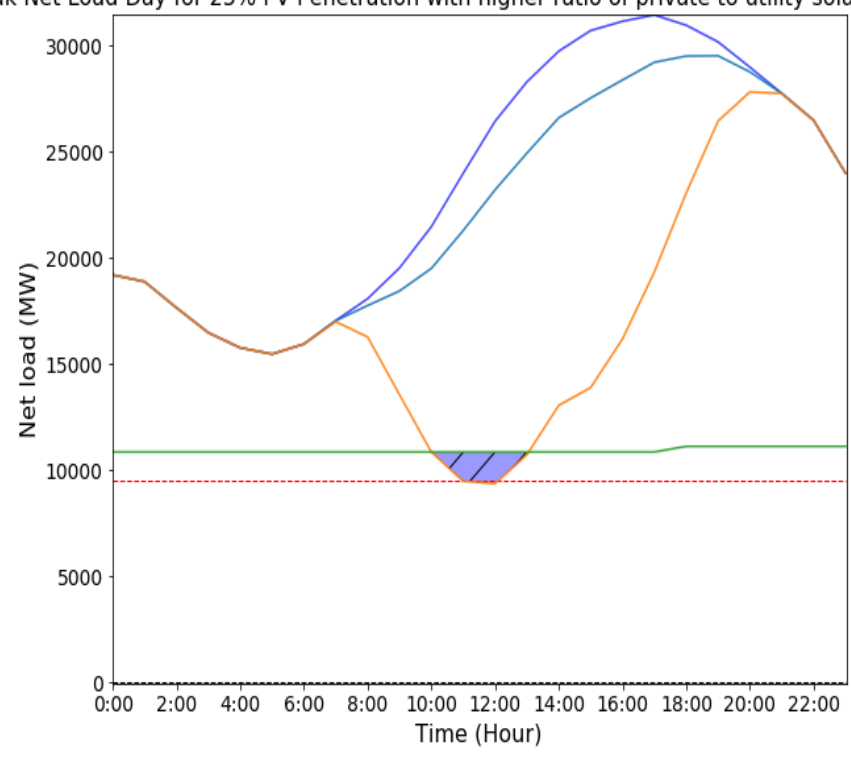

- Load

-...-. Nuclear

- Load - Private PV

- Load - All PV

Flexibility Limit

7 Curtailed PV energy

* Net load analysis for DEP and DEC

Storage $=2.2 \mathrm{GW}$

Scenario 8: Based on $25 \%$ solar energy penetration scenario,

higher ratio of private to utility solar are added to the system

Solar PV capacity $=20,547 \mathrm{MW}$

Daily \% Zero CO2 Generation : $64 \%$

Hours of curtailment $=4$ hours

$\%$ Curtailed energy $=2.13 \%$

Max. instantaneous curtailment $=1496 \mathrm{MW}$

Max. up ramp $=3722 \mathrm{MW} / \mathrm{h}$ at $18: 00$

Max. down ramp $=-2716 \mathrm{MW} / \mathrm{h}$ at 09:00

Daily ramp range $=-7147 \mathrm{MW} / \mathrm{day}$

Flexibility limit $=\{($ Must-Run + Nuclear + Hydro $)-$ Storage $\}$

Flexibility limit $=\{(3368+9528+173)-2200\}=10869$ MW @ 12:00

** Penetration by energy is annual and pre-curtailment

** Flexibility Limit: Assumes nuclear gen. running constantly

at full capacity with no outages

** Storage has sufficient energy to utilize full pumping capacity

over hours of surplus solar power and optimized for energy arbitrage 
Fall Peak Net Load Day for $25 \%$ PV Penetration with higher ratio of private to utility solar added to the system

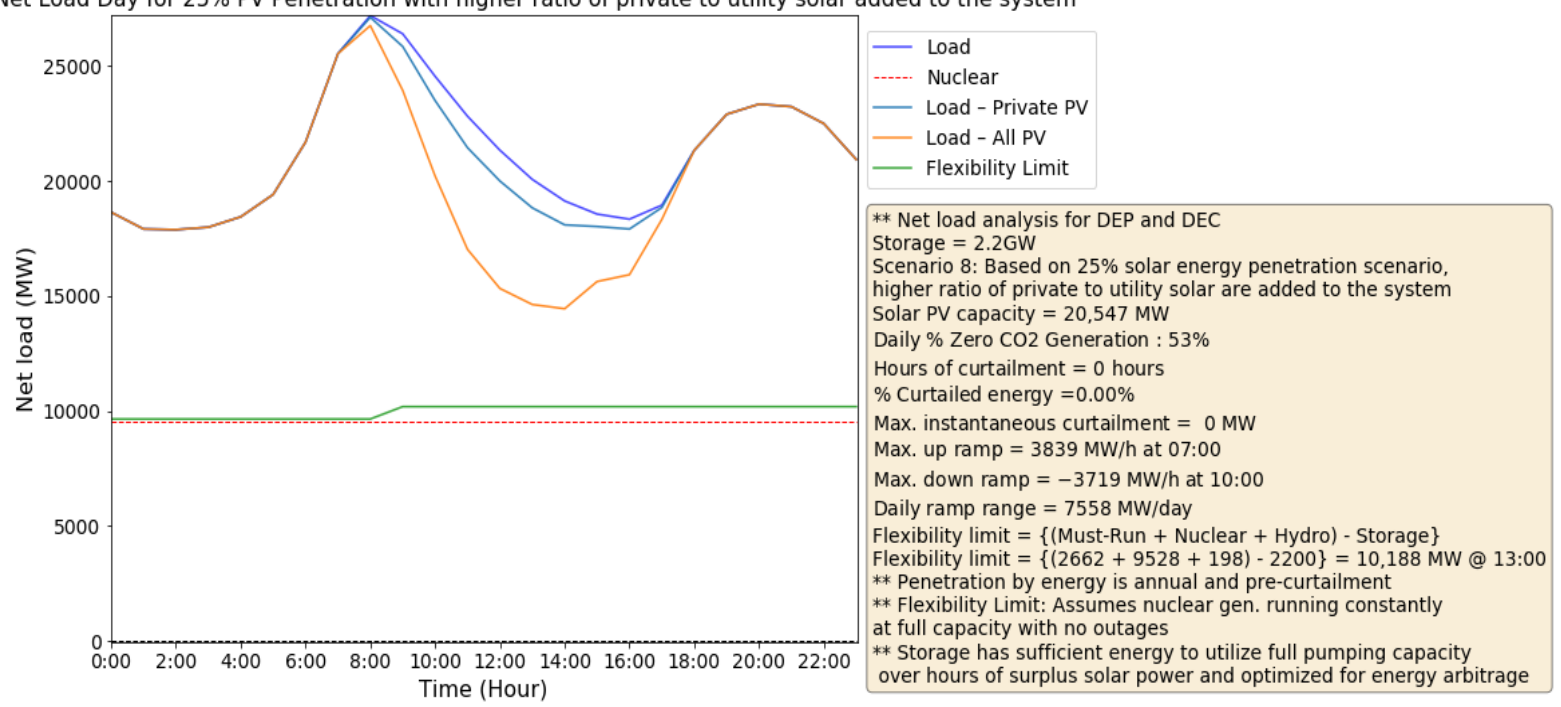

Winter Peak Net Load Day for $25 \%$ PV Penetration with higher ratio of private to utility solar added to the system

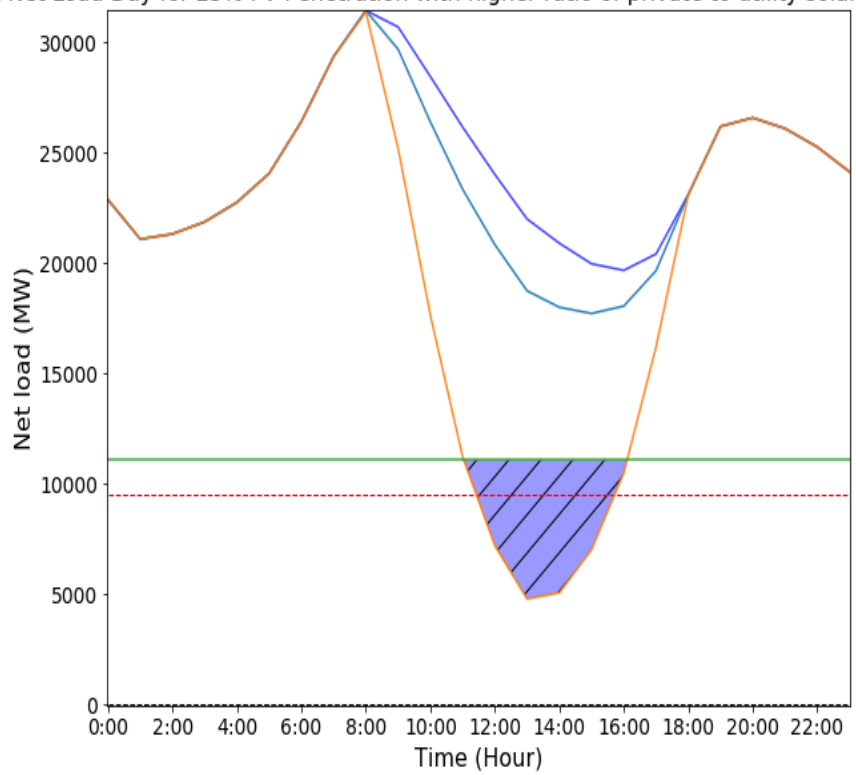

- Load

Nuclear

- Load - Private PV

Load - All PV

- Flexibility Limit

/ Curtailed PV energy

** Net load analysis for DEP and DEC

Storage $=2.2 \mathrm{GW}$

Scenario 8: Based on $25 \%$ solar energy penetration scenario,

higher ratio of private to utility solar are added to the system

Solar PV capacity $=20,547 \mathrm{MW}$

Daily \% Zero CO2 Generation : $56 \%$

Hours of curtailment $=5$ hours

$\%$ Curtailed energy $=19.34 \%$

Max. instantaneous curtailment $=6302 \mathrm{MW}$

Max. up ramp $=6887 \mathrm{MW} / \mathrm{h}$ at 18:00

Max. down ramp $=-7553 \mathrm{MW} / \mathrm{h}$ at $10: 00$

Daily ramp range $=-4210 \mathrm{MW} / \mathrm{day}$

Flexibility limit $=\{($ Must-Run + Nuclear + Hydro $)-$ Storage $\}$

Flexibility limit $=\{(3368+9528+401)-2200\}=11,097$ MW @ 13:00

** Penetration by energy is annual and pre-curtailment

** Flexibility Limit: Assumes nuclear gen. running constantly

at full capacity with no outages

** Storage has sufficient energy to utilize full pumping capacity

Time (Hour)

over hours of surplus solar power and optimized for energy arbitrage 


\section{Scenario 9: 25\% PV Penetration and Additional Storage}

\section{Seasonal Low Net Load Days}
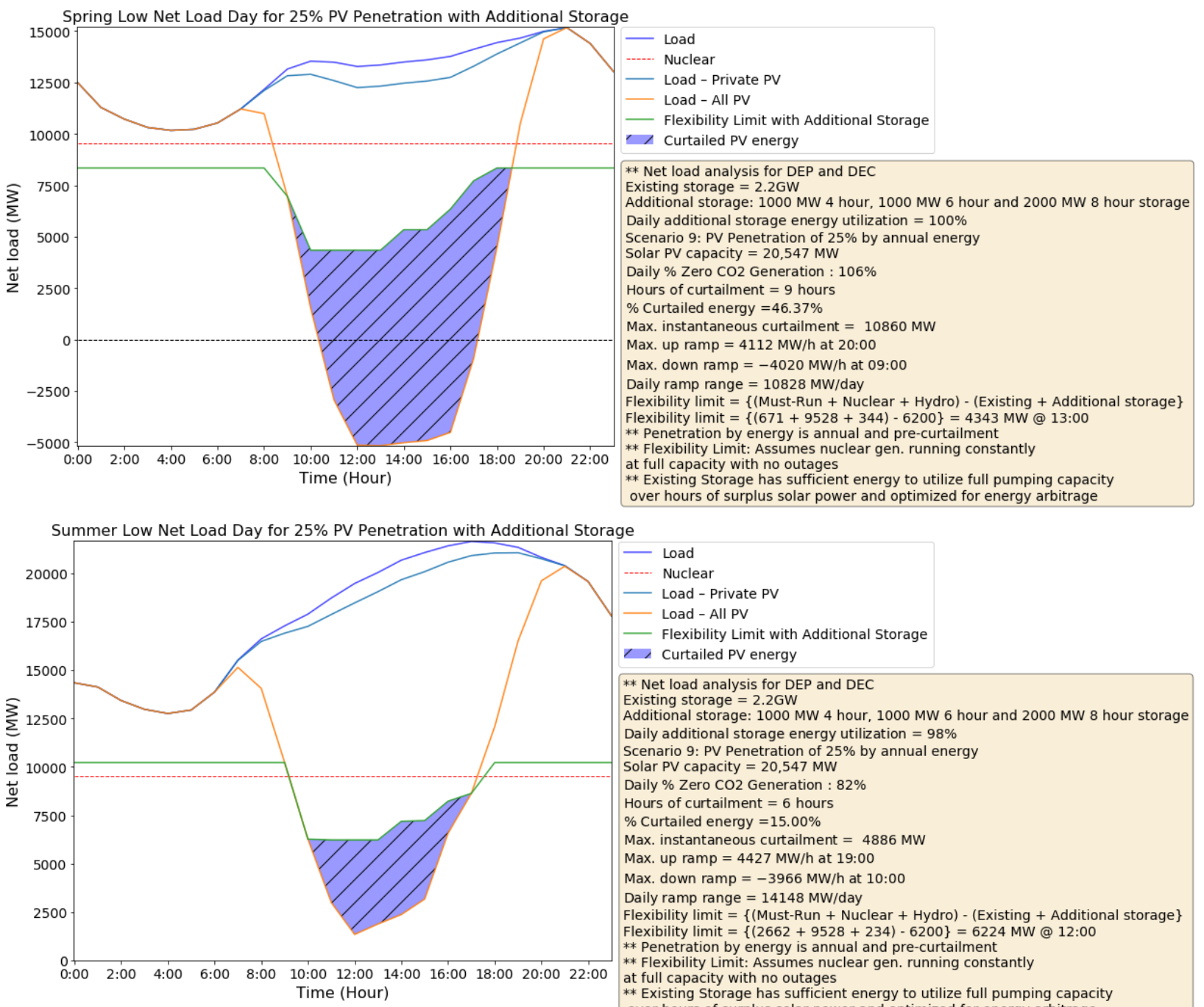

Load
Nuclear
Load - Private PV
Load - All PV
Flexibility Limit with Additional Storage
Curtailed PV energy
** Net load analysis for DEP and DEC
Existing storage $=2.2 \mathrm{GW}$
Additional storage: $1000 \mathrm{MW} 4$ hour, $1000 \mathrm{MW} 6$ hour and 2000 MW 8 hour storage
Daily additional storage energy utilization $=98 \%$
Scenario $9:$ PV Penetration of $25 \%$ by annual energy
Solar PV capacity $=20,547$ MW
Daily $\%$ Zero CO2 Generation $: 82 \%$
Hours of curtailment $=6$ hours
$\%$ Curtailed energy $=15.00 \%$
Max. instantaneous curtailment $=4886$ MW
Max. up ramp $=4427$ MW/h at $19: 00$
Max. down ramp $=-3966$ MW/h at $10: 00$
Daily ramp range $=14148$ MW/day
Flexibility limit $=\{($ Must-Run + Nuclear + Hydro $)$ - (Existing + Additional storage $\}$
Flexibility limit $=\{(2662+9528+234)-6200\}=6224$ MW $@ 12: 00$
** Penetration by energy is annual and pre-curtailment
** Flexibility Limit: Assumes nuclear gen. running constantly
at full capacity with no outages
** Existing Storage has sufficient energy to utilize full pumping capacity
over hours of surplus solar power and optimized for energy arbitrage

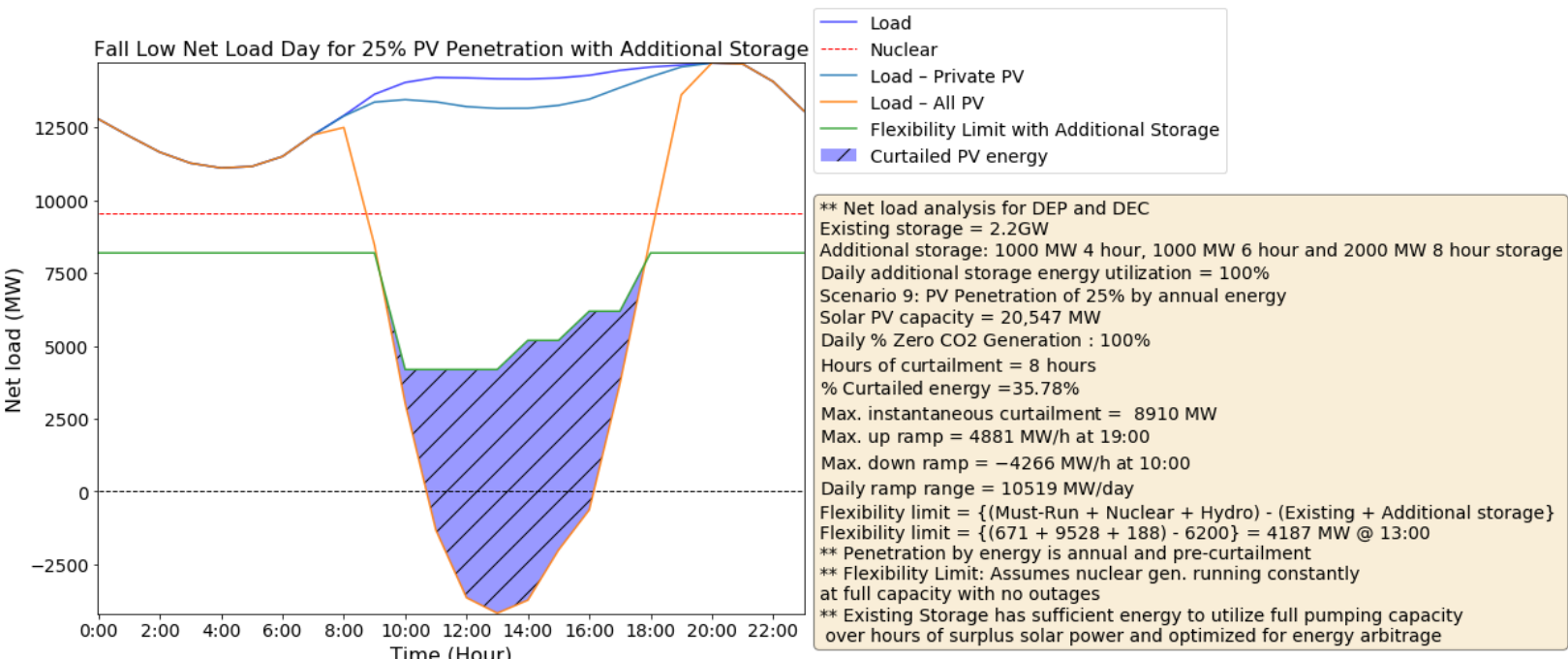

This report is available at no cost from the National Renewable Energy Laboratory (NREL) at www.nrel.gov/publications. 


\section{Seasonal Peak Net Load Days}

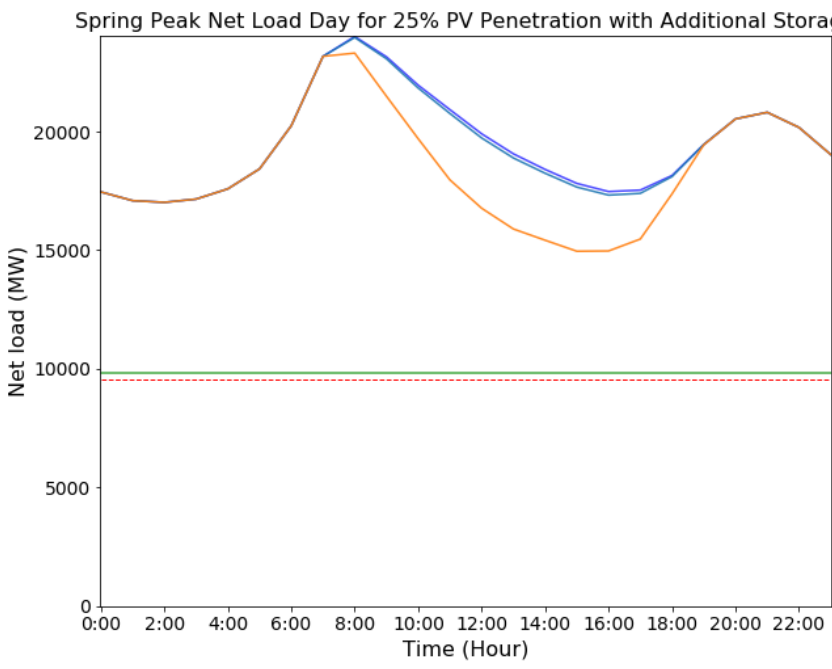

Load
Nuclear
Load - Private PV
Load - All PV
F* Nexibility Limit with Additional Storage
Existing storage $=2.2 \mathrm{GW}$
Additional storage: $1000 \mathrm{MW} 4$ hour, $1000 \mathrm{MW} 6$ hour and 2000 MW 8 hour storage
Daily additional storage energy utilization $=0 \%$
Scenario $9:$ PV Penetration of $25 \%$ by annual energy
Solar PV capacity $=20,547 \mathrm{MW}$
Daily \% Zero CO2 Generation : $56 \%$
Hours of curtailment $=0$ hours
$\%$ Curtailed energy $=0.00 \%$
Max. instantaneous curtailment $=0 \mathrm{MW}$
Max. up ramp $=2927 \mathrm{MW} / \mathrm{h}$ at $07: 00$
Max. down ramp $=-1818 \mathrm{MW} / \mathrm{h}$ at $09: 00$
Daily ramp range $=8355 \mathrm{MW} / \mathrm{day}$
Flexibility limit $=\{$ (Must-Run + Nuclear + Hydro $)$ - (Existing + Additional storage $\}$
Flexibility limit $=\{(2125+9528+393)-2200\}=9846$ MW $@ 13: 00$
** Penetration by energy is annual and pre-curtailment
** Flexibility Limit: Assumes nuclear gen. running constantly
at full capacity with no outages
** Existing Storage has sufficient energy to utilize full pumping capacity
over hours of surplus solar power and optimized for energy arbitrage

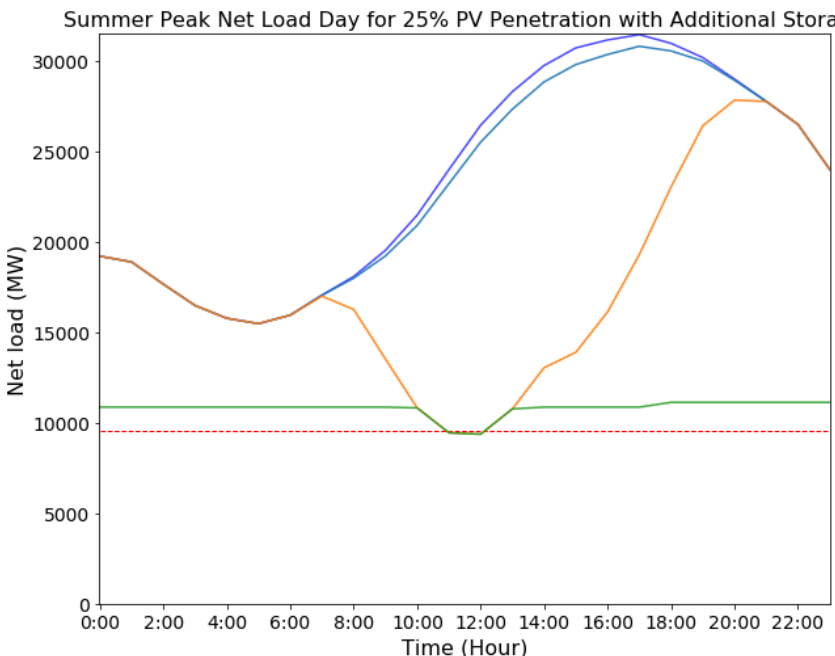

- Load

Nuclear

- Load - Private PV

- Load - All PV

- Flexibility Limit with Additional Storage

* Net load analysis for DEP and DEC

Existing storage $=2.2 \mathrm{GW}$

dditional storage: 1000 MW 4 hour, 1000 MW 6 hour and 2000 MW 8 hour storage

Daily additional storage energy utilization $=11 \%$

Scenario 9: PV Penetration of $25 \%$ by annual energy

Dar PVacity $=20,547 \mathrm{MW}$

Daily \% Zero CO2 Generation : $65 \%$

Hours of curtailment $=0$ hours

$\%$ Curtailed energy $=0.00 \%$

Max. instantaneous curtailment $=0 \mathrm{MW}$

Max. up ramp $=3741 \mathrm{MW} / \mathrm{h}$ at $18: 00$

Max. down ramp $=-2735 \mathrm{MW} / \mathrm{h}$ at 09:00

Daily ramp range $=18456 \mathrm{MW} /$ day

Flexibility limit $=\{($ Must-Run + Nuclear + Hydro $)-($ Existing + Additional storage $\}$

Flexibility limit $=\{(3368+9528+173)-(2200+1495)\}=9374 \mathrm{MW} @ 12: 00$

* Penetration by energy is annual and pre-curtailment

* Flexibility Limit: Assumes nuclear gen. running constantly

** Existing Storage has sufficient energy to utilize full pumping capacity

over hours of surplus solar power and optimized for energy arbitrage

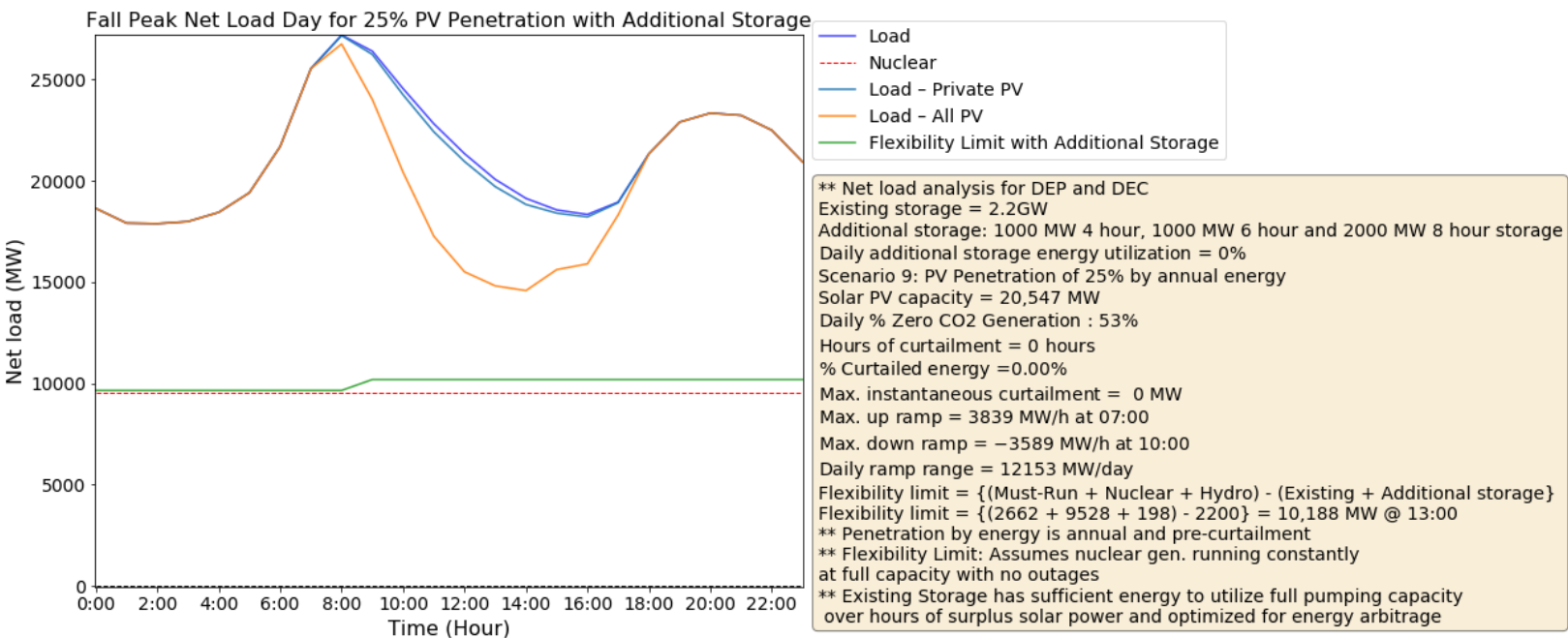

This report is available at no cost from the National Renewable Energy Laboratory (NREL) at www.nrel.gov/publications. 


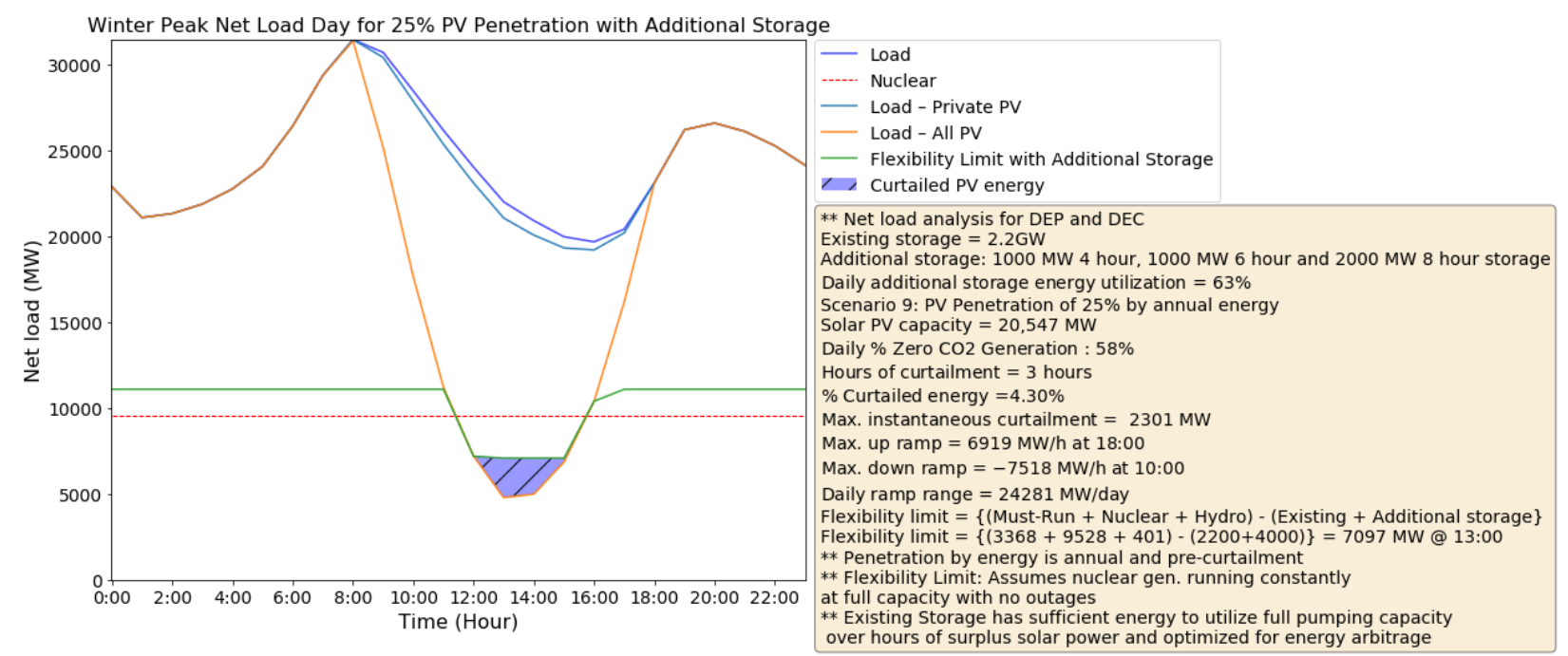

This report is available at no cost from the National Renewable Energy Laboratory (NREL) at www.nrel.gov/publications. 


\section{Scenario 10: 25\% PV Penetration and Generation Retirement}

\section{Seasonal Low Net Load Days}
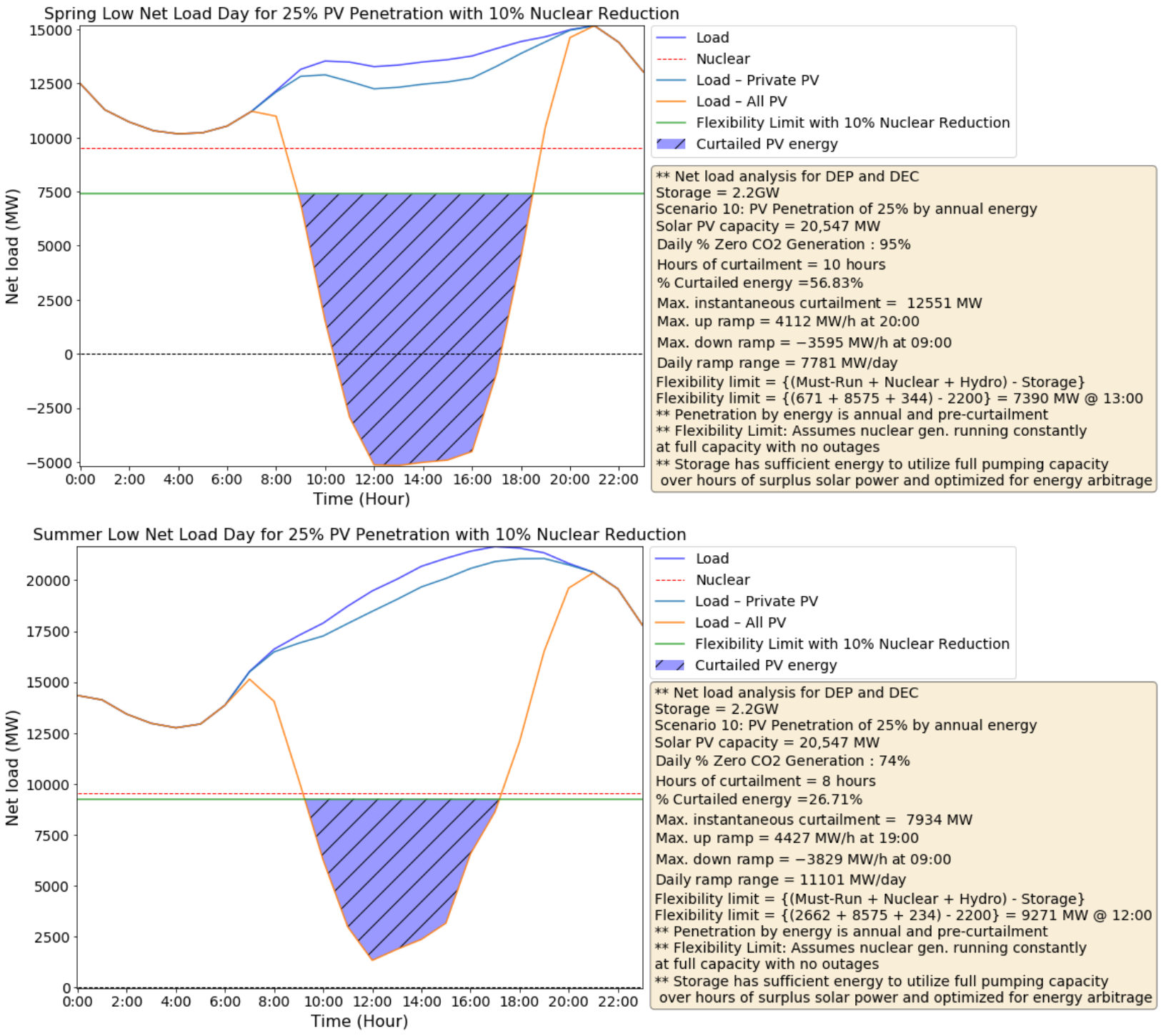

- Load

---.- Nuclear

- Load - Private PV

Load - All PV

— Flexibility Limit with $10 \%$ Nuclear Reduction $\checkmark$ Curtailed PV energy

** Net load analysis for DEP and DEC

Storage $=2.2 \mathrm{GW}$

Scenario 10: PV Penetration of $25 \%$ by annual energy

Solar PV capacity $=20,547 \mathrm{MW}$

Daily \% Zero CO2 Generation : $74 \%$

Hours of curtailment $=8$ hours

$\%$ Curtailed energy $=26.71 \%$

Max. instantaneous curtailment $=7934 \mathrm{MW}$

Max. up ramp $=4427 \mathrm{MW} / \mathrm{h}$ at 19:00

Max. down ramp $=-3829 \mathrm{MW} / \mathrm{h}$ at 09:00

Daily ramp range $=11101 \mathrm{MW} /$ day

Flexibility limit $=\{$ (Must-Run + Nuclear + Hydro $)-$ Storage $\}$

Flexibility limit $=\{(2662+8575+234)-2200\}=9271 \mathrm{MW} @ 12: 00$

** Penetration by energy is annual and pre-curtailment

** Flexibility Limit: Assumes nuclear gen. running constantly

at full capacity with no outages

** Storage has sufficient energy to utilize full pumping capacity Time (Hour) 


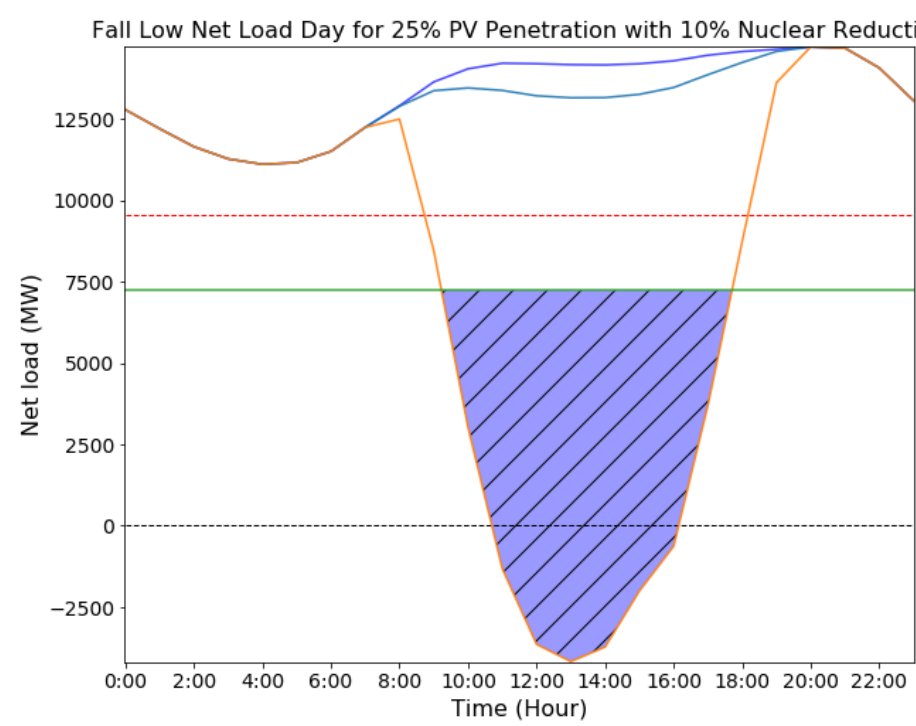

\begin{tabular}{l}
\hline Load \\
\hline Nuclear \\
Load - Private PV \\
Load - All PV \\
Flexibility Limit with $10 \%$ Nuclear Reduction \\
** Net load analysis for DEP and DEC \\
Storage $=2.2$ GW \\
Scenario $10:$ PV Penetration of $25 \%$ by annual energy \\
Solar PV capacity $=20,547$ MW \\
Daily \% Zero CO2 Generation : $89 \%$ \\
Hours of curtailment $=8$ hours \\
$\%$ Curtailed energy $=49.41 \%$ \\
Max. instantaneous curtailment $=11404$ MW \\
Max. up ramp $=4881$ MW/h at $19: 00$ \\
Max. down ramp $=-4037$ MW/h at $09: 00$ \\
Daily ramp range $=7472$ MW/day \\
Flexibility limit $=\{($ Must-Run + Nuclear + Hydro $)-$ Storage $\}$ \\
Flexibility limit $=\{(671+8575+188)-2200\}=7,234$ MW $@ 13: 00$ \\
** Penetration by energy is annual and pre-curtailment \\
** Flexibility Limit: Assumes nuclear gen. running constantly \\
at full capacity with no outages \\
** Storage has sufficient energy to utilize full pumping capacity \\
over hours of surplus solar power and optimized for energy arbitrage
\end{tabular}
Time (Hour) 


\section{Seasonal Peak Net Load Days}

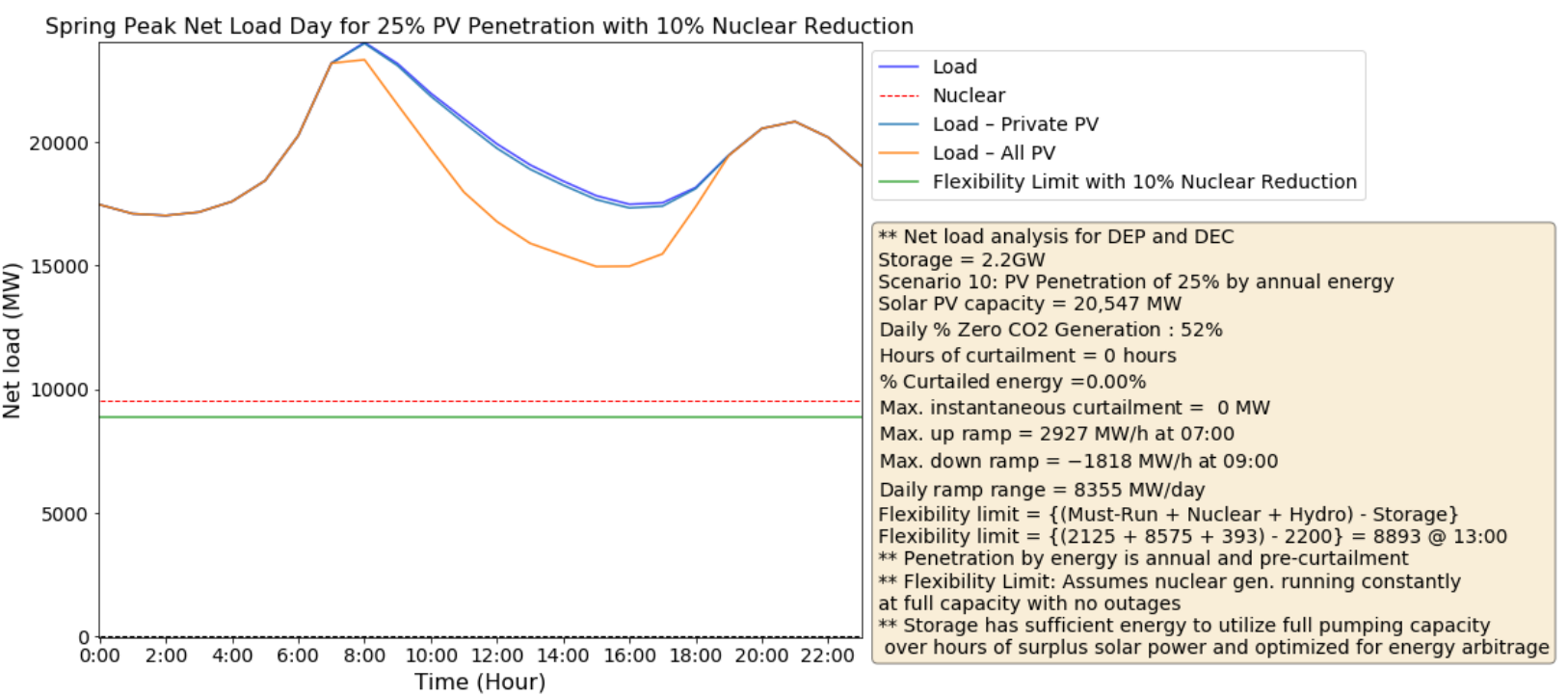

\section{Summer Peak Net Load Day for 25\% PV Penetration with 10\% Nuclear Reduction}

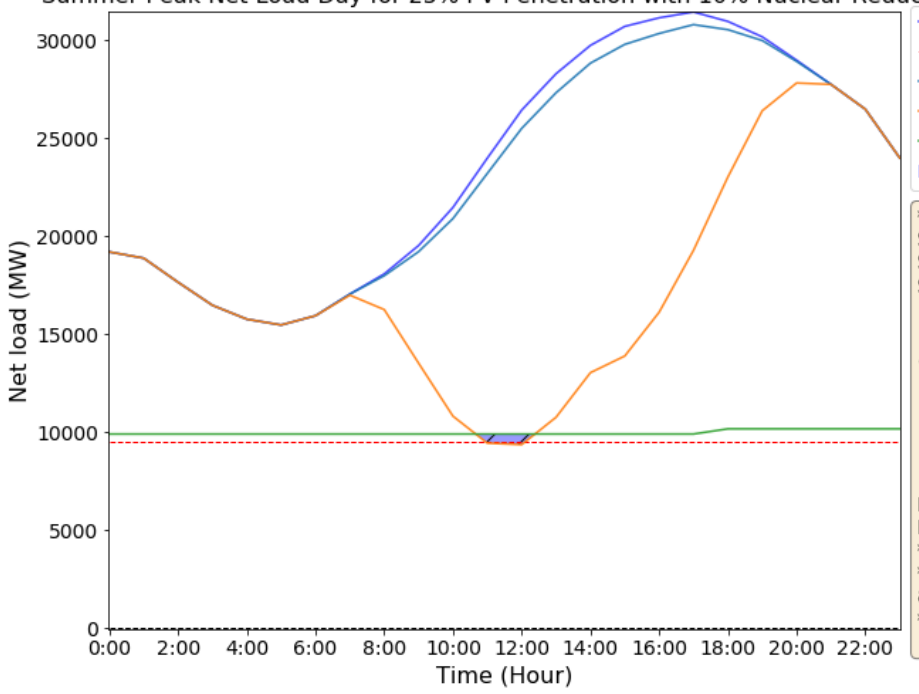

Load

_ Load - Private PV

L Load - All PV

- Flexibility Limit with $10 \%$ Nuclear Reduction

Z. Curtailed PV energy

** Net load analysis for DEP and DEC

Storage $=2.2 \mathrm{GW}$

Scenario 10: PV Penetration of $25 \%$ by annual energy

Solar PV capacity $=20,547 \mathrm{MW}$

Daily \% Zero $\mathrm{CO} 2$ Generation : $60 \%$

Hours of curtailment $=2$ hours

$\%$ Curtailed energy $=0.71 \%$

Max. instantaneous curtailment $=542 \mathrm{MW}$

Max. up ramp $=3741 \mathrm{MW} / \mathrm{h}$ at 18:00

Max. down ramp $=-2735 \mathrm{MW} / \mathrm{h}$ at 09:00

Daily ramp range $=18456 \mathrm{MW} /$ day

Flexibility limit $=\{($ Must-Run + Nuclear + Hydro $)-$ Storage $\}$

Flexibility limit $=\{(3368+8575+173)-2200\}=9916 @ 12: 00$

** Penetration by energy is annual and pre-curtailment

** Flexibility Limit: Assumes nuclear gen. running constantly

at full capacity with no outages

** Storage has sufficient energy to utilize full pumping capacity

over hours of surplus solar power and optimized for energy arbitrage 


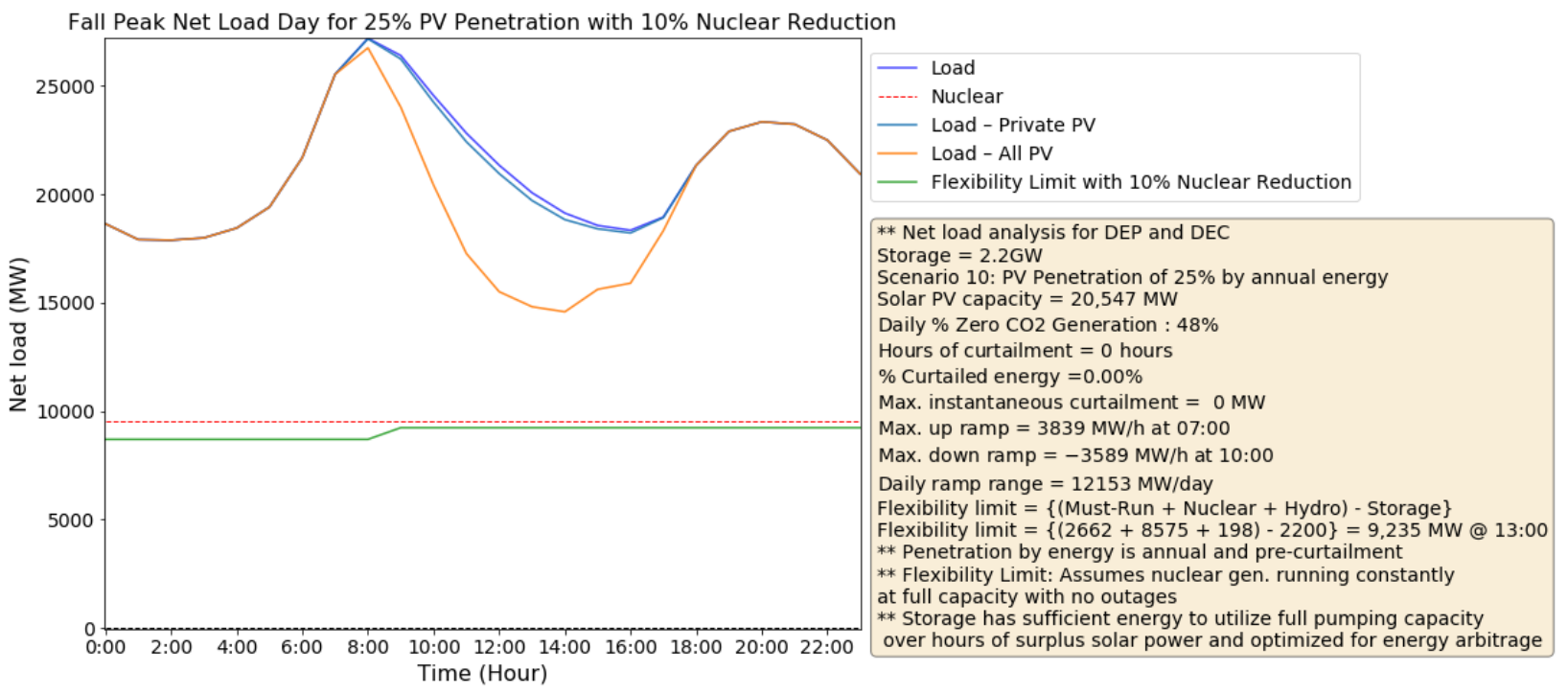

Winter Peak Net Load Day for 25\% PV Penetration with 10\% Nuclear Reduction

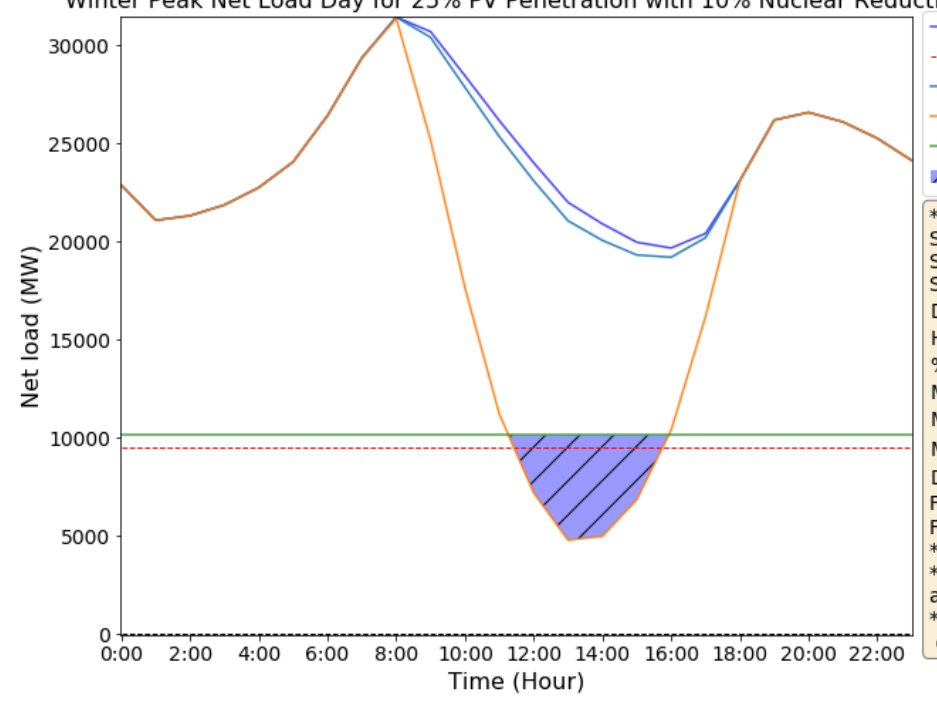

L Load

Nuclear

- Load - Private PV

Load - All PV

- Flexibility Limit with $10 \%$ Nuclear Reduction

7 Curtailed PV energy

** Net load analysis for DEP and DEC

storage $=2.2 \mathrm{GW}$

Scenario 10: PV Penetration of $25 \%$ by annual energy

Solar PV capacity $=20,547 \mathrm{MW}$

Daily \% Zero $\mathrm{CO} 2$ Generation : $53 \%$

Hours of curtailment $=4$ hours

$\%$ Curtailed energy $=15.50 \%$

Max. instantaneous curtailment $=5348 \mathrm{MW}$

Max. up ramp $=6919 \mathrm{MW} / \mathrm{h}$ at $18: 00$

Max. down ramp $=-7518 \mathrm{MW} / \mathrm{h}$ at 10:00

Daily ramp range $=21234 \mathrm{MW} /$ day

Flexibility limit $=\{$ (Must-Run + Nuclear + Hydro $)$ - Storage $\}$

Flexibility limit $=\{(3368+8575+401)-2200\}=10,144 @ 13: 00$

** Penetration by energy is annual and pre-curtailment

** Flexibility Limit: Assumes nuclear gen. running constantly

at full capacity with no outages

** Storage has sufficient energy to utilize full pumping capacity

Time (Hour) 
Scenario 11: 30\% PV and 5\% Wind Penetration

Seasonal Low Net Load Days

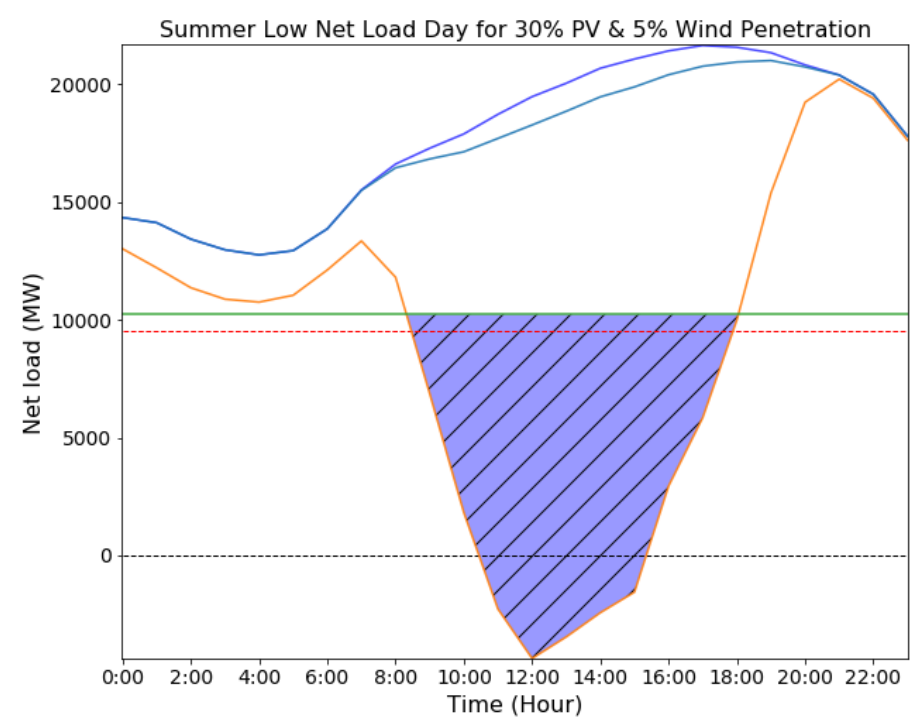

- Load

-.-.- Nuclear

- Load - Private PV

L Load - All PV - $5 \%$ Wind

- Flexibility Limit

$\checkmark$ Curtailed PV energy

** Net load analysis for DEP and DEC

Storage $=2.2 \mathrm{GW}$

Scenario $11: 30 \%$ PV and 5\% Wind Penetration by annual energy

Solar PV capacity $=24,656 \mathrm{MW}$

Wind capacity $=2,426 \mathrm{MW}$

Daily \% Zero CO2 Generation : $84 \%$

Hours of curtailment $=10$ hours

$\%$ Solar curtailed energy $=38.26 \%$

$\%$ Wind curtailed energy $=3.17 \%$

Max. solar instantaneous curtailment $=13326 \mathrm{MW}$

Max. wind instantaneous curtailment $=1279 \mathrm{MW}$

Max. up ramp $=5163 \mathrm{MW} / \mathrm{h}$ at 19:00

Max. down ramp $=-1775 \mathrm{MW} / \mathrm{h}$ at 23:00

Daily ramp range $=10000 \mathrm{MW} /$ day

Flexibility limit $=\{($ Must-Run + Nuclear + Hydro $)-$ Storage $\}$

Flexibility limit $=\{(2662+9528+234)-2200\}=10224 \mathrm{MW} @ 12: 00$

** Penetration by energy is annual and pre-curtailment

** Flexibility Limit: Assumes nuclear gen. running constantly

at full capacity with no outages

** Storage has sufficient energy to utilize full pumping capacity over hours of surplus solar power and optimized for energy arbitrage

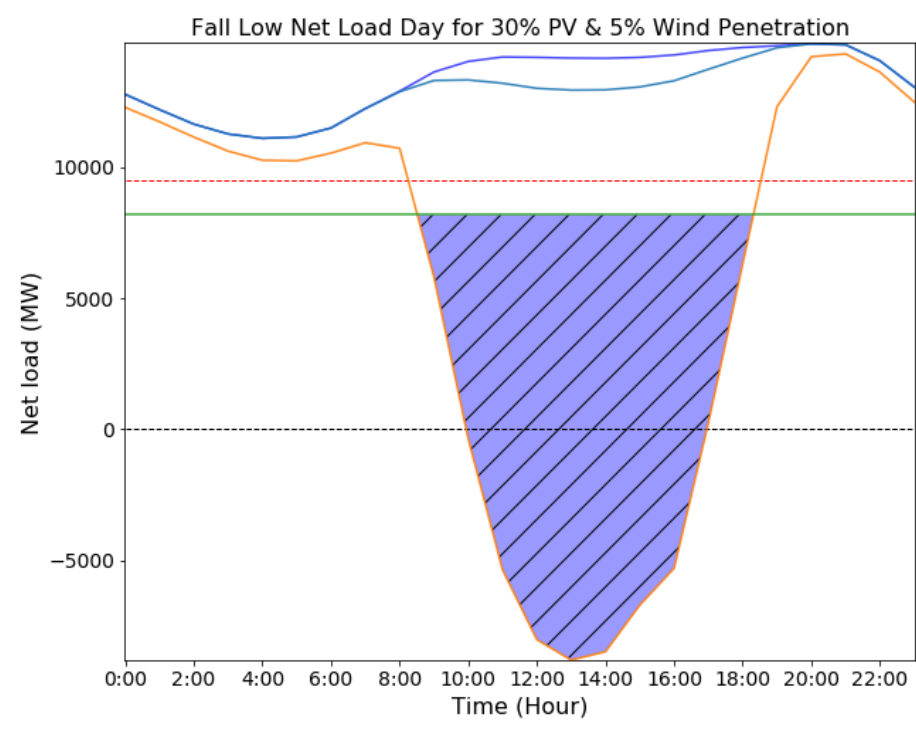

- Load

Nuclear

— Load - Private PV

L Load - All PV - $5 \%$ Wind

- Flexibility Limit

/ Curtailed PV energy

** Net load analysis for DEP and DEC

Storage $=2.2 \mathrm{GW}$

Scenario 11: $30 \%$ PV and 5\% Wind Penetration by annual energy

Solar PV capacity $=24,656 \mathrm{MW}$

Wind capacity $=2,426 \mathrm{MW}$

Daily \% Zero CO2 Generation : $98 \%$

Hours of curtailment $=10$ hours

$\%$ Solar curtailed energy $=56.92 \%$

$\%$ Wind curtailed energy $=3.91 \%$

Max. solar instantaneous curtailment $=16273 \mathrm{MW}$

Max. wind instantaneous curtailment $=1164 \mathrm{MW}$

Max. up ramp $=4119 \mathrm{MW} / \mathrm{h}$ at 19:00

Max. down ramp $=-2537 \mathrm{MW} / \mathrm{h}$ at 09:00

Daily ramp range $=6135 \mathrm{MW} /$ day

Flexibility limit $=\{$ (Must-Run + Nuclear + Hydro $)-$ Storage $\}$

Flexibility limit $=\{(671+9528+188)-2200\}=8187 \mathrm{MW} @ 13: 00$

** Penetration by energy is annual and pre-curtailment

** Flexibility Limit: Assumes nuclear gen. running constantly

at full capacity with no outages

at full capacity with no outages
** Storage has sufficient energy to utilize full pumping capacity

** Storage has sufficient energy to utilize full pumping capacity
over hours of surplus solar power and optimized for energy arbitrage

This report is available at no cost from the National Renewable Energy Laboratory (NREL) at www.nrel.gov/publications. 


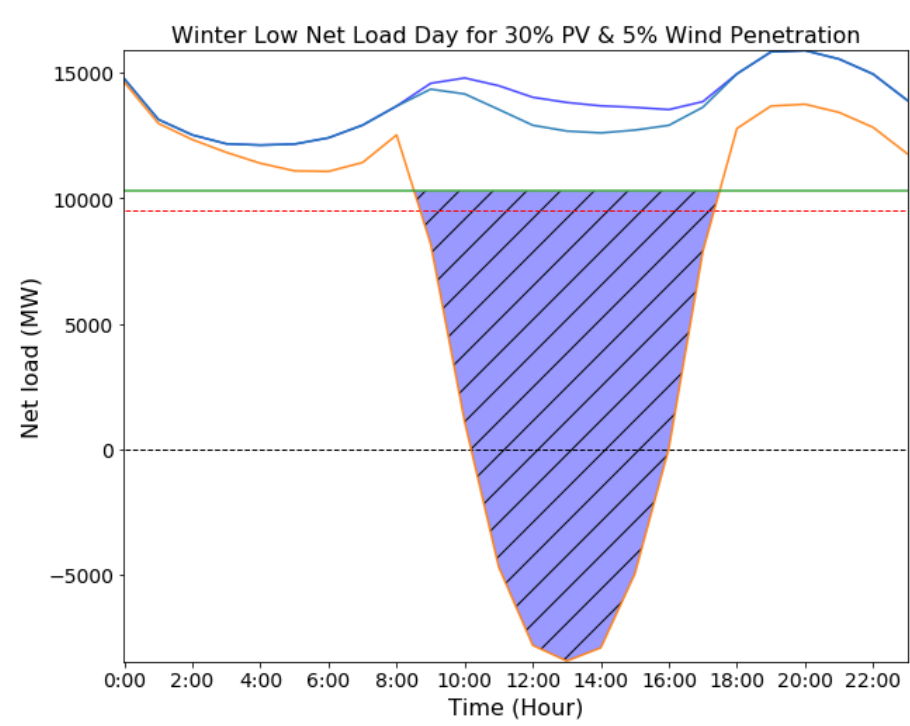

Load

Nuclear

L Load - Private PV

- Load - All PV - $5 \%$ Wind

- Flexibility Limit

I Curtailed PV energy

** Net load analysis for DEP and DEC

Storage $=2.2 \mathrm{GW}$

Scenario 11: 30\% PV and 5\% Wind Penetration by annual energy

Solar PV capacity $=24,656 \mathrm{MW}$

Wind capacity $=2,426 \mathrm{MW}$

Daily \% Zero CO2 Generation : $87 \%$

Hours of curtailment $=9$ hours

$\%$ Solar curtailed energy $=59.89 \%$

$\%$ Wind curtailed energy $=7.30 \%$

Max. solar instantaneous curtailment $=17084 \mathrm{MW}$

Max. wind instantaneous curtailment $=1794 \mathrm{MW}$

Max. up ramp $=2502 \mathrm{MW} / \mathrm{h}$ at 18:00

Max. down ramp $=-2241 \mathrm{MW} / \mathrm{h}$ at 09:00

Daily ramp range $=4338 \mathrm{MW} /$ day

Flexibility limit $=\{($ Must-Run + Nuclear + Hydro $)-$ Storage $\}$

Flexibility limit $=\{(2662+9528+298)-2200\}=10288 \mathrm{MW} @ 13: 00$

** Penetration by energy is annual and pre-curtailment

** Flexibility Limit: Assumes nuclear gen. running constantly

at full capacity with no outages

** Storage has sufficient energy to utilize full pumping capacity

over hours of surplus solar power and optimized for energy arbitrage 


\section{Seasonal Peak Net Load Days}
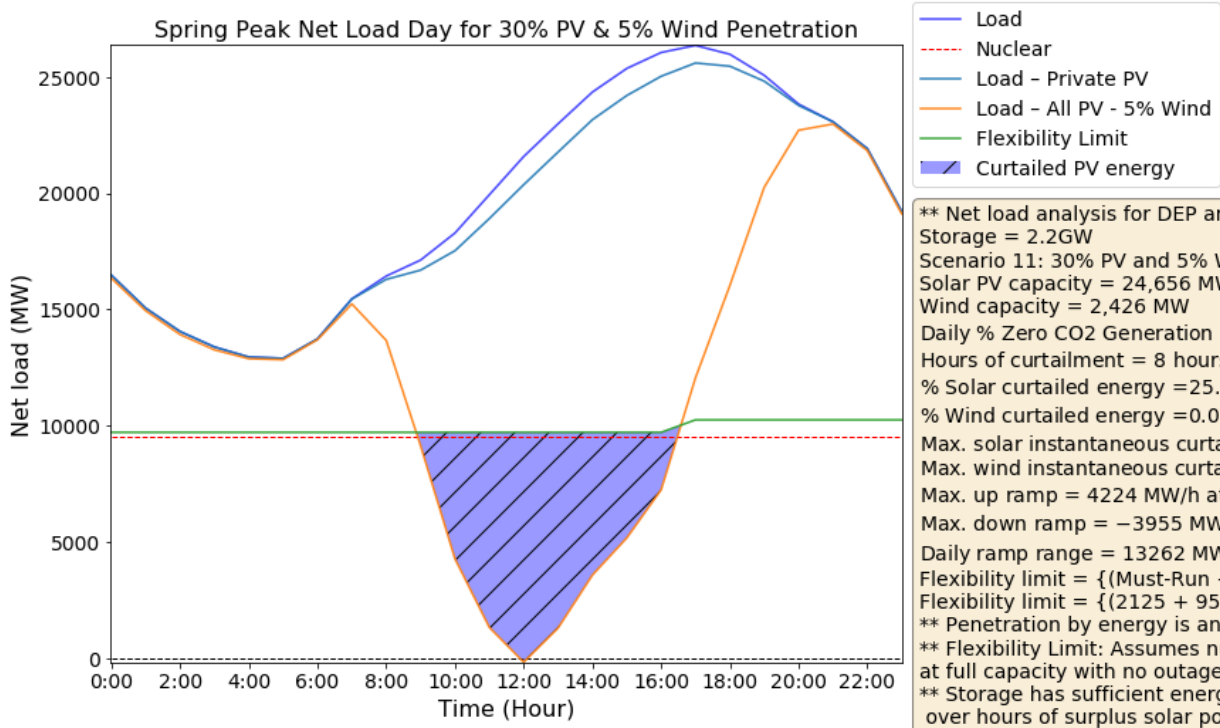

* Net load analysis for DEP and DEC

Storage $=2.2 \mathrm{GW}$

Scenario 11: $30 \%$ PV and 5\% Wind Penetration by annual energy Solar PV capacity $=24,656 \mathrm{MW}$

Wind capacity $=2,426 \mathrm{MW}$

Daily \% Zero $\mathrm{CO} 2$ Generation : $77 \%$

Hours of curtailment $=8$ hours

$\%$ Solar curtailed energy $=25.73 \%$

$\%$ Wind curtailed energy $=0.05 \%$

Max. solar instantaneous curtailment $=9872 \mathrm{MW}$

Max. wind instantaneous curtailment $=14 \mathrm{MW}$

Max. up ramp $=4224 \mathrm{MW} / \mathrm{h}$ at 19:00

Max. down ramp $=-3955 \mathrm{MW} / \mathrm{h}$ at 09:00

Daily ramp range $=13262 \mathrm{MW} /$ day

Flexibility limit $=\{($ Must-Run + Nuclear + Hydro $)-$ Storage $\}$

Flexibility limit $=\{(2125+9528+262)-2200\}=9715$ MW @ 12:00

** Penetration by energy is annual and pre-curtailment

** Flexibility Limit: Assumes nuclear gen. running constantly

at full capacity with no outages

** Storage has sufficient energy to utilize full pumping capacity

over hours of surplus solar power and optimized for energy arbitrage

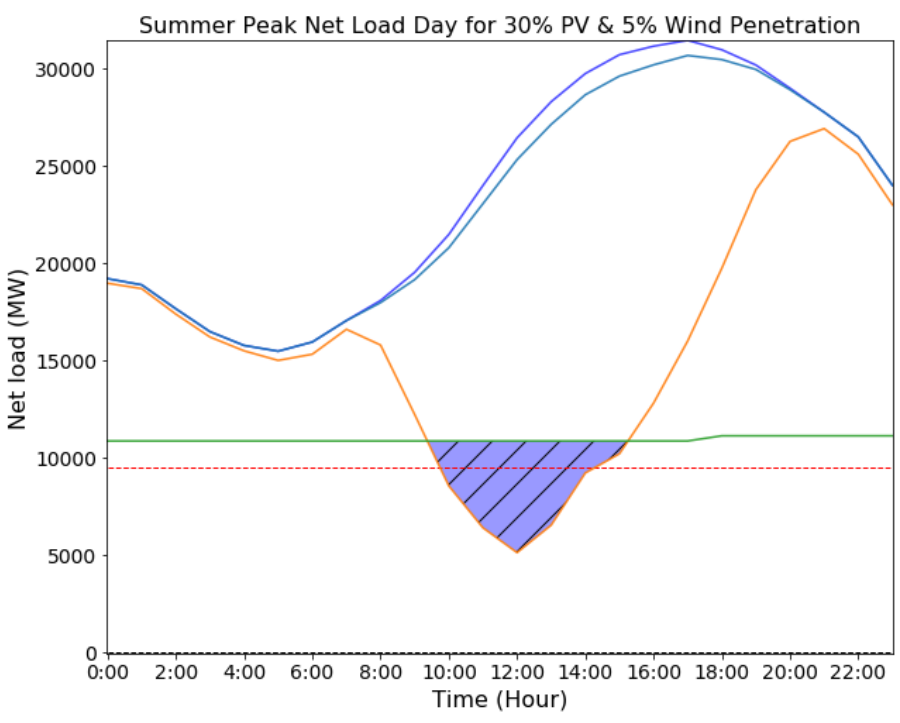

- Load

Nuclear

L Load - Private PV

- Load - All PV - $5 \%$ Wind

Flexibility Limit

$\triangle$ Curtailed PV energy

* Net load analysis for DEP and DEC

Storage $=2.2 \mathrm{GW}$

Scenario 11 : $30 \% \mathrm{PV}$ and $5 \%$ Wind Penetration by annual energy

Solar PV capacity $=24,656 \mathrm{MW}$

Wind capacity $=2,426 \mathrm{MW}$

Daily \% Zero $\mathrm{CO} 2$ Generation : $69 \%$

Hours of curtailment $=6$ hours

$\%$ Solar curtailed energy $=10.15 \%$

$\%$ Wind curtailed energy $=0.26 \%$

Max. solar instantaneous curtailment $=5515 \mathrm{MW}$

Max. wind instantaneous curtailment $=223 \mathrm{MW}$

Max. up ramp $=4043 \mathrm{MW} / \mathrm{h}$ at 19:00

Max. down ramp $=-3571 \mathrm{MW} / \mathrm{h}$ at 09:00

Daily ramp range $=16052 \mathrm{MW} /$ day

Flexibility limit $=\{$ (Must-Run + Nuclear + Hydro $)-$ Storage $\}$

Flexibility limit $=\{(3368+9528+173)-2200\}=10869 \mathrm{MW} @ 12: 00$

** Penetration by energy is annual and pre-curtailment

** Flexibility Limit: Assumes nuclear gen. running constantly

at full capacity with no outages

** Storage has sufficient energy to utilize full pumping capacity

over hours of surplus solar power and optimized for energy arbitrage 


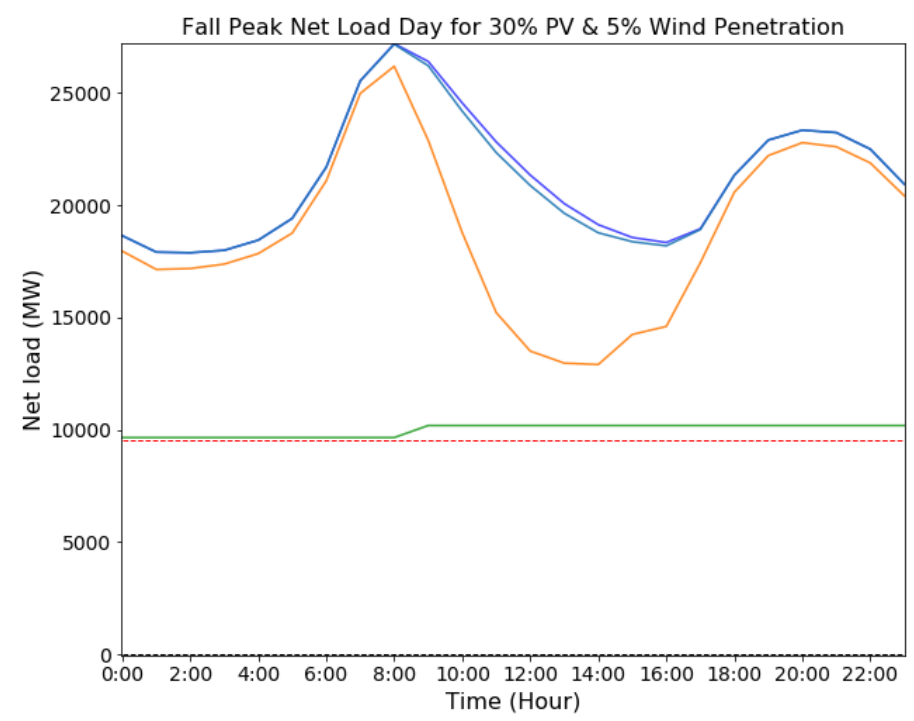

Load

-.-.- Nuclear

- Load - Private PV

Load - All PV - $5 \%$ Wind

- Flexibility Limit

** Net load analysis for DEP and DEC

Storage $=2.2 \mathrm{GW}$

Scenario 11: 30\% PV and 5\% Wind Penetration by annual energy

Solar PV capacity $=24,656 \mathrm{MW}$

Wind capacity $=2,426 \mathrm{MW}$

Daily \% Zero CO2 Generation : $58 \%$

Hours of curtailment $=0$ hours

$\%$ Solar curtailed energy $=0.00 \%$

$\%$ Wind curtailed energy $=0.00 \%$

Max. solar instantaneous curtailment $=0 \mathrm{MW}$

Max. wind instantaneous curtailment $=0 \mathrm{MW}$

Max. up ramp $=3889 \mathrm{MW} / \mathrm{h}$ at 7:00

Max. down ramp $=-4105 \mathrm{MW} / \mathrm{h}$ at 10:00

Daily ramp range $=13260 \mathrm{MW} /$ day

Flexibility limit $=\{($ Must-Run + Nuclear + Hydro $)-$ Storage $\}$
Flexibility limit $=\{(2662+9528+198)-2200\}=10,188$ MW $@ 13: 00$

Flexibility limit $=\{(2662+9528+198)-2200\}=10,1$
$* *$ Penetration by energy is annual and pre-curtailment

** Flexibility Limit: Assumes nuclear gen. running constantly

at full capacity with no outages

** Storage has sufficient energy to utilize full pumping capacity over hours of surplus solar power and optimized for energy arbitrage

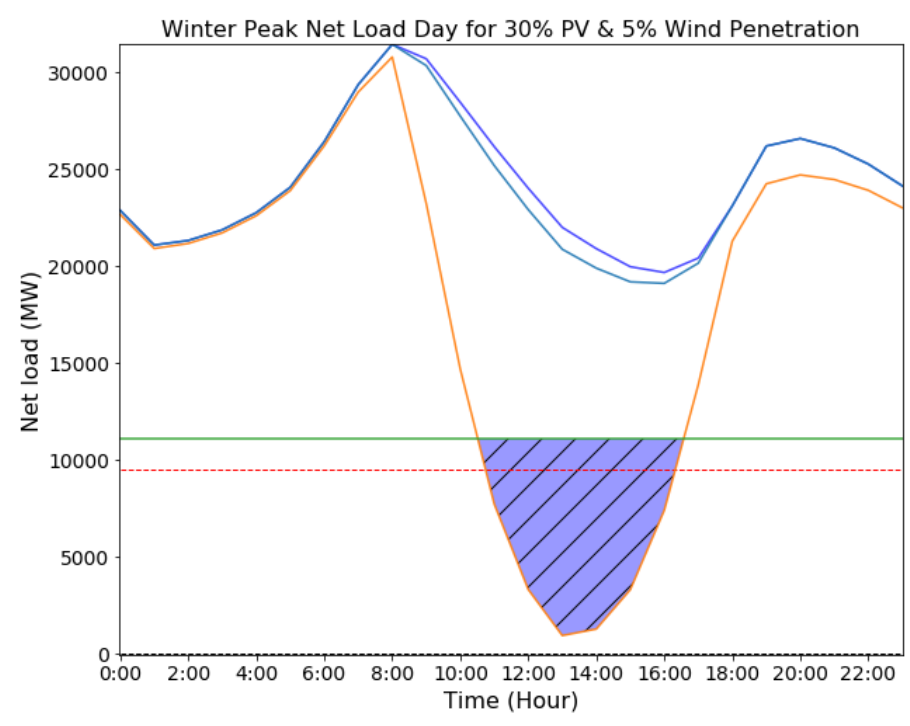

- Load

Nuclear

- Load - Private PV

Load - All PV - $5 \%$ Wind

Flexibility Limit

$\triangle$ Curtailed PV energy

** Net load analysis for DEP and DEC

Storage $=2.2 \mathrm{GW}$

Scenario 11: $30 \%$ PV and 5\% Wind Penetration by annual energy

Solar PV capacity $=24,656 \mathrm{MW}$

Wind capacity $=2,426 \mathrm{MW}$

Daily \% Zero CO2 Generation : $60 \%$

Hours of curtailment $=6$ hours

$\%$ Solar curtailed energy $=27.64 \%$

$\%$ Wind curtailed energy $=1.02 \%$

Max. solar instantaneous curtailment $=9953 \mathrm{MW}$

Max. wind instantaneous curtailment $=432 \mathrm{MW}$

Max. up ramp $=7404 \mathrm{MW} / \mathrm{h}$ at 18:00

Max. down ramp $=-8538 \mathrm{MW} / \mathrm{h}$ at 10:00

Daily ramp range $=19692 \mathrm{MW} /$ day

Flexibility limit $=\{($ Must-Run + Nuclear + Hydro $)-$ Storage $\}$

Flexibility limit $=\{(3368+9528+401)-2200\}=11,097 \mathrm{MW} @ 13: 00$

** Penetration by energy is annual and pre-curtailment

** Flexibility Limit: Assumes nuclear gen. running constantly

at full capacity with no outages

** Storage has sufficient energy to utilize full pumping capacity

over hours of surplus solar power and optimized for energy arbitrage 


\section{Scenario 12: DEC and DEP Modeled as Separate Balancing Authorities with 5\%, $10 \%$, and $15 \%$ PV Penetration}

Seasonal Low Net Load Days: 5\% PV Penetration

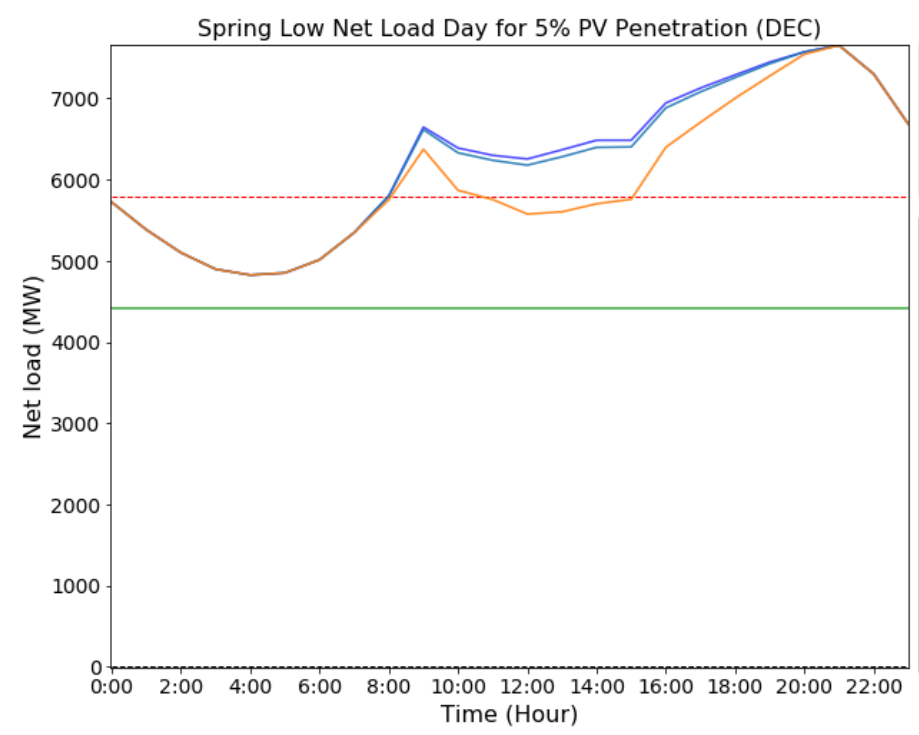

- Load

-...-. Nuclear

- Load - Private PV

- Load - All PV

- Flexibility Limit

** Net load analysis for DEC

Storage $=2140 \mathrm{MW}$

Scenario 12: PV Penetration of $5 \%$ by annual energy

Solar PV capacity $=1,339 \mathrm{MW}$

Daily \% Zero CO2 Generation : $102 \%$

Hours of curtailment $=0$ hours

$\%$ Curtailed energy $=0.00 \%$

Max. instantaneous curtailment $=0 \mathrm{MW}$

Max. up ramp $=641 \mathrm{MW} / \mathrm{h}$ at 16:00

Max. down ramp $=-955 \mathrm{MW} / \mathrm{h}$ at 00:00

Daily ramp range $=2829 \mathrm{MW} /$ day

Flexibility limit $=\{($ Must-Run + Nuclear + Hydro $)-$ Storage $\}$

Flexibility limit $=\{(520+5793+235)-2140\}=4408 \mathrm{MW} @ 13: 00$

** Penetration by energy is annual and pre-curtailment

** Flexibility Limit: Assumes nuclear gen. running constantly

at full capacity with no outages

** Storage has sufficient energy to utilize full pumping capacity

over hours of surplus solar power and optimized for energy arbitrage

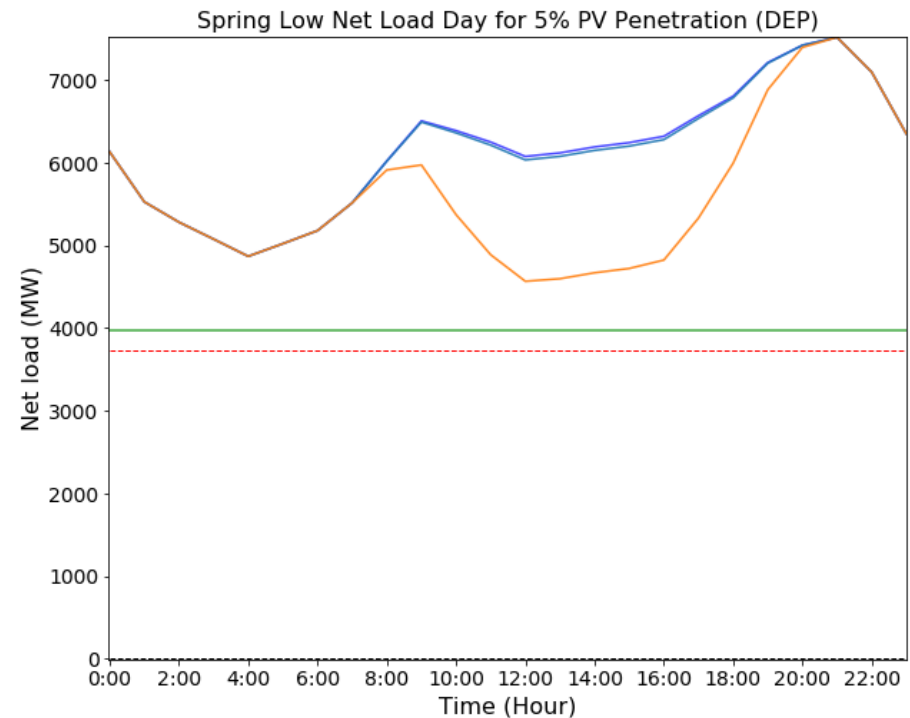

- Load

Nuclear

- Load - Private PV

- Load - All PV

- Flexibility Limit

\section{** Net load analysis for DEP}

Storage $=12 \mathrm{MW}$

Scenario 12: PV Penetration of $5 \%$ by annual energy

Solar PV capacity $=903 \mathrm{MW}$

Daily \% Zero CO2 Generation : $71 \%$

Hours of curtailment $=0$

$\% \%$ Curtailed energy $=0$

Max. instantaneous curtailment $=0$

Max. up ramp $=889 \mathrm{MW} / \mathrm{h}$ at 19:00

Max. down ramp $=-747 \mathrm{MW} / \mathrm{h}$ at 23:00

Daily ramp range $=3545 \mathrm{MW} /$ day

Flexibility limit $=\{($ Must-Run + Nuclear + Hydro $)-$ Storage $\}$

Flexibility limit $=\{(151+3735+98)-12\}=3972 \mathrm{MW} @ 13: 00$

** Penetration by energy is annual and pre-curtailment

** Flexibility Limit: Assumes nuclear gen. running constantly

at full capacity with no outages

** Storage has sufficient energy to utilize full pumping capacity

over hours of surplus solar power and optimized for energy arbitrage

Time (Hour) 


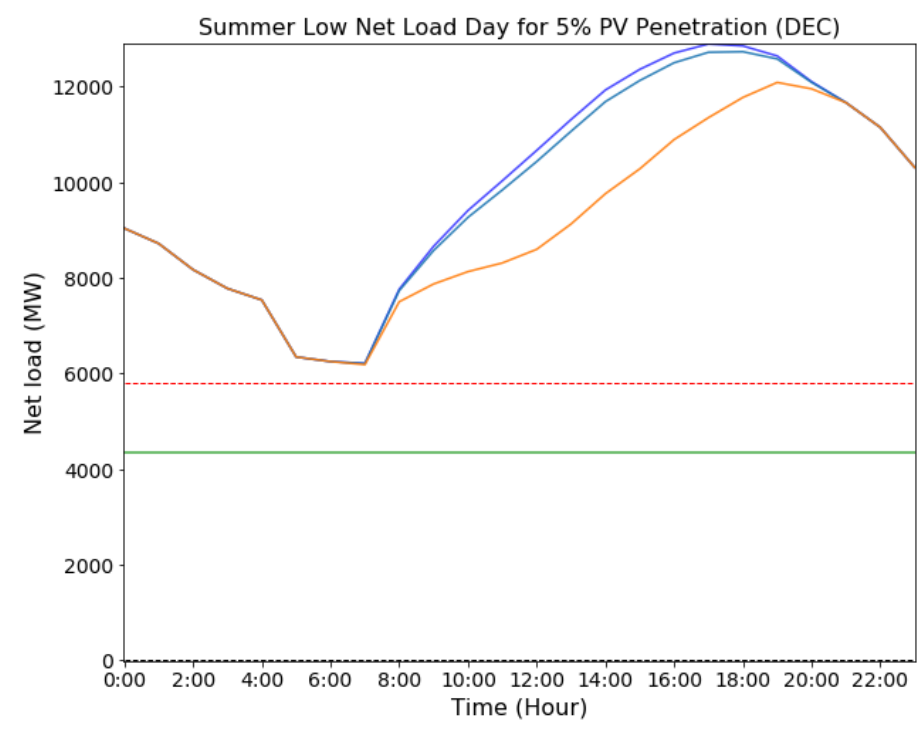

- Load

Nuclear

- Load - Private PV

- Load - All PV

- Flexibility Limit

** Net load analysis for DEC

storage $=2140 \mathrm{MW}$

Scenario 12: PV Penetration of $5 \%$ by annual energy

Solar PV capacity $=1,339 \mathrm{MW}$

Daily \% Zero CO2 Generation : $69 \%$

Hours of curtailment $=0$ hours

$\%$ Curtailed energy $=0.00 \%$

Max. instantaneous curtailment $=0 \mathrm{MW}$

Max. up ramp $=1316 \mathrm{MW} / \mathrm{h}$ at 08:00

Max. down ramp $=-1191 \mathrm{MW} / \mathrm{h}$ at 05:00

Daily ramp range $=5904 \mathrm{MW} /$ day

Flexibility limit $=\{$ (Must-Run + Nuclear + Hydro $)-$ Storage $\}$

Flexibility limit $=\{(520+5793+168)-2140\}=4341 \mathrm{MW} @ 13: 00$

** Penetration by energy is annual and pre-curtailment

** Flexibility Limit: Assumes nuclear gen. running constantly

at full capacity with no outages

** Storage has sufficient energy to utilize full pumping capacity

over hours of surplus solar power and optimized for energy arbitrage

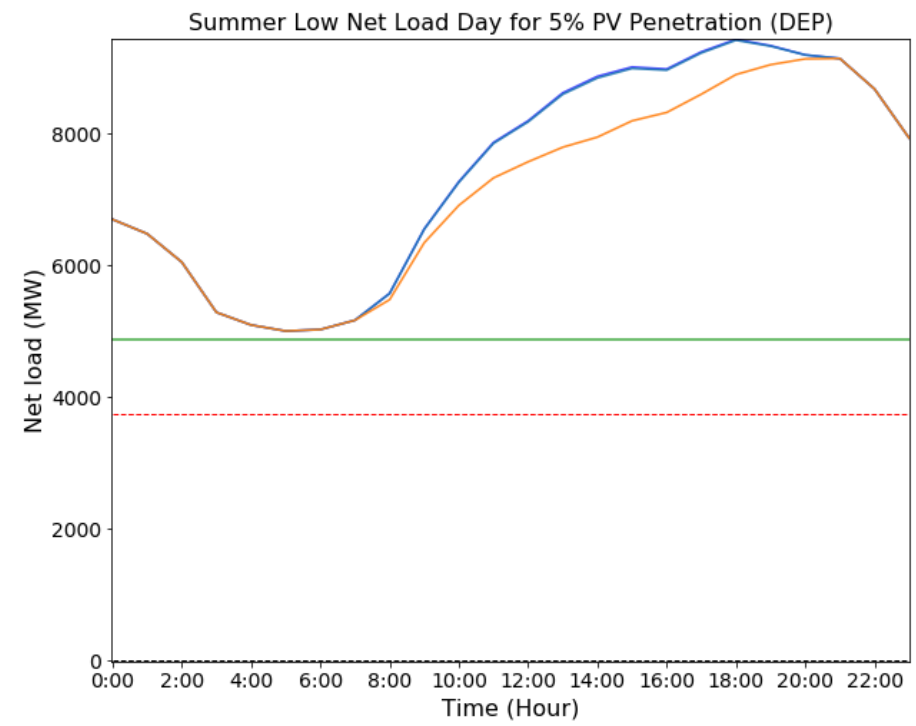

- Load

.... Nuclear

- Load - Private PV

- Load - All PV

- Flexibility Limit

** Net load analysis for DEP

Storage $=12 \mathrm{MW}$

Scenario 12: PV Penetration of $5 \%$ by annual energy

Solar PV capacity $=903 \mathrm{MW}$

Daily \% Zero CO2 Generation : $56 \%$

Hours of curtailment $=0$

$\% \%$ Curtailed energy $=0$

Max. instantaneous curtailment $=0$

Max. up ramp $=864 \mathrm{MW} / \mathrm{h}$ at 09:00

Max. down ramp $=-762 \mathrm{MW} / \mathrm{h}$ at 03:00

Daily ramp range $=4268 \mathrm{MW} /$ day

Flexibility limit $=\{($ Must-Run + Nuclear + Hydro $)-$ Storage $\}$

Flexibility limit $=\{(1107+3735+39)-12\}=4869 \mathrm{MW} @ 13: 00$

** Penetration by energy is annual and pre-curtailment

** Flexibility Limit: Assumes nuclear gen. running constantly

at full capacity with no outages

* Storage has sufficient energy to utilize full pumping capacity

over hours of surplus solar power and optimized for energy arbitrage

Time (Hour) 


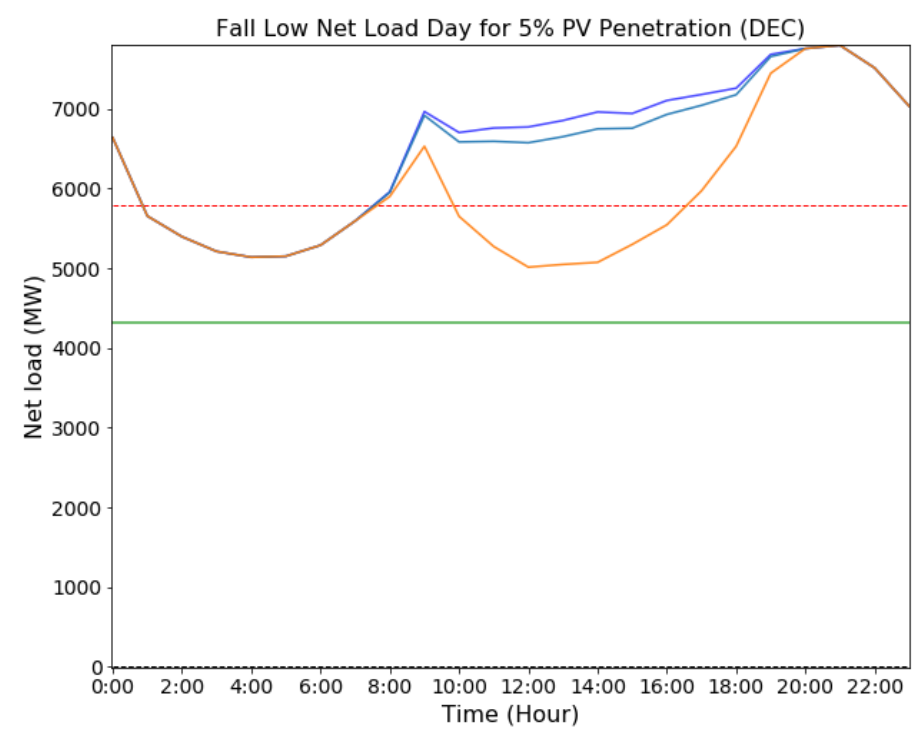

- Load

-..-. Nuclear

- Load - Private PV

L Load - All PV

- Flexibility Limit

** Net load analysis for DEC

Storage $=2140 \mathrm{MW}$

Scenario 12: PV Penetration of $5 \%$ by annual energy

Solar PV capacity $=1,339 \mathrm{MW}$

Daily \% Zero CO2 Generation : $100 \%$

Hours of curtailment $=0$ hours

$\%$ Curtailed energy $=0.00 \%$

Max. instantaneous curtailment $=0 \mathrm{MW}$

Max. up ramp $=916 \mathrm{MW} / \mathrm{h}$ at 19:00

Max. down ramp $=-983 \mathrm{MW} / \mathrm{h}$ at $01: 00$

Daily ramp range $=2782 \mathrm{MW} /$ day

Flexibility limit $=\{$ (Must-Run + Nuclear + Hydro $)-$ Storage $\}$

Flexibility limit $=\{(520+5793+141)-2140\}=4314 \mathrm{MW} @ 13: 00$

** Penetration by energy is annual and pre-curtailment

** Flexibility Limit: Assumes nuclear gen. running constantly

at full capacity with no outages

** Storage has sufficient energy to utilize full pumping capacity

over hours of surplus solar power and optimized for energy arbitrage

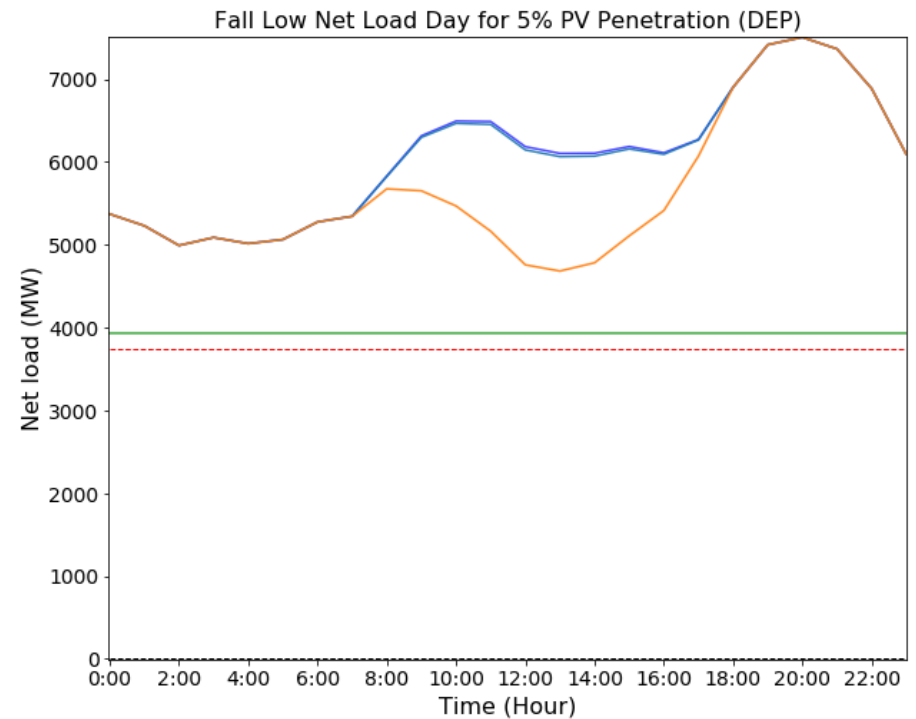

- Load

Nuclear

- Load - Private PV

- Load - All PV

- Flexibility Limit

* Net load analysis for DEP

torage $=12 \mathrm{MW}$

Scenario 12: PV Penetration of $5 \%$ by annual energy

Solar PV capacity $=903 \mathrm{MW}$

Daily \% Zero CO2 Generation : $69 \%$

Hours of curtailment $=0$ hours

$\%$ Curtailed energy $=0.00 \%$

Max. instantaneous curtailment $=0 \mathrm{MW}$

Max. up ramp $=831 \mathrm{MW} / \mathrm{h}$ at 18:00

Max. down ramp $=-794 \mathrm{MW} / \mathrm{h}$ at 23:00

Daily ramp range $=2823 \mathrm{MW} /$ day

Flexibility limit $=\{($ Must-Run + Nuclear + Hydro $)-$ Storage $\}$

Flexibility limit $=\{(151+3735+50)-12\}=3924 \mathrm{MW} @ 13: 00$

** Penetration by energy is annual and pre-curtailment

** Flexibility Limit: Assumes nuclear gen. running constantly

at full capacity with no outages

* Storage has sufficient energy to utilize full pumping capacity

over hours of surplus solar power and optimized for energy arbitrage

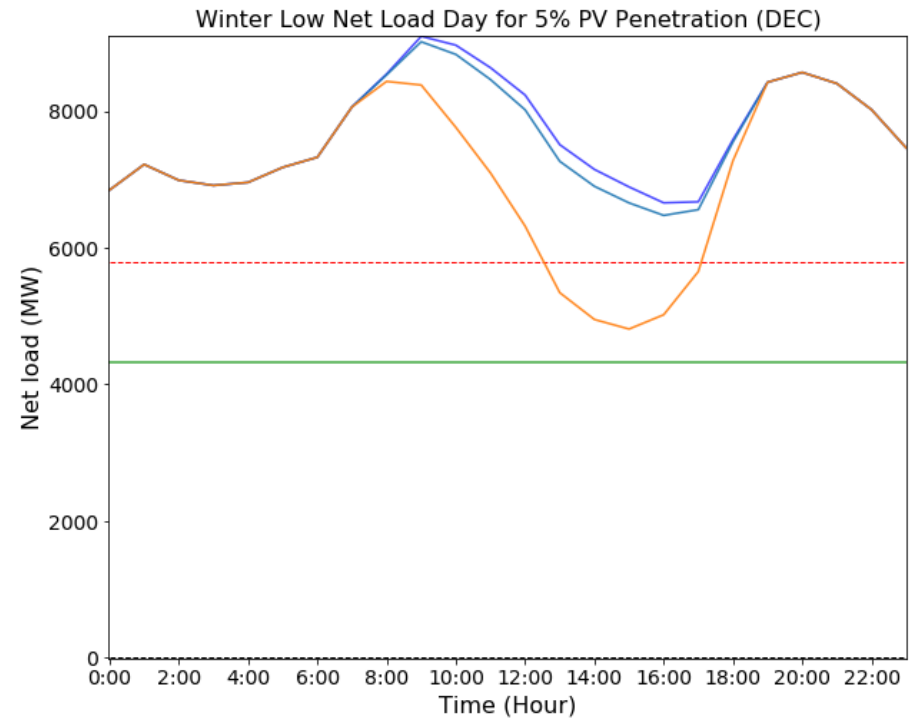

- Load

-.... Nuclear

Load - Private PV

- Load - All PV

Flexibility Limit

\section{** Net load analysis for DEC}

Storage $=2140 \mathrm{MW}$

Scenario 12: PV Penetration of $5 \%$ by annual energy

Solar PV capacity $=1,339 \mathrm{MW}$

Daily \% Zero CO2 Generation : $86 \%$

Hours of curtailment $=0$ hours

$\%$ Curtailed energy $=0.00 \%$

Max. instantaneous curtailment $=0 \mathrm{MW}$

Max. up ramp $=1622 \mathrm{MW} / \mathrm{h}$ at 18:00

Max. down ramp $=-974 \mathrm{MW} / \mathrm{h}$ at 13:00

Daily ramp range $=3756 \mathrm{MW} /$ day

Flexibility limit $=\{$ (Must-Run + Nuclear + Hydro $)-$ Storage $\}$

Flexibility limit $=\{(520+5793+156)-2140\}=4329 \mathrm{MW} @ 13: 00$

** Penetration by energy is annual and pre-curtailment

** Flexibility Limit: Assumes nuclear gen. running constantly

** Storage has sufficient energy to utilize full pumping capacity
at full capacity with no outages

*ver hours of surplus solar power and optimized for energy arbitrage
over 


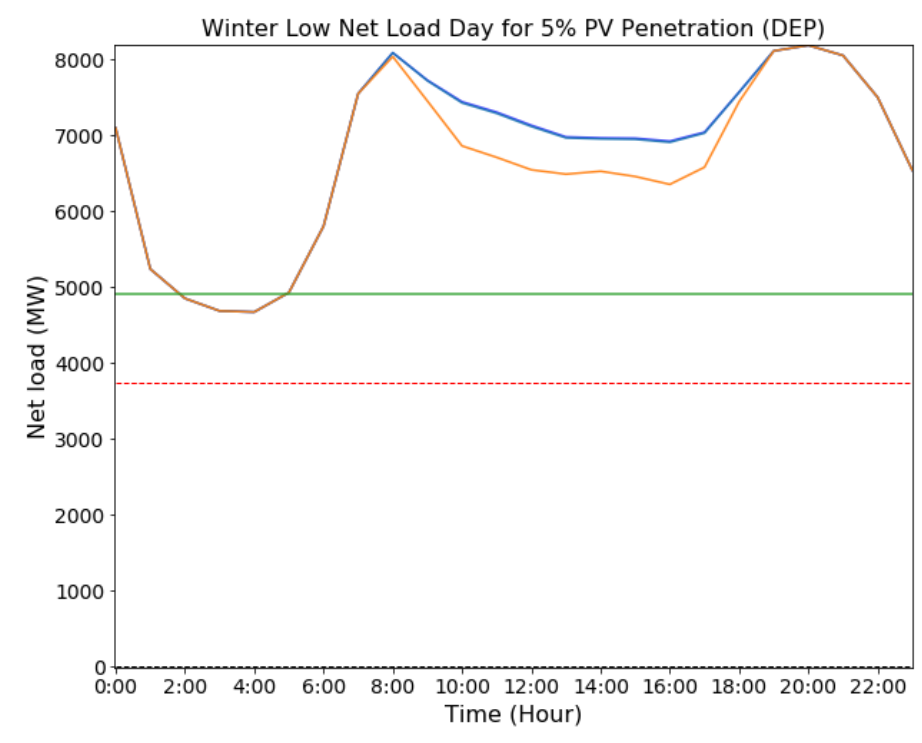

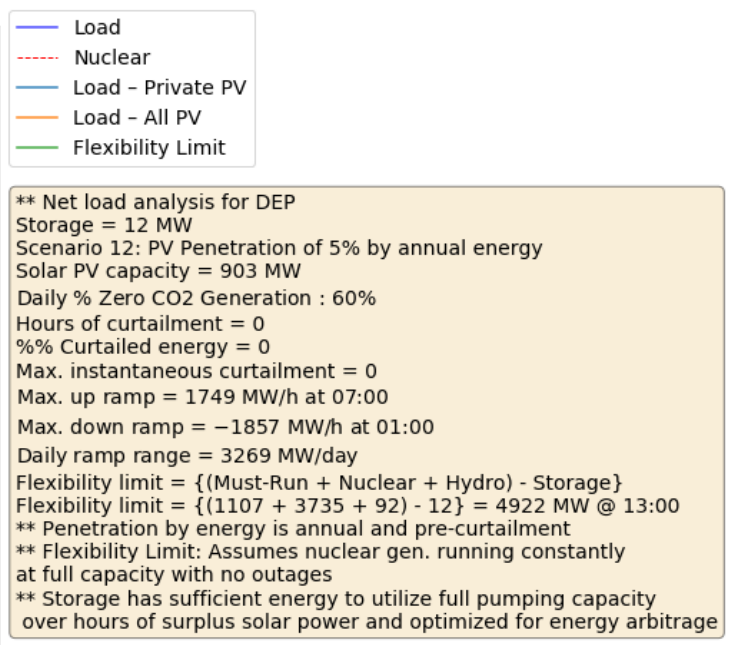

This report is available at no cost from the National Renewable Energy Laboratory (NREL) at www.nrel.gov/publications. 


\section{Seasonal Peak Net Load Days: 5\% PV Penetration}

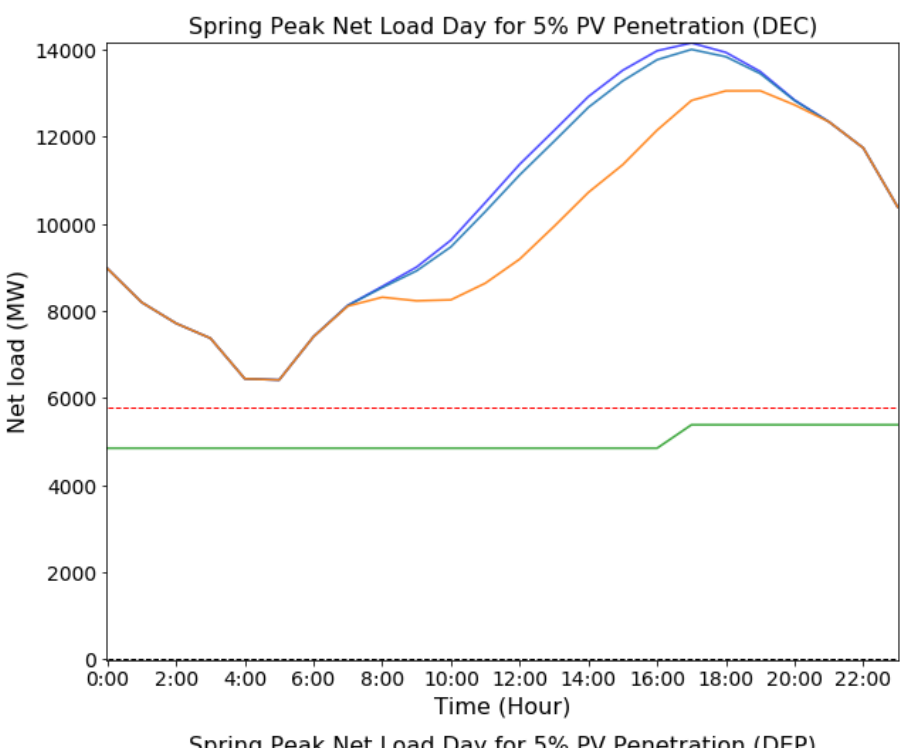

- Load

-.-.- Nuclear

- Load - Private PV

L Load - All PV

- Flexibility Limit

* Net load analysis for DEC

Storage $=2140 \mathrm{MW}$

Scenario 1: PV Penetration of $5 \%$ by annual energy

Solar PV capacity $=1,339 \mathrm{MW}$

Daily \% Zero CO2 Generation : $67 \%$

Hours of curtailment $=0$

$\%$ Curtailed energy $=0$

Max. instantaneous curtailment $=0 \mathrm{MW}$

Max. up ramp $=994 \mathrm{MW} / \mathrm{h}$ at 06:00

Max. down ramp $=-1355 \mathrm{MW} / \mathrm{h}$ at 23:00

Daily ramp range $=6642 \mathrm{MW} /$ day

Flexibility limit $=\{($ Must-Run + Nuclear + Hydro $)-$ Storage $\}$

Flexibility limit $=\{(1018+5793+180)-2140\}=4851 \mathrm{MW} @ 13: 00$

** Penetration by energy is annual and pre-curtailment

** Flexibility Limit: Assumes nuclear gen. running constantly

at full capacity with no outages

a* full capacity with no outages
** Storage has sufficient energy to utilize full pumping capacity

over hours of surplus solar power and optimized for energy arbitrage

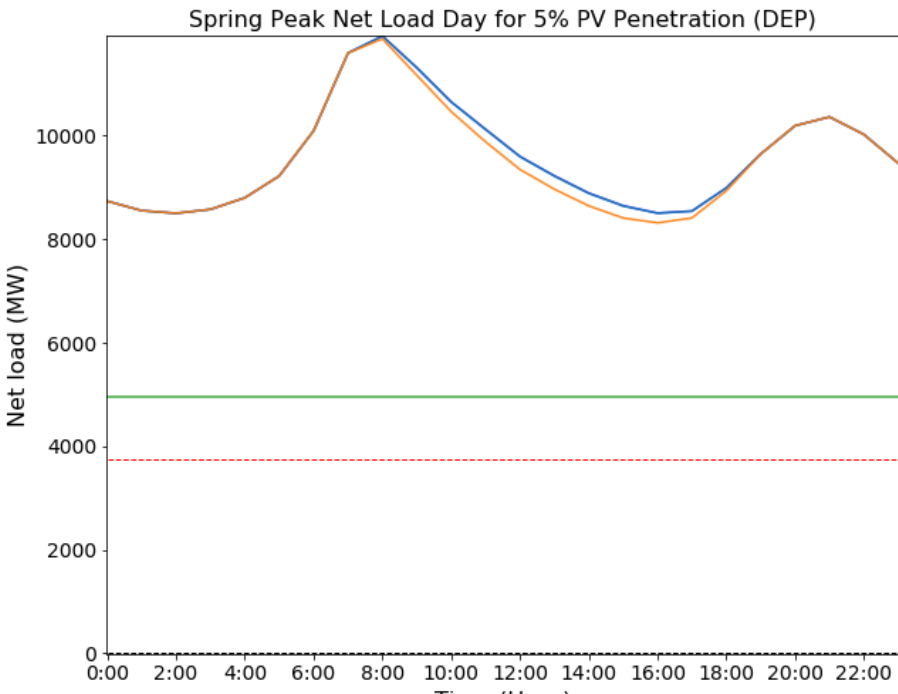

- Load

-.... Nuclear

L Load - Private PV

— Load - All PV

- Flexibility Limit

** Net load analysis for DEP

Storage $=12 \mathrm{MW}$

Scenario 1: PV Penetration of $5 \%$ by annual energy

Solar PV capacity $=903 \mathrm{MW}$

Daily \% Zero CO2 Generation : $41 \%$

Hours of curtailment $=0$

$\%$ Curtailed energy $=0$

Max. instantaneous curtailment $=0 \mathrm{MW}$

Max. up ramp $=1502 \mathrm{MW} / \mathrm{h}$ at 07:00

Max. down ramp $=-703 \mathrm{MW} / \mathrm{h}$ at 09:00

Daily ramp range $=3552 \mathrm{MW} /$ day

Flexibility limit $=\{$ (Must-Run + Nuclear + Hydro $)-$ Storage $\}$

Flexibility limit $=\{(1107+3735+120)-12\}=4950 \mathrm{MW} @ 15: 00$

** Penetration by energy is annual and pre-curtailment

** Flexibility Limit: Assumes nuclear gen. running constantly

at full capacity with no outages
** Storage has sufficient energy to utilize full pumping capacity

over hours of surplus solar power and optimized for energy arbitrage

Time (Hour)

This report is available at no cost from the National Renewable Energy Laboratory (NREL) at www.nrel.gov/publications. 


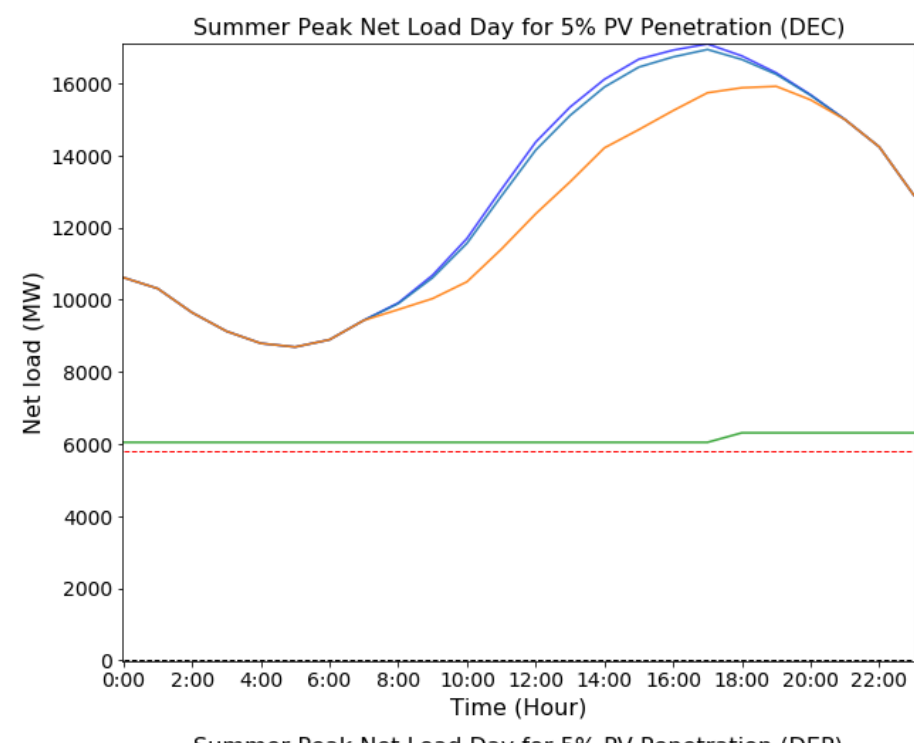

- Load

-.... Nuclear

L Load - Private PV

- Load - All PV

Flexibility Limit

* Net load analysis for DEC

Storage $=2140 \mathrm{MW}$

Scenario 1: PV Penetration of $5 \%$ by annual energy

Solar PV capacity $=1,339 \mathrm{MW}$

Daily \% Zero CO2 Generation : 53\%

Hours of curtailment $=0$

$\%$ Curtailed energy $=0$

Max. instantaneous curtailment $=0 \mathrm{MW}$

Max. up ramp $=982 \mathrm{MW} / \mathrm{h}$ at $12: 00$

Max. down ramp $=-1331 \mathrm{MW} / \mathrm{h}$ at 23:00

Daily ramp range $=7226 \mathrm{MW} /$ day

Flexibility limit $=\{($ Must-Run + Nuclear + Hydro $)-$ Storage $\}$

Flexibility limit $=\{(2261+5793+130)-2140\}=6044 \mathrm{MW} @ 13: 00$

** Penetration by energy is annual and pre-curtailment

** Flexibility Limit: Assumes nuclear gen. running constantly

at full capacity with no outages

** Storage has sufficient energy to utilize full pumping capacity over hours of surplus solar power and optimized for energy arbitrage

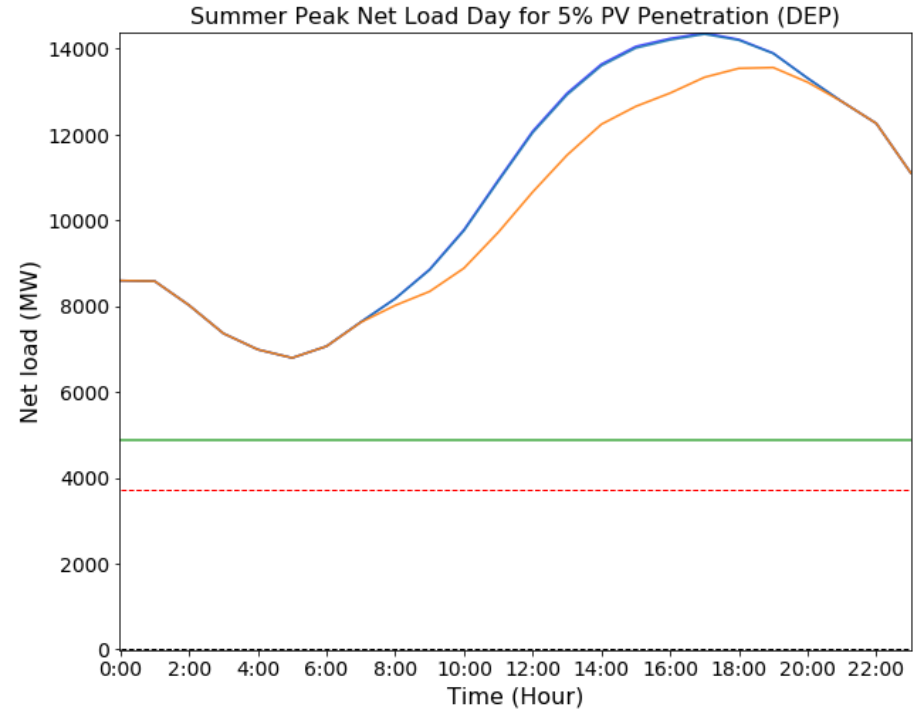

- Load

-.-.. Nuclear

- Load - Private PV

- Load - All PV

- Flexibility Limit

** Net load analysis for DEP

Storage $=12 \mathrm{MW}$

Scenario 1: PV Penetration of $5 \%$ by annual energy

Solar PV capacity $=903 \mathrm{MW}$

Daily \% Zero CO2 Generation : $41 \%$

Hours of curtailment $=0$

$\%$ Curtailed energy $=0$

Max. instantaneous curtailment $=0 \mathrm{MW}$

Max. up ramp $=939 \mathrm{MW} / \mathrm{h}$ at $12: 00$

Max. down ramp $=-1151 \mathrm{MW} / \mathrm{h}$ at 23:00

Daily ramp range $=6768 \mathrm{MW} /$ day

Flexibility limit $=\{$ (Must-Run + Nuclear + Hydro $)-$ Storage $\}$

Flexibility limit $=\{(1107+3735+43)-12\}=4873 \mathrm{MW} @ 13: 00$

** Penetration by energy is annual and pre-curtailment

** Flexibility Limit: Assumes nuclear gen. running constantly

at full capacity with no outages

** Storage has sufficient energy to utilize full pumping capacity

over hours of surplus solar power and optimized for energy arbitrage

This report is available at no cost from the National Renewable Energy Laboratory (NREL) at www.nrel.gov/publications. 


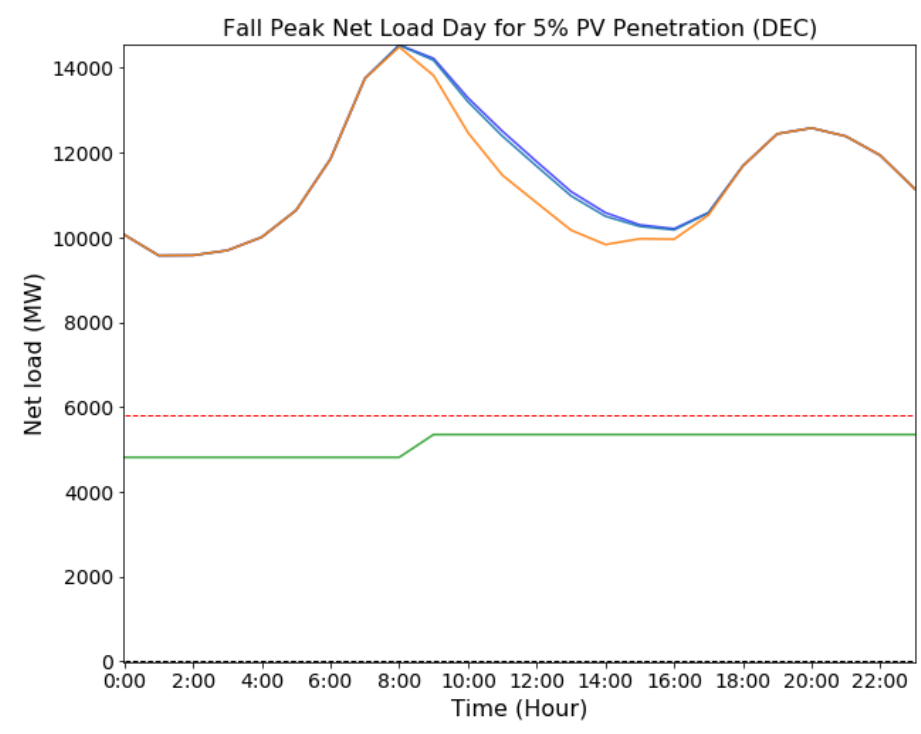

- Load

Nuclear

- Load - Private PV

— Load - All PV

Flexibility Limit

** Net load analysis for DEC

Storage $=2140 \mathrm{MW}$

Scenario 1: PV Penetration of $5 \%$ by annual energy

Solar PV capacity $=1,339 \mathrm{MW}$

Daily \% Zero CO2 Generation : $54 \%$

Hours of curtailment $=0$

$\%$ Curtailed energy $=0$

Max. up ramp $=1897 \mathrm{MW} / \mathrm{h}$ at 07:00

Max. down ramp $=-1346 \mathrm{MW} / \mathrm{h}$ at 10:00

Daily ramp range $=4918 \mathrm{MW} /$ day

Flexibility limit $=\{$ (Must-Run + Nuclear + Hydro $)-$ Storage $\}$

Flexibility limit $=\{(1555+5793+142)-2140\}=5350 \mathrm{MW} @ 13: 00$

** Penetration by energy is annual and pre-curtailment

** Flexibility Limit: Assumes nuclear gen. running constantly

at full capacity with no outages

** Storage has sufficient energy to utilize full pumping capacity

over hours of surplus solar power and optimized for energy arbitrage

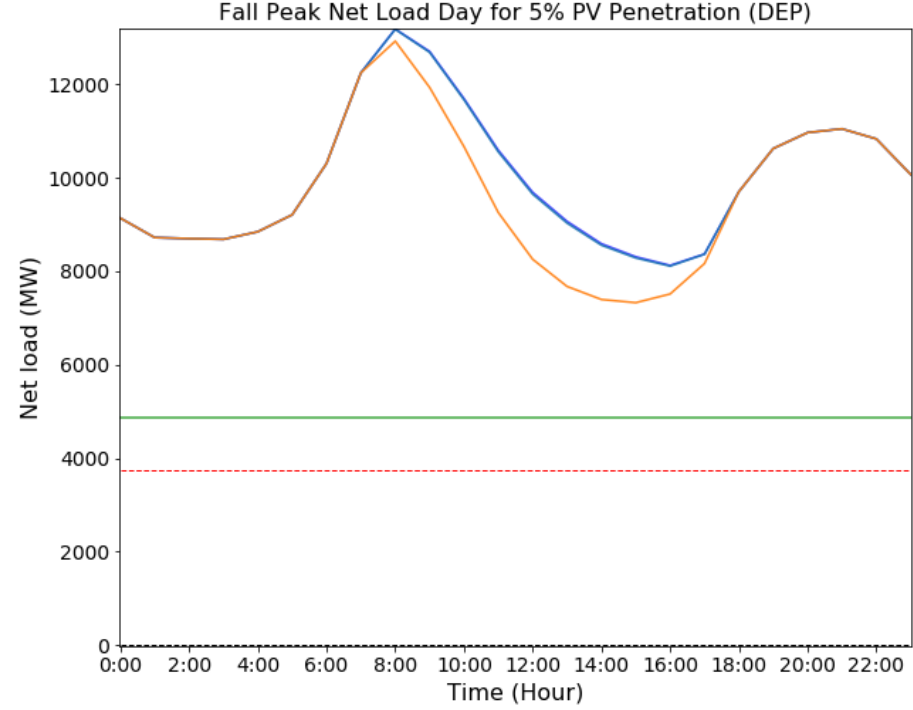

- Load

-.-.. Nuclear

- Load - Private PV

- Load - All PV

Flexibility Limit

** Net load analysis for DEP

Storage $=12 \mathrm{MW}$

Scenario 1: PV Penetration of $5 \%$ by annual energy

Solar PV capacity $=903 \mathrm{MW}$

Daily \% Zero CO2 Generation : $42 \%$

Hours of curtailment $=0$

Max. instantaneous curtailment $=0 \mathrm{MW}$

Max. up ramp $=1936 \mathrm{MW} / \mathrm{h}$ at 07:00

Max. down ramp $=-1410 \mathrm{MW} / \mathrm{h}$ at $11: 00$

Daily ramp range $=5588 \mathrm{MW} /$ day

Flexibility limit $=\{($ Must-Run + Nuclear + Hydro $)-$ Storage $\}$
Flexibility limit $=\{(1107+3735+50)-12\}=4880 \mathrm{MW} @ 13: 00$

** Penetration by energy is annual and pre-curtailment

** Flexibility Limit: Assumes nuclear gen. running constantly

at full capacity with no outages

* Storage has sufficient energy to utilize full pumping capacity

over hours of surplus solar power and optimized for energy arbitrage

Time (Hour)

This report is available at no cost from the National Renewable Energy Laboratory (NREL) at www.nrel.gov/publications. 


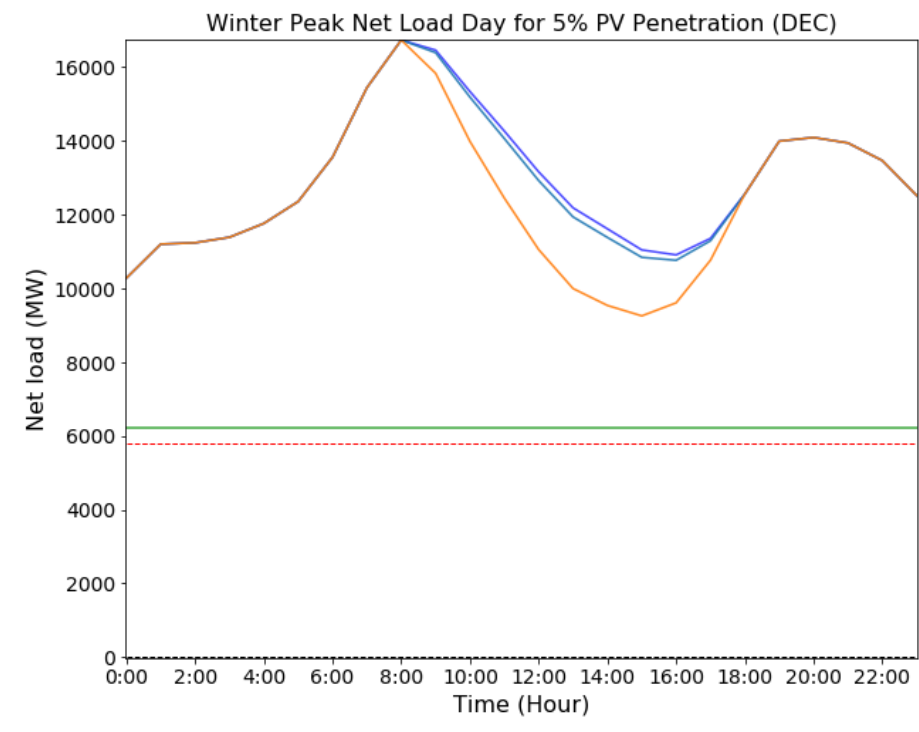

Load

Nuclear

- Load - Private PV

— Load - All PV

- Flexibility Limit

** Net load analysis for DEC

Storage $=2140 \mathrm{MW}$

Scenario 1: PV Penetration of $5 \%$ by annual energy

Solar PV capacity $=1,339 \mathrm{MW}$

Daily \% Zero CO2 Generation : $52 \%$

Hours of curtailment $=0$

$\%$ Curtailed energy $=0$

Max. up ramp $=1883 \mathrm{MW} / \mathrm{h}$ at 07:00

Max. down ramp $=-1848 \mathrm{MW} / \mathrm{h}$ at 10:00

Daily ramp range $=7475 \mathrm{MW} /$ day

Flexibility limit $=\{$ (Must-Run + Nuclear + Hydro $)-$ Storage $\}$

Flexibility limit $=\{(2261+5793+298)-2140\}=6212 \mathrm{MW} @ 13: 00$

** Penetration by energy is annual and pre-curtailment

** Flexibility Limit: Assumes nuclear gen. running constantly

at full capacity with no outages

** Storage has sufficient energy to utilize full pumping capacity

over hours of surplus solar power and optimized for energy arbitrage

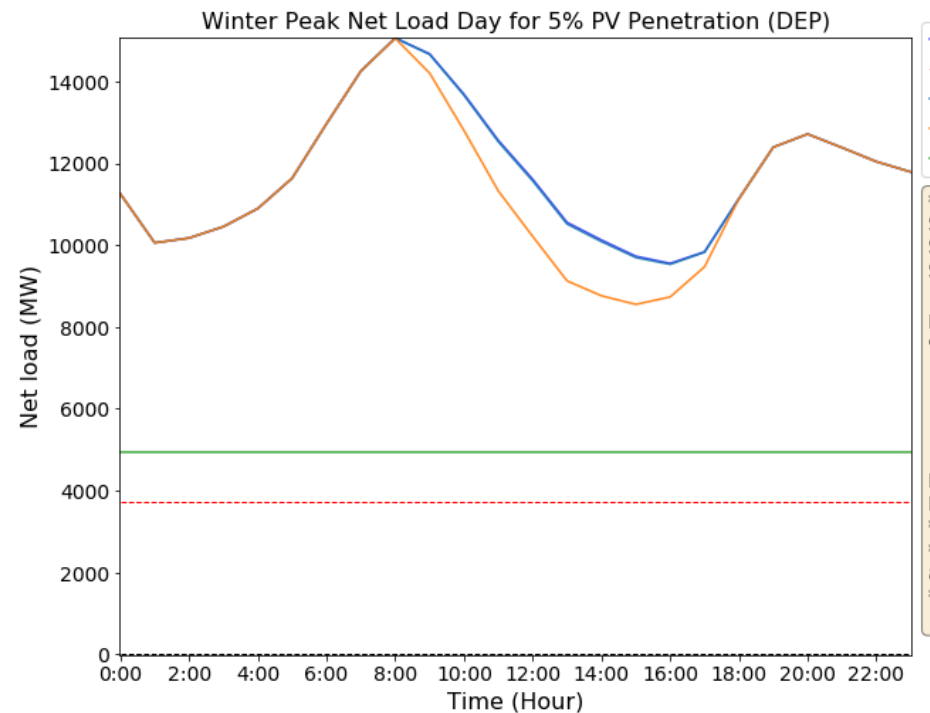

- Load

Nuclear

_ Load - Private PV

- Load - All PV

- Flexibility Limit

** Net load analysis for DEP

Storage $=12 \mathrm{MW}$

Scenario 1: PV Penetration of $5 \%$ by annual energy

Solar PV capacity $=903 \mathrm{MW}$

Daily \% Zero $\mathrm{CO} 2$ Generation : $36 \%$

Hours of curtailment $=0$

$\%$ Curtailed energy $=0$

Max. instantaneous curtailment $=0 \mathrm{MW}$

Max. up ramp $=1662 \mathrm{MW} / \mathrm{h}$ at $18: 00$

Max. down ramp $=-1480 \mathrm{MW} / \mathrm{h}$ at 11:00

Daily ramp range $=6501 \mathrm{MW} /$ day

Flexibility limit $=\{$ (Must-Run + Nuclear + Hydro $)-$ Storage $\}$

Flexibility limit $=\{(1107+3735+103)-12\}=4933 \mathrm{MW} @ 15: 00$

** Penetration by energy is annual and pre-curtailment

** Flexibility Limit: Assumes nuclear gen. running constantly

at full capacity with no outages

** Storage has sufficient energy to utilize full pumping capacity

over hours of surplus solar power and optimized for energy arbitrage

This report is available at no cost from the National Renewable Energy Laboratory (NREL) at www.nrel.gov/publications. 


\section{Seasonal Low Net Load Days: 10\% PV Penetration}

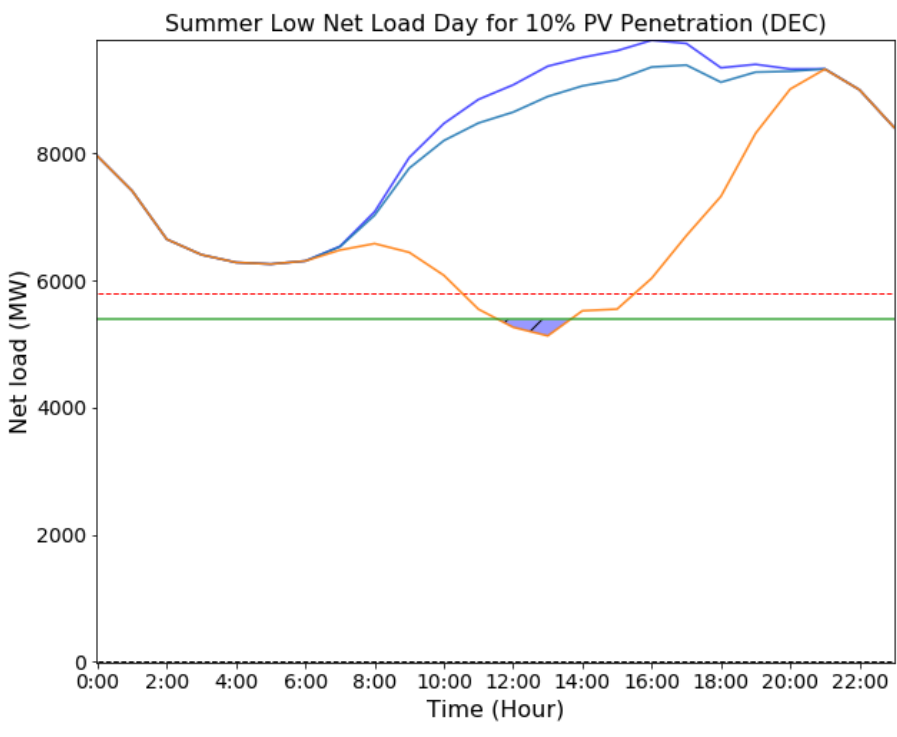

- Load

-.-.- Nuclear

— Load - Private PV

L Load - All PV

- Flexibility Limit

$\checkmark$ Curtailed PV energy

** Net load analysis for DEC

Storage $=2140 \mathrm{MW}$

Scenario 12: PV Penetration of $10 \%$ by annual energy

Solar PV capacity $=2,677 \mathrm{MW}$

Daily \% Zero CO2 Generation : $89 \%$

Hours of curtailment $=2$ hours

$\%$ Curtailed energy $=1.09 \%$

Max. instantaneous curtailment $=252 \mathrm{MW}$

Max. up ramp $=990 \mathrm{MW} / \mathrm{h}$ at 19:00

Max. down ramp $=-760 \mathrm{MW} / \mathrm{h}$ at $02: 00$

Daily ramp range $=3938 \mathrm{MW} /$ day

Flexibility limit $=\{($ Must-Run + Nuclear + Hydro $)-$ Storage $\}$

Flexibility limit $=\{(1555+5793+168)-2140\}=5376 \mathrm{MW} @ 13: 00$

** Penetration by energy is annual and pre-curtailment

** Flexibility Limit: Assumes nuclear gen. running constantly

at full capacity with no outages

** Storage has sufficient energy to utilize full pumping capacity

over hours of surplus solar power and optimized for energy arbitrage

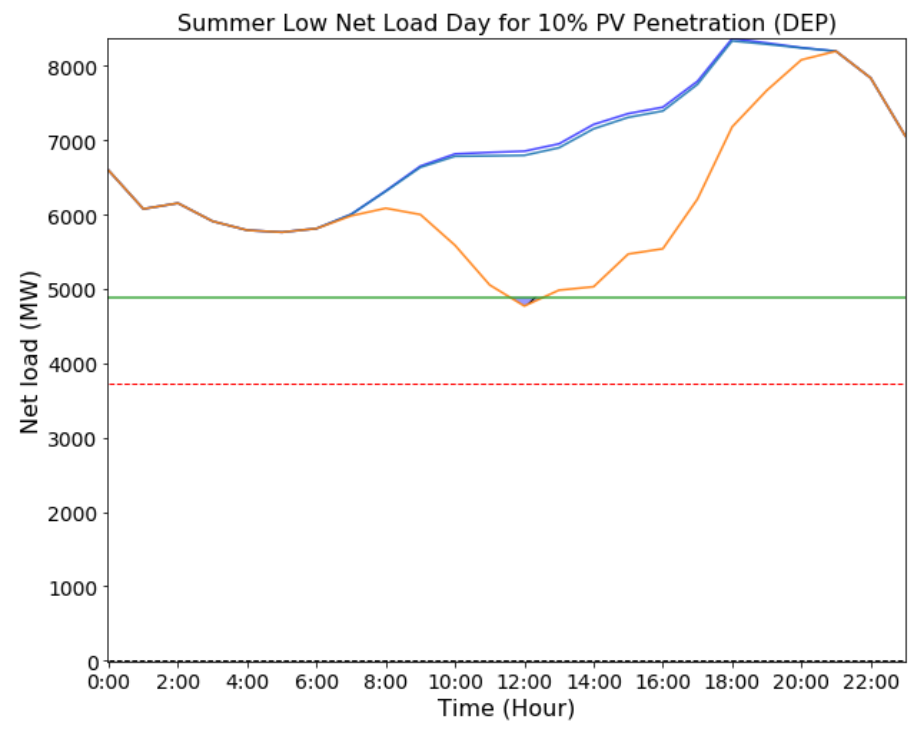

- Load

-..-. Nuclear

Load - Private PV

- Load - All PV

- Flexibility Limit

$\checkmark$ Curtailed PV energy

* Net load analysis for DEP

Storage $=12 \mathrm{MW}$

Scenario 12: PV Penetration of $10 \%$ by annual energy

Solar PV capacity $=1,805 \mathrm{MW}$

Daily \% Zero CO2 Generation : $65 \%$

Hours of curtailment $=1$ hours

$\%$ Curtailed energy $=0.67 \%$

Max. instantaneous curtailment $=117 \mathrm{MW}$

Max. up ramp $=970 \mathrm{MW} / \mathrm{h}$ at $18: 00$

Max. down ramp $=-779 \mathrm{MW} / \mathrm{h}$ at 23:00

Daily ramp range $=3309 \mathrm{MW} /$ day

Flexibility limit $=\{($ Must-Run + Nuclear + Hydro $)-$ Storage $\}$

Flexibility limit $=\{(1107+3735+59)-12\}=4889 \mathrm{MW} @ 13: 00$

** Penetration by energy is annual and pre-curtailment

** Flexibility Limit: Assumes nuclear gen. running constantly

at full capacity with no outages

* Storage has sufficient energy to utilize full pumping capacity

over hours of surplus solar power and optimized for energy arbitrage

This report is available at no cost from the National Renewable Energy Laboratory (NREL) at www.nrel.gov/publications. 


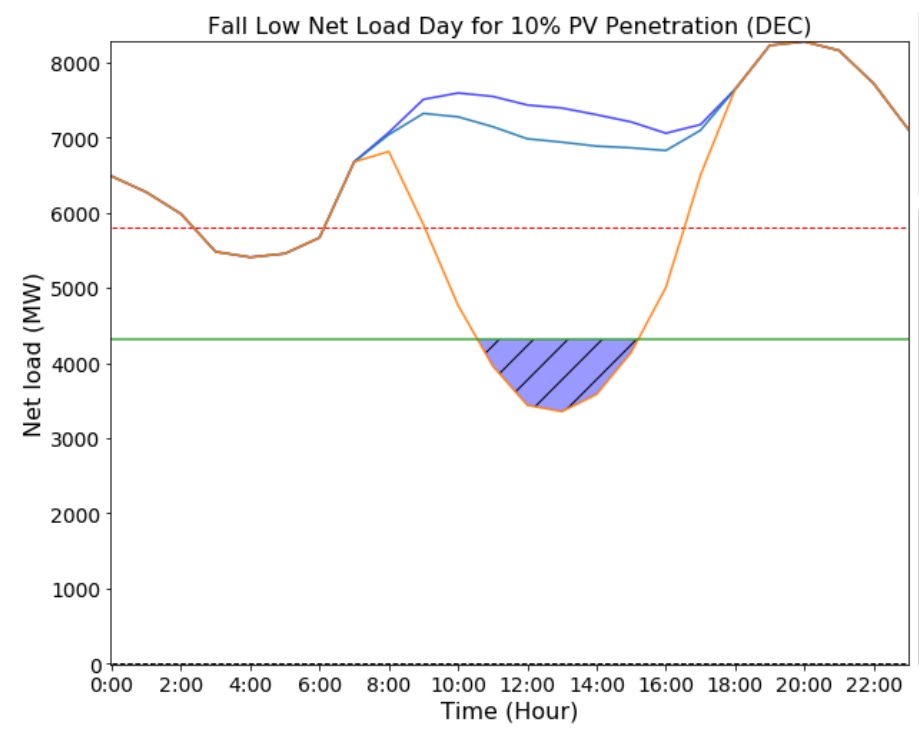

- Load

---.- Nuclear

- Load - Private PV

L Load - All PV

Flexibility Limit

$\checkmark$ Curtailed PV energy

** Net load analysis for DEC

Storage $=2140 \mathrm{MW}$

Scenario 12: PV Penetration of $10 \%$ by annual energy

Solar PV capacity $=2,677 \mathrm{MW}$

Daily \% Zero CO2 Generation : $102 \%$

Hours of curtailment $=5$ hours

$\%$ Curtailed energy $=11.99 \%$

Max. instantaneous curtailment $=961 \mathrm{MW}$

Max. up ramp $=1493 \mathrm{MW} / \mathrm{h}$ at 17:00

Max. down ramp $=-1072 \mathrm{MW} / \mathrm{h}$ at 10:00

Daily ramp range $=3958 \mathrm{MW} /$ day

Flexibility limit $=\{($ Must-Run + Nuclear + Hydro $)-$ Storage $\}$

Flexibility limit $=\{(520+5793+142)-2140\}=4315$ MW @ 13:00

** Penetration by energy is annual and pre-curtailment

** Flexibility Limit: Assumes nuclear gen. running constantly

at full capacity with no outages

** Storage has sufficient energy to utilize full pumping capacity

over hours of surplus solar power and optimized for energy arbitrage

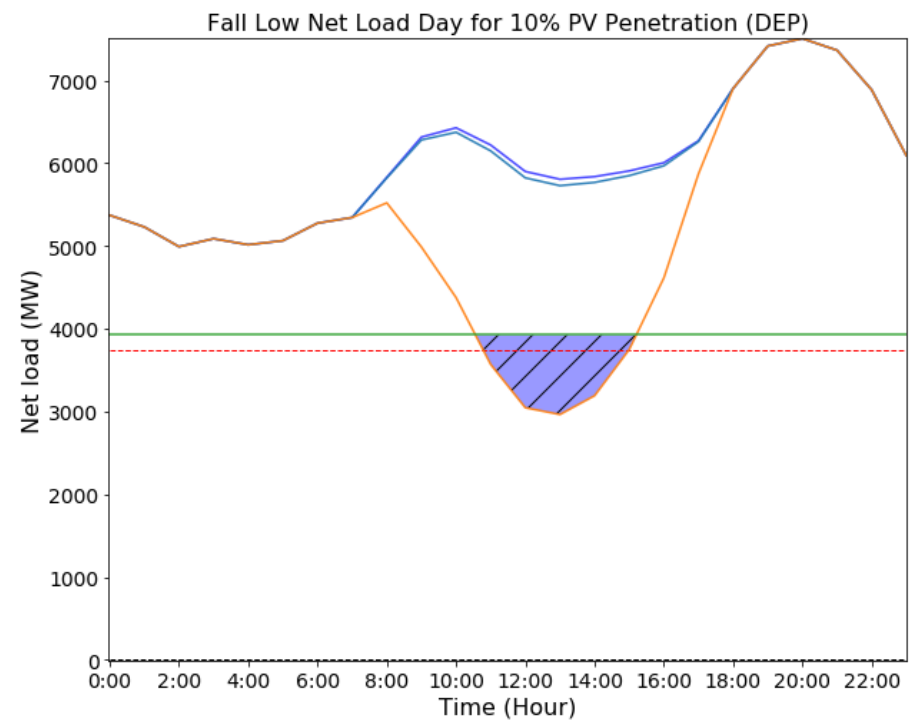

- Load

-.... Nuclear

Load - Private PV

L Load - All PV

- Flexibility Limit

$\checkmark$. Curtailed PV energy

** Net load analysis for DEP

Storage $=12 \mathrm{MW}$

Scenario 12: PV Penetration of $10 \%$ by annual energy

Solar PV capacity $=1,805 \mathrm{MW}$

Daily \% Zero $\mathrm{CO} 2$ Generation : $74 \%$

Hours of curtailment $=5$ hours

$\%$ Curtailed energy $=16.65 \%$

Max. instantaneous curtailment $=961 \mathrm{MW}$

Max. up ramp $=1258 \mathrm{MW} / \mathrm{h}$ at 18:00

Max. down ramp $=-794 \mathrm{MW} / \mathrm{h}$ at 11:00

Daily ramp range $=3582 \mathrm{MW} /$ day

Flexibility limit $=\{($ Must-Run + Nuclear + Hydro $)-$ Storage $\}$

Flexibility limit $=\{(151+3735+50)-12\}=3924 \mathrm{MW} @ 13: 00$

** Penetration by energy is annual and pre-curtailment

** Flexibility Limit: Assumes nuclear gen. running constantly

at full capacity with no outages

** Storage has sufficient energy to utilize full pumping capacity over hours of surplus solar power and optimized for energy arbitrage

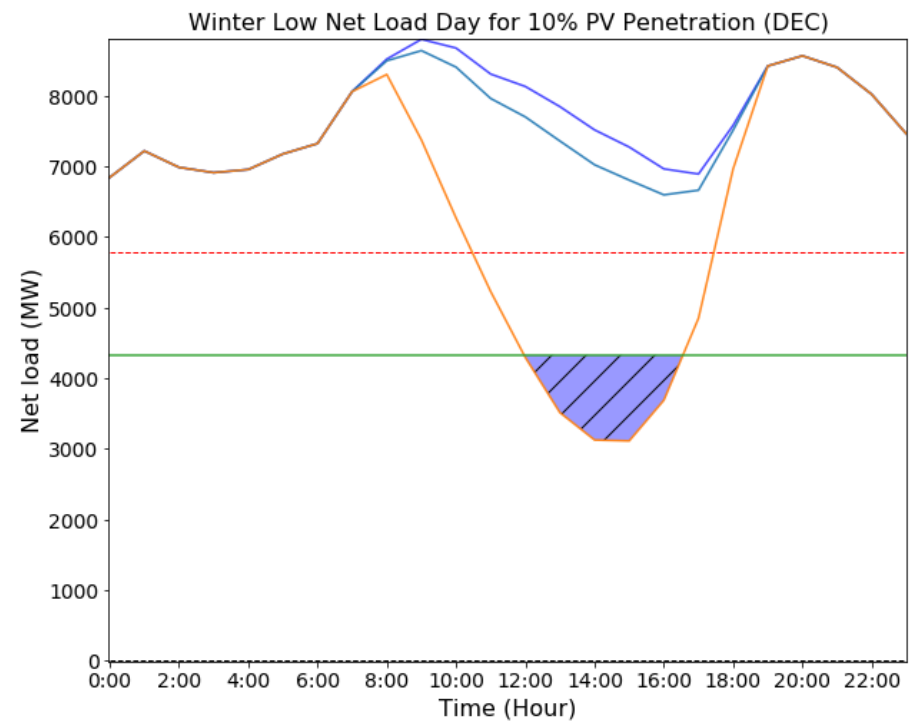

Load

Nuclear

- Load - Private PV

L Load - All PV

- Flexibility Limit

$\neg$ C Curtailed PV energy

\section{** Net load analysis for DEC}

Storage $=2140 \mathrm{MW}$

Scenario 12: PV Penetration of $10 \%$ by annual energy

Solar PV capacity $=2,677 \mathrm{MW}$

Daily \% Zero CO2 Generation : $94 \%$

Hours of curtailment $=5$ hours

$\%$ Curtailed energy $=13.11 \%$

Max. instantaneous curtailment $=1216 \mathrm{MW}$

Max. up ramp $=2114 \mathrm{MW} / \mathrm{h}$ at $18: 00$

Max. down ramp $=-1104 \mathrm{MW} / \mathrm{h}$ at 10:00

Daily ramp range $=4238 \mathrm{MW} /$ day

Flexibility limit $=\{$ (Must-Run + Nuclear + Hydro $)-$ Storage $\}$

Flexibility limit $=\{(520+5793+156)-2140\}=4329 \mathrm{MW} @ 14: 00$

** Penetration by energy is annual and pre-curtailment

** Flexibility Limit: Assumes nuclear gen. running constantly

at full capacity with no outages

** Storage has sufficient energy to utilize full pumping capacity

over hours of surplus solar power and optimized for energy arbitrage

Time (Hour) 


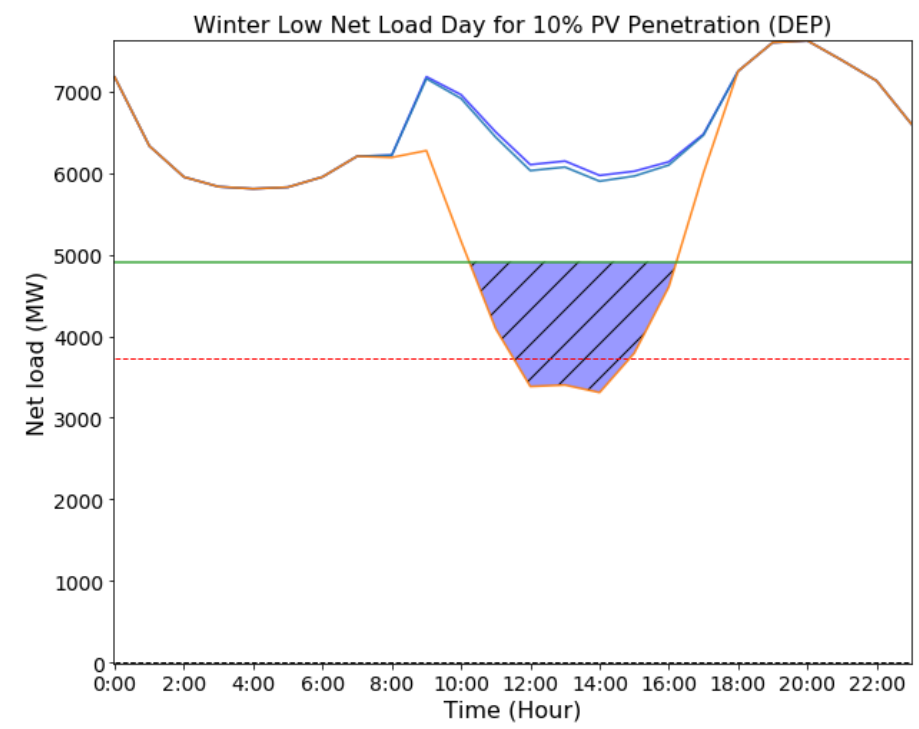

Load

-.-.- Nuclear

- Load - Private PV

L Load - All PV

Flexibility Limit

$\checkmark$ Curtailed PV energy

** Net load analysis for DEP

Storage $=12 \mathrm{MW}$

Scenario 12: PV Penetration of $10 \%$ by annual energy

Solar PV capacity $=1,805 \mathrm{MW}$

Daily \% Zero CO2 Generation : $66 \%$

Hours of curtailment $=6$ hours

$\%$ Curtailed energy $=39.34 \%$

Max. instantaneous curtailment $=1600 \mathrm{MW}$

Max. up ramp $=1245 \mathrm{MW} / \mathrm{h}$ at 18:00

Max. down ramp $=-1109 \mathrm{MW} / \mathrm{h}$ at 10:00

Daily ramp range $=2709 \mathrm{MW} /$ day

Flexibility limit $=\{$ (Must-Run + Nuclear + Hydro $)-$ Storage $\}$

Flexibility limit $=\{(1107+3735+81)-12\}=4911 \mathrm{MW} @ 13: 00$

** Penetration by energy is annual and pre-curtailment

** Flexibility Limit: Assumes nuclear gen. running constantly

at full capacity with no outages
** Storage has sufficient energy to utilize full pumping capacity

** Storage has sufficient energy to utilize full pumping capacity
over hours of surplus solar power and optimized for energy arbitrage

Time (Hour)

This report is available at no cost from the National Renewable Energy Laboratory (NREL) at www.nrel.gov/publications. 
Seasonal Peak Net Load Days: 10\% PV Penetration

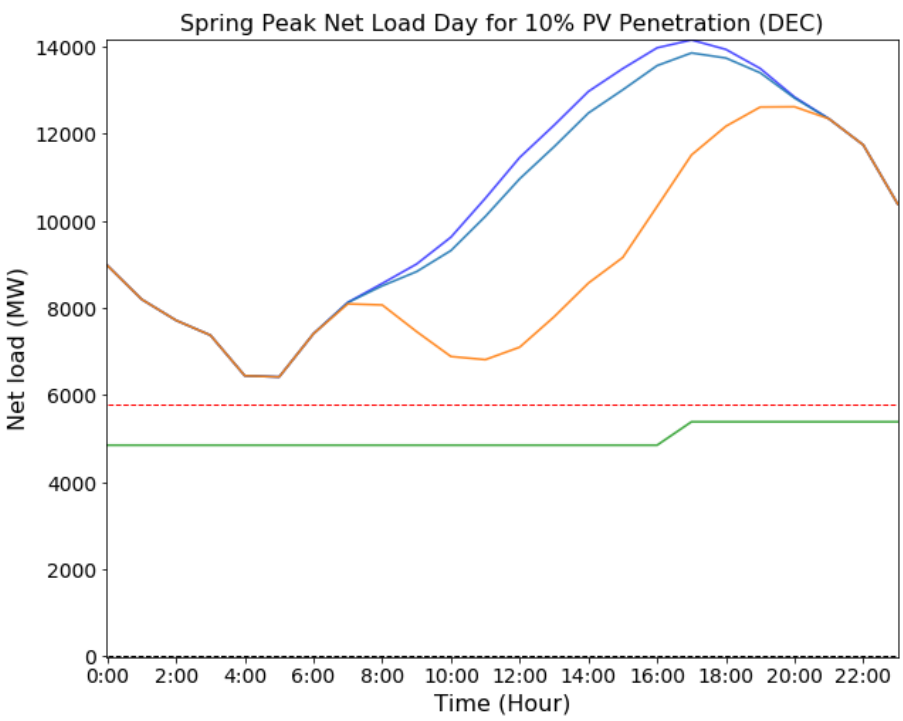

- Load

-.-... Nuclear

- Load - Private PV

L Load - All PV

- Flexibility Limit

** Net load analysis for DEC

Storage $=2140 \mathrm{MW}$

Scenario 2: PV Penetration of $10 \%$ by annual energy

Solar PV capacity $=2,677 \mathrm{MW}$

Daily \% Zero CO2 Generation : $73 \%$

Hours of curtailment $=0$

$\%$ Curtailed energy $=0$

Max. instantaneous curtailment $=0 \mathrm{MW}$

Max. up ramp $=1182 \mathrm{MW} / \mathrm{h}$ at 17:00

Max. down ramp $=-1355 \mathrm{MW} / \mathrm{h}$ at 23:00

Daily ramp range $=6205 \mathrm{MW} /$ day

Flexibility limit $=\{$ (Must-Run + Nuclear + Hydro $)-$ Storage $\}$

Flexibility limit $=\{(1018+5793+180)-2140\}=4851 \mathrm{MW} @ 13: 00$

** Penetration by energy is annual and pre-curtailment

** Flexibility Limit: Assumes nuclear gen. running constantly

at full capacity with no outages

Storage has sufficient energy to utilize full pumping capacity over hours of surplus solar power and optimized for energy arbitrage

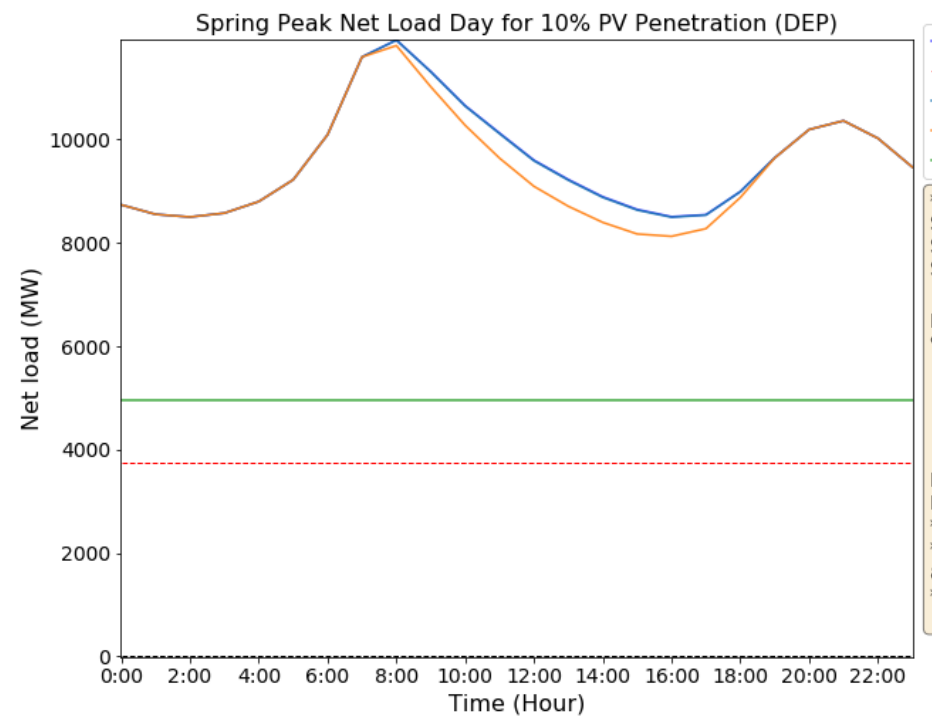

- Load

Nuclear

- Load - Private PV

Load - All PV

- Flexibility Limit

** Net load analysis for DEP

Storage $=12 \mathrm{MW}$

Scenario 2: PV Penetration of $10 \%$ by annual energy

Solar PV capacity $=1,805 \mathrm{MW}$

Daily \% Zero $\mathrm{CO} 2$ Generation : $42 \%$

Hours of curtailment $=0$

$\%$ Curtailed energy $=0$

Max. instantaneous curtailment $=0 \mathrm{MW}$

Max. up ramp $=1502 \mathrm{MW} / \mathrm{h}$ at 07:00

Max. down ramp $=-798 \mathrm{MW} / \mathrm{h}$ at 09:00

Daily ramp range $=3687 \mathrm{MW} /$ day

Flexibility limit $=\{($ Must-Run + Nuclear + Hydro $)-$ Storage $\}$

Flexibility limit $=\{(1107+3735+120)-12\}=4950 \mathrm{MW} @ 13: 00$

** Penetration by energy is annual and pre-curtailment

** Flexibility Limit: Assumes nuclear gen. running constantly

at full capacity with no outages

** Storage has sufficient energy to utilize full pumping capacity

over hours of surplus solar power and optimized for energy arbitrage

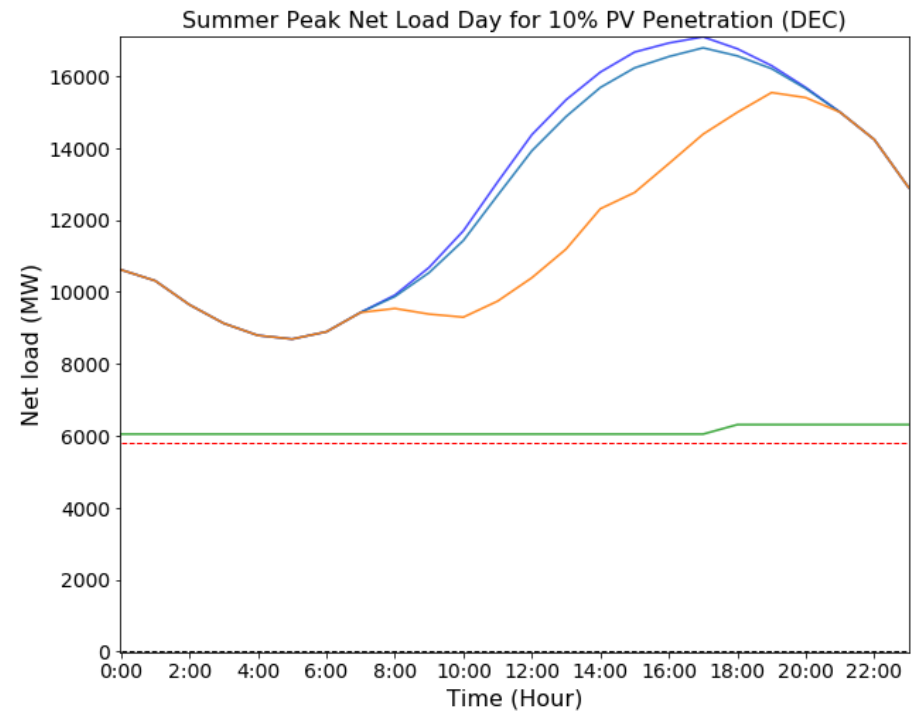

- Load

Nuclear

- Load - Private PV

- Load - All PV

- Flexibility Limit

** Net load analysis for DEC

Storage $=2140 \mathrm{MW}$

Scenario 2: PV Penetration of $10 \%$ by annual energy

Solar PV capacity $=2,677 \mathrm{MW}$

Daily \% Zero CO2 Generation : $58 \%$

Hours of curtailment $=0$

$\%$ Curtailed energy $=0$

Max. instantaneous curtailment $=0 \mathrm{MW}$

Max. up ramp $=1118 \mathrm{MW} / \mathrm{h}$ at $14: 00$

Max. down ramp $=-1331 \mathrm{MW} / \mathrm{h}$ at 23:00

Daily ramp range $=6852 \mathrm{MW} /$ day

Flexibility limit $=\{($ Must-Run + Nuclear + Hydro $)-$ Storage $\}$

Flexibility limit $=\{(2261+5793+130)-2140\}=6044 \mathrm{MW} @ 13: 00$

** Penetration by energy is annual and pre-curtailment

** Flexibility Limit: Assumes nuclear gen. running constantly

at full capacity with no outages

** Storage has sufficient energy to utilize full pumping capacity over hours of surplus solar power and optimized for energy arbitrage

This report is available at no cost from the National Renewable Energy Laboratory (NREL) at www.nrel.gov/publications. 


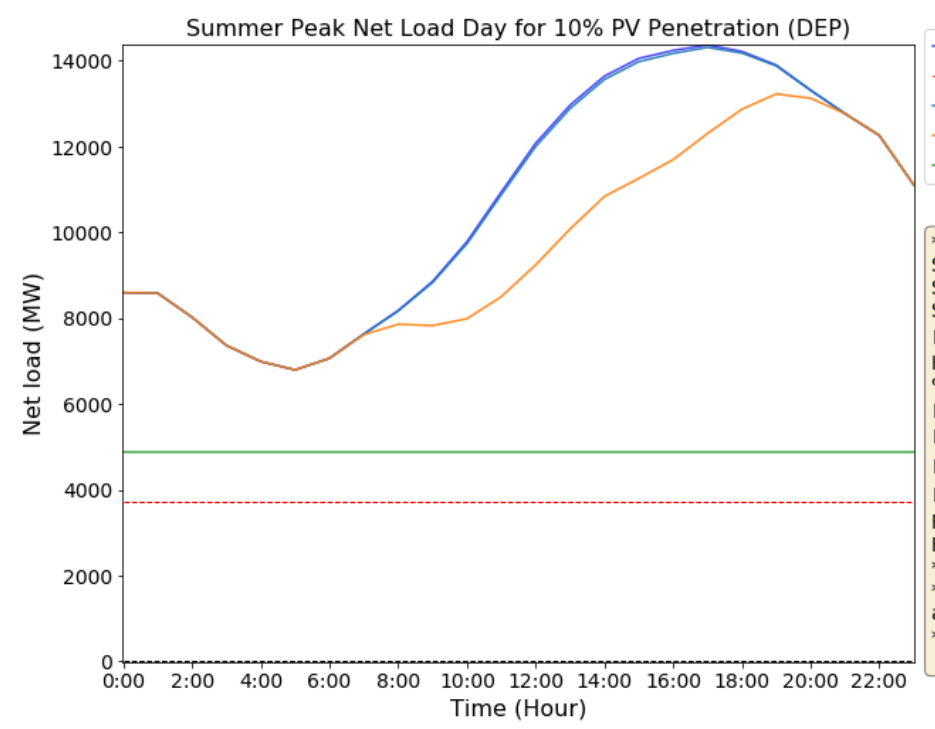

- Load

-... Nuclear

- Load - Private PV

L Load - All PV

- Flexibility Limit

** Net load analysis for DEP

Storage $=12 \mathrm{MW}$

Scenario 2: PV Penetration of $10 \%$ by annual energy

Solar PV capacity $=1,805 \mathrm{MW}$

Daily \% Zero $\mathrm{CO} 2$ Generation : $45 \%$

Hours of curtailment $=0$

$\%$ Curtailed energy $=0$

Max. instantaneous curtailment $=0 \mathrm{MW}$

Max. up ramp $=833 \mathrm{MW} / \mathrm{h}$ at 13:00

Max. down ramp $=-1151 \mathrm{MW} / \mathrm{h}$ at 23:00

Daily ramp range $=6432 \mathrm{MW} /$ day

Flexibility limit $=\{($ Must-Run + Nuclear + Hydro $)-$ Storage $\}$

Flexibility limit $=\{(1107+3735+43)-12\}=4873 \mathrm{MW} @ 13: 00$

** Penetration by energy is annual and pre-curtailment

** Flexibility Limit: Assumes nuclear gen. running constantly

at full capacity with no outages

** Storage has sufficient energy to utilize full pumping capacity

over hours of surplus solar power and optimized for energy arbitrage

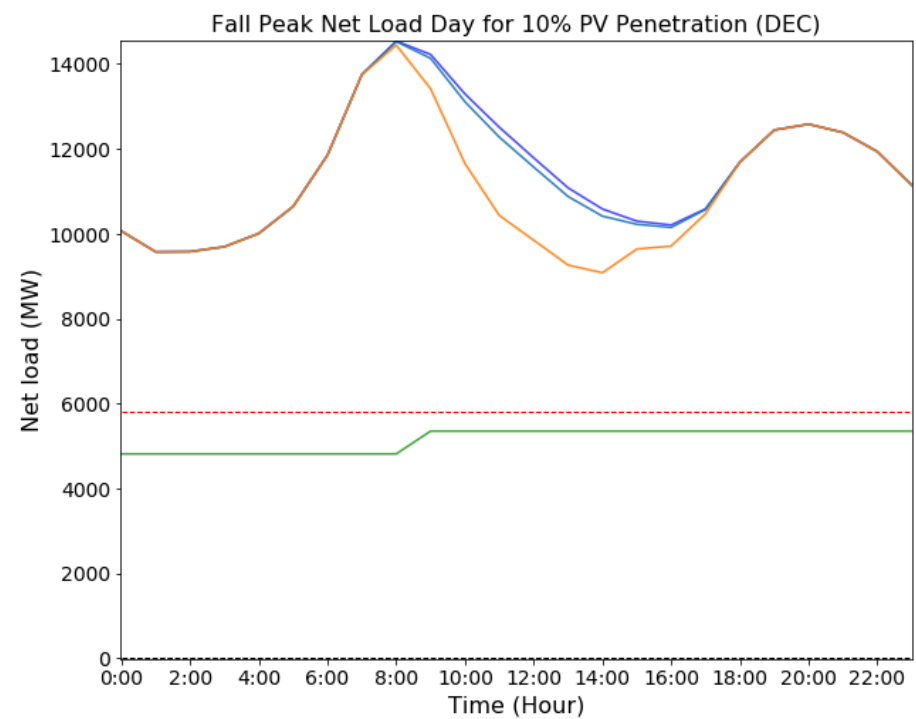

- Load

-.--.. Nuclear

— Load - Private PV

Load - All PV

- Flexibility Limit

* Net load analysis for DEC

Storage $=2140 \mathrm{MW}$

Scenario 2: PV Penetration of $10 \%$ by annual energy

Solar PV capacity $=2,677 \mathrm{MW}$

Daily \% Zero CO2 Generation : $56 \%$

Hours of curtailment $=0$

$\%$ Curtailed energy $=0$

Max. instantaneous curtailment $=0 \mathrm{MW}$

Max. up ramp $=1897 \mathrm{MW} / \mathrm{h}$ at 07:00

Max. down ramp $=-1763 \mathrm{MW} / \mathrm{h}$ at 10:00

Daily ramp range $=5362 \mathrm{MW} /$ day

Flexibility limit $=\{($ Must-Run + Nuclear + Hydro $)-$ Storage $\}$

Flexibility limit $=\{(1555+5793+142)-2140\}=5350 \mathrm{MW} @ 13: 00$

** Penetration by energy is annual and pre-curtailment

** Flexibility Limit: Assumes nuclear gen. running constantly

at full capacity with no outages

** Storage has sufficient energy to utilize full pumping capacity

over hours of surplus solar power and optimized for energy arbitrage

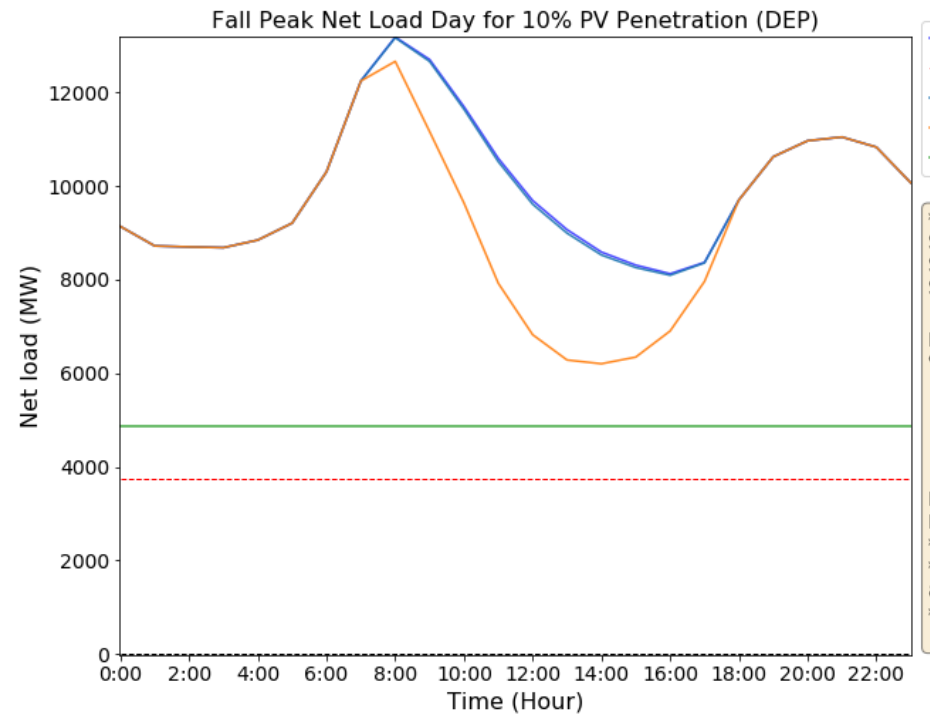

L Load

Nuclear

- Load - Private PV

- Load - All PV

- Flexibility Limit

* Net load analysis for DEP

Storage $=12 \mathrm{MW}$

Scenario 2: PV Penetration of $10 \%$ by annual energy

Solar PV capacity $=1,805 \mathrm{MW}$

Daily \% Zero CO2 Generation : $46 \%$

Hours of curtailment $=0$

$\%$ Curtailed energy $=0$

Max. instantaneous curtailment $=0 \mathrm{MW}$

Max. up ramp $=1936 \mathrm{MW} / \mathrm{h}$ at 07:00

Max. down ramp $=-1714 \mathrm{MW} / \mathrm{h}$ at $11: 00$

Daily ramp range $=6451 \mathrm{MW} /$ day

Flexibility limit $=\{($ Must-Run + Nuclear + Hydro $)-$ Storage $\}$

Flexibility limit $=\{(1107+3735+50)-12\}=4880 \mathrm{MW} @ 13: 00$

** Penetration by energy is annual and pre-curtailment

** Flexibility Limit: Assumes nuclear gen. running constantly

at full capacity with no outages

* Storage has sufficient energy to utilize full pumping capacity

over hours of surplus solar power and optimized for energy arbitrage

This report is available at no cost from the National Renewable Energy Laboratory (NREL) at www.nrel.gov/publications. 


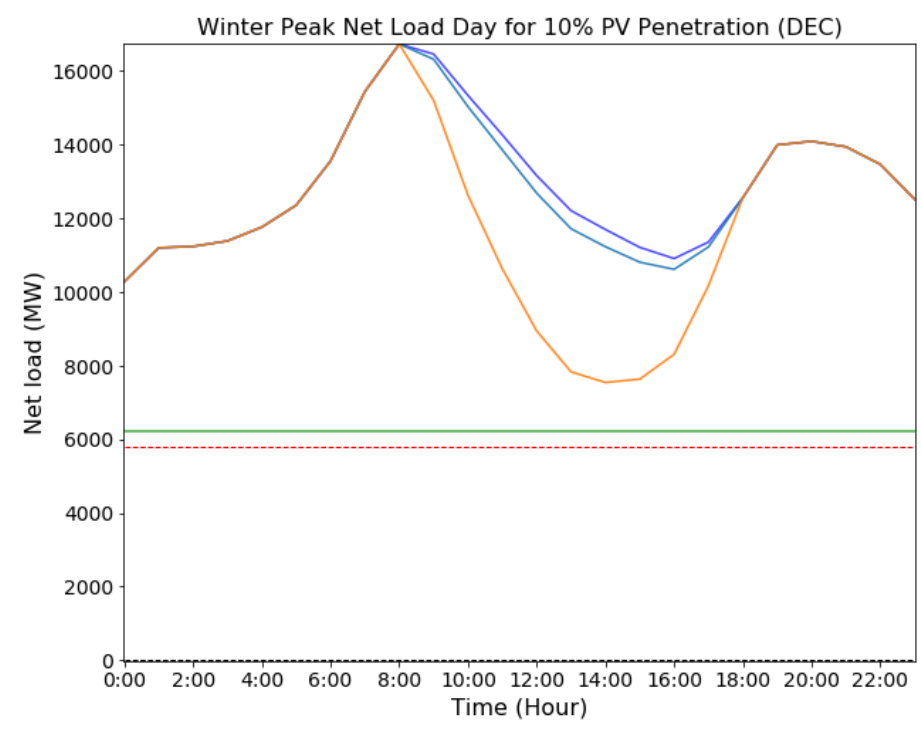

- Load

Nuclear

_ Load - Private PV

- Load - All PV

_ Flexibility Limit

** Net load analysis for DEC

Storage $=2140 \mathrm{MW}$

Scenario 2: PV Penetration of $10 \%$ by annual energy

Solar PV capacity $=2,677 \mathrm{MW}$

Daily \% Zero CO2 Generation : $57 \%$

Hours of curtailment $=0$

Max. instantaneous curtailment $=0 \mathrm{MW}$

Max. up ramp $=2384 \mathrm{MW} / \mathrm{h}$ at 18:00

Max. down ramp $=-2573 \mathrm{MW} / \mathrm{h}$ at 10:00

Daily ramp range $=9185 \mathrm{MW} /$ day

Flexibility limit $=\{($ Must-Run + Nuclear + Hydro $)-$ Storage $\}$
Flexibility limit $=\{(2261+5793+298)-2140\}=6212 \mathrm{MW} @ 13: 00$

** Penetration by energy is annual and pre-curtailment

** Flexibility Limit: Assumes nuclear gen. running constantly

at full capacity with no outages

* Storage has sufficient energy to utilize full pumping capacity

over hours of surplus solar power and optimized for energy arbitrage

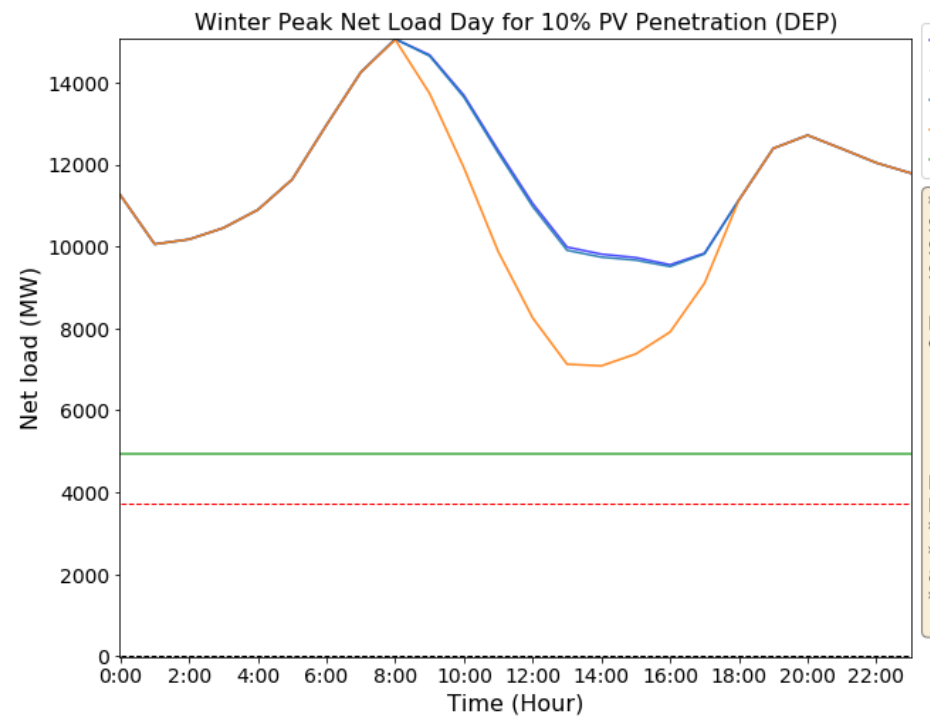

L Load

-.-.- Nuclear

— Load - Private PV

Load - All PV

- Flexibility Limit

** Net load analysis for DEP

Storage $=12 \mathrm{MW}$

Scenario 2: PV Penetration of $10 \%$ by annual energy

Solar PV capacity $=1,805 \mathrm{MW}$

Daily \% Zero CO2 Generation : $40 \%$

Hours of curtailment $=0$

$\%$ Curtailed energy $=0$

Max. instantaneous curtailment $=0 \mathrm{MW}$

Max. up ramp $=2027 \mathrm{MW} / \mathrm{h}$ at $18: 00$

Max. down ramp $=-2049 \mathrm{MW} / \mathrm{h}$ at 11:00

Daily ramp range $=7959 \mathrm{MW} /$ day

Flexibility limit $=\{$ (Must-Run + Nuclear + Hydro $)-$ Storage $\}$

Flexibility limit $=\{(1107+3735+103)-12\}=4933 \mathrm{MW} @ 13: 00$

** Penetration by energy is annual and pre-curtailment

** Flexibility Limit: Assumes nuclear gen. running constantly

at full capacity with no outages

** Storage has sufficient energy to utilize full pumping capacity

over hours of surplus solar power and optimized for energy arbitrage

This report is available at no cost from the National Renewable Energy Laboratory (NREL) at www.nrel.gov/publications. 
Seasonal Low Net Load Days: 15\% PV Penetration

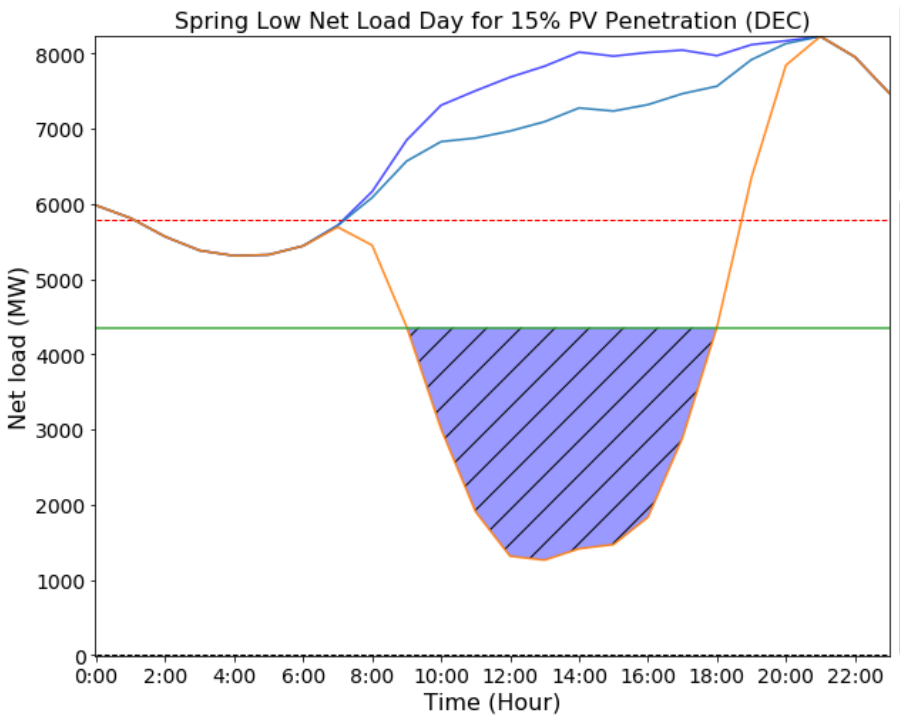

L Load

-.-.-. Nuclear

- Load - Private PV

- Load - All PV

Flexibility Limit

$\checkmark$ Curtailed PV energy

** Net load analysis for DEC

Storage $=2140 \mathrm{MW}$

Scenario 12: PV Penetration of $15 \%$ by annual energy

Solar PV capacity $=4,016 \mathrm{MW}$

Daily \% Zero CO2 Generation : $120 \%$

Hours of curtailment $=8$ hours

$\%$ Curtailed energy $=35.11 \%$

Max. instantaneous curtailment $=3089 \mathrm{MW}$

Max. up ramp $=1988 \mathrm{MW} / \mathrm{h}$ at 19:00

Max. down ramp $=-1330 \mathrm{MW} / \mathrm{h}$ at $00: 00$

Daily ramp range $=3872 \mathrm{MW} /$ day

Flexibility limit $=\{$ (Must-Run + Nuclear + Hydro $)-$ Storage $\}$

Flexibility limit $=\{(\{(520+5793+235)-2140\}=4408 \mathrm{MW} @ 13: 00$

** Penetration by energy is annual and pre-curtailment

** Flexibility Limit: Assumes nuclear gen. running constantly

at full capacity with no outages

** Storage has sufficient energy to utilize full pumping capacity over hours of surplus solar power and optimized for energy arbitrage

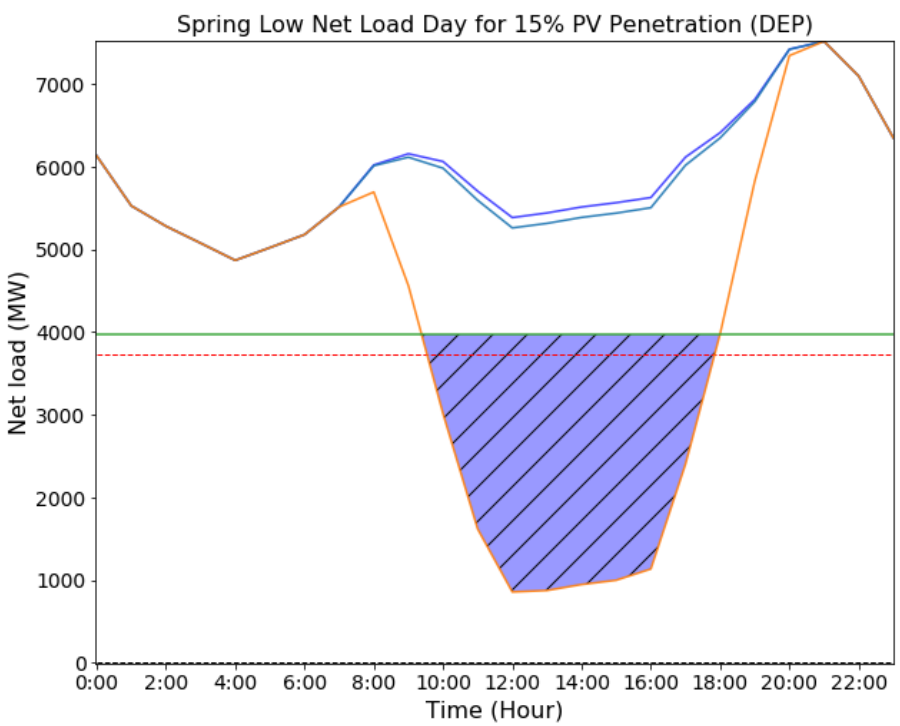

Load

-... Nuclear

- Load - Private PV

L Load - All PV

- Flexibility Limit

$\triangle$ Curtailed PV energy

** Net load analysis for DEP

Storage $=12 \mathrm{MW}$

Scenario 12: PV Penetration of $15 \%$ by annual energy

Solar PV capacity $=2,708 \mathrm{MW}$

Daily \% Zero CO2 Generation : $79 \%$

Hours of curtailment $=8$ hour

$\%$ Curtailed energy $=51.12 \%$

Max. instantaneous curtailment $=3116 \mathrm{MW}$

Max. up ramp $=1847 \mathrm{MW} / \mathrm{h}$ at 19:00

Max. down ramp $=-1133 \mathrm{MW} / \mathrm{h}$ at 09:00

Daily ramp range $=3545 \mathrm{MW} /$ day

Flexibility limit $=\{($ Must-Run + Nuclear + Hydro $)-$ Storage $\}$

Flexibility limit $=\{(151+3735+98)-12\}=3972 \mathrm{MW} @ 13: 00$

** Penetration by energy is annual and pre-curtailment

* Flexibility Limit: Assumes nuclear gen. running constantly

at full capacity with no outages

** Storage has sufficient energy to utilize full pumping capacity

over hours of surplus solar power and optimized for energy arbitrage Time (Hour)

This report is available at no cost from the National Renewable Energy Laboratory (NREL) at www.nrel.gov/publications. 


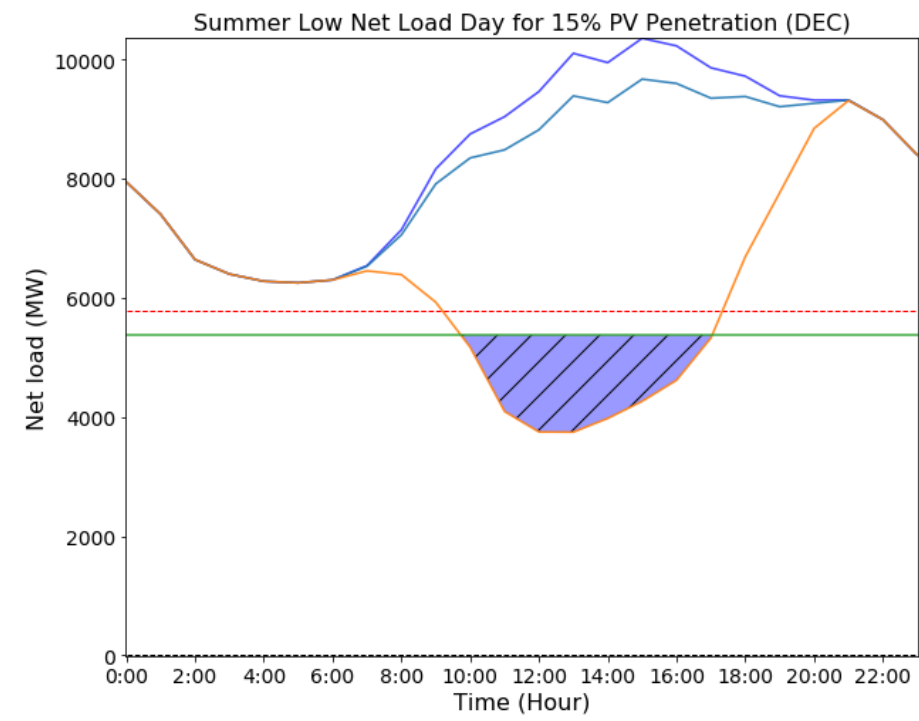

- Load

Nuclear

- Load - Private PV

L Load - All PV

Flexibility Limit

$\triangle$ Curtailed PV energy

** Net load analysis for DEC

Storage $=2140 \mathrm{MW}$

Scenario 12: PV Penetration of $15 \%$ by annual energy

Solar PV capacity $=4,016 \mathrm{MW}$

Daily \% Zero $\mathrm{CO} 2$ Generation : $117 \%$

Hours of curtailment $=8$ hours

$\%$ Curtailed energy $=15.81 \%$

Max. instantaneous curtailment $=1630 \mathrm{MW}$

Max. up ramp $=1314 \mathrm{MW} / \mathrm{h}$ at 18:00

Max. down ramp $=-760 \mathrm{MW} / \mathrm{h}$ at 02:00

Daily ramp range $=3935 \mathrm{MW} /$ day

Flexibility limit $=\{$ (Must-Run + Nuclear + Hydro $)-$ Storage $\}$

Flexibility limit $=\{(1555+5793+168)-2140\}=5376 \mathrm{MW} @ 13: 00$ ** Penetration by energy is annual and pre-curtailment

** Flexibility Limit: Assumes nuclear gen. running constantly

at full capacity with no outages

** Storage has sufficient energy to utilize full pumping capacity over hours of surplus solar power and optimized for energy arbitrage

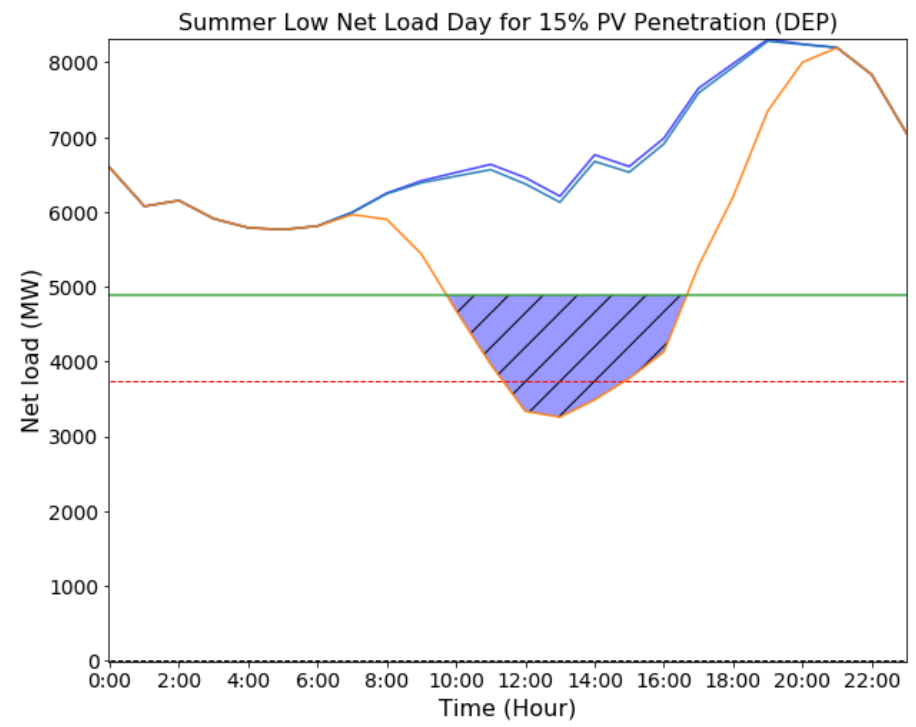

- Load

Nuclear

- Load - Private PV

Load - All PV

Flexibility Limit

$r>$ Curtailed PV energy

** Net load analysis for DEP

Storage $=12 \mathrm{MW}$

Scenario 12: PV Penetration of $15 \%$ by annual energy

Solar PV capacity $=2,708 \mathrm{MW}$

Daily \% Zero $\mathrm{CO} 2$ Generation : $68 \%$

Hours of curtailment $=7$ hour

$\%$ Curtailed energy $=28.87 \%$

Max. instantaneous curtailment $=1630 \mathrm{MW}$

Max. up ramp $=1148 \mathrm{MW} / \mathrm{h}$ at 19:00

Max. down ramp $=-779 \mathrm{MW} / \mathrm{h}$ at 23:00

Daily ramp range $=3309 \mathrm{MW} /$ day

Flexibility limit $=\{$ (Must-Run + Nuclear + Hydro $)-$ Storage $\}$

Flexibility limit $=\{(1107+3735+59)-12\}=4889 \mathrm{MW} @ 13: 00$

** Penetration by energy is annual and pre-curtailment

** Flexibility Limit: Assumes nuclear gen. running constantly

at full capacity with no outages

** Storage has sufficient energy to utilize full pumping capacity

over hours of surplus solar power and optimized for energy arbitrage

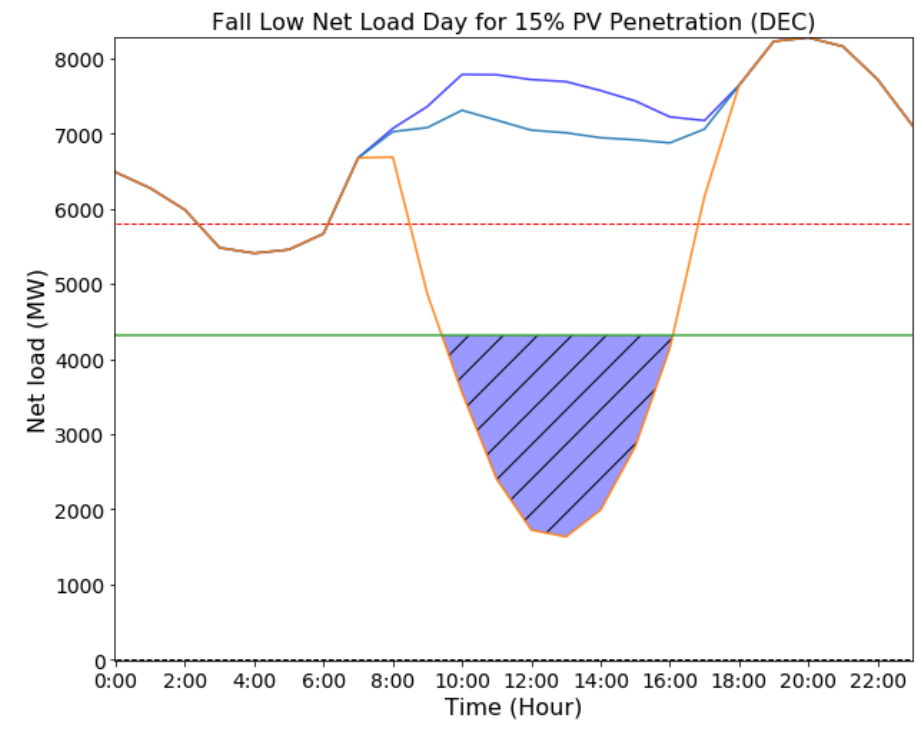

- Load

Nuclear

- Load - Private PV

- Load - All PV

- Flexibility Limit

C Curtailed PV energy

** Net load analysis for DEC

\section{Storage $=2140 \mathrm{MW}$}

Scenario 12: PV Penetration of $15 \%$ by annual energy

Solar PV capacity $=4,016 \mathrm{MW}$

Daily \% Zero CO2 Generation : $126 \%$

Hours of curtailment $=7$ hours

$\%$ Curtailed energy $=30.74 \%$

Max. instantaneous curtailment $=2680 \mathrm{MW}$

Max. up ramp $=1846 \mathrm{MW} / \mathrm{h}$ at 17:00

Max. down ramp $=-1824 \mathrm{MW} / \mathrm{h}$ at 09:00

Daily ramp range $=3958 \mathrm{MW} /$ day

Flexibility limit $=\{$ (Must-Run + Nuclear + Hydro $)-$ Storage $\}$

Flexibility limit $=\{(520+5793+142)-2140\}=4315 \mathrm{MW} @ 13: 00$

** Penetration by energy is annual and pre-curtailment

** Flexibility Limit: Assumes nuclear gen. running constantly

at full capacity with no outages

** Storage has sufficient energy to utilize full pumping capacity over hours of surplus solar power and optimized for energy arbitrage 

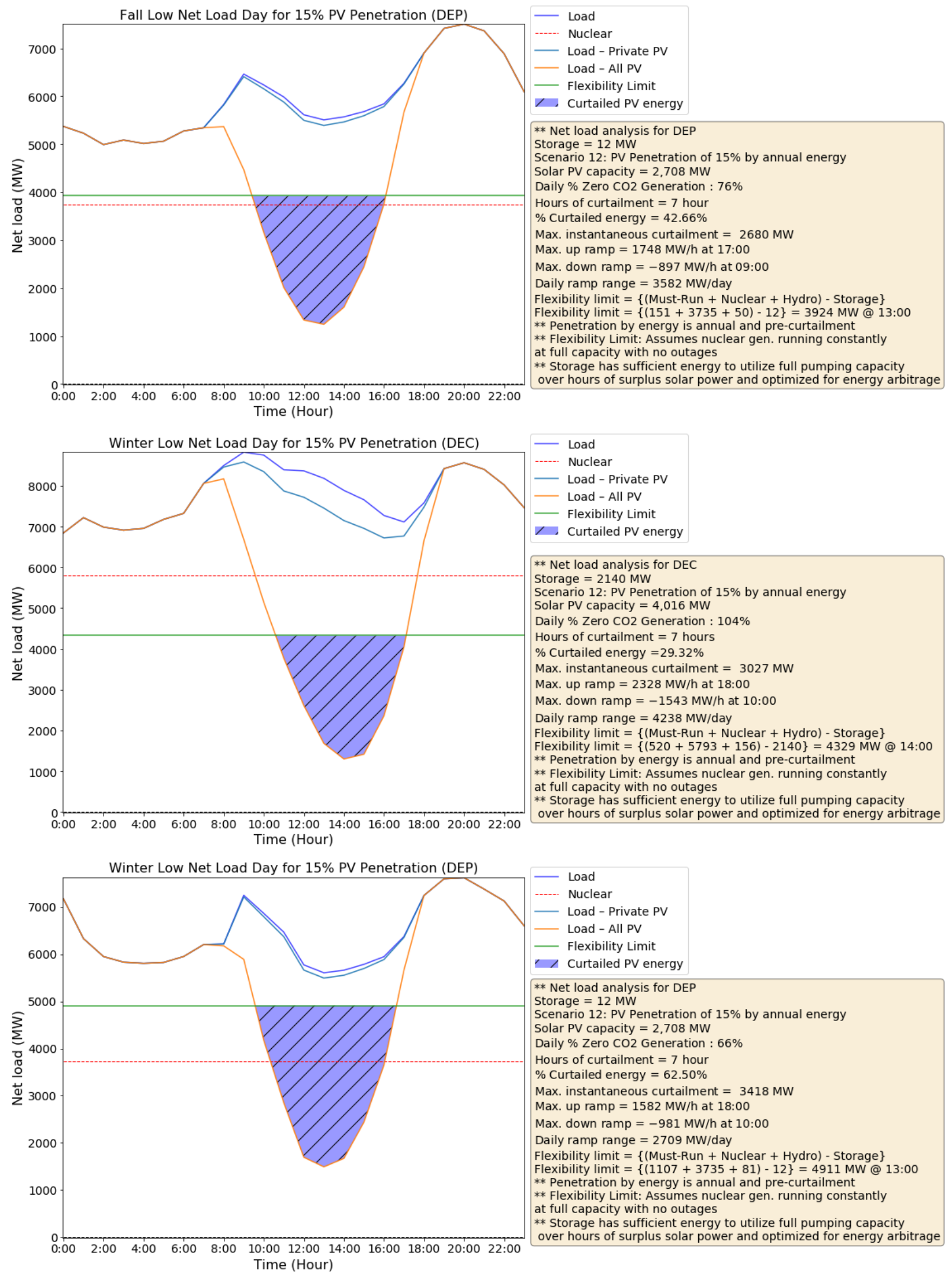

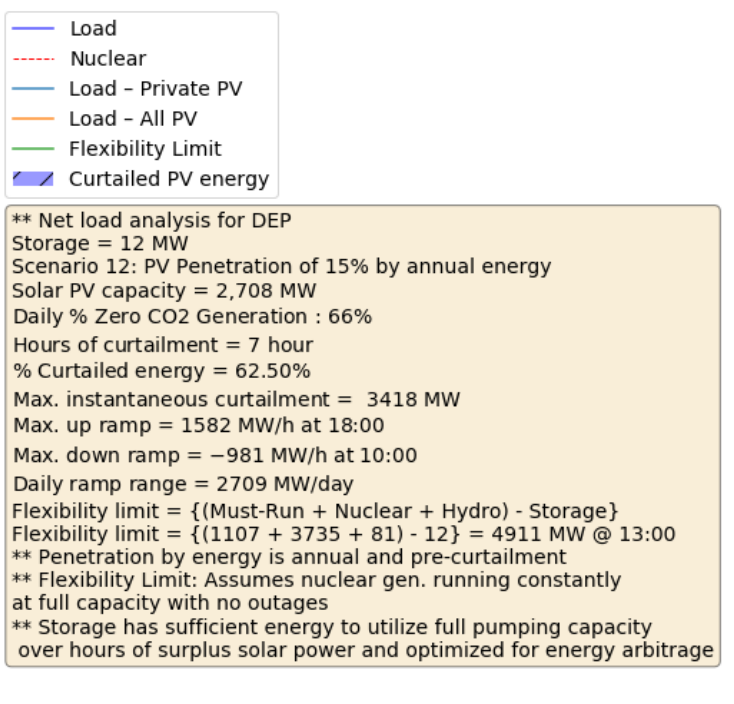


Seasonal Peak Net Load Days: 15\% PV Penetration

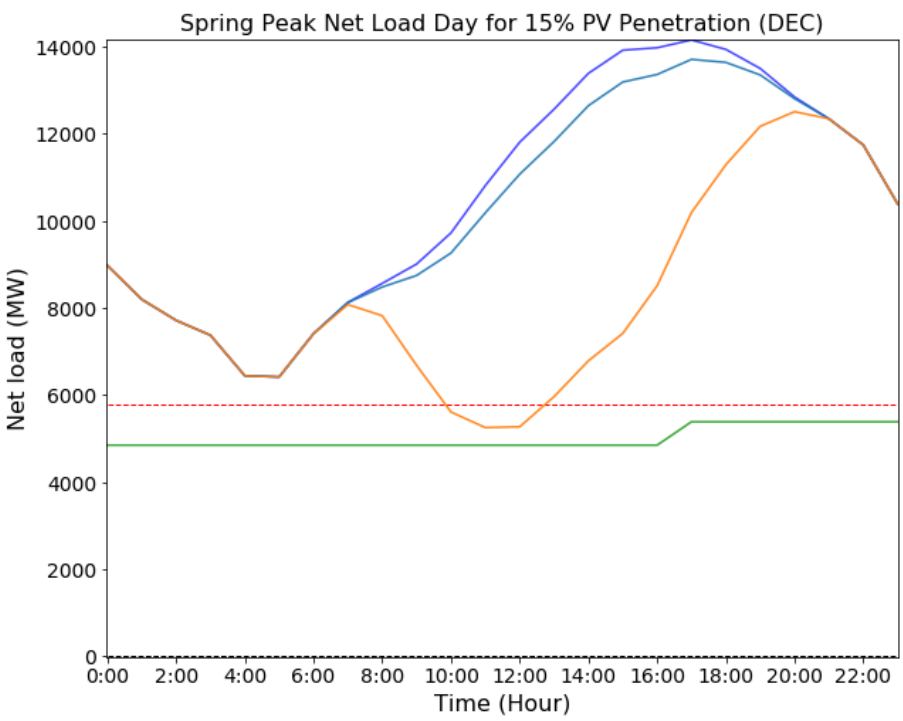

- Load

-..-. Nuclear

- Load - Private PV

Load - All PV

- Flexibility Limit

** Net load analysis for DEC

Storage $=2140 \mathrm{MW}$

Scenario 2: PV Penetration of $15 \%$ by annual energy

Solar PV capacity $=4,016 \mathrm{MW}$

Daily \% Zero $\mathrm{CO} 2$ Generation : $90 \%$

Hours of curtailment $=0 \%$

$\%$ Curtailed energy $=0.00 \%$

Max. instantaneous curtailment $=0 \mathrm{MW}$

Max. up ramp $=1683 \mathrm{MW} / \mathrm{h}$ at $17: 00$

Max. down ramp $=-1355 \mathrm{MW} / \mathrm{h}$ at 23:00

Daily ramp range $=7660 \mathrm{MW} /$ day

Flexibility limit $=\{$ (Must-Run + Nuclear + Hydro $)-$ Storage $\}$

Flexibility limit $=\{(1018+5793+180)-2140\}=4851 \mathrm{MW} @ 13: 00$

** Penetration by energy is annual and pre-curtailment

** Flexibility Limit: Assumes nuclear gen. running constantly

at full capacity with no outages

** Storage has sufficient energy to utilize full pumping capacity over hours of surplus solar power and optimized for energy arbitrage

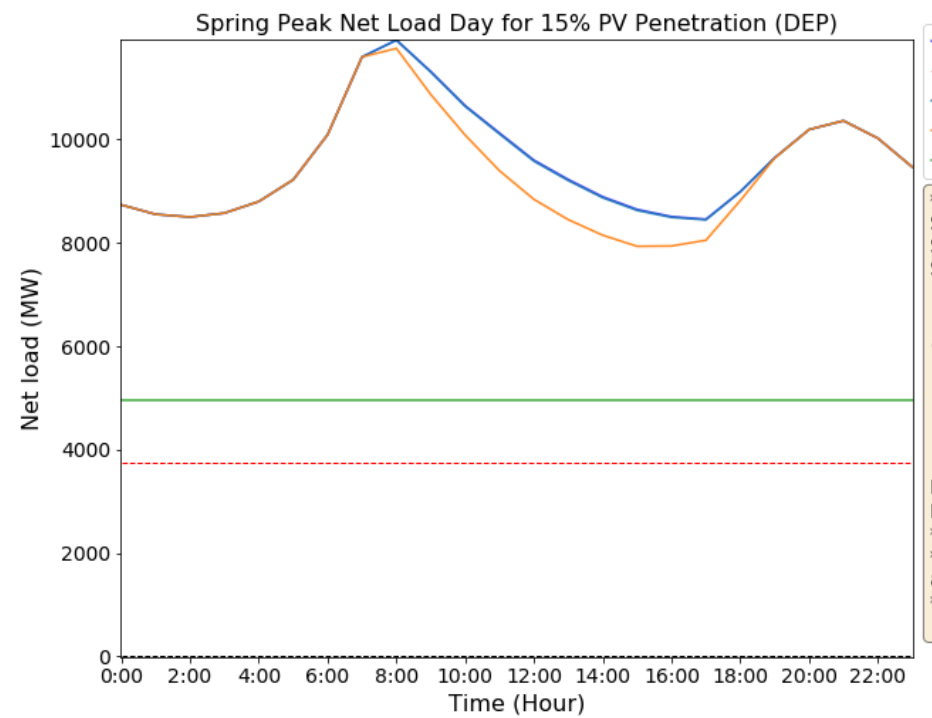

- Load

Nuclear

- Load - Private PV

- Load - All PV

- Flexibility Limit

** Net load analysis for DEP

Storage $=12 \mathrm{MW}$

Scenario 2: PV Penetration of $15 \%$ by annual energy

Solar PV capacity $=2,708 \mathrm{MW}$

Daily \% Zero CO2 Generation : $43 \%$

Hours of curtailment $=0$ hour

$\%$ Curtailed energy $=0.00 \%$

Max. instantaneous curtailment $=0 \mathrm{MW}$

Max. up ramp $=1502 \mathrm{MW} / \mathrm{h}$ at 07:00

Max. down ramp $=-892 \mathrm{MW} / \mathrm{h}$ at 09:00

Daily ramp range $=3826 \mathrm{MW} /$ day

Flexibility limit $=\{($ Must-Run + Nuclear + Hydro $)-$ Storage $\}$

Flexibility limit $=\{(1107+3735+120)-12\}=4950 \mathrm{MW} @ 13: 00$

** Penetration by energy is annual and pre-curtailment

** Flexibility Limit: Assumes nuclear gen. running constantly

at full capacity with no outages

** Storage has sufficient energy to utilize full pumping capacity

over hours of surplus solar power and optimized for energy arbitrage

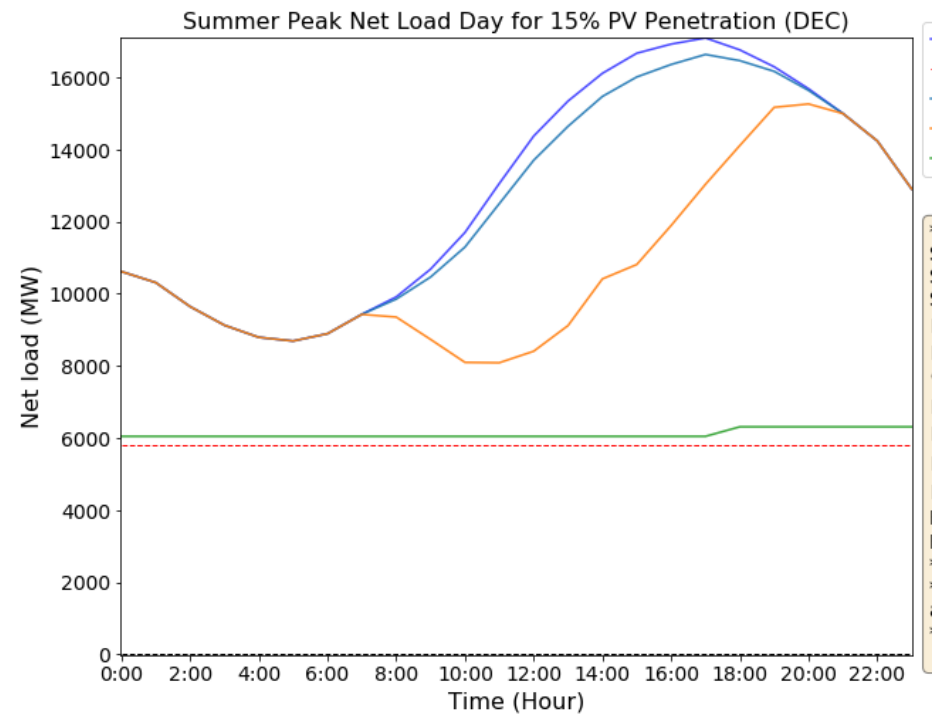

- Load

-.... Nuclear

- Load - Private PV

- Load - All PV

- Flexibility Limit

\section{** Net load analysis for DEC}

Storage $=2140 \mathrm{MW}$

Scenario 2: PV Penetration of $15 \%$ by annual energy

Solar PV capacity $=4,016 \mathrm{MW}$

Daily \% Zero CO2 Generation : $75 \%$

Hours of curtailment $=0 \%$

$\%$ Curtailed energy $=0.00 \%$

Max. instantaneous curtailment $=0 \mathrm{MW}$

Max. up ramp $=1294 \mathrm{MW} / \mathrm{h}$ at $14: 00$

Max. down ramp $=-1331 \mathrm{MW} / \mathrm{h}$ at 23:00

Daily ramp range $=7173 \mathrm{MW} /$ day

Flexibility limit $=\{($ Must-Run + Nuclear + Hydro $)-$ Storage $\}$

Flexibility limit $=\{(2261+5793+130)-2140\}=6044 \mathrm{MW} @ 13: 00$

** Penetration by energy is annual and pre-curtailment

** Flexibility Limit: Assumes nuclear gen. running constantly

at full capacity with no outages

** Storage has sufficient energy to utilize full pumping capacity

over hours of surplus solar power and optimized for energy arbitrage

This report is available at no cost from the National Renewable Energy Laboratory (NREL) at www.nrel.gov/publications. 


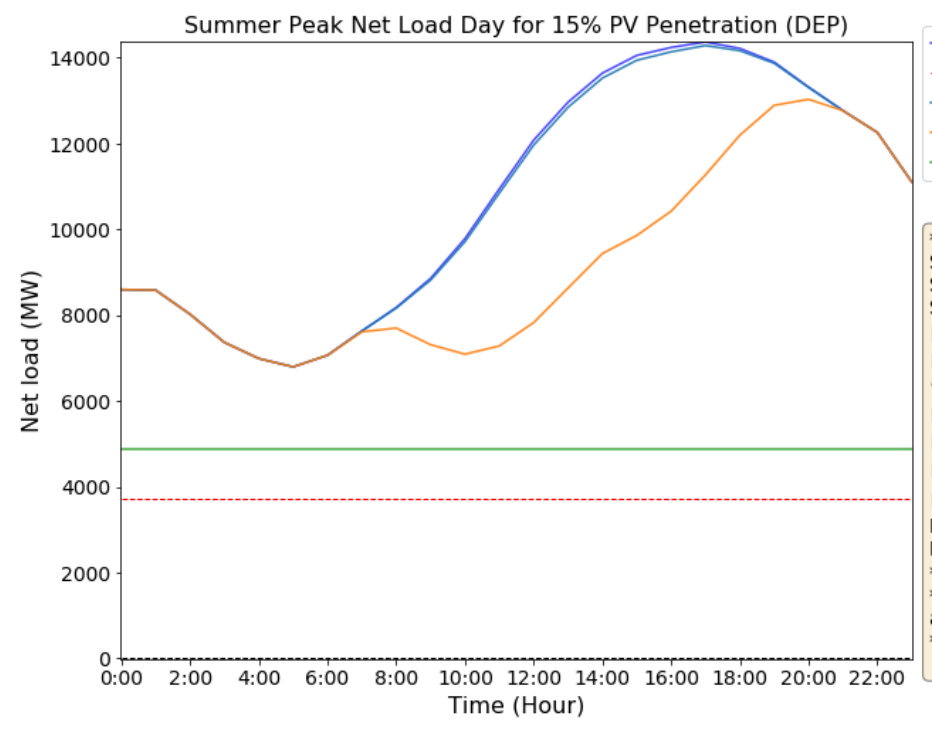

- Load

-... Nuclear

- Load - Private PV

L Load - All PV

- Flexibility Limit

** Net load analysis for DEP

Storage $=12 \mathrm{MW}$

Scenario 2: PV Penetration of $15 \%$ by annual energy

Solar PV capacity $=2,708 \mathrm{MW}$

Daily \% Zero CO2 Generation : $49 \%$

Hours of curtailment $=0$ hour

$\%$ Curtailed energy $=0.00 \%$

Max. instantaneous curtailment $=0 \mathrm{MW}$

Max. up ramp $=924 \mathrm{MW} / \mathrm{h}$ at 07:00

Max. down ramp $=-1151 \mathrm{MW} / \mathrm{h}$ at 09:00

Daily ramp range $=6237 \mathrm{MW} /$ day

Flexibility limit $=\{($ Must-Run + Nuclear + Hydro $)-$ Storage $\}$

Flexibility limit $=\{(1107+3735+43)-12\}=4873$ MW @ 13:00

** Penetration by energy is annual and pre-curtailment

** Flexibility Limit: Assumes nuclear gen. running constantly

at full capacity with no outages

* Storage has sufficient energy to utilize full pumping capacity

over hours of surplus solar power and optimized for energy arbitrage

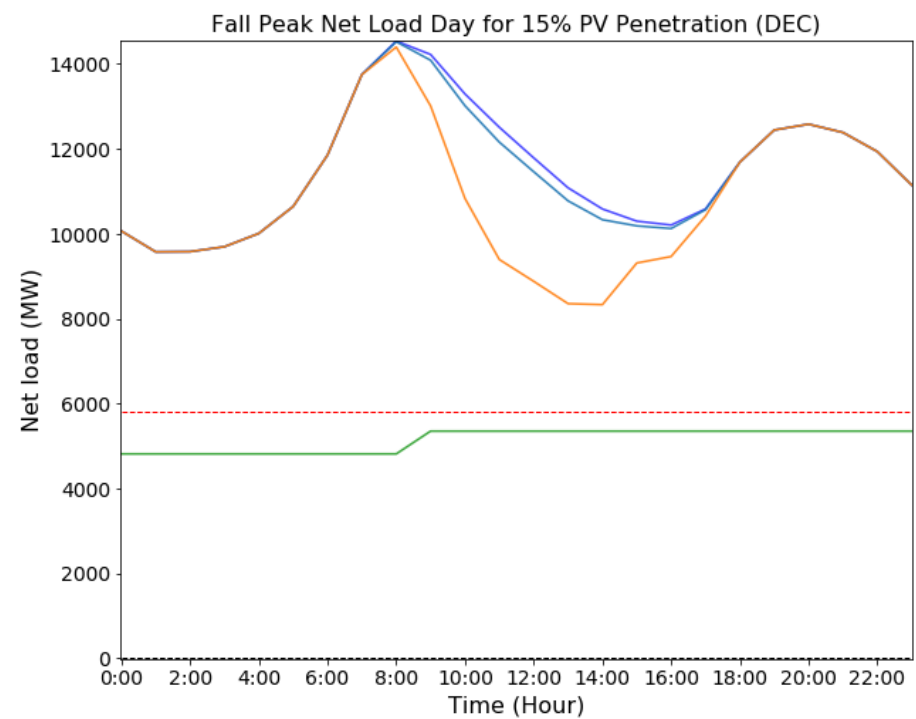

- Load

-.-.- Nuclear

_ Load - Private PV

Load - All PV

- Flexibility Limit

* Net load analysis for DEC

Storage $=2140 \mathrm{MW}$

Scenario 2: PV Penetration of $15 \%$ by annual energy

Solar PV capacity $=4,016 \mathrm{MW}$

Daily \% Zero $\mathrm{CO} 2$ Generation : $69 \%$

Hours of curtailment $=0 \%$

$\%$ Curtailed energy $=0.00 \%$

Max. instantaneous curtailment $=0 \mathrm{MW}$

Max. up ramp $=1897 \mathrm{MW} / \mathrm{h}$ at 07:00

Max. down ramp $=-2179 \mathrm{MW} / \mathrm{h}$ at 10:00

Daily ramp range $=6066 \mathrm{MW} /$ day

Flexibility limit $=\{$ (Must-Run + Nuclear + Hydro $)-$ Storage $\}$

Flexibility limit $=\{(1555+5793+142)-2140\}=5350 \mathrm{MW} @ 13: 00$

** Penetration by energy is annual and pre-curtailment

** Flexibility Limit: Assumes nuclear gen. running constantly

at full capacity with no outages

** Storage has sufficient energy to utilize full pumping capacity
at full capacity with no outages

over hours of surplus solar power and optimized for energy arbitrage

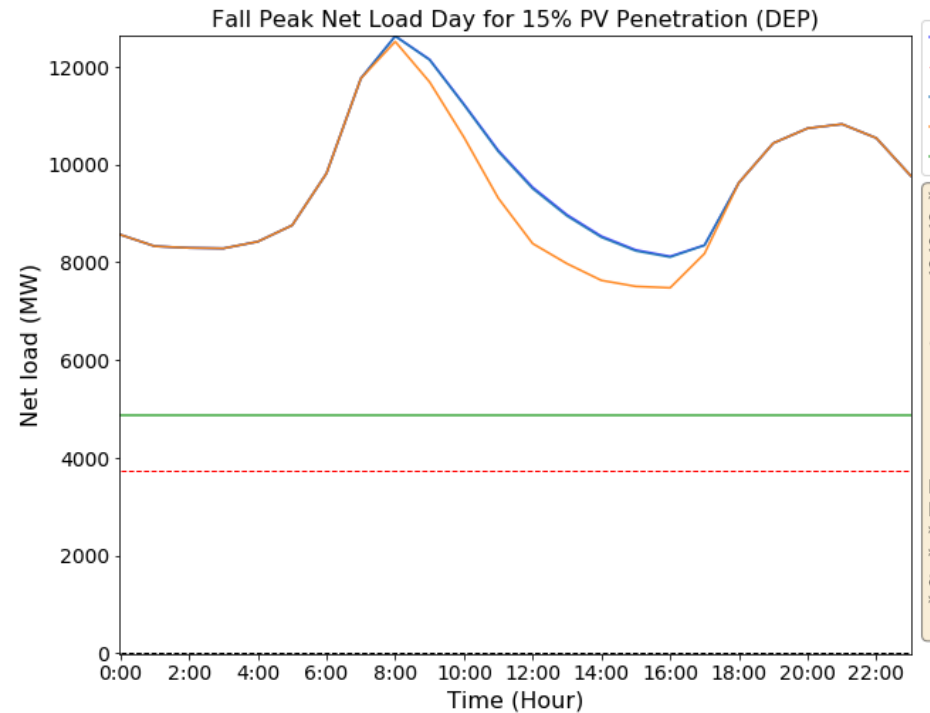

- Load

Nuclear

- Load - Private PV

- Load - All PV

- Flexibility Limit

** Net load analysis for DEP

Storage $=12 \mathrm{MW}$

Scenario 2: PV Penetration of $15 \%$ by annual energy

Solar PV capacity $=2,708 \mathrm{MW}$

Daily \% Zero CO2 Generation : $42 \%$

Hours of curtailment $=0$ hour

$\%$ Curtailed energy $=0.00 \%$

Max. instantaneous curtailment $=0 \mathrm{MW}$

Max. up ramp $=1941 \mathrm{MW} / \mathrm{h}$ at 07:00

Max. down ramp $=-1247 \mathrm{MW} / \mathrm{h}$ at 11:00

Daily ramp range $=5038 \mathrm{MW} /$ day

Flexibility limit $=\{$ (Must-Run + Nuclear + Hydro $)-$ Storage $\}$

Flexibility limit $=\{(1107+3735+50)-12\}=4880 \mathrm{MW} @ 13: 00$

** Penetration by energy is annual and pre-curtailment

** Flexibility Limit: Assumes nuclear gen. running constantly

at full capacity with no outages

** Storage has sufficient energy to utilize full pumping capacity

over hours of surplus solar power and optimized for energy arbitrage

This report is available at no cost from the National Renewable Energy Laboratory (NREL) at www.nrel.gov/publications. 


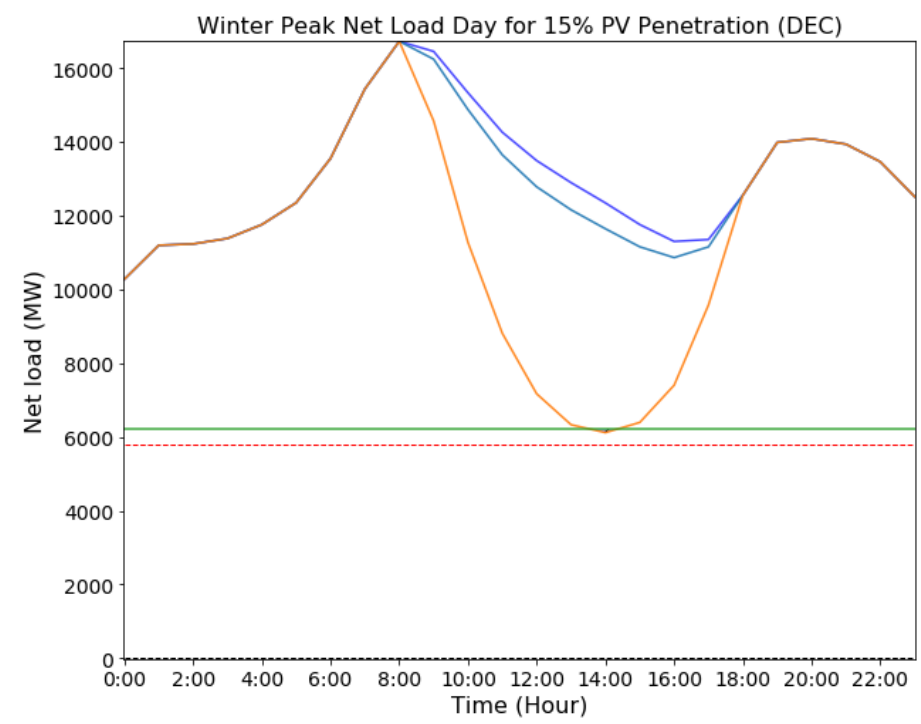

- Load

----. Nuclear

- Load - Private PV

- Load - All PV

_ Flexibility Limit

$\triangle$ Curtailed PV energy

** Net load analysis for DEC

Storage $=2140 \mathrm{MV}$

Scenario 2: PV Penetration of $15 \%$ by annual energy

Solar PV capacity $=4,016 \mathrm{MW}$

Daily \% Zero CO2 Generation : $71 \%$

Hours of curtailment $=1 \%$

$\%$ Curtailed energy $=0.23 \%$

Max. instantaneous curtailment $=95 \mathrm{MW}$

Max. up ramp $=2975 \mathrm{MW} / \mathrm{h}$ at 18:00

Max. down ramp $=-3299 \mathrm{MW} / \mathrm{h}$ at 10:00

Daily ramp range $=10514 \mathrm{MW} /$ day

Flexibility limit $=\{($ Must-Run + Nuclear + Hydro $)-$ Storage $\}$

Flexibility limit $=\{(2261+5793+298)-2140\}=6212 \mathrm{MW} @ 13: 00$

** Penetration by energy is annual and pre-curtailment

** Flexibility Limit: Assumes nuclear gen. running constantly

at full capacity with no outages

** Storage has sufficient energy to utilize full pumping capacity

over hours of surplus solar power and optimized for energy arbitrage

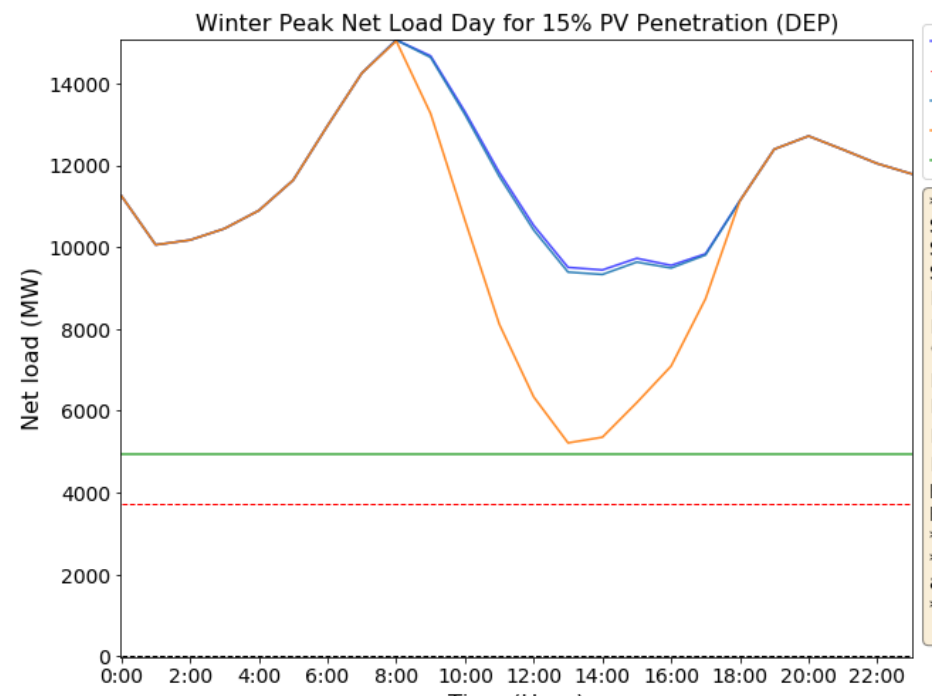

- Load

-...- Nuclear

- Load - Private PV

— Load - All PV

- Flexibility Limit

** Net load analysis for DEP

Storage $=12 \mathrm{MW}$

Scenario 2: PV Penetration of $15 \%$ by annual energy

Solar PV capacity $=2,708 \mathrm{MW}$

Daily \% Zero CO2 Generation : $44 \%$

Hours of curtailment $=0$ hour

$\%$ Curtailed energy $=0.00 \%$

Max. instantaneous curtailment $=0 \mathrm{MW}$

Max. up ramp $=2393 \mathrm{MW} / \mathrm{h}$ at 18:00

Max. down ramp $=-2610 \mathrm{MW} / \mathrm{h}$ at 10:00

Daily ramp range $=9822 \mathrm{MW} /$ day

Flexibility limit $=\{($ Must-Run + Nuclear + Hydro $)-$ Storage $\}$

Flexibility limit $=\{\{(1107+3735+103)-12\}=4933 \mathrm{MW} @ 13: 00$

** Penetration by energy is annual and pre-curtailment

** Flexibility Limit: Assumes nuclear gen. running constantly

at full capacity with no outages

** Storage has sufficient energy to utilize full pumping capacity

over hours of surplus solar power and optimized for energy arbitrage

Time (Hour)

This report is available at no cost from the National Renewable Energy Laboratory (NREL) at www.nrel.gov/publications. 


\section{A.5 Geospatial Analysis}

Several maps were produced for the purpose of visualizing available solar and wind resource in North \& South Carolina, and show the typical exclusions applied in our technical potential analysis. The technical potential shows a broad overview of technically developable resources. This type of analysis does not take into account economic or market factors.

The technical potential analysis uses time-series data to calculate potential system generation across multiple years or weather data. This type of analysis can be useful for narrowing down places for further exploration for development.

\section{Capacity Factors}

Capacity factors were produced for photovoltaic (PV) and wind generating systems using the System Advisor Model (SAM) (Freeman et al., 2018). Input resource time-series data for calculating capacity factors include the National Solar Radiation Database (NSRDB) (Sengupta et al., 2018) for PV systems, and the Wind Integration National Dataset (WIND) Toolkit (Draxl, Clifton, Hodge, \& McCaa, 2015) for wind systems. The capacity factors produced reflect the multi-year mean capacity factors across all available resource years. For the NSRDB, this encompasses the years 1998-2017 inclusive, for the WIND Toolkit, this covers years 2007-2013 inclusive.

The system configurations used in this analysis are described below:

\section{PV}

\begin{tabular}{|l|l|}
\hline Array Type & 1-Axis Tracking \\
\hline Azimuth & 180 Degrees (South) \\
\hline Tilt & 0 Degrees \\
\hline Module Type & Standard \\
\hline Inverter Efficiency & $96 \%$ \\
\hline DC/AC Ratio & 1.3 \\
\hline Losses & $14.07 \%$ \\
\hline
\end{tabular}




\begin{tabular}{|l|l|l|}
\hline & Land-Based & Offshore \\
\hline Hub Height & $80 \mathrm{~m}$ & $100 \mathrm{~m}$ \\
\hline Wind Shear Coefficient & 0.143 & 0.143 \\
\hline $\begin{array}{l}\text { Rotor Diameter } \\
\text { Wind Turbulence } \\
\text { Coefficient }\end{array}$ & $92 \mathrm{~m} / 108 \mathrm{~m} / 117 \mathrm{~m}$ & $155 \mathrm{~m}$ \\
\hline Losses & 0.10 & 0.10 \\
\hline Availability & $15 \%$ & $15 \%$ \\
\hline
\end{tabular}

Rotor diameter and power curves for land-based turbines depends on multi-year mean wind speed using the logic below:

- ws* $<=5.5 \mathrm{~m} / \mathrm{s}: 117 \mathrm{~m}$ Rotor Diameter

- $5.5 \mathrm{~m} / \mathrm{s}<\mathrm{ws}<=10 \mathrm{~m} / \mathrm{s}: 108 \mathrm{~m}$ Rotor Diameter

_ ws $>10 \mathrm{~m} / \mathrm{s}: 92 \mathrm{~m}$ Rotor Diameter

*ws $=$ wind speed $(\mathrm{m} / \mathrm{s})$

\section{Exclusions}

In order to determine locations for further investigation of new PV or wind development, assumptions are made based on land categories and use-type to exclude locations from consideration. The exclusions used in this analysis may be adjusted and new data used in the future to account for more locally-sourced data or other assumptions that aren't considered at this time.

PV

The land exclusions used for PV include the following:

\begin{tabular}{|l|}
\hline Slope $>5 \%$ \\
\hline Urban Areas \\
\hline Water and Wetlands \\
\hline Parks and Landmarks \\
\hline $\begin{array}{l}\text { National Parks and Other Environmentally or } \\
\text { Culturally Sensitive Areas }\end{array}$ \\
\hline
\end{tabular}


Wind

The land exclusions used for wind analysis include the following:

\begin{tabular}{|l|}
\hline Slope $>20 \%$ \\
\hline Urban Areas \\
\hline Water and Wetlands \\
\hline Forests \\
\hline $\begin{array}{l}\text { National Parks and Other Environmentally or } \\
\text { Culturally Sensitive Areas }\end{array}$ \\
\hline
\end{tabular}

\section{Maps}

The results of the Technical Potential analysis are visualized in maps and web application layers. The descriptions of the maps can be found below. Due to their large size, they have been sent to Duke in a separate file.

1. Duke GHI-01.jpg: Multi-year mean Global Horizontal Irradiance (GHI) from the NSRDB.

2. Duke GHI with Exclusions-01.jpg: Multi-year mean GHI from the NSRDB with excluded areas removed using the PV exclusion logic listed above.

3. Duke PV CF-01.jpg: Multi-year mean capacity factors using the PV system configurations listed above.

4. Duke PV with Exclusions-01.jpg: Multi-year mean capacity factors using the PV system configurations listed above and excluded areas removed using the PV exclusion logic listed above.

5. Duke Wind Speed 80-01.jpg: Multi-year mean wind speed from the WIND Toolkit.

6. Duke Wind Speed 80 with Exclusions-01.jpg: Multi-year mean wind speed from the WIND Toolkit with excluded areas removed using the wind exclusion logic listed above.

7. Duke Wind CF-01.jpg: Multi-year mean capacity factors using the wind system configurations listed above.

8. Duke Wind CF with Exclusions-01.jpg: Multi-year mean capacity factors using the wind system configurations listed above with excluded areas removed using the wind exclusion logic listed above. 